\title{
Air Quality Effects of Alternative Fuels: Final Report
}

\author{
P. Guthrie, M. Ligocki, R. Looker, and J. Cohen \\ Systems Applications International, Inc.
}

NREL Technical Monitors: Paul Bergeron and Michelle Bergin

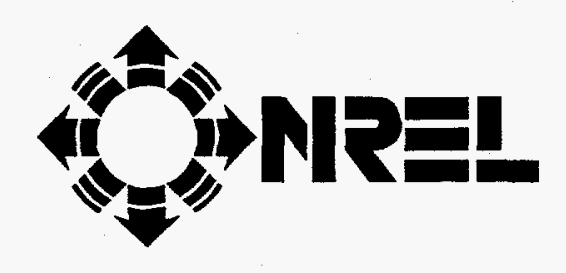

National Renewable Energy Laboratory

1617 Cole Boulevard

Golden, Colorado 80401-3393

A national laboratory of the

U.S. Department of Energy

Managed by the Midwest Research Institute MASTER
For the U.S. Department of Energy Under Contract No. DE-AC36-83CH10093

Prepared under Subcontract Number YCC-4-14072-02 November 1997

DUSTRIBUTON OF THIS DOCUMENT IS UNLMMTED 


\section{NOTICE}

This report was prepared as an account of work sponsored by an agency of the United States govemment. Neither the United States government nor any agency thereof, nor any of their employees, makes any warranty, express or implied, or assumes any legal liability or responsibility for the accuracy, completeness, or usefulness of any information, apparatus, product, or process disclosed, or represents that its use would not infringe privately owned rights. Reference herein to any specific commercial product, process, or service by trade name, trademark, manufacturer, or otherwise does not necessarily constitute or imply its endorsement, recommendation, or favoring by the United States government or any agency thereof. The views and opinions of authors expressed herein do not necessarily state or reflect those of the United States government or any agency thereof.

Available to DOE and DOE contractors from:

Office of Scientific and Technical Information (OSTI)

P.O. Box 62

Oak Ridge, TN 37831

Prices available by calling (423) $576-8401$

Available to the public from:

National Technical Information Service (NTIS)

U.S. Department of Commerce

5285 Port Royal Road

Springtield, VA 22161

(703) $487-4650$ 


\section{DISCLAIMER}

Portions of this document may be illegible electronic image products. Images are produced from the best available original document. 


\section{Contents}

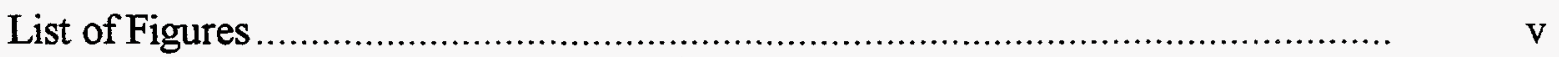

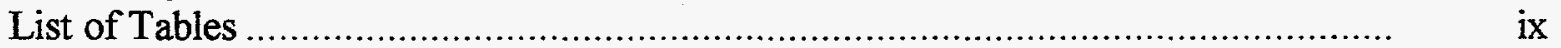

Executive Summary.................................................................................... xiii

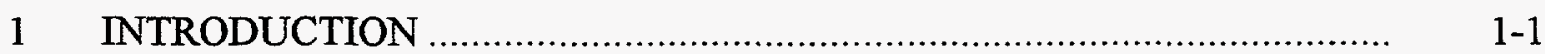

2 BASE-CASE EMISSION INVENTORIES .............................................. 2-1

UAM Emission Inventory Requirements ...........................................

Overview of EPS .......................................................................... 2-1

Emission Speciation for UAM-Tox ................................................. 2-2

Base-Year Inventories...............................................................

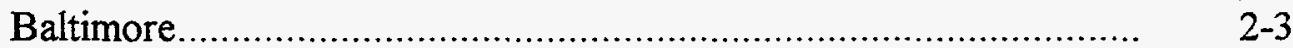

Los Angeles.........................................................................

3 BASE-YEAR MODELING RESULTS ……......................................... 3-1

Comparison of UAM-Tox to Standard UAM ...................................... 3-1

Base-Case UAM-Tox Model Results and Performance ......................... 3- 3-4

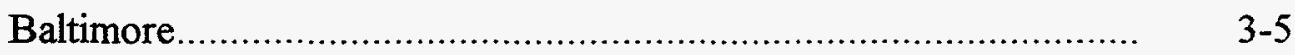

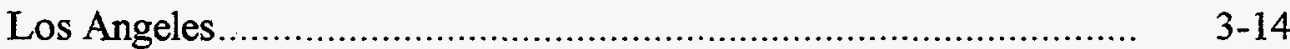

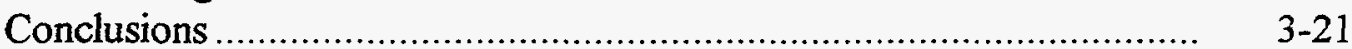

$4 \quad$ FUTURE-YEAR INVENTORY PREPARATION ………........................... 4-1

Inventory Projections....................................................................

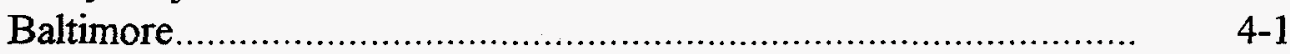

Los Angeles......................................................................... 4-2

Fuel-Specific Inventory Components................................................ 4-3

Using the Alternative Fuels Database ............................................ 4-3

Methodologies and Results for Calculating Measured Emission Ratios and Speciation Profiles............................................................ 4-4

Calculation of CNG-RFG MERs.............................................. 4-4

Calculation of M85-RFG MERs...............................................

Calculation of Speciation Profiles.......................................................... 4- 4-6

Gasoline Marketing/Bulk Storage Sources ..................................... 4-7

Projected 2020 Emission Totals ..................................................... 4-12

Baltimore

Los Angeles............................................................................ 4-15

Speciation of Initial and Boundary Conditions................................ 4- 4-19 
iv

5 MODELING RESULTS

Differences Between Air Quality Impacts of Fuels.

Ozone.

$\mathrm{NO}_{2}$

Formaldehyde

Acetaldehyde

Benzene.

1,3-Butadiene

Summary of Fuel Effects

6

CONCLUSIONS

CHG

M85
$5-1$

$5-1$

$5-1$

$5-3$

$5-3$

$5-4$

$5-5$

5-6

$5-7$

6-1

6-1

6-1

R-1

References

Appendix A: CHEMICAL MECHANISM OF THE UAM-TOX MODEL Appendix B: EMISSION DENSITY PLOTS

Final Report -October 1997 


\section{Figures}

3-1 Comparison of $\mathrm{NO}_{2}$ photolysis rates used in the standard UAM, UAM-

Tox, and UAM-V models.

3-2 Comparison of formaldehyde photolysis rates used in the standard UAM UAM-Tox, and UAM-V models

3-3 Comparison of higher aldehyde photolysis rates used in the standard UAM, UAM-Tox, and UAM-V models .

3-4 Comparison of peak ozone, as a function of initial $\mathrm{RHC} / \mathrm{NO}_{\mathrm{x}}$, predicted by OZIPM4 using the chemical mechanisms in the standard UAM, UAM-Tox version 6.0, and UAM-Tox version 6.22 .

3-5 Baltimore modeling domain

3-6 Maximum simulated ozone concentrations in the Baltimore domain: UAMTox predictions for 5-6 July 1988

3-7 Simulated and observed ozone concentrations at monitoring sites in the Baltimore domain for the 5-6 July 1988 base episode .

3-8 Simulated and observed $\mathrm{NO}_{2}$ concentrations at monitoring sites in the Baltimore domain for the 5-6 July 1988 base episode.

3-9 Maximum simulated RHC concentrations in the Baltimore modeling domain: UAM-Tox predictions for the 5-6 July 1988 base episode

3-10 Hourly simulated $\mathrm{RHC} / \mathrm{NO}_{\mathrm{x}}$ in the Baltimore domain: UAM-Tox predictions for the 5-6 July 1988 base episode, 0500-0600, 0600-0700, 0700-0800, 0800-0900 July 6

3-11 Daily average simulated benzene, 1,3-butadiene, primary formaldehyde, secondary formaldehyde, total formaldehyde, primary acetaldehyde, secondary acetaldehyde, and total acetaldehyde concentrations in the Baltimore domain: UAM-Tox predictions for July 6, 1988

3-12 Simulated primary, secondary, and total formaldehyde and acetaldehyde concentrations in the Baltimore domain: UAM-Tox predictions for the 5-6 July 1988 base episode.

3-13 Los Angeles modeling domain..... 
3-14 Maximum simulated ozone concentrations in the Los Angeles domain:

UAM-Tox predictions for 27-28 August 1987

3-15 Simulated and observed ozone concentrations at monitoring sites in the Los Angeles domain for the 26-28 August 1987 base episode.

3-16 Maximum simulated $\mathrm{NO}_{2}$ concentrations in the Los Angeles domain: UAM-Tox predictions for 27-28 August 1987

3-17. Simulated and observed $\mathrm{NO}_{2}$ concentrations at monitoring sites in the Los Angeles domain for the 26-28 August 1987 base episode

3-18 Simulated and observed RHC concentrations at monitoring sites in the Los Angeles domain for the 27-28 August 1987 base episode

3-19 Simulated and observed $\mathrm{RHC} / \mathrm{NO}_{\mathrm{x}}$ at monitoring sites in the Los Angeles domain for the 27-28 August 1987 base episode

3-20 Simulated and observed PAR concentrations at monitoring sites in the Los Angeles domain for the 27-28 August 1987 base episode

3-21 Simulated and observed OLE concentrations at monitoring sites in the Los Angeles domain for the 27-28 August 1987 base episode

3-22 Simulated and observed IOLE concentrations at monitoring sites in the Los Angeles domain for the 27-28 August 1987 base episode

3-23 Simulated and observed TOL concentrations at monitoring sites in the Los Angeles domain for the 27-28 August 1987 base episode

3-24 Simulated and observed XYL concentrations at monitoring sites in the Los Angeles domain for the 27-28 August 1987 base episode

3-25 Simulated and observed ISOP concentrations at monitoring sites in the Los Angeles domain for the 27-28 August 1987 base episode

3-26 Daily average simulated primary formaldehyde, secondary formaldehyde, and total formaldehyde concentrations in the Los Angeles domain: UAM-Tox predictions for 27-28 August 1987.

3-27 Daily average simulated primary and secondary acetaldehyde concentrations in the Los Angeles domain: UAM-Tox predictions for 27-28 August 1987...

3-28 Daily average simulated benzene concentrations in the Los Angeles domain: UAM-Tox predictions for 27-28 August 1987

3-29 Daily average simulated 1,3-butadiene concentrations in the Los Angeles domain: UAM-Tox predictions for 27-28 August 1987 
3-30 Simulated and observed formaldehyde concentrations at monitoring sites in the Los Angeles domain for 27-28 August 1987.

3-31 Simulated and observed acetaldehyde concentrations at monitoring sites in the Los Angeles domain for 27-28 August 1987.

3-32 Simulated and observed benzene concentrations at monitoring sites in the Los Angeles domain for 27-28 August 1987.

3-33 Simulated and observed 1,3-butadiene concentrations at monitoring sites in the Los Angeles domain for 27-28 August 1987.

5-1 Difference in maximum simulated ozone concentrations on August 28, 1987. NREL Los Angeles (SCAB) Domain. UAM-Tox (6.22) 2020 M85 - 2020 RFG

5-2 Difference in maximum simulated ozone concentrations on August 28, 1987. NREL Los Angeles (SCAB) Domain. UAM-Tox (6.22) 2020 CNG - 2020 RFG

5-3 Difference in maximum simulated ozone concentrations on July 6, 1988. NREL Baltimore domain. UAM-Tox (6.22) 2020 M85 - 2020 RFG.

5-4 Difference in maximum simulated ozone concentrations on July 6, 1988. NREL Baltimore domain. UAM-Tox (6.22) 2020 CNG - 2020 RFG

5-5 Difference in maximum simulated $\mathrm{NO}_{2}$ concentrations on August 28, 1987 NREL Los Angeles (SCAB) domain. UAM-Tox (6.22) 2020 CNG - 2020 RFG

5-6 Difference in maximum simulated $\mathrm{NO}_{2}$ concentrations on July 6, 1988 . NREL Baltimore domain. UAM-Tox (6.22) 2020 CNG - 2020 RFG

5-7 Daily average total formaldehyde concentrations on July 6, 1988.

Baltimore domain. UAM-Tox (6.22) 2020 M85.

5-8 Daily average total acetaldehyde concentrations on July 6, 1988. Baltimore domain. UAM-Tox \&6.22) 2020 RFG, M85, and CNG

5-9 Daily average benzene concentrations on August 28, 1987. Los Angeles domain. UAM-Tox (6.22) 2020 M85. 


\section{Tables}

2-1 Input and output species for UAM-Tox emission inventories for this study .....

2-2 Baltimore base year emissions for 5-6 July 1988 .

2-3 Speciated anthropogenic emissions, Baltimore, 5-6 July 1988

2-4 Los Angeles base year emissions, 26-28 August 1987

2-5 Speciated anthropogenic emissions, Los Angeles, 26-28 August 1987

3-1 Initial RHC CBM species composition, from 1987 Los Angeles anthropogenic inventory

3-2 Effect of individual changes in mechanism, photolysis, and deposition on peak ozone predictions

3-3 Ozone monitoring sites within the Baltimore UAM modeling region

3-4 Comparison of simulated peak ozone in Baltimore for the EPA, AAMA, and NREL base cases

3-5 Comparison of ozone model performance for AAMA and NREL base simulations for 6 July 1988

3-6 Summary of Baltimore emission inventories for AAMA and NREL base cases: 5 July 1988

3-7 RHC composition and MIR reactivity for the Baltimore base case inventory ...

3-8 Comparison of simulated 24-hour average formaldehyde concentrations to observed values at two Washington sites.

3-9 Comparison of simulated 24-hour average acetaldehyde concentrations to observed values at two Washington sites.

3-10 Comparison of simulated benzene concentrations to observed values at two Washington sites.

3-11 Comparison of simulated butadiene concentrations to observed values at two Washington sites. 
3-13 Comparison of simulated peak ozone for Los Angeles AQMP and NREL base cases.

3-14 Ozone model performance for the NREL Los Angeles base simulation for 27 and 28 August 1987.

3-15 Summary of emission inventories for the August 1987 Los Angeles episode, AQMP and NREL base cases

3-16 RHC composition and MIR reactivity for the Los Angeles base-case anthropogenic inventory.

4-1 MERs for CNG-RFG

4-2 Emission rates, MERs, and standard deviations of MERs for M85-RFG

4-3 Most prevalent species in terms of weight fraction for CNG speciation profiles

4-4 Most prevalent species in terms of weight fraction for M85 speciation profiles

4-5 Most prevalent species in terms of weight fraction for RFG speciation profiles

4-6 Amounts of CB4 species and potential ozone production for CNG speciation profiles.

4-7 Amounts of CB4 species and potential ozone production for M85 speciation profiles.

4-8 Amounts of CB4 species and potential ozone production for RFG speciation profiles.

4-9 Adjustment factors for alternative fuels applied to gasoline-related stationary sources for Baltimore and Los Angeles

4-10 Baltimore projected emissions for July weekday, 2020. Fuels RFG, M85, and $\mathrm{CNG}$

4-11 Speciated emissions, Baltimore, 5 July 1988 projected to 2020. Fuels RFG, $\mathrm{M} 85$, and CNG.

4-12 Los Angeles projected emissions for August weekday, 2020. Fuels RFG, $\mathrm{M} 85$, and $\mathrm{CNG}$

4-13 Speciated emissions, Los Angeles, 26 August 1987, projected to 2020.

Fuels RFG, M85, and CNG 
4-14 Percent change in emissions of toxic species due to fuel substitution relative to RFG.

4-15 Background concentrations and scaling factors for future year conditions for Los Angeles and Baltimore.

5-1 Simulated daily maximum ozone for Los Angeles

5-2 Simulated daily maximum ozone for Baltimore

5-3 Ozone areal exposure

5-4 Simulated Los Angeles total formaldehyde concentrations

5-5 Simulated Baltimore total formaldehyde concentrations ............................ $\quad 5-4$

5-6 Simulated Los Angeles maximum acetaldehyde concentrations ................... $\quad 5-4$

5-7 Simulated Baltimore maximum acetaldehyde concentrations ....................... $\quad 5-5$

5-8 Simulated Los Angeles maximum benzene concentrations ...........................

5-9 Simulated Baltimore/DC urban area highest benzene concentrations .............. $5-9$

5-10 Simulated Los Angeles maximum butadiene concentrations .....................

5-11 Simulated Baltimore/DC urban area maximum butadiene concentrations......... 5-7 


\section{EXECUTIVE SUMMARY}

In support of the Alternative Fuels Utilization Program a comparison of the potential air quality effects of alternative transportation fuels is being carried out for the National Renewable Energy Laboratory (NREL). This report presents the results of Phase 1 of this program, focusing on reformulated gasoline (RFG), methanol blended with 15 percent gasoline (M85), and compressed natural gas (CNG).

The fuels are compared in terms of their effects on simulated future concentrations of ozone and mobile source air toxics (formaldehyde, acetaldehyde, benzene, and 1,3-butadiene) in a photochemical grid model. The fuel comparisons were carried out for the future year 2020 and assumed complete replacement of gasoline in the projected light-duty gasoline fleet by each of the candidate fuels. The model simulations were carried out for the areas surrounding Los Angeles and Baltimore/DC, and other (non-mobile) sources of atmospheric emissions were projected according to published estimates of economic and population growth, and planned emission control measures specific to each modeling domain. To provide a sense of scale, the future-year results are compared to a future-year run with all gasoline vehicle emissions removed ("NoGV").

The mobile source contribution in the year 2020 was projected according to the standard methods appropriate to each domain (California Air Resources Board methodology for Los Angeles and US EPA methodology for Baltimore/DC). In both cases there was concern that the projected mobile source emissions of ozone precursors would be too small to support unambiguous differentiation of the potential effects of fuel changes on air quality. (A number of published studies indicate that current estimates of mobile source emissions may be too low, particularly in the Los Angeles domain, by as much as a factor of two.) The projected mobile source emissions of reactive hydrocarbons from gasoline vehicles were thus doubled with respect to the standard estimates. Only gasoline vehicle emissions were altered for the fuel comparisons; diesel emissions were projected and held constant.

Speciated vehicle emissions were developed from the most recent data available on both exhaust and evaporative emissions from current technology vehicles in the Federal fleet. These data were obtained from the NREL Alternative Fuels Data Center.

As a check to see whether the aggregate emissions with the doubled estimate of gasoline vehicle emissions would be consistent with observations, a model performance evaluation was made for the base year in each city (the period 27-28 August 1987 for Los Angeles and the period 5-6 July 1988 for Baltimore). Results indicate that both base cases with the doubled mobile source emissions estimates fall within EPA guidelines for acceptable model performance for air quality modeling.

The results of this Phase 1 fuel comparison indicate that the use of M85 is likely to produce similar ozone and air toxics levels as those projected from the use of RFG, both for Los 
Angeles (using a California definition of RFG) and for Baltimore (using a Federal definition of RFG). Substitution of CNG is projected to produce significantly lower levels of ozone and the mobile source air toxics than those projected for either RFG or M85. The relative benefits of CNG substitution are consistent in both modeling domains. These results are illustrated in Figure ES-1, which compares peak ozone for the three fuels in the two cities on the second simulation day. Table ES-1 shows a similar comparison for areal exposure (a measure of the overall amount of ozone in the domain over the course of a day) and for areal extent of regions of elevated ozone concentrations (above the stated thresholds).

The projection methodologies used in developing the future-year inventories for this fuel comparison are subject to a great deal of uncertainty, and the detailed changes in modeled concentration distributions depend on the meteorological conditions being simulated. The quantitative comparison of fuel effects presented below is thus likely to be sensitive to alternative assumptions. The consistency of the results for two very different modeling domains, using very different assumptions as to future emission control measures, lends credibility to the qualitative differentiation among these fuels and offers some hope that these results will prove robust during planned sensitivity studies in Phase 2 of this program.

Los Angeles

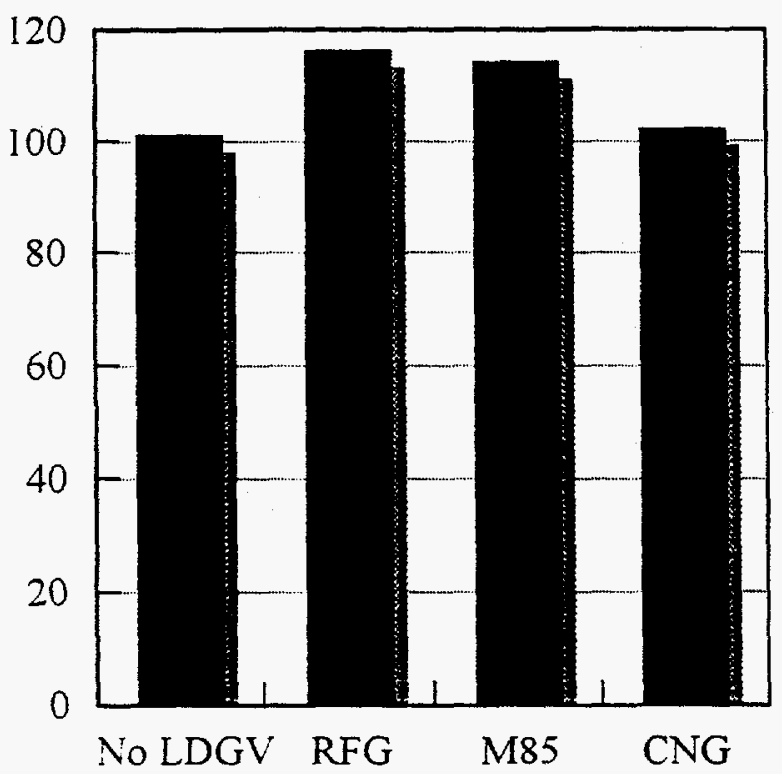

Baltimore

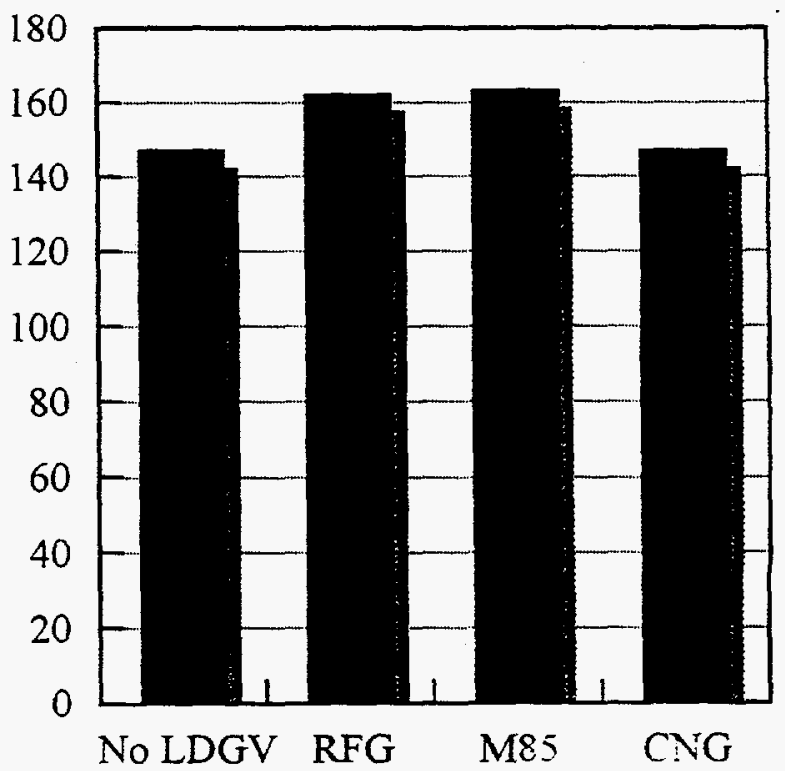

FIGURE ES-1. Simulated ozone levels $(\mathrm{ppb})$ under four different fuel scenarios.

TABLE ES-1. Ozone areal exposure.

\begin{tabular}{|lrrr|}
\hline & RFG & \multicolumn{1}{c}{ M85 } & \multicolumn{1}{c|}{ CNG } \\
\hline Baltimore (6 July) & & & \\
Areal Exposure $\left(10^{4} \mathrm{ppm}-\mathrm{hr}-\mathrm{km}^{2}\right)$ & 7.45 & 7.41 & 6.90 \\
Area above $120 \mathrm{ppb}\left(10^{3} \mathrm{hr}-\mathrm{km}^{2}\right)$ & 12.48 & 10.50 & 5.30 \\
Los Angeles (28 August) & & & \\
Areal Exposure $\left(10^{4} \mathrm{ppm}-\mathrm{hr}^{2}-\mathrm{km}^{2}\right)$ & 6.40 & 6.40 & 6.02 \\
Area above $90 \mathrm{ppb}\left(10^{3} \mathrm{hr}-\mathrm{km}^{2}\right)$ & 7.83 & 7.38 & 1.18 \\
\hline
\end{tabular}




\section{INTRODUCTION}

Despite over two decades of effort directed at improving air quality, many of our largest and most concentrated urban areas still experience regular exposures to pollution levels in excess of the National Ambient Air Quality Standards. Many sources of ozone precursors and other forms of air pollution have been identified, but in the most heavily polluted urban areas motor vehicle emissions remain one of the largest sources of hydrocarbons and $\mathrm{NO}_{\mathrm{x}}$, the crucial precursors for ozone formation. One of the goals of the Department of Energy Alternative Fuel Utilization Program is to assess the potential benefits to air quality of replacement of gasoline by other fuels. As part of this assessment the National Renewable Energy Laboratory (NREL) has commissioned a study of air quality effects using photochemical grid model simulations of hypothetical fuel replacement scenarios. The objective of this study is a clear differentiation among possible alternative fuels in terms of their potential effects on ozone, on other criteria pollutants, and on air toxics associated with motor vehicle emissions.

The basis for this comparison among alternative fuels in Phase 1 is a set of photochemical grid model runs carried out for each of three fuels and two cities. The measures of difference between the fuels will be differences in modeled distributions of ozone, its precursors, and mobile source toxic species. Results are compared for two candidate alternative fuels against reformulated gasoline.

In order to have interpretable distributions in a grid model, the inventories and inputs used for the fuel comparison must satisfy several criteria:

- The study must use realistic underlying conditions, including meteorology and boundary conditions.

- The study must use city-specific nonmobile source emissions so that the distribution of VOC/NO ${ }_{x}$ ratios and the reactivity of the nonmobile VOC contribution are representative for each city (e.g., large or small biogenic contributions).

- The selection of a future year to be represented in the modeling, which is necessary to specify the controls on nonmobile sources, must not bias the study among the fuels. Substantial use of alternative fuels is unlikely to be achieved before 2020 , and the year 2020 was selected for the nominal future year for projection of inventories in this study.

While automobile emissions have been reduced greatly over the last two decades, there are a number of indications that current emissions remain a greater contribution to overall hydrocarbon emissions than would be predicted by available models of mobile source emissions. These indications include ambient air analyses, tunnel studies, source-receptor analyses, and remotely sensed surveys of high-emitter vehicles. The reasons for possible underpredictions by current emission models are many, and any actual underprediction may vary in space and time. Overall, however, the evidence is consistent with an underestimate of as much as a factor of two. This is largely based on recent ambient atmospheric measurements and receptor modeling studies (Fujita et al., 1992, 1994; Harley et al., 1992; Lewis et al., 1993). A large uncertainty is also indicated by the range of emission estimates derived from tunnel studies (Ingalls et al., 1989, 1990). As described in the Modeling 
Protocol, this study is based on mobile source inventories which are a factor of two higher than those generated by the standard mobile source emission models MOBILE and EMFAC. In addition, to avoid ambiguity, we have assumed that all gasoline vehicles are operated on the alternate fuel of interest for each simulation (i.e., 100 percent replacement of GV component).

The use of doubled HC emissions is not presented as an argument that this is a "correct" modification of the mobile source emission estimates. Rather, we assume it for the sake of maximizing differentiation among the fuels. The fact that the model performance statistics are better (see Section 3, below) than those obtained without the doubling is interesting. However, the important point is that the doubling does not produce a base case atmosphere which has drastically different photochemical properties than the observed atmosphere, as judged by the ozone production. The differential fuel effects on air quality (in relative terms) are thus not likely to be greatly different if some smaller multiplier is chosen.

The fuels studied during Phase 1 of this project are 85 percent methanol (M85) and compressed natural gas (CNG).

In what follows we describe the base-case Model Performance Evaluation (MPE), the inventory development and projection procedures used, and the results of the modeling of air quality in the future year 2020 for the three fuels in Los Angeles and Baltimore.

The photochemical grid model used for this study is UAM-Tox, an enhanced version of the Urban Airshed Model or UAM modeling system, the tool recommended by the EPA for regulatory evaluation of air quality control strategies. "Urban Airshed Model" and "UAM" are registered service marks of Systems Applications International, Inc. 


\section{BASE-YEAR EMISSION INVENTORIES}

The NREL modeling domains and episodes were selected so as to utilize existing modeling input databases including the emission inputs. The selected domains and episodes were Baltimore, 5-6 July 1988, and Los Angeles, 26-28 August 1987.

\section{UAM EMISSION INVENTORY REQUIREMENTS}

The UAM system is the EPA-recommended tool for regulatory evaluation of air quality control strategies (EPA, 1991). This model (and derivatives such as UAM-Tox) simulates the hour-by-hour photochemistry occurring for each grid cell in the modeling domain. Accordingly, it is desirable that the input emissions data contain a comparable level of resolution. Because of the infeasibility of considering every reaction of every organic species found in an urban atmosphere, photochemical models such as the UAM model generally group pollutants to limit the number of reactions and species to a reasonable level while permitting reasonable accuracy in predicting ozone formation. The UAM model employs version IV of the Carbon Bond Mechanism (CBM), which classifies each carbon atom in an organic molecule according to its bond type. VOC emissions must be disaggregated into carbon-bond classes prior to model application. The model also requires that $\mathrm{NO}_{\mathrm{x}}$ emissions be distributed as $\mathrm{NO}$ and $\mathrm{NO}_{2}$. For the UAM-Tox, additional explicit toxic species, and additional lumped organic species, are required.

The UAM modeling inventory must also be spatially resolved at the grid-cell level for each hour of the modeling episode. For area and mobile source categories, emissions are often estimated at the county level. If so, the county-level emissions must be spatially allocated over the grid cells within each county. The existing inventory from which the modeling inventory is developed generally contains annual average rates or, for the peak ozone season, daily emission rates; the emissions in the baseline inventory must be adjusted to reflect the conditions of the ozone episode being modeled, including seasonal adjustments for temperature or activity levels (if baseline emissions are reported as annual averages) as well as adjustments for the day of the week. In addition, daily emissions must be allocated to the hours of the modeling episode.

\section{OVERVIEW OF EPS}

To help develop the detailed emission inventories required for photochemical modeling for this analysis, the EPA's UAM Emissions Preprocessor System (EPS) was used. This system, developed by SAI under the sponsorship of the EPA Office of Air Quality Planning and Standards, is a series of computer programs that perform the intensive data manipulations necessary to adapt a county-level annual or seasonal emission inventory for modeling use. The Los Angeles inventory was prepared using the original version of EPS (EPS1) (EPA, 1990) because the base inventory was provided in EPS1 format. The Baltimore inventory was prepared using the more recent EPS2 version (EPA, 1992a). EPS2 provides the capabilities to support the CAAA requirements, to conform to EPA emission inventory 
requirements, and to allow the evaluation of proposed control measures for meeting Reasonable Further Progress regulations and special study concerns.

The core EPS system is a series of FORTRAN modules that incorporate spatial, temporal, and chemical resolution into an emissions inventory used for photochemical modeling. Input files that must be created specific to each modeling region include (1) projection factors used to forecast or backcast emission rates from the year of input emissions to the episode modeling year, (2) gridded area, population, and land-use surrogates used to spatially allocate area source emissions, and (3) digitized link data used to spatially allocate selected source categories (routinely mobile sources). Point, area, and mobile source emission data are usually processed separately through the EPS system to facilitate data tracking for quality control and the use of the data in evaluating the effects of alternative proposed control strategies on predicted air pollutant concentrations.

\section{EMISSION SPECIATION FOR UAM-TOX}

The species incorporated into the inventory development for UAM-Tox applications are shown in Table 2-1. These species include the standard UAM species, additional toxic species (ACET, BENZ, and BUTA), other additional species required by the UAM-Tox mechanism (IOLE, ALDX), and species added for this study (METH, MTBE). A complete list of UAM-Tox species names and abbreviations is provided in Appendix A.

A set of speciation split factors must be provided for disaggregation of VOC emissions. These split factors are obtained using detailed speciation profiles, a set of cross-reference files that map speciation profiles to source categories, and a method for allocating the detailed speciation into the UAM-Tox condensed species. For Los Angeles we used the California Air Resources Board recommended default speciation profiles and source category crossreferences. For Baltimore we used the EPA default speciation profiles (EPA, 1992c), as modified for use with the UAM-Tox (Ligocki et al., 1992). The exception is the onroad mobile portion of the inventories, for which the same profiles were used for both Baltimore and Los Angeles to provide consistency.

Further detail on the UAM-Tox chemistry may be found in Section 3 and Appendix A.

TABLE 2-1. Input and output species for UAM-Tox emission inventories for this study.

\begin{tabular}{|ccccc|}
\hline Input & \multicolumn{4}{c|}{ Output } \\
\hline VOC & OLE & PHCHO & PAR & ACET \\
& TOL & PACET & XYL & ALDX \\
& ETH & METH & ISOP & MTBE \\
& IOLE & BENZ & FORM & BUTA \\
\hdashline$N_{x}$ & NO & $\mathrm{NO}_{2}$ & & \\
\hline CO & CO & & & \\
\hline
\end{tabular}




\section{BASE-YEAR INVENTORIES}

Base-year UAM-Tox modeling inventories were developed for the Baltimore modeling domain for 5-6 July 1988 and for the Los Angeles modeling domain for 26-28 August 1987. In both cases, the modeling inventories were adapted from UAM inventories previously developed.

\section{Baltimore}

The Baltimore UAM-Tox inventory is based on the UAM inventory developed for a previous study of motor vehicle emissions in the Northeast (Morris et al., 1994). A complete description of the development of the inventory is provided in that document. Briefly, stationary and nonroad mobile emissions were obtained from the Maryland draft SIP inventory, supplemented by the EPA Interim 1990 Inventory (EPA, 1993) for states other than Maryland. Onroad mobile emissions were developed using MOBILE5 emission rates in conjunction with vehicle miles traveled (VMT) data from state and local agencies. The MOBILE5 inputs included local information on fuel volatility (RVP) and inspection/maintenance (IM) programs. Onroad mobile emissions were spatially allocated using links to represent major roadways and other spatial surrogates for minor roadways.

The onroad mobile emissions were developed using day-specific temperatures for 5 and 6 July 1988. The remainder of the anthropogenic inventory was prepared to represent an August weekday, and is the same for both episode days. Biogenic emissions, prepared using the EPA Biogenic Emission Information System (BEIS), were developed using day-specific information as well.

After the completion of the emission processing, the onroad mobile VOC emissions for gasoline vehicles were multiplied by a factor of two. As described in Section 1, as well as in the modeling protocol for this study (Guthrie et al., 1995), this was done to provide an upper bound estimate of actual in-use emissions from onroad gasoline vehicles so that a clear distinction can be made among fuels.

Emission totals for criteria pollutants for the Baltimore domain are presented in Table 2-2 for both episode days. Speciated anthropogenic emissions are presented in Table 2-3.

Hydrocarbon emissions in these tables are described as reactive hydrocarbons (RHC) and as total hydrocarbons (THC). In this context, RHC is the sum of the emissions of those species considered reactive in the UAM-Tox. Components of RHC are listed above RHC in Table 23 beginning with OLE and ending with MTBE. Because RHC includes the aldehydes but not methane, it is analogous to the "NMOG" definition of hydrocarbons in the EPA convention, with the exception that benzene is not included. In this report THC also includes the aldehydes. RHC does not include methane (METH) or the toxic species benzene (BENZ) or 1,3-butadiene (BUTA). In the UAM-Tox, these species are toxic tracers; their contribution to reactivity is included in the standard UAM species PAR and OLE. RHC emissions from onroad mobile and biogenic sources were higher on 6 July due to higher temperatures on that day. 
TABLE 2-2a. Baltimore base year emissions for 5 July 1988.

\begin{tabular}{|c|c|c|c|c|c|c|c|c|}
\hline \multirow[t]{2}{*}{ Source Type } & \multicolumn{2}{|r|}{$\mathrm{NO}_{\mathrm{x}}$} & \multicolumn{2}{|r|}{ RHC } & \multicolumn{2}{|r|}{ THC } & \multicolumn{2}{|r|}{$\mathrm{CO}$} \\
\hline & (tpd) & (kg/day/capita) & (tpd) & (kg/day/capita) & (tpd) & $\overline{(\mathrm{kg} / \text { day/capita) }}$ & (tpd) & (kg/day/capita) \\
\hline Onroad MV & 894.67 & 0.073 & 2304.38 & 0.189 & 2525.60 & 0.207 & 8511.01 & 0.699 \\
\hline Refuel/Bulk Storage & 0.00 & 0.000 & 165.30 & 0.014 & 167.53 & 0.014 & 0 & 0.000 \\
\hline Other Area \& Nonroad & 516.74 & 0.042 & 1761.19 & 0.145 & 2312.55 & 0.190 & 2898.68 & 0.238 \\
\hline Other Points & & & & & & & & \\
\hline Elevated & 749.78 & 0.062 & 197.72 & 0.016 & 212.88 & 0.017 & 440.97 & 0.036 \\
\hline Low-level & 22.17 & 0.002 & 140.13 & 0.012 & 155.06 & 0.013 & 13.75 & 0.001 \\
\hline Total Anthropogenic & 2183.36 & 0.180 & 4568.72 & 0.375 & 5373.62 & 0.441 & 11864.41 & 0.974 \\
\hline Biogenic & 16.77 & 0.001 & 1273.76 & 0.105 & 1273.76 & 0.105 & 0 & 0.000 \\
\hline Total & 2200.13 & 0.181 & 5842.48 & 0.480 & 6647.38 & 0.546 & 11864.41 & 0.974 \\
\hline
\end{tabular}

TABLE 2-2b. Baltimore base year emissions for 6 July 1988 .

\begin{tabular}{|c|c|c|c|c|c|c|c|c|}
\hline \multirow[t]{2}{*}{ Source Type } & \multicolumn{2}{|r|}{$\mathrm{NO}_{\mathrm{x}}$} & \multicolumn{2}{|r|}{ RHC } & \multicolumn{2}{|r|}{ THC } & \multicolumn{2}{|r|}{$\mathrm{CO}$} \\
\hline & (tpd) & (kg/day/capita) & (tpd) & (kg/day/capita) & (tpd) & $\overline{\text { (kg/day/capita) }}$ & (tpd) & (kg/day/capita) \\
\hline Onroad MV & 878.46 & 0.072 & 2729.59 & 0.224 & 2967.16 & 0.244 & 9035.24 & 0.742 \\
\hline Refuel/Bulk Storage & 0.00 & 0.000 & 165.30 & 0.014 & 167.53 & 0.014 & 0 & 0.000 \\
\hline Other Area \& Nonroad & 516.74 & 0.042 & 1761.19 & 0.145 & 2312.55 & 0.190 & 2898.68 & 0.238 \\
\hline Other Points & & & & & & & & \\
\hline Elevated & 749.78 & 0.062 & 197.72 & 0.016 & 212.88 & 0.017 & 440.97 & 0.036 \\
\hline Low-level & 22.17 & 0.002 & 140.13 & 0.012 & 155.06 & 0.013 & 13.75 & 0.001 \\
\hline Total Anthropogenic & 2167.15 & 0.178 & 4993.93 & 0.410 & 5815.18 & 0.477 & 12388.64 & 1.017 \\
\hline Biogenic & 16.77 & 0.001 & 1484.56 & 0.122 & 1494.56 & 0.123 & 0 & 0.000 \\
\hline Total & 2183.92 & 0.179 & 6478.49 & 0.532 & 7309.74 & 0.600 & 12388.64 & 1.017 \\
\hline
\end{tabular}


TABLE 2-3a. Speciated anthropogenic emissions, Baltimore, 5 July 1988.

\begin{tabular}{|c|c|c|c|c|}
\hline Species & $\begin{array}{c}\text { Area and } \\
\text { Low Level Point }\end{array}$ & $\begin{array}{l}\text { Onroad } \\
\text { Mobile }\end{array}$ & $\begin{array}{c}\text { Elevated } \\
\text { Point }\end{array}$ & $\begin{array}{c}\text { Total } \\
\text { Anthropogenic }\end{array}$ \\
\hline NO & 485.03 & 805.51 & 675.31 & 1965.84 \\
\hline NO2 & 53.89 & 89.16 & 74.47 & 217.52 \\
\hline NOx & 538.91 & 894.67 & 749.78 & 2183.36 \\
\hline OLE & 121.54 & 85.99 & 2.83 & 210.37 \\
\hline PAR & 1365.11 & 1612.33 & 97.62 & 3075.07 \\
\hline TOL & 235.03 & 205.99 & 70.68 & 511.70 \\
\hline XYL & 147.59 & 176.21 & 22.13 & 345.94 \\
\hline FORM & 0.71 & 8.12 & 0.00 & 8.83 \\
\hline ALDX & 8.27 & 5.71 & 0.81 & 14.78 \\
\hline ETH & 76.33 & 95.15 & 0.82 & 172.31 \\
\hline $\mathrm{MEOH}$ & 0.70 & 6.52 & 0.42 & 7.63 \\
\hline ETOH & 65.40 & 6.27 & 0.00 & 71.68 \\
\hline ISOP & 3.46 & 1.98 & 0.00 & 5.44 \\
\hline ACET & 3.18 & 15.65 & 0.00 & 18.83 \\
\hline PACET & 4.46 & 4.23 & 0.77 & 9.46 \\
\hline PHCHO & 9.37 & 10.64 & 0.70 & 20.72 \\
\hline IOLE & 19.47 & 64.56 & 0.01 & 84.04 \\
\hline CRES & 3.57 & 5.01 & 0.93 & 9.51 \\
\hline MTBE & 2.42 & 0.00 & 0.00 & 2.42 \\
\hline $\mathrm{RHC}$ & 2066.61 & 2304.38 & 197.72 & 4568.72 \\
\hline BENZ & 49.33 & 81.41 & 9.23 & 139.97 \\
\hline BUTA & 8.68 & 8.53 & 0.76 & 17.97 \\
\hline METH & 510.52 & 131.28 & 5.16 & 646.96 \\
\hline THC & 2635.14 & 2525.60 & 212.88 & 5373.62 \\
\hline $\mathrm{CO}$ & 2912.43 & 8511.01 & 440.97 & 11864.41 \\
\hline
\end{tabular}


TABLE 2-3b. Speciated anthropogenic emissions, Baltimore, 6 July 1988.

\begin{tabular}{|c|c|c|c|c|}
\hline Species & $\begin{array}{c}\text { Area and } \\
\text { Low Level Point }\end{array}$ & $\begin{array}{l}\text { Onroad } \\
\text { Mobile }\end{array}$ & $\begin{array}{c}\text { Elevated } \\
\text { Point } \\
\end{array}$ & $\begin{array}{c}\text { Total } \\
\text { Anthropogenic }\end{array}$ \\
\hline NO & 485.03 & 790.31 & 675.31 & 1950.64 \\
\hline $\mathrm{NO} 2$ & 53.89 & 88.15 & 74.47 & 216.51 \\
\hline NOx & 538.91 & 878.46 & 749.78 & 2167.15 \\
\hline OLE & 121.54 & 98.33 & 2.83 & 222.70 \\
\hline PAR & 1365.11 & 1955.95 & 97.62 & 3418.68 \\
\hline TOL & 235.03 & 228.19 & 70.68 & 533.90 \\
\hline XYL & 147.59 & 194.54 & 22.13 & 364.26 \\
\hline FORM & 0.71 & 9.09 & 0.00 & 9.80 \\
\hline ALDX & 8.27 & 6.31 & 0.81 & 15.38 \\
\hline ETH & 76.33 & 100.09 & 0.82 & 177.24 \\
\hline $\mathrm{MEOH}$ & 0.70 & 8.30 & 0.42 & 9.41 \\
\hline ETOH & 65.40 & 7.96 & 0.00 & 73.37 \\
\hline ISOP & 3.46 & 2.17 & 0.00 & 5.63 \\
\hline ACET & 3.18 & 19.45 & 0.00 & 22.63 \\
\hline PACET & 4.46 & 4.44 & 0.77 & 9.67 \\
\hline PHCHO & 9.37 & 11.33 & 0.70 & 21.41 \\
\hline IOLE & 19.47 & 78.24 & 0.01 & 97.72 \\
\hline CRES & 3.57 & 5.21 & 0.93 & 9.70 \\
\hline MTBE & 2.42 & 0.00 & 0.00 & 2.42 \\
\hline $\mathrm{RHC}$ & 2066.61 & 2729.59 & 197.72 & 4993.93 \\
\hline BENZ & 49.33 & 91.45 & 9.23 & 150.02 \\
\hline BUTA & 8.68 & 9.02 & 0.76 & 18.46 \\
\hline METH & 510.52 & 137.09 & 5.16 & 652.78 \\
\hline THC & 2635.14 & 2967.16 & 212.88 & 5815.18 \\
\hline $\mathrm{CO}$ & 2912.43 & 9035.24 & 440.97 & 12388.64 \\
\hline
\end{tabular}


Table 2-2 distinguishes between emissions from refueling/bulk storage and other stationary area and point sources. This was done to facilitate comparisons to the future-year inventories, in which refueling/bulk storage emissions are adjusted for fuel effects.

Emissions in Table 2-2 are also expressed on a per-capita basis, in order to compare to those for the Los Angeles inventory. RHC emissions from anthropogenic sources in the Baltimore domain are on the order of $0.4 \mathrm{~kg} /$ day per capita. Per capita $\mathrm{NO}_{\mathrm{x}}$ emissions are on the order of $0.18 \mathrm{~kg} /$ day.

Emission density plots for the Baltimore base inventory are provided in Appendix B.

\section{Los Angeles}

The Los Angeles UAM-Tox modeling inventory was obtained from a base inventory used by the South Coast Air Quality Management District in its draft 1994 Air Quality Management Plan (AQMP) (SCAQMD, 1994). Onroad mobile emissions in this inventory were obtained using the EMFAC7F emission factor model. Onroad mobile emissions for Los Angeles were spatially allocated using the Direct Travel Impact Model (DTIM) (Fieber et al., 1994). This is a more sophisticated technique than that used for the Baltimore inventory, because exact locations, traffic volumes, and speeds and temperatures by time of day are used to allocate emissions to grid cells.

As with the Baltimore inventory, day-specific inventories were prepared for onroad mobile and biogenic emissions. In addition, the portion of the onroad mobile RHC inventory that was due to gasoline vehicles was multiplied by two, as described for the Baltimore inventory.

Table 2-4 summarizes the criteria pollutant emission totals for the Los Angeles domain for 26, 27, and 28 August 1987. Speciated emissions are provided in Table 2-5. Emission density plots for the Los Angeles base inventory are provided in Appendix B.

The per capita RHC emission totals in Table $2-4$ are on the order of $0.16 \mathrm{~kg} / \mathrm{day}$, or about 40 percent of those in the Baltimore inventory. Per capita $\mathrm{NO}_{\mathrm{x}}$ emissions are on the order of 0.1 $\mathrm{kg} /$ day, or about 60 percent of those in the Baltimore inventory.

Comparison of Tables 2-2 and 2-4 also shows that biogenic emissions are a much larger component of the Baltimore inventory than they are of the Los Angeles inventory. The speciated emissions in Tables 2-3 and 2-5 illustrate other differences between the two inventories. Methane emissions are much larger in the Los Angeles inventory. The toxic species BENZ and BUTA are much higher in the Baltimore inventory; in fact, BUTA is essentially missing from all components of the Los Angeles inventory except onroad mobile. 
TABLE 2-4a. Los Angeles base year emissions, 26 August 1987.

\begin{tabular}{|c|c|c|c|c|c|c|c|c|}
\hline \multirow[t]{2}{*}{ Source Type } & \multicolumn{2}{|r|}{$\mathrm{NO}_{\mathrm{x}}$} & \multicolumn{2}{|r|}{ RHC } & \multicolumn{2}{|r|}{ THC } & \multicolumn{2}{|r|}{$\mathrm{CO}$} \\
\hline & $(\mathrm{tpd})$ & (kg/day/capita) & (tpd) & (kg/day/capita) & $(\mathrm{tpd})$ & (kg/day/capita) & (tpd) & (kg/day/capita) \\
\hline Onroad MV & 732 & 0.045 & 1727 & 0.106 & 1943 & 0.119 & 5586 & 0.342 \\
\hline Refuel/Bulk Storage & & & 26 & 0.002 & 26 & 0.002 & & \\
\hline Other Area \& Nonroad & 580 & 0.035 & 627 & 0.038 & 1491 & 0.091 & 1526 & 0.093 \\
\hline Other Points & & & & & & & & \\
\hline Elevated & 144 & 0.009 & 7 & 0.0004 & 14 & 0.001 & 21 & 0.001 \\
\hline Low-level & 152 & 0.009 & 267 & 0.016 & 324 & 0.020 & 182 & 0.011 \\
\hline Total Anthropogenic & 1608 & 0.098 & 2655 & 0.162 & 3798 & 0.232 & 7315 & 0.448 \\
\hline Biogenic & & & 257 & 0.016 & 257 & 0.016 & & \\
\hline Total & 1608 & 0.098 & 2912 & 0.178 & 4055 & 0.248 & 7315 & 0.448 \\
\hline
\end{tabular}

TABLE 2-4b. Los Angeles base year emissions, 27 August 1987.

\begin{tabular}{|c|c|c|c|c|c|c|c|c|}
\hline \multirow[t]{2}{*}{ Source Type } & \multicolumn{2}{|r|}{$\mathrm{NO}_{\mathrm{x}}$} & \multicolumn{2}{|r|}{$\mathrm{RHC}$} & \multicolumn{2}{|r|}{ THC } & \multicolumn{2}{|r|}{$\mathrm{CO}$} \\
\hline & $(\mathrm{tpd})$ & (kg/day/capita) & (tpd) & (kg/day/capita) & (tpd) & (kg/day/capita) & (tpd) & (kg/day/capita) \\
\hline Onroad MV & 726 & 0.045 & 1798 & 0.110 & 2010 & 0.123 & 5408 & 0.331 \\
\hline Refuel/Bulk Storage & & & 26 & 0.002 & 26 & 0.002 & & \\
\hline Other Area \& Nonroad & 580 & 0.035 & 627 & 0.038 & 1491 & 0.091 & 1526 & 0.093 \\
\hline Other Points & & & & & & & & \\
\hline Elevated & 144 & 0.009 & 7 & 0.0004 & 14 & 0.001 & 21 & 0.001 \\
\hline Low-level & 152 & 0.009 & 267 & 0.016 & 324 & 0.020 & 182 & 0.011 \\
\hline Total Anthropogenic & 1602 & 0.098 & 2726 & 0.166 & 3866 & 0.236 & 7137 & 0.437 \\
\hline Biogenic & & & 336 & 0.021 & 336 & 0.021 & & \\
\hline Total & 1602 & 0.098 & 3062 & 0.187 & 4202 & 0.257 & 7137 & 0.437 \\
\hline
\end{tabular}


TABLE 2-4c. Los Angeles base year emissions, 28 August 1987.

\begin{tabular}{|c|c|c|c|c|c|c|c|c|}
\hline \multirow[t]{2}{*}{ Source Type } & \multicolumn{2}{|r|}{$\mathrm{NO}_{\mathrm{x}}$} & \multicolumn{2}{|r|}{ RHC } & \multicolumn{2}{|r|}{ THC } & \multicolumn{2}{|r|}{$\mathrm{CO}$} \\
\hline & (tpd) & (kg/day/capita) & (tpd) & (kg/day/capita) & (tpd) & (kg/day/capita) & (tpd) & (kg/day/capita) \\
\hline Onroad MV & 726 & 0.045 & 1799 & 0.110 & 2010 & 0.123 & 5581 & 0.342 \\
\hline Refuel/Bulk Storage & & & 26 & 0.002 & 26 & 0.002 & & \\
\hline Other Area \& Nonroad & 580 & 0.035 & 627 & 0.038 & 1491 & 0.091 & 1526 & 0.093 \\
\hline Other Points & & & & & & & & \\
\hline Elevated & 151 & 0.009 & 7 & 0.0004 & 14 & 0.001 & 21 & 0.001 \\
\hline Low-level & 152 & 0.009 & 267 & 0.016 & 324 & 0.020 & 182 & 0.011 \\
\hline Total Anthropogenic & 1609 & 0.098 & 2728 & 0.167 & 3867 & 0.236 & 7311 & 0.448 \\
\hline Biogenic & & & 370 & 0.023 & 370 & 0.023 & & \\
\hline Total & 1609 & 0.098 & 3098 & 0.190 & 4237 & 0.259 & 7311 & $0: 448$ \\
\hline
\end{tabular}


TABLE 2-5a. Speciated anthropogenic emissions (tpd), Los Angeles, 26 August 1987.

\begin{tabular}{|c|c|c|c|c|}
\hline Species & $\begin{array}{c}\text { Area and } \\
\text { Low Level Point }\end{array}$ & $\begin{array}{l}\text { Onroad } \\
\text { Mobile }\end{array}$ & $\begin{array}{c}\text { Elevated } \\
\text { Point }\end{array}$ & $\begin{array}{c}\text { Total } \\
\text { Anthropogenic }\end{array}$ \\
\hline NO & 695.94 & 658.59 & 136.34 & 1490.87 \\
\hline NO2 & 36.68 & 72.95 & 7.17 & 116.80 \\
\hline NOx & 732.61 & 731.54 & 143.52 & 1607.67 \\
\hline OLE & 18.55 & 70.84 & 0.21 & 89.60 \\
\hline PAR & 665.73 & 1120.70 & 4.81 & 1791.25 \\
\hline TOL & 126.13 & 180.09 & 1.09 & 307.30 \\
\hline XYL & 48.54 & 159.30 & 0.23 & 208.06 \\
\hline FORM & 0.09 & 7.14 & 0.00 & 7.23 \\
\hline ALDX & 1.87 & 5.50 & 0.00 & 7.37 \\
\hline ETH & 28.85 & 100.79 & 0.14 & 129.78 \\
\hline MEOH & 0.16 & 1.94 & 0.00 & 2.10 \\
\hline ETOH & 22.34 & 2.01 & 0.04 & 24.39 \\
\hline ISOP & 0.01 & 1.97 & 0.00 & 1.98 \\
\hline ACET & 0.24 & 8.74 & 0.00 & 8.98 \\
\hline PACET & 2.56 & 4.55 & 0.00 & 7.11 \\
\hline PHCHO & 4.50 & 11.79 & 0.31 & 16.60 \\
\hline IOLE & 1.23 & 46.87 & 0.00 & 48.10 \\
\hline CRES & 0.07 & 5.12 & 0.00 & 5.19 \\
\hline MTBE & 0.00 & 0.00 & 0.00 & 0.00 \\
\hline $\mathrm{RHC}$ & 920.87 & 1727.34 & 6.83 & 2655.04 \\
\hline BENZ & 13.65 & 71.05 & 0.28 & 84.97 \\
\hline BUTA & 0.16 & 9.23 & 0.01 & 9.41 \\
\hline METH & 907.16 & 134.98 & 6.73 & 1048.87 \\
\hline THC & 1841.84 & 1942.60 & 13.85 & 3798.29 \\
\hline $\mathrm{CO}$ & 1707.49 & 5581.50 & 20.99 & 7309.97 \\
\hline
\end{tabular}


TABLE 2-5b. Speciated anthropogenic emissions (tpd), Los Angeles, 27

August 1987.

\begin{tabular}{|c|c|c|c|c|}
\hline Species & $\begin{array}{c}\text { Area and } \\
\text { Low Level Point }\end{array}$ & $\begin{array}{l}\text { Onroad } \\
\text { Mobile }\end{array}$ & $\begin{array}{c}\text { Elevated } \\
\text { Point } \\
\end{array}$ & $\begin{array}{c}\text { Total } \\
\text { Anthropogenic }\end{array}$ \\
\hline NO & 695.94 & 653.57 & 136.34 & 1485.84 \\
\hline NO2 & 36.68 & 72.49 & 7.17 & 116.33 \\
\hline NOx & 732.61 & 726.06 & 143.52 & 1602.19 \\
\hline OLE & 18.55 & 71.89 & 0.21 & 90.65 \\
\hline PAR & 665.73 & 1191.75 & 4.81 & 1862.29 \\
\hline TOL & 126.13 & 178.50 & 1.09 & 305.72 \\
\hline XYL & 48.54 & 158.03 & 0.23 & 206.80 \\
\hline FORM & 0.09 & 7.15 & 0.00 & 7.24 \\
\hline ALDX & 1.87 & 5.50 & 0.00 & 7.37 \\
\hline ETH & 28.85 & 98.77 & 0.14 & 127.77 \\
\hline $\mathrm{MEOH}$ & 0.16 & 2.09 & 0.00 & 2.25 \\
\hline ETOH & 22.34 & 2.20 & 0.04 & 24.58 \\
\hline ISOP & 0.01 & 1.97 & 0.00 & 1.97 \\
\hline ACET & 0.24 & 9.47 & 0.00 & 9.71 \\
\hline PACET & 2.56 & 4.48 & 0.00 & 7.04 \\
\hline PHCHO & 4.50 & 11.70 & 0.31 & 16.51 \\
\hline IOLE & 1.23 & 49.77 & 0.00 & 51.00 \\
\hline CRES & 0.07 & 4.94 & 0.00 & 5.01 \\
\hline MTBE & 0.00 & 0.00 & 0.00 & 0.00 \\
\hline RHC & 920.87 & 1798.20 & 6.83 & 2725.90 \\
\hline BENZ & 13.65 & 71.25 & 0.28 & 85.18 \\
\hline BUTA & 0.16 & 9.16 & 0.01 & 9.33 \\
\hline METH & 907.16 & 131.05 & 6.73 & 1044.95 \\
\hline THC & 1841.84 & 2009.67 & 13.85 & 3865.36 \\
\hline $\mathrm{CO}$ & 1707.49 & 5408.48 & 20.99 & 7136.96 \\
\hline
\end{tabular}


TABLE 2-5c. Speciated anthropogenic emissions (tpd), Los Angeles, 28 August 1987.

\begin{tabular}{|lrrrc|}
\hline \multicolumn{1}{|c}{ Species } & $\begin{array}{r}\text { Area and } \\
\text { Low Level Point }\end{array}$ & \multicolumn{1}{c}{$\begin{array}{r}\text { Onroad } \\
\text { Mobile }\end{array}$} & $\begin{array}{c}\text { Elevated } \\
\text { Point }\end{array}$ & $\begin{array}{c}\text { Total } \\
\text { Anthropogenic }\end{array}$ \\
\hline NO & 695.88 & 653.31 & 143.06 & 1492.25 \\
NO2 & 36.67 & 72.46 & 7.53 & 116.66 \\
NOx & 732.55 & 725.77 & 150.59 & 1608.91 \\
OLE & 18.55 & 71.87 & 0.22 & 90.64 \\
PAR & 665.73 & 1193.59 & 4.87 & 1864.19 \\
TOL & 126.12 & 178.26 & 1.09 & 305.47 \\
XYL & 48.53 & 157.81 & 0.23 & 206.57 \\
FORM & 0.10 & 7.14 & 0.00 & 7.24 \\
ALDX & 1.88 & 5.49 & 0.00 & 7.37 \\
ETH & 28.86 & 98.53 & 0.15 & 127.54 \\
MEOH & 0.16 & 2.12 & 0.00 & 2.28 \\
ETOH & 22.34 & 2.22 & 0.04 & 24.60 \\
ISOP & 0.01 & 1.96 & 0.00 & 1.97 \\
ACET & 0.24 & 9.50 & 0.00 & 9.74 \\
PACET & 1841.83 & 2010.41 & 14.30 & 3866.54 \\
PHCHO & 2.56 & 4.47 & 0.00 & 7.03 \\
IOLE & 4.50 & 11.67 & 0.32 & 16.49 \\
CRES & 1.22 & 49.85 & 0.00 & 51.07 \\
MTBE & 0.07 & 4.92 & 0.00 & 4.99 \\
RHC & 0.00 & 0.00 & 0.00 & 0.00 \\
BENZ & 920.87 & 1799.40 & 6.92 & 2727.19 \\
BUTA & 13.65 & 71.19 & 0.28 & 85.12 \\
METH & 0.17 & 9.14 & 0.01 & 9.32 \\
THC & 907.14 & 130.68 & 7.09 & 1044.91 \\
CO & & & & 7311.27 \\
\hline
\end{tabular}




\section{BASE-YEAR MODELING RESULTS}

The UAM-Tox model was applied to the 5-6 July 1988 Baltimore and 26-28 August 1987 Los Angeles episodes using inventories with doubled RHC emissions for onroad gasoline vehicles, as described in Section 2. In this section, the results are presented and compared to previous simulations for the Baltimore and Los Angeles areas. (Figures for this section begin on page 3-22.)

The most significant difference between the NREL base simulations and previous base simulations is expected to be due to the doubled onroad RHC inventory. However, because previous studies also used different versions of the UAM, we first investigated the differences in model results that might be attributable solely to the use of the UAM-Tox. This section begins with a comparison of the UAM-Tox ozone predictions to those from the standard UAM. The remainder of the section covers the base-year modeling results for the Baltimore and Los Angeles areas, including the assessment of model performance for ozone, precursors, and toxics.

\section{COMPARISON OF UAM-TOX (V. 6.22) TO STANDARD UAM}

This study utilized a nonregulatory version of the UAM model, here called UAM-Tox and originally described by Ligocki and Whitten (1992). As described in the modeling protocol, this version differs from the standard UAM primarily in its more detailed treatment of olefins and aldehydes. Specifically, the UAM higher aldehyde species (ALD2) is disaggregated into three species in the UAM-Tox: IOLE, representing internal olefins, ACET (acetaldehyde), and ALDX (higher aldehydes). Earlier comparisons had shown the UAM-Tox peak ozone predictions to match standard UAM predictions to within \pm 8 ppb everywhere in the Baltimore-Washington modeling domain (Ligocki et al., 1992). The UAM-Tox tended to predict higher ozone in Baltimore, whereas the standard UAM tended to predict higher ozone in Washington. Since the simulated ozone peaks were on the order of $160 \mathrm{ppb}$, these differences were on the order of \pm 5 percent of the peak, although some were larger on a percentage basis in outlying areas.

For this application, some additional minor updates were made to the UAM-Tox notably the addition of methane as an explicit species (METH). Others are described in the modeling protocol (Guthrie et al., 1995). In addition to those updates, the product distributions of the olefin reactions were updated to more accurately reflect the expected production of acetaldehyde (ACET) and higher aldehydes (ALDX). The result was to decrease ACET production and increase ALDX production. In the original (6.0) version, the ACET:ALDX product distribution was 50:50 for the OLE reactions and 75:25 for the IOLE reactions. In the 6.22 version, it is 38:62 in the OLE reactions and 60:40 in the IOLE reactions. This update was based on more recent and comprehensive average ambient concentration data for olefins. This version is referred to as UAM-Tox 6.22. The complete mechanism is provided in Appendix A.

In addition to the differences in the mechanisms, there are differences in the photolysis and deposition rates used in the corresponding versions of the UAM model. In the standard 
UAM system, aldehydes are considered nondepositing species, whereas in the UAM-Tox, deposition of these species is included.

Figures 3-1 and 3-2 show the $\mathrm{NO}_{2}$ and $\mathrm{FORM} \rightarrow \mathrm{HO} 2$ photolysis rates used in the standard UAM, the UAM-Tox, and SAI's regional model UAM-V (SAI, 1996). The UAM-V model uses photolysis rates that are a function of altitude and are believed to represent the state of the science. The UAM-Tox photolysis rates are matched to the UAM-V values at an altitude of $640 \mathrm{~m}$, intended to represent the mid-afternoon mixed layer. The standard UAM program contains much higher values for formaldehyde photolysis and somewhat higher values for $\mathrm{NO}_{2}$ photolysis.

The UAM-Tox also contains an additional photolysis reaction for higher aldehydes (ALDX). In the standard UAM model, all $\mathrm{C}_{2}$ and higher aldehydes (ALD2) photolyze at the acetaldehyde photolysis rate, which is quite low. Figure 3-3 shows the UAM-Tox photolysis rates for ACET and ALDX, along with the UAM and UAM-V rates for ALD2. The UAMTox photolysis rates for acetaldehyde are nearly identical to those in the standard UAM model.

Ideally, the UAM-Tox 6.22 model should be compared against the standard UAM model for the particular scenarios used for the present study, especially for the Los Angeles domain, for which the two versions have never been compared. Instead, a less computationally intensive approach was utilized, in which the two versions were compared under a variety of RHC/NO ${ }_{x}$ conditions using the photochemical box model OZIPM4 (Hogo and Gery, 1988). In addition, the original UAM-Tox version (version 6.0) was included in the comparison, in order to illustrate the differences in ozone predictions between that version and the 6.22 version.

Since the OZIPM model does not treat deposition, the effects of the differing deposition rates were approximated using additional decay reactions for formaldehyde, acetaldehyde, and higher aldehydes. The deposition velocity for formaldehyde used in the UAM-Tox corresponds to approximately 1 percent per hour removal rate; the deposition velocities for other aldehydes correspond to approximately 0.25 percent per hour removal rate. The treatments of photolysis and deposition are identical in the 6.0 and 6.22 versions of the UAM-Tox.

The differences in ozone predictions among the standard UAM model, the UAM-Tox 6.0, and the UAM-Tox 6.22 versions were investigated as a function of initial $\mathrm{NO}_{\mathrm{x}}$ for a constant initial RHC concentration of $500 \mathrm{ppbC}$. These results were obtained from OZIPM simulations with no emissions or dilution. The initial RHC composition was obtained from the base 1987 anthropogenic RHC inventory for Los Angeles developed for this study. It is given in Table 3-1. Note that this inventory includes the doubled onroad gasoline vehicle RHC emissions. 
TABLE 3-1. Initial RHC CBM species composition, from 1987 Los Angeles anthropogenic inventory.

\begin{tabular}{|lcc|}
\hline Species & Tox Fraction & Std Fraction \\
\hline OLE & 0.0388 & 0.0388 \\
PAR & 0.6746 & 0.6746 \\
TOL & 0.1155 & 0.1176 \\
XYL & 0.0784 & 0.0784 \\
ETH & 0.045 & 0.045 \\
ISOP & 0.00075 & 0.00075 \\
FORM & 0.0089 & 0.0089 \\
ALD2 & - & 0.027 \\
ACET & 0.006 & - \\
ALDX & 0.0028 & - \\
IOLE & 0.018 & - \\
MEOH & 0.0007 & 0.0007 \\
ETOH & 0.0092 & 0.0092 \\
CRES & 0.002 & - \\
\hline
\end{tabular}

These simulations are based on $500 \mathrm{ppbC}$ RHC, not VOC or ROG. RHC excludes nonreactive components of VOC (such as portions of propane, acetylene, etc.). An RHC concentration of $500 \mathrm{ppbC}$ corresponds roughly to a VOC concentration of $550-600 \mathrm{ppbC}$.

Figure 3-4 shows the peak ozone concentrations produced by these three UAM versions as a function of RHC/NO ${ }_{x}$. The agreement among the standard UAM, UAM-Tox 6.0, and UAMTox 6.22 models is very good at initial $\mathrm{RHC} / \mathrm{NO}_{x}$ of 10 or greater. At lower initial $\mathrm{RHC} / \mathrm{NO}_{\mathrm{x}}$, the Tox versions produce higher peak ozone estimates than the standard UAM, and the 6.22 version produces slightly higher ozone estimates than the 6.0 version. At an initial $\mathrm{RHC} / \mathrm{NO}_{\mathrm{x}}$ of 5-6, the difference between the UAM-Tox 6.22 and standard UAM model is approximately $10 \mathrm{ppb}$.

These results help explain the finding by Ligocki et al. (1992) that the UAM-Tox produced higher peak ozone than the standard UAM model in Baltimore and lower peak ozone in Washington. The Baltimore area behaved as a low $\mathrm{HC} / \mathrm{NO}_{\mathrm{x}}$ area $\left(\mathrm{NO}_{\mathrm{x}}\right.$ reductions caused ozone increases) in that study, whereas the Washington area behaved as a high $\mathrm{HC} / \mathrm{NO}_{\mathrm{x}}$ area $\left(\mathrm{NO}_{\mathrm{x}}\right.$ reductions led to greater ozone decreases than equivalent $\mathrm{VOC}$ reductions).

Figure 3-4 illustrates the net effect of all of the changes between the standard UAM and UAM-Tox models. It is also of interest to understand which of the individual changes are the most significant. In Table 3-2, the peak ozone predictions for initial $\mathrm{RHC} / \mathrm{NO}_{\mathrm{x}}$ of 6 and 10 are shown for intermediate versions of these mechanisms. One parameter is 
TABLE 3-2. Effect of individual changes in mechanism, photolysis, and deposition on peak ozone predictions (ppb).

\begin{tabular}{|lcc|}
\hline \multicolumn{1}{|c}{ Version description } & RHC/NO $_{\mathrm{x}}=6$ & RHC/NO $_{\mathrm{x}}=10$ \\
\hline Standard UAM & 122.40 & 214.82 \\
Standard UAM with UAM-Tox photolysis rates & 110.36 & 207.26 \\
$\begin{array}{l}\text { Standard UAM with UAM-Tox photolysis rates, and updated } \\
\text { radical termination reactions }\end{array}$ & 113.71 & 207.54 \\
$\begin{array}{l}\text { Standard UAM with UAM-Tox photolysis rates, updated } \\
\text { radical termination, and aldehyde deposition }\end{array}$ & 112.22 & 206.94 \\
$\begin{array}{l}\text { UAM-Tox (addition of IOLE chem) with ALDX photolysis } \\
\text { equal to ALD2 }\end{array}$ & 114.61 & 205.67 \\
UAM-Tox version 6.22 & 133.10 & 212.22 \\
\hline
\end{tabular}

changed at a time, to illustrate the effects of each change. The change in photolysis rates from standard UAM to UAM-Tox rates causes a 7-12 ppb decrease in peak ozone. This is to be expected since both the $\mathrm{NO}_{2}$ and formaldehyde photolysis rates are reduced. The addition of the $\mathrm{XO} 2 \mathrm{~N}$ and $\mathrm{OH}$ radical termination reactions and HONO formation rate, as described in the modeling protocol, have little effect on peak ozone at $\mathrm{RHC} / \mathrm{NO}_{\mathrm{x}}$ of 10 , but increase peak ozone slightly in the lower $\mathrm{RHC} / \mathrm{NO}_{\mathrm{x}}$ case.

The addition of aldehyde deposition reduces peak ozone further by about $1 \mathrm{ppb}$. At this point, the two versions are identical except for the UAM-Tox mechanism changes. The change to the UAM-Tox mechanism, consisting of the addition of IOLE/ACET/ALDX chemistry, causes very little change in peak ozone, with a slight decrease $(0.7 \mathrm{ppb})$ occurring at the high $\mathrm{RHC} / \mathrm{NO}_{\mathrm{x}}$ and a slight increase $(2.4 \mathrm{ppb})$ occurring at the low $\mathrm{RHC} / \mathrm{NO}_{\mathrm{x}}$. However, the UAM-Tox mechanism IOLE chemistry also causes the ozone to rise earlier in the day than in the standard case. For example, simulated ozone values at noon are $10 \mathrm{ppb}$ higher in the IOLE case than in the standard case. Finally, the addition of the higher photolysis rates for ALDX causes a large increase in peak ozone of $7 \mathrm{ppb}$ at the high RHC/NO ${ }_{x}$ and $18.5 \mathrm{ppb}$ at the low $\mathrm{RHC} / \mathrm{NO}_{\mathrm{x}}$. The net effect of all these individual changes is an $11 \mathrm{ppb}$ increase in peak ozone at the low $\mathrm{RHC}_{\mathrm{NO}}$, and a $3 \mathrm{ppb}$ decrease in peak ozone at the high $\mathrm{RHC} / \mathrm{NO}_{\mathrm{x}}$.

This exercise illustrates the sensitivity of peak ozone to photolysis rates, since the greatest changes in Table 3-2 occur when photolysis rates are changed. However, in terms of the difference between the UAM-Tox and standard UAM models, the IOLE chemistry is also important since the direction of its effect is different under high and low RHC/NO conditions.

\section{BASE-CASE UAM-TOX MODEL RESULTS AND PERFORMANCE}

Both the 5-6 July 1988 Baltimore and the 26-28 August 1987 Los Angeles episodes were selected for modeling in this study because substantial effort had already gone into developing base-case model inputs and assessing model performance. Model results for the two base episodes were compared to available observations as well as to previous modeling results. Comparisons were conducted not only for ozone, but for ozone precursors and 
toxics as well. Quantitative model performance statistics were calculated for ozone and compared to EPA guidelines for acceptable model performance.

\section{Baltimore}

The Baltimore modeling domain contains both the Baltimore and Washington metropolitan areas, and extends northward into Pennsylvania. The episode selected for modeling is 5-6 July 1988. This period was part of a major regional ozone episode during which extraordinarily high ozone levels were recorded throughout the eastern U.S. Although high ozone levels were recorded in the Baltimore-Washington area from 5 July through 11 July, the 5-6 July period is used for modeling because it occurred near the beginning of the regional episode, and ozone concentrations in the Baltimore area were relatively unaffected by transport from outside the region.

Figure 3-5 shows the Baltimore modeling domain and the locations of the monitoring sites. These sites and site abbreviations are listed in Table 3-3.

The base simulation for the 5-6 July 1988 episode (Carr et al., 1992) was originally developed by SAI for the EPA Office of Air Quality Planning and Standards (OAQPS). Two base simulations were performed: one with wind fields from the Regional Oxidant Model (ROM) and one with wind fields from the UAM Diagnostic Wind Model (DWM). These simulations will be referred to as EPA-ROM and EPA-DWM. The next relevant application (Ligocki et al., 1992), performed for the EPA Office of Policy, Planning, and Evaluation (OPPE), compared the UAM-Tox model to the standard UAM model. These simulations will be referred to as the OPPE Tox and standard base simulation. These four EPA simulations used older model input fields (MV emissions derived from MOBILE4.1 rather than MOBILE5a, and different wind fields and mixing heights, etc.). The NREL base simulation utilized model inputs from a more recent application for the American Automobile Manufacturers Association (AAMA) (Morris et al., 1994), which will be referred to as the AAMA base simulation. The previous simulations were three-day simulations (5-7 July); for the NREL study the last day was dropped because significant ozone transport from the Philadelphia area occurred on that day, as discussed in the modeling protocol. In all cases, boundary concentrations were obtained from the ROM simulation for that episode.

Differences between the AAMA and NREL base cases are:

- The AAMA simulation used the standard UAM (version 6.20); the NREL simulation used UAM-Tox (version 6.22).

- The NREL simulation used an inventory with doubled onroad gasoline vehicle VOC emissions, resulting in a 31 percent increase in anthropogenic $\mathrm{RHC}$ emissions (see Table 2-2).

Comparisons will also be presented between the NREL base case and the earlier OPPE UAM-Tox application. There are more significant differences in the model inputs (emissions and meteorological) between these two simulations. 
TABLE 3-3. Ozone monitoring sites within the Baltimore UAM modeling region.

\begin{tabular}{|c|c|c|c|}
\hline Site & Abbrev. & UTM-N & UTM-E \\
\hline Harrisburg & HSBG & 4456.3 & 342.9 \\
\hline Hershey & HRSH & 4459.1 & 357.0 \\
\hline Kutztown & KZTN & 4484.5 & 433.5 \\
\hline Lancaster City & LNCR & 4433.2 & 390.2 \\
\hline Bellefonte & BLFT & 4400.0 & 457.5 \\
\hline Claymont & CLYT & 4406.8 & 446.5 \\
\hline Chester & CSTR & 4409.5 & 467.9 \\
\hline Norristown & NSTN & 4440.0 & 473.5 \\
\hline Baltimore & BLTM & 4352.7 & 360.8 \\
\hline Cockeysville & CKYV & 4369.0 & 359.7 \\
\hline Edgewood & EDWD & 4362.8 & 388.3 \\
\hline Essex & ESEX & 4356.8 & 372.4 \\
\hline Military Reservation & MLRS & 4365.4 & 370.3 \\
\hline Reistertown & RSTW & 4363.1 & 348.0 \\
\hline Winfield & WNFD & 4367.8 & 324.2 \\
\hline York & YORK & 4425.1 & 354.9 \\
\hline Alexandria & ALXD & 4297.5 & 322.5 \\
\hline Anne Arundel & ANAR & 4307.1 & 356.7 \\
\hline Arlington & ARLN & 4302.8 & 321.3 \\
\hline Fairfax & FRFX & 4301.9 & 299.4 \\
\hline Fort Meade & FTMD & 4329.2 & 350.6 \\
\hline Greenbelt & GRBT & 4320.4 & 341.8 \\
\hline McLean & MCLN & 4311.3 & 309.4 \\
\hline Mt. Vernon & MTVN & 4290.0 & 319.4 \\
\hline Rockville & RKVL & 4331.3 & 317.8 \\
\hline Seven Comers & SVCO & 4304.1 & 314.1 \\
\hline Suitland-Silver Hill & SUSV & 4302.1 & 332.4 \\
\hline Washington, D.C. & WSTN & 4315.8 & 324.8 \\
\hline Dover & DOVR & 4333.2 & 456.8 \\
\hline Lums Pond State Park & LSPD & 4379.3 & 437.0 \\
\hline Faquier & FQUR & 4261.8 & 258.5 \\
\hline Hughesville & HGVL & 4266.3 & 342.1 \\
\hline Seaford & SFRD & 4278.0 & 446.7 \\
\hline Wicomico & WMCO & 4245.1 & 430.9 \\
\hline
\end{tabular}




\section{Ozone}

Table 3-4 summarizes simulated peak ozone for these six simulations. The first day, 5 July, is generally considered a model spin-up day and is not used for model performance evaluation; however, both days are presented.

TABLE 3-4. Comparison of simulated peak ozone (ppb) in Baltimore for the EPA, AAMA, and NREL base cases.

\begin{tabular}{|lcc|}
\hline \multicolumn{1}{|c}{ Simulation } & 5 July & 6 July \\
\hline Measured & 178 & 194 \\
EPA-ROM base & 149 & 154 \\
EPA-DWM base & 155 & 182 \\
OPPE Tox base & 151 & 169 \\
OPPE standard base & 152 & 166 \\
AAMA base & 148 & 170 \\
NREL base (this study) & 172 & 208 \\
\hline
\end{tabular}

Table 3-4 shows that:

- The NREL simulation predicts higher peak ozone for both days than all previous simulations, in better agreement with measured values.

- The NREL simulation produced 16 percent higher peak ozone than the AAMA simulation on 5 July and 22 percent higher peak ozone on 6 July.

- The differences in peak ozone among the previous OPPE and AAMA simulations are minor; differences between these simulations are primarily in spatial patterns of simulated ozone.

- The differences between peak ozone in the OPPE Tox and OPPE standard simulations are minor; thus, the majority of the differences between the NREL and AAMA simulations cannot be attributed to the use of the UAM-Tox model.

Table 3-5 presents quantitative model performance statistics for the NREL base simulation and compares them to model performance statistics from the earlier AAMA study and to the EPA guidelines for acceptable model performance. For all three of the statistical measures presented, the NREL simulation is well within the recommended ranges, and performance for two of the three measures is better than the performance achieved in the previous AAMA base simulation. The NREL simulation has lower unpaired peak accuracy and mean relative error than the AAMA simulation, but slightly higher unsigned relative error. The combination of lower mean relative error and higher unsigned relative error means that the NREL-simulated ozone at monitoring sites generally agreed with observations slightly less well than the AAMA simulation, but that underpredictions were balanced by overpredictions. 
TABLE 3-5. Comparison of ozone model performance for AAMA and NREL base simulations for 6 July 1988 .

\begin{tabular}{|lccc|}
\hline \multicolumn{1}{|c}{ Measure } & $\begin{array}{c}\text { Recommended } \\
\text { Range }\end{array}$ & AAMA & NREL \\
\hline Unpaired peak accuracy $^{*}(\%)$ & $< \pm 15-20$ & -12 & +7 \\
Mean relative error ${ }^{*}(\%)$ & $< \pm 5-15$ & -15 & -5 \\
Mean unsigned relative error (\%) & $<30-35$ & 24 & 27 \\
\hline
\end{tabular}

"Defined as (simulated - observed)/observed

Figure 3-6 shows isopleth plots of daily maximum hourly ozone for the NREL simulation for 5 and 6 July. These plots show that peak observed ozone on both days is very localized: on 5 July, Washington DC reported $178 \mathrm{ppb}$ whereas no other sites exceeded $150 \mathrm{ppb}$, and on 6 July, Edgewood (near Baltimore) reported $194 \mathrm{ppb}$ whereas no other site exceeded $150 \mathrm{ppb}$. The isopleth plots also show that the apparent good agreement between simulated and observed peak ozone for 5 July (Table 3-4) is misleading, since the simulated and observed peaks are in two completely different locations. For 6 July the agreement is better, with the simulated peak located slightly to the northwest of the observed peak.

Because the modeling domain contains two distinct urban areas, it is useful to examine the peak ozone in each subdomain. For 5 July, the simulated Baltimore-area peak of $172 \mathrm{ppb}$ is considerably higher than the observed peak of $144 \mathrm{ppb}$ and is displaced to the northeast of the observed peak, across the Pennsylvania border. Simulated ozone concentrations in Pennsylvania are much higher than the observed values on 5 July.

The simulated Washington-area peak of approximately $150 \mathrm{ppb}$ is lower than the isolated high ozone observation at Washington DC, and is displaced to the north of this peak and the second-highest ozone peak in the Washington area (141 ppb at Rockville).

For 6 July, the Baltimore simulated peak of $208 \mathrm{ppb}$ is slightly higher than the observed peak of $194 \mathrm{ppb}$ at Edgewood, and is again somewhat to the north. In the absence of observations north of Edgewood, we cannot determine whether this location of the peak is accurate. However, the Washington-area simulated peaks of approximately $200 \mathrm{ppb}$ are much higher than the observed peaks of $142 \mathrm{ppb}$ at Mount Vernon and $137 \mathrm{ppb}$ at Anne Arundel.

No adjustments to the meteorological inputs to improve spatial ozone patterns were attempted, since considerable effort had been expended in that area in previous studies, and the performance measures were within the recommended range.

Ozone time series for the NREL simulation are presented in Figure 3-7. Sites in this figure (and in Figure 3-8) are presented in order of location starting with the southernmost at the bottom of the first page and progressing farther north toward the top of the page and on subsequent pages. In all time series presented in this report, the solid lines represent the simulated value interpolated to the site location, and the shaded area represents the range of simulated concentrations in the grid cells used for the interpolation. For a few sites, no shaded region is shown, because the site was located too close to the domain boundary for interpolation to be performed. Figure 3-7 shows that the model had varying success in reproducing the timing of observed ozone peaks. Some Washington-area simulated ozone 
peaks for 6 July occur 2-3 hours after the observed peak (Arlington, Suitland-Silver), although others (Mount Vernon, Seven Corners) are well replicated. Many Washington-area peaks are overpredicted on 6 July.

Comparison of these time series to those from the earlier AAMA study shows that doubling the onroad gasoline RHC inventory had little effect $(<10 \mathrm{ppb})$ on ozone at some sites, generally those in outlying areas; it increased ozone by up to $40 \mathrm{ppb}$ in urban Baltimore and Washington. At many sites, the simulated ozone rose more rapidly earlier in the day in the NREL simulation, most notably at some suburban Washington sites such as Mount Vernon. This is consistent with expectations for a higher $\mathrm{RHC} / \mathrm{NO}_{\mathrm{x}}$ simulation. Model performance improved for some sites where the AAMA simulation had underpredicted peak ozone, but degraded at other sites where the NREL simulation produced overpredictions.

\section{RHCNOX Issues}

The efficiency of ozone production varies greatly with the balance between RHC (or VOC) and $\mathrm{NO}_{\mathrm{x}}$. When the ratio of $\mathrm{RHC}$ to $\mathrm{NO}_{\mathrm{x}}$ is greater than about 15 ozone production is said to be $\mathrm{NO}_{\mathrm{x}}$-limited; under these conditions reductions in VOC emissions are relatively ineffective in reducing ozone. When the ratio of $\mathrm{RHC} / \mathrm{NO}_{\mathrm{x}}$ is less than about 5 , ozone production is said to be VOC limited; under these conditions reductions in VOC emissions are relatively effective in reducing ozone. The impact of fuel switching is thus likely to be greater in areas of low $\mathrm{VOC} / \mathrm{NO}_{\mathrm{x}}$ ratio than in areas where the ratio is high. (With the caveat that increased $\mathrm{NO}_{\mathrm{x}}$ emissions from $\mathrm{CNG}$ use will tend to offset some of the decrease in VOC emissions.)

\section{$R H C$ and $N O_{x}$}

Table 3-6 summarizes the modeling inventories for $\mathrm{RHC}$ and $\mathrm{NO}_{\mathrm{x}}$ for the AAMA and NREL base cases. RHC is expressed on a methane-equivalent basis. The $\mathrm{RHC} / \mathrm{NO}_{\mathrm{x}}$ ratios of the anthropogenic portions of these inventories are obtained by dividing the RHC emissions by 16 and the $\mathrm{NO}_{\mathrm{x}}$ emissions by 46 . Thus, $\mathrm{RHC} / \mathrm{NO}_{\mathrm{x}}$ is 4.5 and 5.9 for the AAMA and NREL inventories, respectively. The corresponding $\mathrm{VOC} / \mathrm{NO}_{\mathrm{x}}$ would be approximately 10 to 15 percent higher.

TABLE 3-6. Summary of Baltimore emission inventories (tpd) for AAMA and NREL base cases: 5 July 1988.

\begin{tabular}{|lrrrrr|}
\hline \multirow{2}{*}{ Component } & \multicolumn{2}{c}{ AAMA } & & \multicolumn{2}{c|}{ NREL } \\
\cline { 2 - 3 } \cline { 6 - 7 } & RHC & NO $_{\mathrm{x}}$ & & RHC & NO $_{\mathrm{x}}$ \\
\hline Onroad mobile & 1169 & 892 & & 2304 & 895 \\
Area & 1925 & 515 & & 1870 & 517 \\
Points & 339 & 772 & & 339 & 773 \\
Total anthropogenic & 3433 & 2179 & & 4513 & 2185 \\
Onroad mobile percent of & $34 \%$ & $41 \%$ & & $51 \%$ & $41 \%$ \\
anthropogenic & & & & & \\
Biogenic & 1275 & 11 & & 1215 & 11 \\
Total emissions & 4708 & 2190 & & 5728 & 2196 \\
\hline
\end{tabular}


The Baltimore simulations performed at SAI for this episode have historically had difficulties with underprediction of observed $\mathrm{NO}_{2}$ (Carr et al., 1992; Ligocki et al., 1992). Only limited (nonspeciated) 6-9 a.m. NMOC measurements are available for this episode; model performance for RHC has historically been good for Baltimore with underpredictions for Washington. However, the RHC underpredictions were less severe than the $\mathrm{NO}_{2}$ underpredictions. Thus, the model has historically overpredicted the observed $H C / \mathrm{NO}_{\mathrm{x}}$ for this domain and episode.

Improved predictions for $\mathrm{NO}_{2}$ were achieved in the AAMA simulation as compared to the earlier EPA simulations. This is due in part to the use of MOBILE5a in generating MV inventories, and in part to other inventory and/or meteorological input differences.

Time series for $\mathrm{NO}_{2}$ are shown in Figure 3-8. In the NREL simulation, model performance for $\mathrm{NO}_{2}$ improved at Essex (Baltimore area) and Fort Meade compared to the AAMA base case. Since the $\mathrm{NO}_{\mathrm{x}}$ inventories were essentially the same for both studies (Table 3-6), the difference may be due to more rapid conversion of $\mathrm{NO}$ to $\mathrm{NO}_{2}$ in the NREL simulation due to the higher hydrocarbon levels. The model still underpredicts $\mathrm{NO}_{2}$ at most other sites. Comparisons of simulated and observed $\mathrm{NO}_{2}$ concentrations should always be made cautiously, since measured values at a single ground-level point may reflect microscale emissions and thus may not represent average concentrations throughout the grid cell volume. In addition, reported $\mathrm{NO}_{\mathrm{x}}$ concentrations include portions of ambient levels of other nitrogenous species such as $\mathrm{PAN}$ and $\mathrm{HNO}_{2}$, although this artifact is not likely to have a large effect on the highest $\mathrm{NO}_{\mathrm{x}}$ measurements.

An isopleth plot of simulated RHC for 6 July is presented in Figure 3-9. Observed 6-9 a.m. NMOC values in both Baltimore and Washington were on the order of $600 \mathrm{ppbC}$ on 6 July. Simulated RHC values in Baltimore are considerably higher ( $>1000 \mathrm{ppbC})$ and are in poorer agreement with observations than the earlier OPPE study (the AAMA study did not examine model performance for RHC). As discussed above, RHC should be 10-15 percent lower than NMOC because the nonreactive portions of several major NMOC constituents are excluded.

Hourly RHC/NO plots for the 0500 to 0900 LST period on 6 July are shown in Figure 3-10. Simulated $\mathrm{RHC} / \mathrm{NO}_{\mathrm{x}}$ vary widely over the domain, with values reaching 80-100 in outlying areas of the domain. In the urban Baltimore and Washington areas, simulated $R H C / \mathrm{NO}_{x}$ were 6-8. Thus the simulated $\mathrm{RHC} / \mathrm{NO}_{\mathrm{x}}$ values are somewhat higher than the inventory value, due to the effects of aged and transported material.

Table 3-7 shows the RHC composition and reactivity for the Baltimore inventory. Reactivity is determined by the MIR scale and represents the incremental ozone produced by an incremental addition of each species under conditions that lead to the maximum incremental effect. The MIR factors do not necessarily represent the reactivity of each species in any given UAM simulation, but are the best available means for weighting RHC emissions according to their reactivity towards ozone formation. In Table 3-7, emissions and reactivity for the onroad mobile inventory and the remainder of the low-level anthropogenic inventory (stationary plus nonroad) are presented. The elevated point sources and biogenic emissions are not included.

The comparison in Table 3-7 indicates that onroad mobile and other low-level anthropogenic RHC emissions in the Baltimore inventory are similar in specific reactivity, and that the contribution of onroad mobile sources to total reactivity is similar to its contribution to 
emissions. As discussed later in this section, a very different result was found for the Los Angeles inventory. The relative reactivity of mobile and stationary source emissions, as well as the $\mathrm{RHC} / \mathrm{NO}_{\mathrm{x}}$ ratio of the inventory, both impact the sensitivity of the model predictions to changes in the mobile RHC inventory.

\section{Toxics}

Isopleth plots of daily average toxic concentrations are given in Figure 3-11 for 6 July. These were compared to the OPPE Tox base case. For 5 July, the OPPE daily averages are for the hours 0500-2400, whereas the NREL averages are for 0000-2400. This will lead to lower averages for that day for the NREL simulation. The comparison is therefore limited to 6 July.

TABLE 3-7. RHC composition and MIR reactivity for the Baltimore base case inventory.

\begin{tabular}{|c|c|c|c|c|}
\hline \multirow[b]{2}{*}{ Species } & \multicolumn{2}{|c|}{ Onroad mobile } & \multicolumn{2}{|c|}{ Other low-level } \\
\hline & $\begin{array}{l}\text { Emissions } \\
\text { (tpd) }\end{array}$ & Reactivity & $\begin{array}{l}\text { Emissions } \\
\quad \text { (tpd) }\end{array}$ & Reactivity \\
\hline OLE & 86 & 1246 & 122 & 1761 \\
\hline PAR & 1612 & 1673 & 1365 & 1416 \\
\hline TOL & 206 & 318 & 235 & 362 \\
\hline XYL & 176 & 1260 & 148 & 1055 \\
\hline ETH & 95 & 665 & 76 & 533 \\
\hline ISOP & 2.0 & 26 & 3.5 & 45 \\
\hline PFORM & 10.6 & 184 & 9.4 & 162 \\
\hline FORM & 8.1 & 141 & 0.7 & 12 \\
\hline PACET & 4.2 & 38 & 4.5 & 40 \\
\hline ACET & 15.7 & 142 & 3.2 & 29 \\
\hline ALDX & 5.7 & 64 & 8.3 & 93 \\
\hline IOLE & 65 & 936 & 19.5 & 282 \\
\hline CRES & 5.0 & 8 & 3.6 & 6 \\
\hline MEOH & 6.5 & 8 & 0.7 & 1 \\
\hline ETOH & 6.3 & 13 & 65 & 130 \\
\hline METH & 131 & 1 & 510 & 5 \\
\hline Total & 2436 & 6721 & 2575 & 5935 \\
\hline Percent of total & $49 \%$ & $53 \%$ & $51 \%$ & $47 \%$ \\
\hline Specific reactivity & & 2.76 & & 2.31 \\
\hline Total w/o METH & 2304 & 6720 & 2064 & 5930 \\
\hline Percent of total w/o METH & $53 \%$ & $53 \%$ & $47 \%$ & $47 \%$ \\
\hline Specific reactivity w/o METH & & 2.92 & & 2.87 \\
\hline
\end{tabular}

No day-specific toxics observation data are available for this episode; comparisons were made on a site-specific basis for two Washington sites with average and maximum values from the summers of 1989 and 1990 (McAllister et al., 1989, 1991a,b; Radian 1991). Since 
no meteorological episodes similar to the July 1988 episode occurred during 1989 and 1990 , the range of toxic concentrations observed in those years may not represent the values that occurred during July 1988. On the other hand, measured aldehyde levels during July 1988 at other sites in the eastern U.S. are not unusually high by comparison to other months (PEI, 1989).

Formaldehyde. Total daily average formaldehyde in the Baltimore and Washington urban areas was 1-2 ppb (15-30 percent) higher for 6 July in the NREL simulation compared to the OPPE simulation. The observed, OPPE simulated, and NREL simulated values at two Washington are sites are summarized in Table 3-8. Observed formaldehyde concentrations are much higher in 1990 than in 1989. This is apparently due to the addition of an ozone scrubber in the aldehyde sampling system in 1990 (Radian, 1991). Thus, the 1989 observations are likely to be low, and the best comparison is probably with the 1990 values. The NREL simulation produced concentrations that are comparable to the average measured values for both sites for the summer of 1990 .

TABLE 3-8. Comparison of simulated 24-hour average formaldehyde concentrations $(\mathrm{ppb})$ to observed values at two Washington sites.

\begin{tabular}{|rcrrrr|}
\hline & \multicolumn{2}{c}{ Observed } & & \multicolumn{2}{c|}{ Simulated } \\
\cline { 2 - 3 } \cline { 5 - 6 } Site & Average & Maximum & & OPPE & NREL \\
\hline W1DC, 1989 & 4.40 & 5.81 & 5.03 & 6.60 \\
W1DC, 1990 & 7.02 & 9.88 & & \\
W2DC, 1989 & 3.05 & 4.12 & & 7.30 & 8.45 \\
W2DC, 1990 & 8.85 & 13.32 & & \\
\hline
\end{tabular}

Acetaldehyde. As discussed above, the UAM-Tox 6.22 used for this project has reduced production of secondary acetaldehyde compared to the OPPE version (6.0); this effect partially counteracted the increase in the RHC inventory. For 6 July, the NREL simulation produced up to $1.5 \mathrm{ppb}$ (40 percent) greater acetaldehyde than the OPPE simulation for Washington, and about $0.5 \mathrm{ppb}$ more acetaldehyde for Baltimore.

Simulated 24-hour average acetaldehyde levels for both the NREL and the OPPE simulations were higher than typical measured levels (Table 3-9), but were similar to 1990 maximum concentrations. The NREL simulation produced more acetaldehyde than the OPPE simulation despite the downward adjustment to the secondary acetaldehyde formation equations.

TABLE 3-9. Comparison of simulated 24-hour average acetaldehyde concentrations (ppb) to observed values at two Washington sites.

\begin{tabular}{|rccccc|}
\hline & \multicolumn{2}{c}{ Observed } & & \multicolumn{2}{c|}{ Simulated } \\
\cline { 2 - 3 } \cline { 5 - 6 } Site & Average & Maximum & & OPPE & NREL \\
\hline W1DC, 1989 & 1.99 & 2.72 & & 3.13 & 3.79 \\
W1DC, 1990 & 2.12 & 3.57 & & & \\
W2DC, 1989 & 1.39 & 2.21 & & 4.06 & 4.15 \\
W2DC, 1990 & 2.86 & 4.46 & & & \\
\hline
\end{tabular}


Simulated contributions of primary and secondary formaldehyde and acetaldehyde, shown in Figure 3-12, are similar to those found in the OPPE simulation (50-90\% secondary for formaldehyde and 85-100\% secondary for acetaldehyde), but the secondary aldehyde peaks simulated to occur around 1000-1100 LST on 6 July are more pronounced in the NREL simulation.

Benzene. Benzene 24-hour averages for 6 July are $0.2-0.5 \mathrm{ppb}(15-40 \%)$ higher in the NREL simulation than in the OPPE simulation. Simulated benzene levels for both the NREL and OPPE simulations are in the same range (1-2 ppb) as average 1989 and 1990 measurements at both Washington sites (Table 3-10). The 6-9 a.m. benzene levels reported in Table 3-10 are from the years 1984-85, and may not represent 1988 levels, since a decreasing trend in benzene is expected for those years.

1,3-Butadiene. Daily average butadiene levels are very low in the NREL simulation $(<0.3$ $\mathrm{ppb}$ in the Baltimore and Washington areas). For Washington, the values are very similar to those obtained in the previous OPPE simulation. For Baltimore, simulated values in the OPPE study were much higher $(0.95 \mathrm{ppb})$. This difference is apparently the result of the difference in the base inventories used, which resulted in a

TABLE 3-10. Comparison of simulated benzene concentrations (ppb) to observed values at two Washington sites.

\begin{tabular}{|lccccc|}
\hline & \multicolumn{2}{c}{ Observed } & & \multicolumn{2}{c|}{ Simulated } \\
\cline { 2 - 3 } \cline { 6 - 7 } Site & Average & Maximum & & OPPE & NREL \\
\hline W1DC 24-hour, 1989 & 1.37 & 2.08 & & 1.19 & 1.36 \\
W1DC 24-hour, 1990 & 1.23 & 2.70 & & & \\
W1DC 6-9 a.m. 1984-85 & 2.78 & 5.59 & & 1.68 & 1.89 \\
W2DC 24-hour, 1989 & 1.48 & 2.12 & & 1.35 & 1.49 \\
W2DC 24-hour, 1990 & 1.77 & 3.41 & & & \\
\hline
\end{tabular}

different speciation for one or more stationary source types in Baltimore. Butadiene levels at two Washington sites are compared in Table 3-11. Both the NREL and OPPE simulations produced 24-hour average concentrations similar to or higher than average measured values for 1989 and 1990, but lower than maximum measured values.

TABLE 3-11. Comparison of simulated butadiene concentrations (ppb) to observed values at two Washington sites.

\begin{tabular}{|lccccc|}
\hline & \multicolumn{2}{c}{ Observed } & & \multicolumn{2}{c|}{ Simulated } \\
\cline { 2 - 3 } \cline { 6 - 7 } Site & Average & Maximum & & OPPE & NREL \\
\hline W1DC 24-hour, 1989 & 0.10 & 0.26 & & 0.12 & 0.18 \\
W1DC 24-hour, 1990 & 0.09 & 0.31 & & & \\
W1DC 6-9 a.m. 1984-85 & 0.54 & 1.40 & & 0.20 & 0.32 \\
W2DC 24-hour, 1989 & 0.19 & 0.35 & & 0.22 & 0.15 \\
W2DC 24-hour, 1990 & 0.18 & 0.51 & & & \\
\hline
\end{tabular}




\section{Summary}

The NREL base simulation produced higher ozone, RHC, and toxic concentrations than the earlier EPA and AAMA simulations. Ozone was generally underpredicted in the AAMA simulation and overpredicted in the NREL simulation. However, both simulations provided adequate model performance. Although ambient VOC data are

very limited, the model appeared to overpredict VOC concentrations. For toxics, the ambient database is sufficiently limited that the only conclusion that can be drawn is that simulated values are in the same range as typical to high measured values.

\section{Los Angeles}

The Los Angeles ozone episode selected for modeling was 26-28 August 1987, which was during the intensive South Coast Air Quality Study (SCAQS). Of all the SCAQS episodes, the 26-28 August period had the highest observed ozone levels. The large quantity of data available means that model performance can be evaluated for VOC and toxics. Table 3-12 lists the monitoring sites, and Figure 3-13 shows their locations.

The model inputs used for this episode are from the 1994 Air Quality Management Plan or AQMP (SCAQMD, 1994). These inputs have also been used for other recent SAI modeling exercises (with standard UAM), and the results matched those in the AQMP.

Differences between the AQMP and NREL base cases are:

- The AQMP simulation used the standard UAM model; the NREL simulation used UAM-Tox (version 6.22).

- The NREL simulation used an inventory with doubled onroad gasoline vehicle RHC emissions.

\section{Ozone}

Table 3-13 summarizes simulated peak ozone for the AQMP and NREL simulations. The first day, 26 August, is a model spin-up day; results for 27 and 28 August are presented and compared to measured ozone peaks.

TABLE 3-12. Los Angeles domain sites and pollutants monitored.

\begin{tabular}{|lll|}
\hline \multicolumn{1}{|c|}{ Site } & \multicolumn{1}{c|}{ County } & \multicolumn{1}{c|}{ Pollutants } \\
\hline Barstow & San Bernardino & $\mathrm{O}_{3}, \mathrm{NO}_{2}$ \\
Banning & Riverside & $\mathrm{O}_{3}$ \\
Azusa & Los Angeles & $\mathrm{O}_{3}, \mathrm{NO}_{2}, \mathrm{VOC}$ \\
Anaheim & Orange & $\mathrm{O}_{3}, \mathrm{NO}_{2}, \mathrm{VOC}$ \\
El Rio & Ventura & $\mathrm{O}_{3}, \mathrm{NO}_{2}$ \\
Crestline & San Bernardino & $\mathrm{O}_{3}$ \\
Costa Mesa & Orange & $\mathrm{O}_{3}, \mathrm{NO}_{2}$ \\
Burbank & Los Angeles & $\mathrm{O}_{3}, \mathrm{NO}_{2}, \mathrm{VOC}$ \\
Hemet & Riverside & $\mathrm{O}_{3}$ \\
Glendora & Los Angeles & $\mathrm{O}_{3}, \mathrm{NO}_{2}$ \\
\hline
\end{tabular}


TABLE 3-12. Concluded.

\begin{tabular}{|lll|}
\hline \multicolumn{1}{|c|}{ Site } & \multicolumn{1}{c|}{ County } & \multicolumn{1}{c|}{ Pollutants } \\
\hline Fontana & San Bernardino & $\mathrm{O}_{3}, \mathrm{NO}_{2}$ \\
El Toro & Orange & $\mathrm{O}_{3}$ \\
Lancaster & Los Angeles & $\mathrm{O}_{3}, \mathrm{NO}_{2}$ \\
La Habra & Los Angeles & $\mathrm{O}_{3}, \mathrm{NO}_{2}$ \\
Indio & Riverside & $\mathrm{O}_{3}$ \\
Hesperia & San Bernardino & $\mathrm{O}_{3}$ \\
Lynwood & Los Angeles & $\mathrm{O}_{3}, \mathrm{NO}_{2}$ \\
Los Angeles (downtown) & Los Angeles & $\mathrm{O}_{3}, \mathrm{NO}_{2}, \mathrm{VOC}$ \\
Los Alamitos & Los Angeles & $\mathrm{O}_{3}$ \\
Long Beach & Los Angeles & $\mathrm{O}_{3}, \mathrm{NO}_{2}$ \\
Palm Springs & Riverside & $\mathrm{O}_{3}, \mathrm{NO}_{2}$ \\
Ojai & Ventura & $\mathrm{O}_{3}$ \\
Norco & Riverside & $\mathrm{O}_{3}$ \\
Newhall & Los Angeles & $\mathrm{O}_{3}$ \\
Piru & Ventura & $\mathrm{O}_{3}$ \\
Pico Rivera & Los Angeles & $\mathrm{O}_{3}, \mathrm{NO}_{2}$ \\
Perris & Riverside & $\mathrm{O}_{3}$ \\
Pasadena & Los Angeles & $\mathrm{O}_{3}, \mathrm{NO}_{2}$ \\
Rubidoux & Riverside & $\mathrm{O}_{3}, \mathrm{NO}_{2}, \mathrm{VOC}$ \\
Reseda & Los Angeles & $\mathrm{O}_{3}, \mathrm{NO}_{2}$ \\
Redlands & San Bernardino & $\mathrm{O}_{3}$ \\
Pomona & Los Angeles & $\mathrm{O}_{3}, \mathrm{NO}_{2}$ \\
Upland & San Bernardino & $\mathrm{O}_{3}, \mathrm{NO}_{2}$ \\
Thousand Oaks & Ventura & $\mathrm{O}_{3}$ \\
Simi Valley & Ventura & $\mathrm{O}_{3}, \mathrm{NO}_{2}$ \\
San Bernardino & San Bernardino & $\mathrm{O}_{3}, \mathrm{NO}_{2}$ \\
Whittier & Los Angeles & $\mathrm{O}_{3}, \mathrm{NO}_{2}$ \\
West Los Angeles & Los Angeles & $\mathrm{O}_{3}, \mathrm{NO}_{2}$ \\
Victorville & San Bernardino & $\mathrm{O}_{3}$ \\
Ventura & Ventura & $\mathrm{O}_{3}$ \\
Hawthorne & Los Angeles & $\mathrm{VOC}$ \\
Long Beach City College & Los Angeles & $\mathrm{VOC}$ \\
Claremont & Los Angeles & $\mathrm{VOC}$ \\
\hline
\end{tabular}

TABLE 3-13. Comparison of simulated peak ozone (ppb) for Los Angeles AQMP and NREL base cases.

\begin{tabular}{|lcc|}
\hline \multicolumn{1}{|c}{ Simulation } & 27 August & 28 August \\
\hline Measured & 240 & 290 \\
AQMP & 161 & 191 \\
NREL base & 269 & 302 \\
\hline
\end{tabular}


Table 3-13 shows that:

- The NREL simulation slightly overpredicted peak ozone for both days whereas the AQMP simulation severely underpredicted peak ozone.

- The NREL simulation produced 67 percent more ozone than the AQMP simulation on 27 August and 58 percent more ozone on 28 August, more closely matching observed values.

If we assume that the majority of the difference between the AQMP and NREL base simulations is due to the difference in motor vehicle emissions rather than the difference in model formulations, comparison to Table 3-4 shows that the Los Angeles simulation is much more sensitive to the increase in VOC emissions than is the Baltimore simulation. This is discussed further below in the RHC/NO section.

Quantitative measures of ozone model performance for the NREL simulation are summarized in Table 3-14. Model performance for 27 August is within the recommended range for all parameters, although the unsigned relative error is near the upper end of the range. However, model performance is not within the recommended range for 28 August, despite the fact that the unpaired peak accuracy is very good. Nonetheless, model performance is greatly improved over the AQMP simulation.

TABLE 3-14. Ozone model performance for the NREL Los Angeles base simulation for 27 and 28 August 1987.

\begin{tabular}{|lccc|}
\hline \multicolumn{1}{|c}{ Measure } & $\begin{array}{c}\text { Recommended } \\
\text { Range }\end{array}$ & 27 August & 28 August \\
\hline Unpaired peak accuracy $^{*}(\%)$ & $< \pm 15-20$ & +12 & +4 \\
Mean relative error ${ }^{*}(\%)$ & $< \pm 5-15$ & -6 & +17 \\
Mean unsigned relative error (\%) & $<30-35$ & 33 & 39 \\
\hline
\end{tabular}

"Defined as (simulated - observed)/observed

Ozone isopleth plots for the NREL base simulation are provided in Figure 3-14. For 27 August, the highest peak ozone values ( $240 \mathrm{ppb}$ ) were observed above $80 \mathrm{~km}$ east of Los Angeles, in Riverside and San Bernardino counties (Redlands and Rubidoux sites). The simulated ozone peak in this subregion was located slightly to the south of the observed peaks, and was of lower magnitude (approximately $200 \mathrm{ppb}$ ). The simulated domain maximum ozone peak (269 ppb) was located $35 \mathrm{~km}$ north of Los Angeles. The nearest monitoring sites (Burbank, Reseda, and Newhall) recorded peak ozone levels of $160 \mathrm{ppb}$ or less. Thus, this peak significantly overestimates ozone in the western portion of the modeling domain.

For 28 August, the highest peak ozone value (290 ppb) was observed in Glendora, in the San Gabriel Valley $50 \mathrm{~km}$ east of Los Angeles. The simulated peak was located $25 \mathrm{~km}$ southeast of the observed peak. However, the magnitude of the simulated peak was $302 \mathrm{ppb}$, in good agreement with the observed Glendora value. Again, high ozone was simulated north of Los Angeles, with a peak of approximately $260 \mathrm{ppb}$ located east of Newhall, in the same location as the 27 August peak. The highest observed ozone in the vicinity was $170 \mathrm{ppb}$ at Burbank.

Time series of simulated and observed ozone are shown in Figure 3-15. The diurnal pattern of the observed ozone peaks is generally well replicated by the model, with simulated 28 
August peaks at San Gabriel Valley sites such as Azusa, Glendora, and Pomona occurring at the same hour as the observed peaks.

\section{$R H C$ and $N O_{x}$}

Table 3-15 summarizes the modeling inventories for $\mathrm{RHC}$ and $\mathrm{NO}_{\mathrm{x}}$ for the AQMP and NREL base cases. The VOC/NO ratio of the anthropogenic portion of the AQMP inventory is 3.1. The $\mathrm{RHC} / \mathrm{NO}_{\mathrm{x}}$ ratio of the anthropogenic NREL inventory is 4.7. The corresponding VOC/NO $/$ ratio would be approximately 10 to 15 percent higher.

Isopleth plots of simulated and observed peak $\mathrm{NO}_{2}$ are given in Figure 3-16. For 27 August, the simulated peak of $120 \mathrm{ppb}$ occurs $5 \mathrm{~km}$ northeast of the downtown L.A. site, which recorded a peak $\mathrm{NO}_{2}$ of $130 \mathrm{ppb}$. Two sites in the San Gabriel Valley, Pomona and Upland, also recorded a peak $\mathrm{NO}_{2}$ of $130 \mathrm{ppb}$, which was not replicated by the model.

TABLE 3-15. Summary of emission inventories (tpd) for the August 1987 Los Angeles episode, AQMP and NREL base cases.

\begin{tabular}{|lrrrrr|}
\hline \multirow{2}{*}{ Component } & \multicolumn{2}{c}{ AQMP } & & \multicolumn{2}{c|}{ NREL } \\
\cline { 2 - 3 } \cline { 5 - 6 } & VOC & NO $_{x}$ & & RHC & NO $_{x}$ \\
\hline Onroad mobile & 856 & 777 & & 1727 & 732 \\
Area and Nonroad & $162^{\mathrm{a}}$ & $438^{\mathrm{a}}$ & & 649 & 580 \\
Points & $660^{\mathrm{b}}$ & $319^{\mathrm{b}}$ & & 279 & 296 \\
Total anthropogenic & 1678 & 1534 & & 2655 & 1608 \\
Onroad mobile percent of & $51 \%$ & $50 \%$ & & $65 \%$ & $46 \%$ \\
anthropogenic & & & & \\
Biogenic & 130 & 0 & & 257 & 0 \\
Total emissions & 1808 & 1534 & & 2912 & 1608 \\
\hline a AQMP totals for nonroad emissions. & & \\
b AQMP totals for stationary (area and point) emissions.
\end{tabular}

For 28 August, the simulated $\mathrm{NO}_{2}$ peak was $212 \mathrm{ppb}$ and significantly overpredicted the downtown Los Angeles peak of $130 \mathrm{ppb}$. The peak $\mathrm{NO}_{2}$ observation occurred at Azusa (between Glendora and Pasadena) and was not replicated by the model. Throughout the domain, the model generally underpredicted $\mathrm{NO}_{2}$ on 27 August and overpredicted on 28 August.

Time-series comparisons of simulated and observed $\mathrm{NO}_{2}$ concentrations are presented in Figure 3-17. The model reproduces observed $\mathrm{NO}_{2}$ peaks reasonably well at many urban sites. For some suburban sites, the model appears to miss the morning peak. By comparison to the $A Q M P$, the morning $\mathrm{NO}_{2}$ peak at some sites is simulated more accurately in the NREL simulation. Since the $\mathrm{NO}_{\mathrm{x}}$ inventories are very similar, the increased morning $\mathrm{NO}_{2}$ is likely due to more rapid conversion of NO in the NREL simulation because of the higher RHC levels.

A wealth of VOC data are available for the 27-28 August episode. At seven sites, hourly speciated VOC observations are available for three time periods $(0600-0700,1100-1200$, and 1500-1600 LST). At two additional sites, hourly speciated VOC observations are 
available for six time periods (0400-0500, 0600-0700, 0800-0900, 1100-1200, 1300-1400, and 1500-1600 LST). These data were converted into UAM-Tox species using the same chemical allocation factors used to process VOC emissions.

Figure 3-18 shows time series of simulated and observed RHC. Simulated and observed values are generally in fairly good agreement, although the diurnal patterns do not always match well. The large shaded areas on these plots indicates that spatial gradients of simulated RHC are large. The model seems to have missed 28 August morning RHC peaks at sites such as Burbank and Azusa.

For all the RHC comparisons presented here, the observations include only identified hydrocarbons, formaldehyde, and acetaldehyde. Inclusion of other species, such as higher aldehydes and unidentified compounds, would increase RHC observations on the order of 30-50 percent.

Time series of simulated and observed $\mathrm{RHC} / \mathrm{NO}_{\mathrm{x}}$ are presented in Figure 3-19. The model predicts $\mathrm{RHC} / \mathrm{NO}_{\mathrm{x}}$ well at several sites (downtown Los Angeles, Anaheim, Long Beach City College, Hawthorne) but overpredicts the ratio at other sites. It is also noteworthy that the simulated morning $\mathrm{RHC} / \mathrm{NO}_{\mathrm{x}}$ tends to be higher than the emission inventory ratio.

Table 3-16 shows the RHC composition and reactivity for the Los Angeles inventory. Compared to the Baltimore inventory, the onroad mobile portion of the Los Angeles inventory accounts for a much larger portion of the total reactivity, despite accounting for a similar portion of RHC emissions. Two differences contribute to this effect:

- The onroad mobile portion of the Los Angeles inventory has a much higher ratio of exhaust to nonexhaust emissions, and hence is more reactive than the Baltimore mobile inventory.

- The rest of the Los Angeles inventory is much lower in reactivity than the corresponding sources in the Baltimore inventory.

A portion of this effect is due to the greater use of natural gas as a fuel in the Los Angeles area, which would lead to emissions with lower average reactivity. However, another factor is the differences in speciation profiles and profile assignments. The Los Angeles inventory used CARB speciation profiles and assignments of profiles to source categories, whereas the Baltimore inventory (and all inventories outside of California) used EPA speciation profiles and assignments.

Figure 3-20 shows time series of observed and simulated PAR concentrations. As the largest component of RHC, the PAR comparison looks very similar to the RHC comparison. Figure 3-21 shows the comparison for OLE, one of the most reactive components of RHC emissions. Again, the agreement is quite good, with simulated values in the same range as observations and often showing similar diurnal patterns. Figure 3-22 shows the comparison for IOLE, another highly reactive inventory component. IOLE concentrations appear to be overpredicted at the downtown Los Angeles and Hawthorne sites but are close to observations at other sites. As shown in Table 3-16, onroad mobile sources are responsible for virtually all of the IOLE in the Los Angeles inventory. 
TABLE 3-16. RHC composition and MIR reactivity for the Los Angeles base-case anthropogenic inventory.

\begin{tabular}{|c|c|c|c|c|}
\hline \multirow[b]{2}{*}{ Species } & \multicolumn{2}{|c|}{ Onroad Mobile } & \multicolumn{2}{|c|}{ Other Low-Level } \\
\hline & $\begin{array}{l}\text { Emissions } \\
\text { (tpd) }\end{array}$ & Reactivity & $\begin{array}{l}\text { Emissions } \\
\quad \text { (tpd) }\end{array}$ & Reactivity \\
\hline OLE & 71 & 1027 & 19 & 269 \\
\hline PAR & 1121 & 1163 & 666 & 691 \\
\hline TOL & 180 & 278 & 126 & 194 \\
\hline $\mathrm{XYL}$ & 159 & 1139 & 49 & 347 \\
\hline ETH & 101 & 704 & 29 & 201 \\
\hline ISOP & 2.0 & 26 & 0 & 0 \\
\hline PFORM & 11.8 & 204 & 4.5 & 78 \\
\hline FORM & 7.1 & 124 & 0.1 & 2 \\
\hline PACET & 4.6 & 41 & 2.6 & 23 \\
\hline ACET & 8.7 & 79 & 0.2 & 2 \\
\hline ALDX & 5.5 & 62 & 1.9 & 21 \\
\hline IOLE & 47 & 679 & 1.2 & 18 \\
\hline CRES & 5.1 & 8 & 0.1 & 0 \\
\hline $\mathrm{MEOH}$ & 1.9 & 2 & 0 & 0 \\
\hline ETOH & 2.0 & 4 & 22 & 45 \\
\hline METH & 135 & 1 & 907 & 9 \\
\hline Total & 1862 & 5541 & 1828 & 1900 \\
\hline Percent of total & $50 \%$ & $74 \%$ & $50 \%$ & $26 \%$ \\
\hline Specific reactivity & & 2.98 & & 1.04 \\
\hline Total w/o METH & 1727 & 5539 & 921 & 1891 \\
\hline Percent of total w/o METH & $65 \%$ & $75 \%$ & $35 \%$ & $25 \%$ \\
\hline Specific reactivity w/o METH & & 3.21 & & 2.05 \\
\hline
\end{tabular}

The comparisons for the aromatic species TOL and XYL are shown in Figures 3-23 and 324. Both TOL and XYL appear to be underpredicted at some sites. In particular, XYL (the more reactive of the two species) is underpredicted at the downtown Los Angeles and Burbank sites.

Finally, the comparison for the biogenic species ISOP is shown in Figure 3-25. Isoprene concentrations match observations fairly well at all sites except Claremont, where the model underpredicts isoprene levels.

Although we attempted to compare the NREL simulated values for these species to those from the AQMP, we were unable to do so, since the values in the AQMP (simulated and observed) appear to be incorrect, or at least appear to have an inconsistency in units used. For example, the simulated and observed XYL values reported in the AQMP are on the order of $80 \mathrm{ppb}$; those in Figure 3-24 are 5-15 ppb. It is possible that the AQMP values are 
actually ppbC, but even if that assumption is made, the observed values reported in the AQMP do not match those derived for this study.

\section{Toxics}

Isopleth plots of simulated daily average toxics concentrations are provided in Figures 3-26 through 3-29. For the aldehydes, separate plots are provided for primary (PHCHO and PACET), secondary (FORM and ACET) and total concentrations (TFORM and TACET).

Formaldehyde. The maximum simulated 24-hour average formaldehyde concentration of $13.5 \mathrm{ppb}$ for 27 August occurred just northwest of Pico Rivera. For 28 August, the peak of $17.5 \mathrm{ppb}$ occurred at the downtown Los Angeles site. These are comparable to the maximum concentrations in the Baltimore simulation. Simulated formaldehyde concentrations over the ocean suggest that the western boundary concentration for formaldehyde may have been too high.

Hourly formaldehyde predictions are compared to observations in Figure 3-30 for the nine sites for which observations were available. In general, the agreement is quite good, with no apparent evidence of systematic over- or underprediction. Predictions match observations particularly well at the Burbank site, underpredict somewhat at Anaheim, and overpredict somewhat at downtown Los Angeles. The simulated values show peaks occurring at various times of the day, generally between 0900 and 1400 LST. At some sites, double peaks are simulated. The observations are not sufficient to assess the accuracy of the simulated diurnal pattern of formaldehyde concentrations. The complex behavior of formaldehyde is due to the fact that peak concentrations are a combination of primary emissions and secondary formation.

Acetaldehyde. The maximum simulated 24-hour average acetaldehyde concentration was $9.0 \mathrm{ppb}$ for 27 August and $13.3 \mathrm{ppb}$ for 28 August (Figure 3-27). The 28 August maximum value is twice the maximum acetaldehyde concentration from the Baltimore domain. Hourly acetaldehyde predictions are compared to observations in Figure 3-31. As with formaldehyde, predictions match observations well at Burbank, underpredict at Anaheim, and overpredict at downtown Los Angeles. There appears to be a trend toward simulated peaks occurring later in the day than the observed peaks at some sites, although this is difficult to determine since most sites have only three data points.

Benzene. The maximum simulated 24-hour average benzene concentration was $5.3 \mathrm{ppb}$ for 27 August and $7.5 \mathrm{ppb}$ for 28 August (Figure 3-28). Hourly benzene predictions are compared to observations in Figure 3-32. At most sites, the agreement is good. Benzene is overpredicted at Hawthorne and underpredicted at Burbank.

Butadiene. The maximum simulated 24-hour average butadiene concentration was $0.66 \mathrm{ppb}$ for 27 August and $0.88 \mathrm{ppb}$ for 28 August (Figure 3-29). Hourly butadiene predictions are compared to observations in Figure 3-33. Butadiene is extremely reactive, and this is apparent by the low values observed and simulated during the afternoon. As with the other RHC and toxic species, the model generally reproduced observations except for missing some of the morning peaks at locations such as Burbank and Azusa. 


\section{CONCLUSIONS}

Model performance for ozone, precursors, and toxics is generally quite good, with few systematic over- or underpredictions. Exceptions are morning peaks of $\mathrm{RHC}$ and $\mathrm{NO}_{2}$ at some suburban sites, which are not reproduced by the model. Although model performance for ozone for 28 August was not within EPA guidelines, this simulation provides better model performance than the AQMP base simulation and is adequate for the purposes of this study.

Comparison of speciated RHC emissions to those in the Baltimore inventory shows that the nonmobile portion of the Baltimore inventory is much more reactive than in the Los Angeles inventory. If the Los Angeles nonmobile inventory is unrealistically low in reactivity, the doubled onroad RHC inventory could be partly compensating for an underprediction in the nonmobile portion of the RHC inventory.

There is some evidence that the doubled onroad mobile inventory resulted in emissions in downtown Los Angeles that were too high (see the IOLE comparison in Figure 3-22). However, there is evidence at several suburban sites (e.g., Burbank, Azusa) that morning onroad mobile emissions in those areas are still underpredicted. This suggests that further investigation of the spatial distribution of the mobile emissions is warranted. 


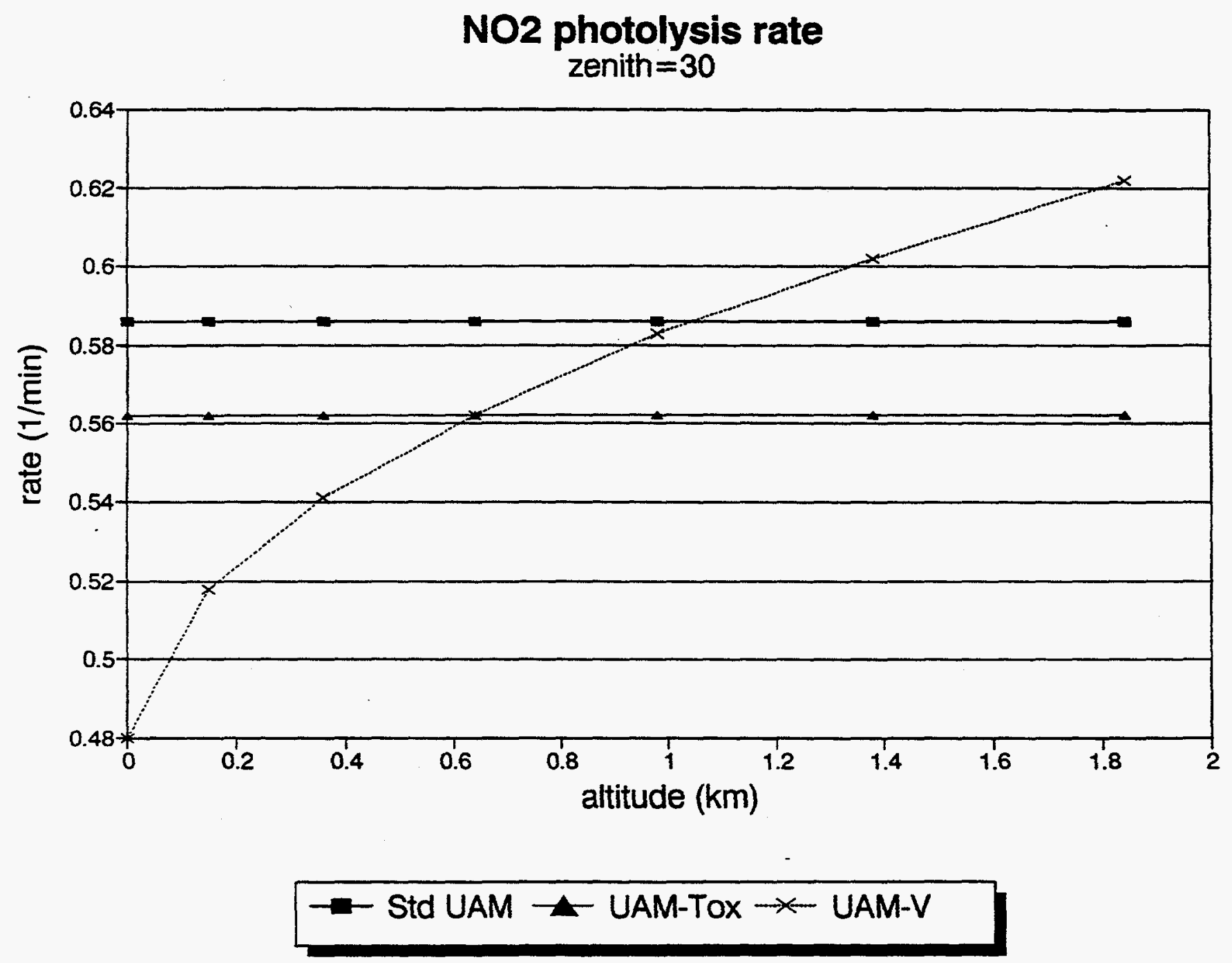

FIGURE 3-1. Comparison of $\mathrm{NO}_{2}$ photolysis rates used in the standard UAM, UAM-Tox, and UAM-V models. 


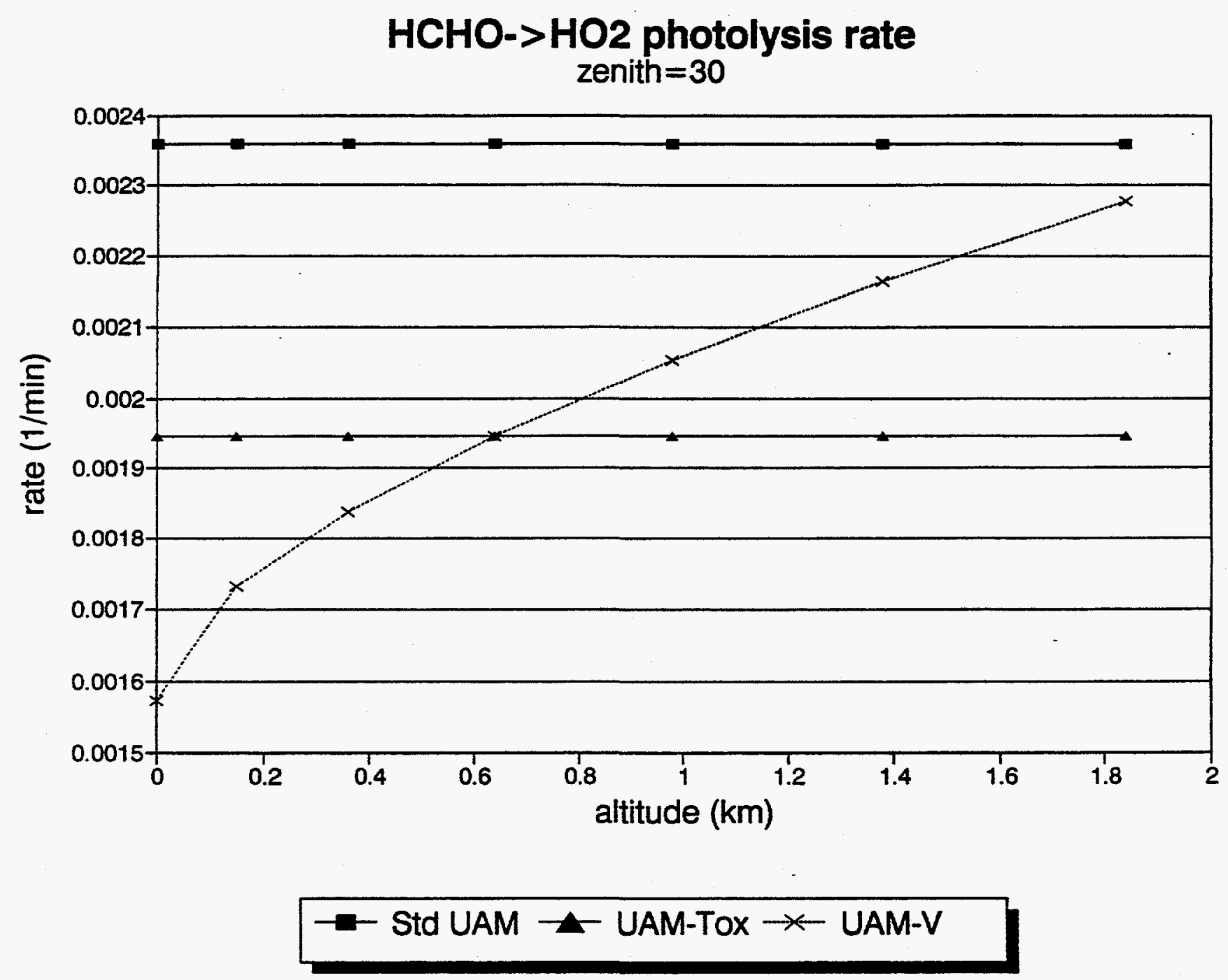

FIGURE 3-2. Comparison of formaldehyde photolysis rates (radical-generating pathway) used in the standard UAM, UAM-Tox, and UAM-V models. 


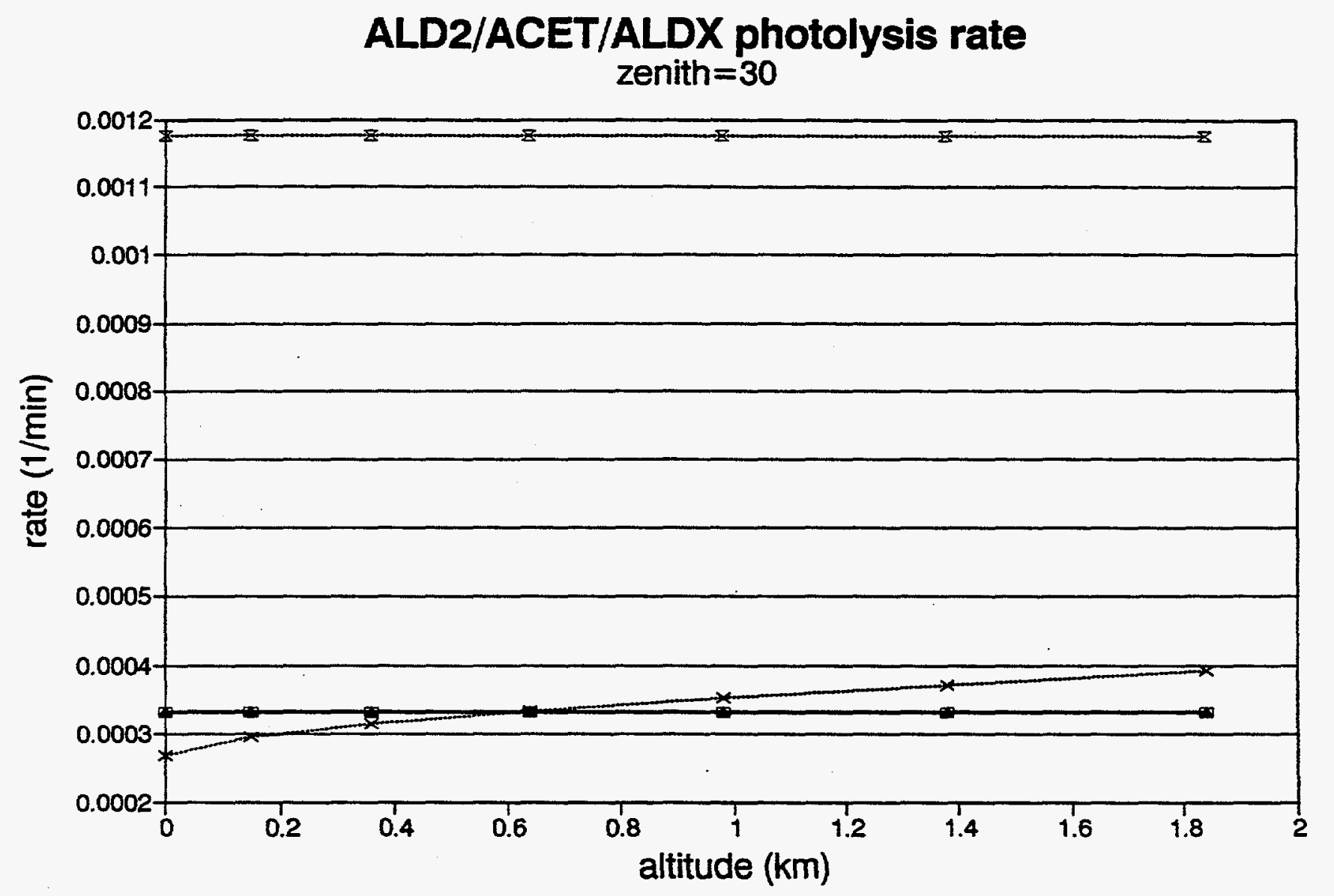

FIGURE 3-3. Comparison of higher aldehyde photolysis rates used in the standard UAM, UAMTox, and UAM-V models. 


\section{CBM4 version comparison $500 \mathrm{ppbC}$ initial RHC}

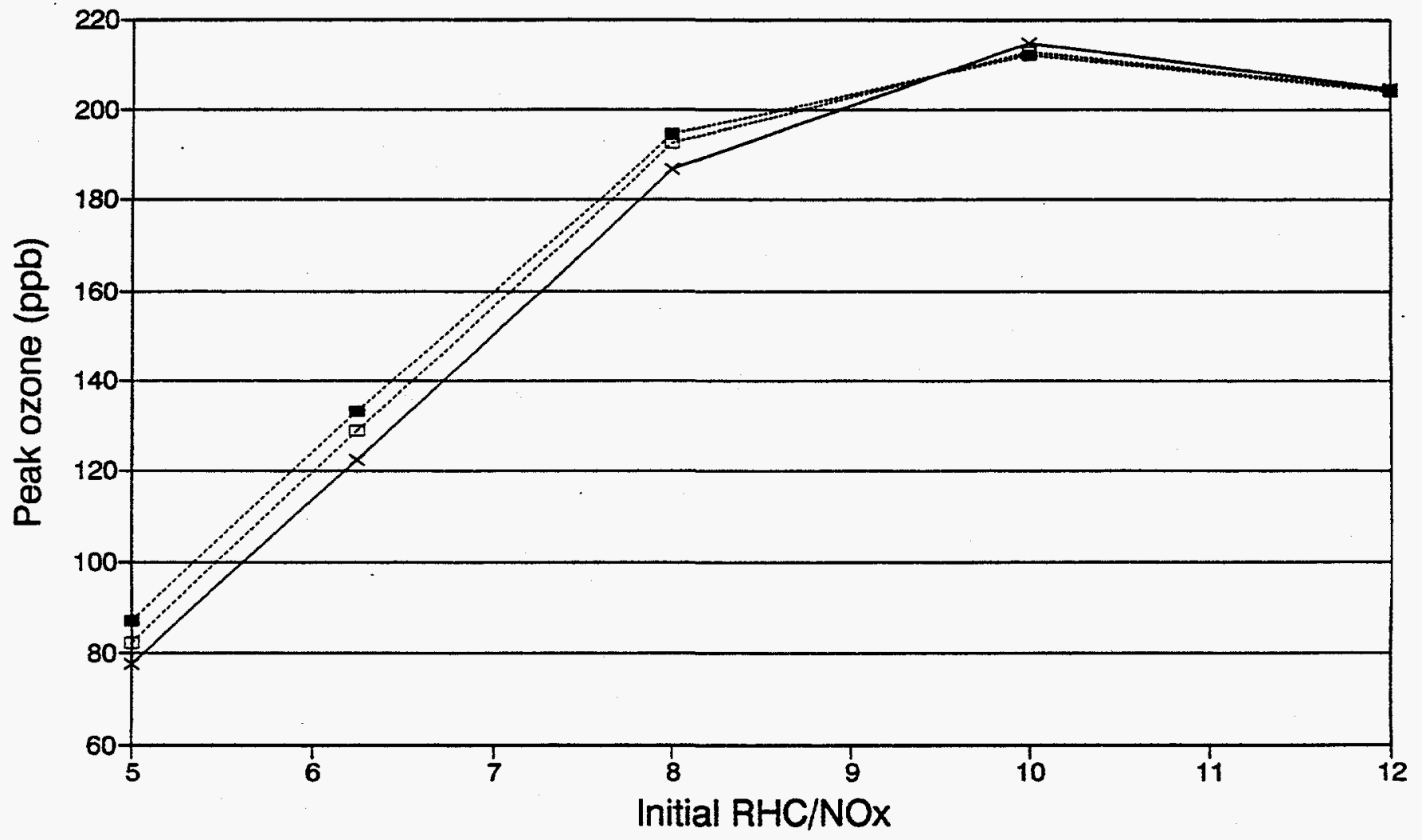

\section{$\leftarrow$ Std UAM $\square$ Tox $6.0 \rightarrow-$ Tox 6.22}

FIGURE 3-4. Comparison of peak ozone, as a function of initial $\mathrm{RHC} / \mathrm{NO}_{\mathrm{x}}$, predicted by OZIPM4 using the chemical mechanisms in the standard UAM, UAM-Tox version 6.0 (Ligocki and Whitten, 1992), and UAM-Tox version 6.22 (this study). 


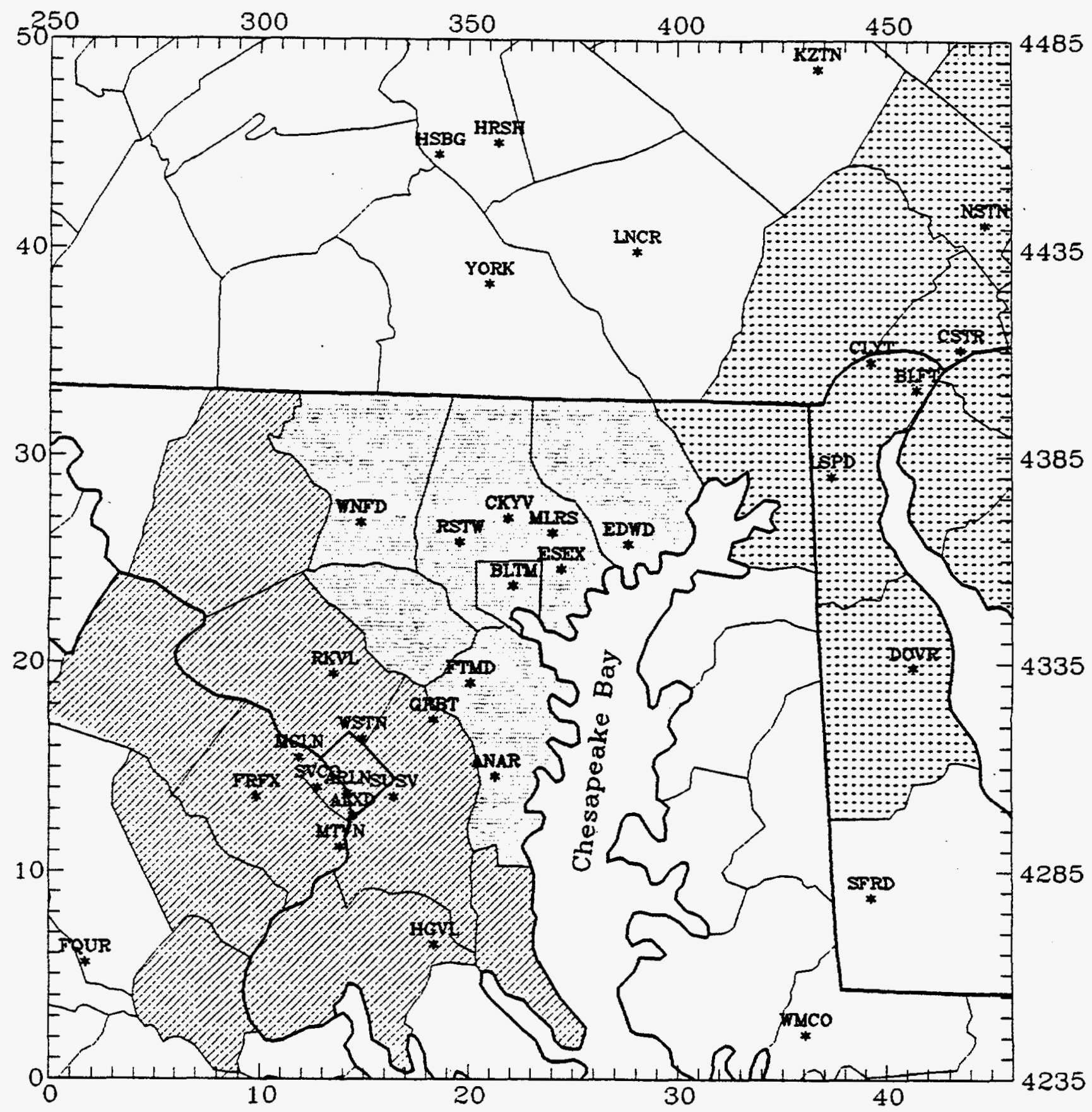

FIGURE 3-5. Baltimore modeling domain. 
LEVEL 1 Ozone (pphm)

Time: 0-2400 July 5, 1988
+ MAXIMUM $=17.2 \mathrm{pphm}$

- MINIMUM $=4.2 \mathrm{pphm}$

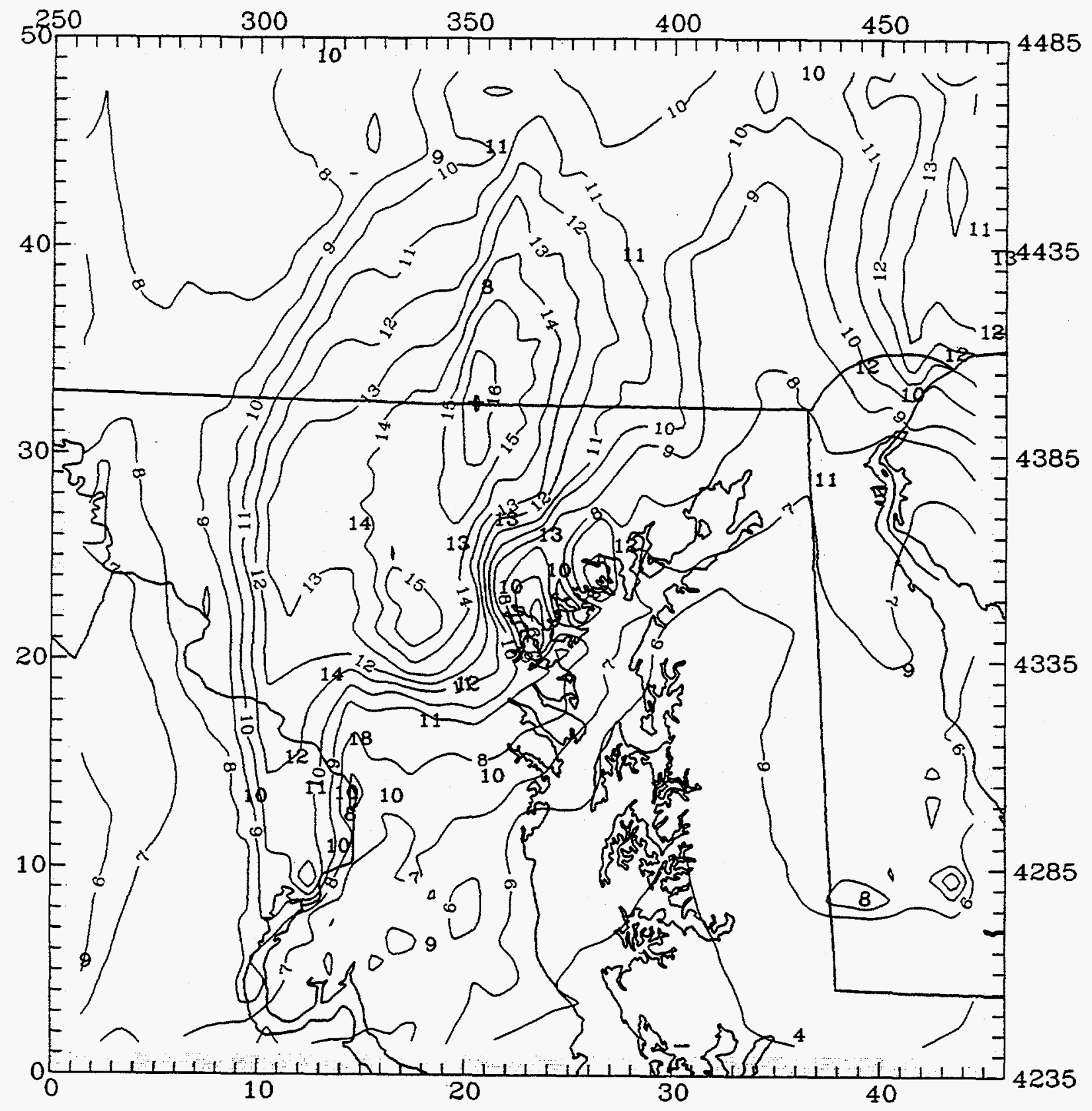

FIGURE 3-6a. Maximum simulated ozone concentrations (pphm) in the Baltimore domain: UAM-Tox predictions for July 5, 1988. 
LEVEL 1 Ozone (pphm)

Time: $0-2400$ July 6,1988
+ MAXIMUM $=20.8 \mathrm{pphm}$

- MINIMUM $=5.7 \mathrm{pphm}$

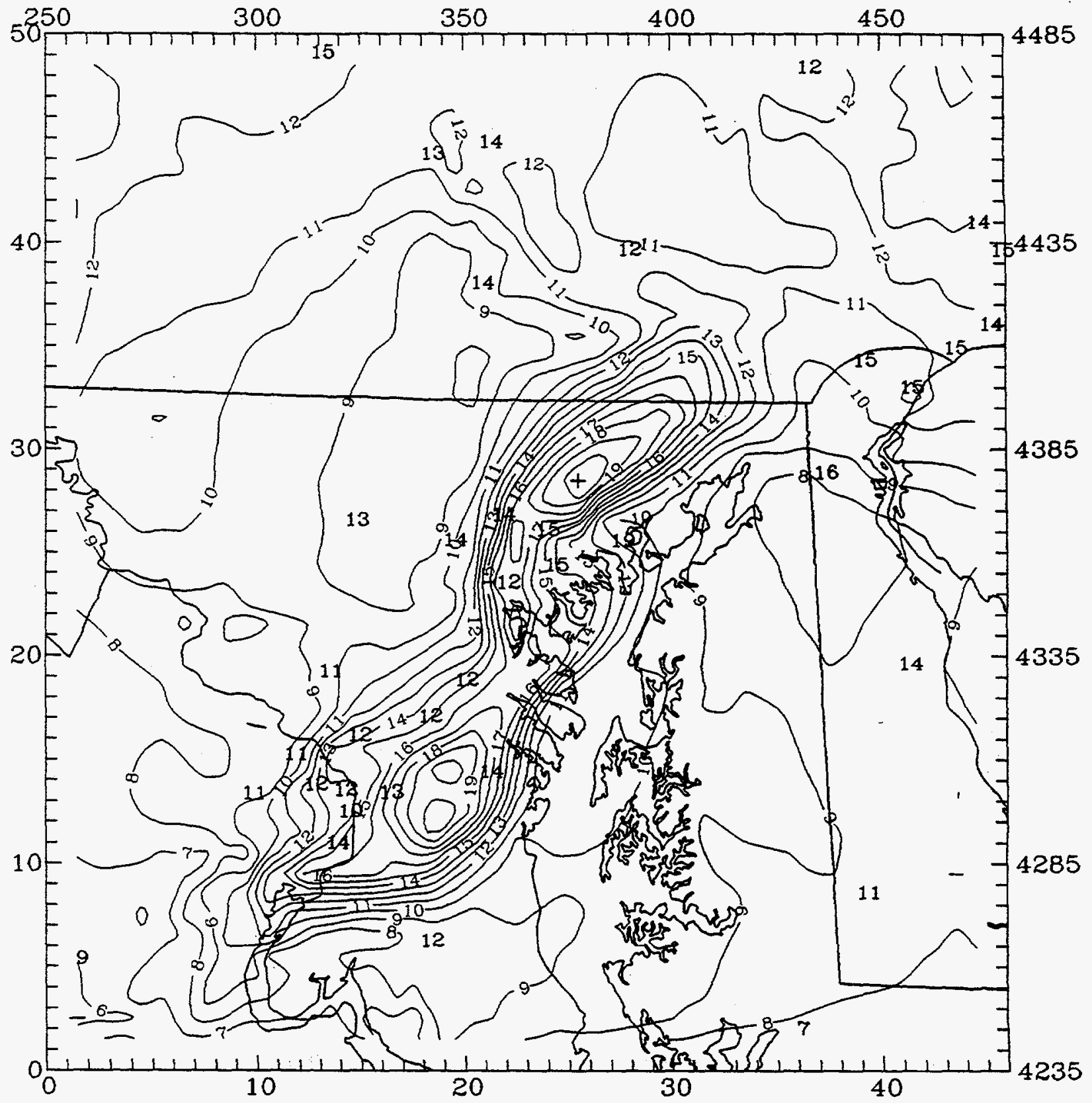

FIGURE 3-6b. Maximum simulated ozone concentrations (pphm) in the Baltimore domain: UAM-Tox predictions for July 6, 1988. 

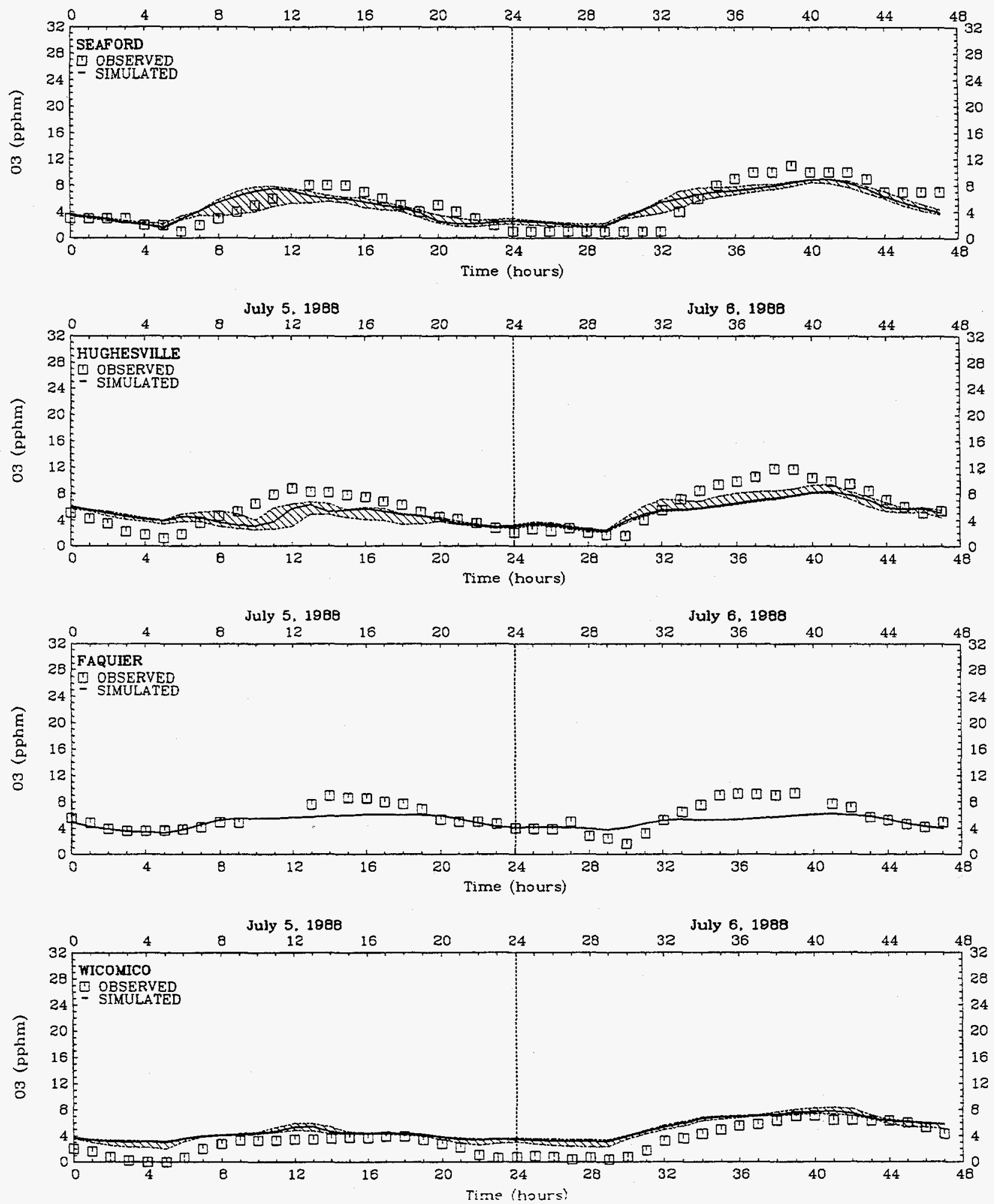

FIGURE 3-7. Simulated and observed ozone concentrations (pphm) at monitoring sites in the Baltimore domain for the July 5-6, 1988 base episode. 

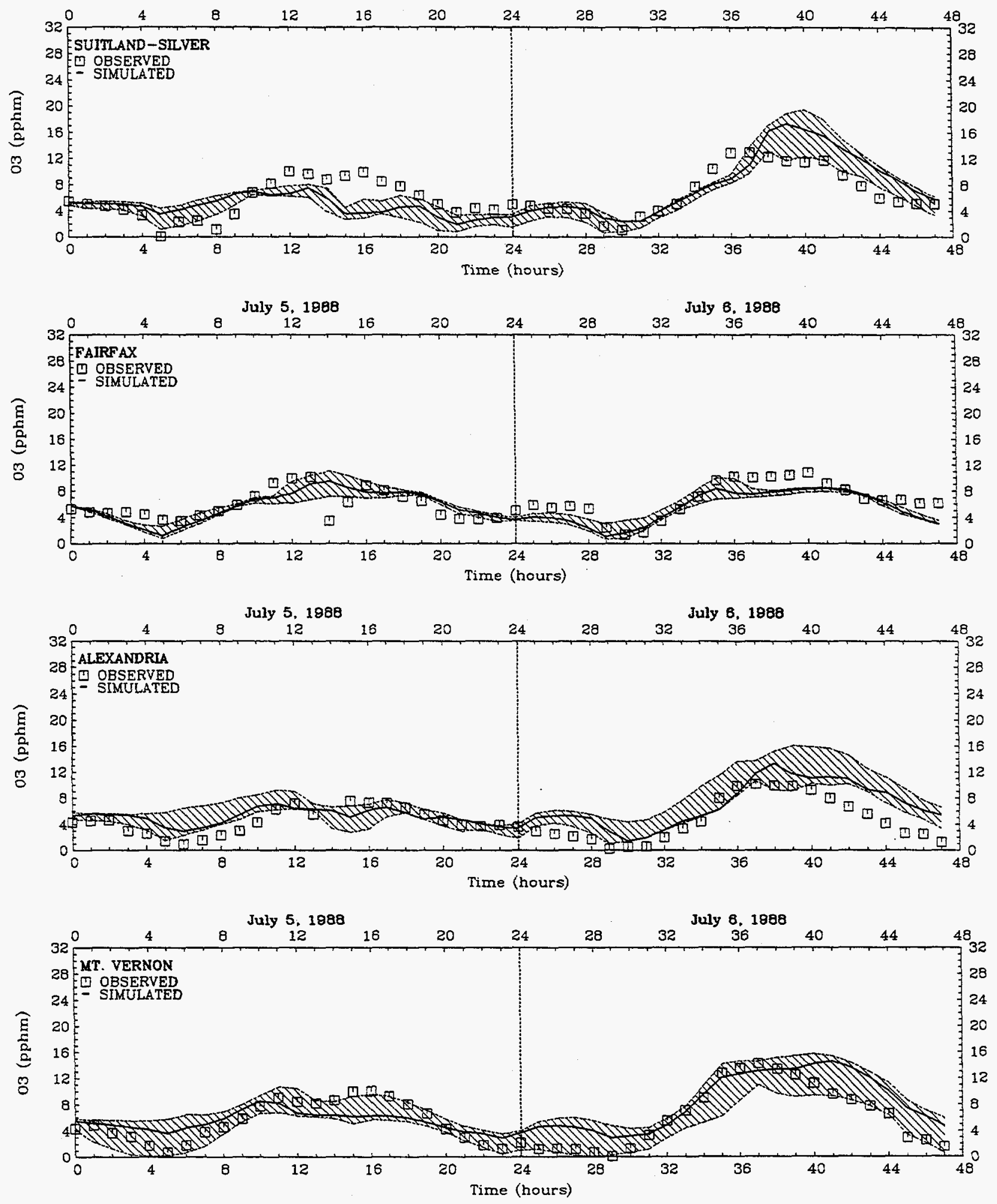

FIGURE 3-7. Continued. 

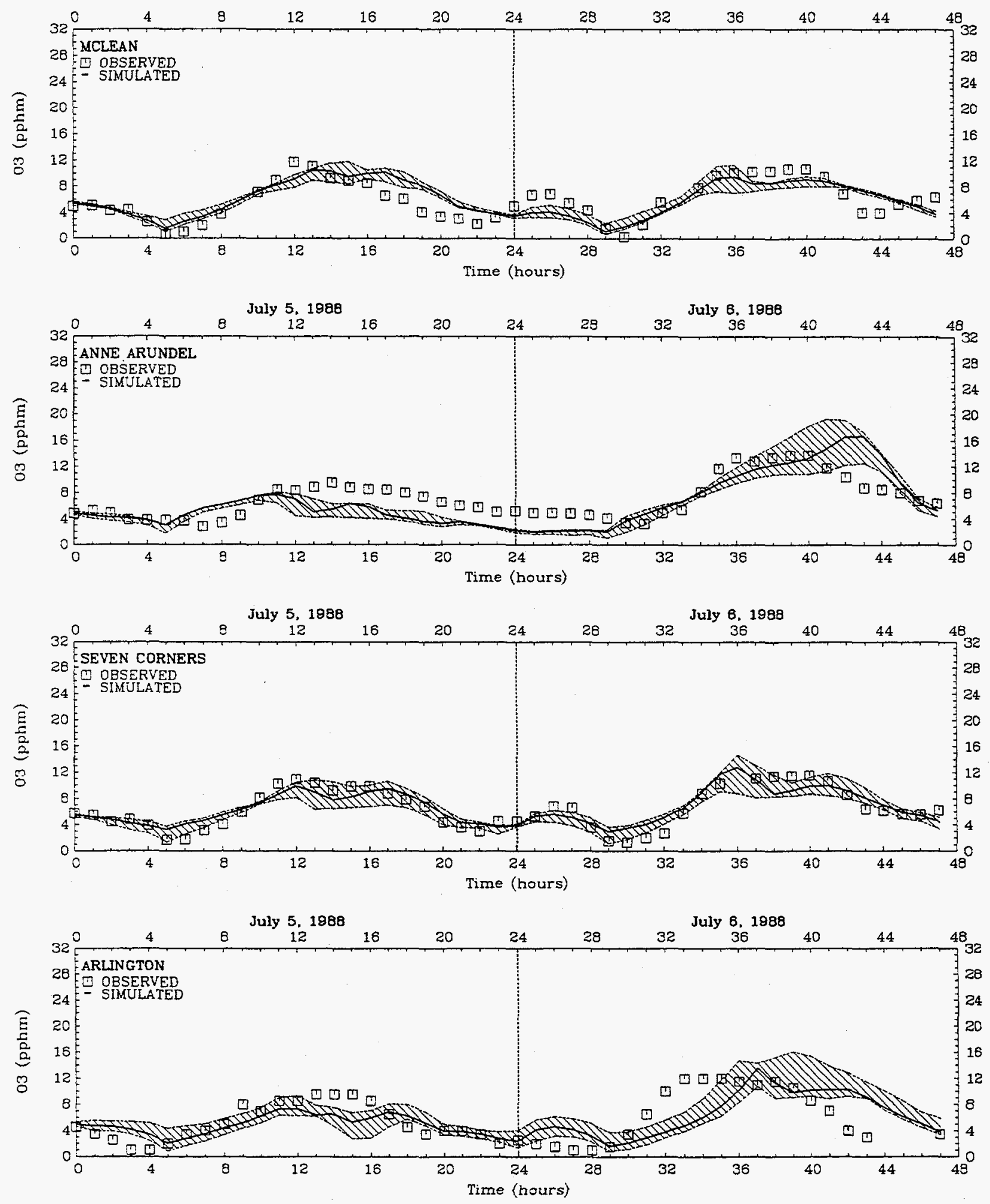

FIGURE 3-7. Continued. 

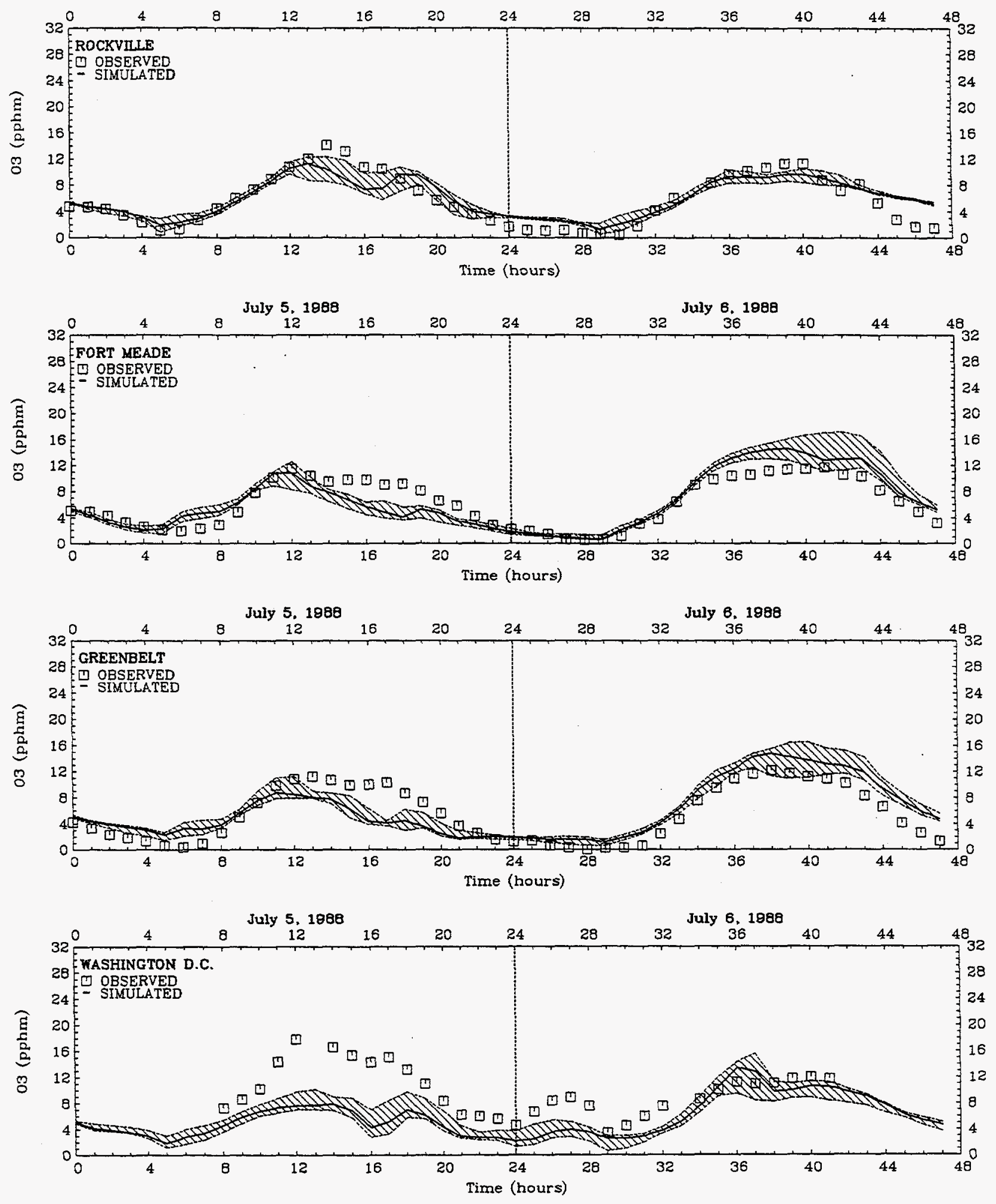

FIGURE 3-7. Continued. 

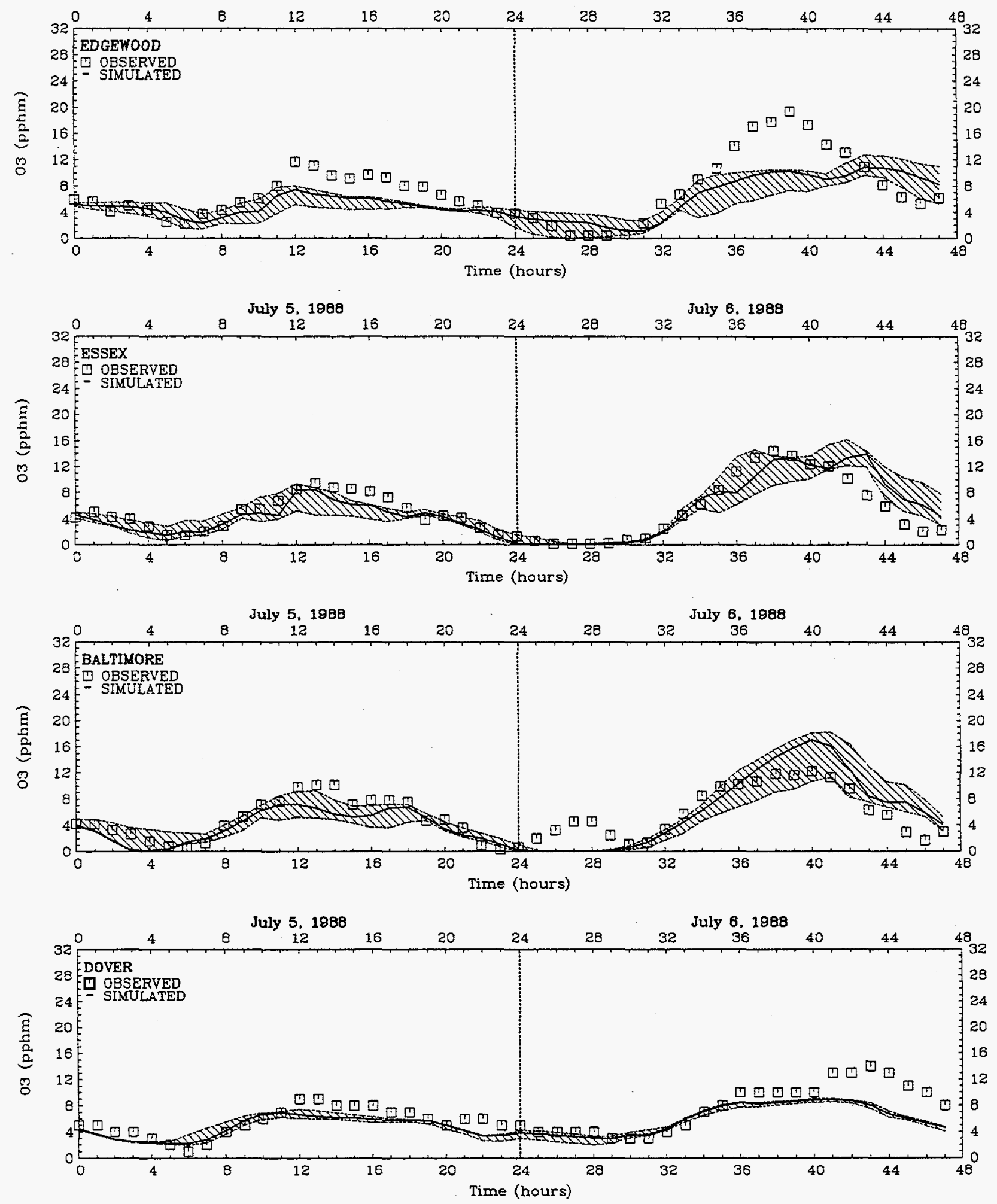

FIGURE 3-7. Continued. 

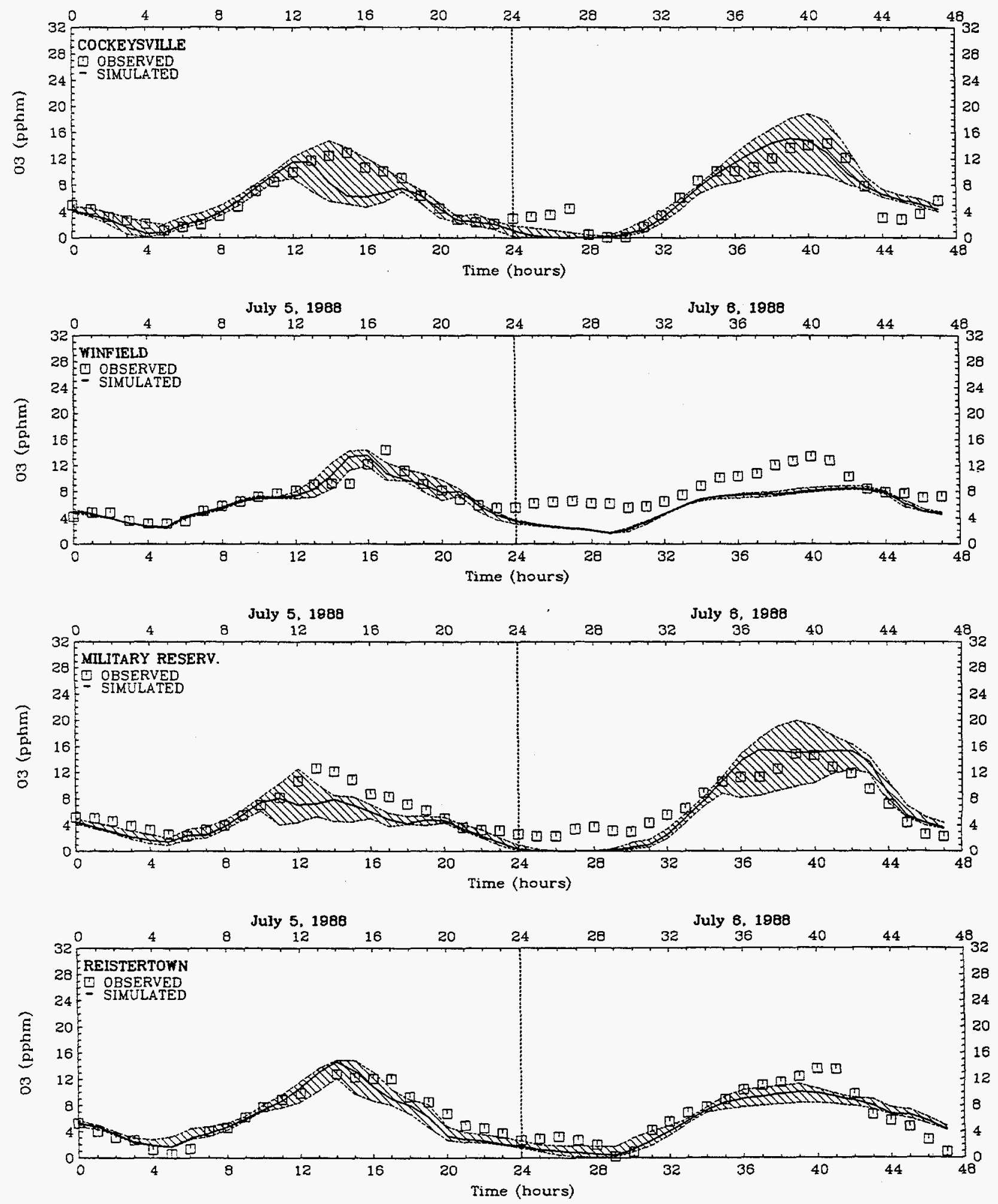

FIGURE 3-7. Continued. 

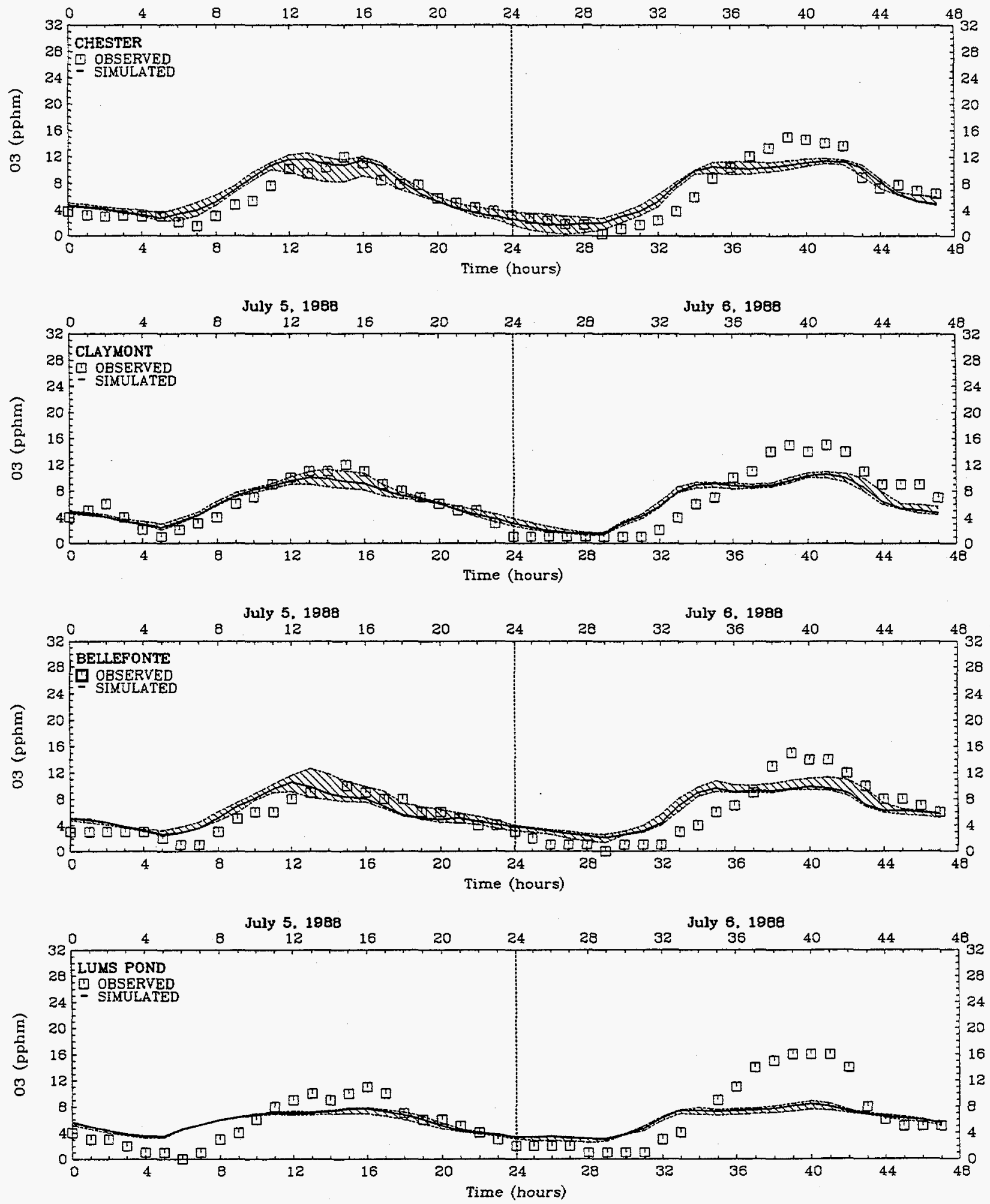

FIGURE 3-7. Continued. 

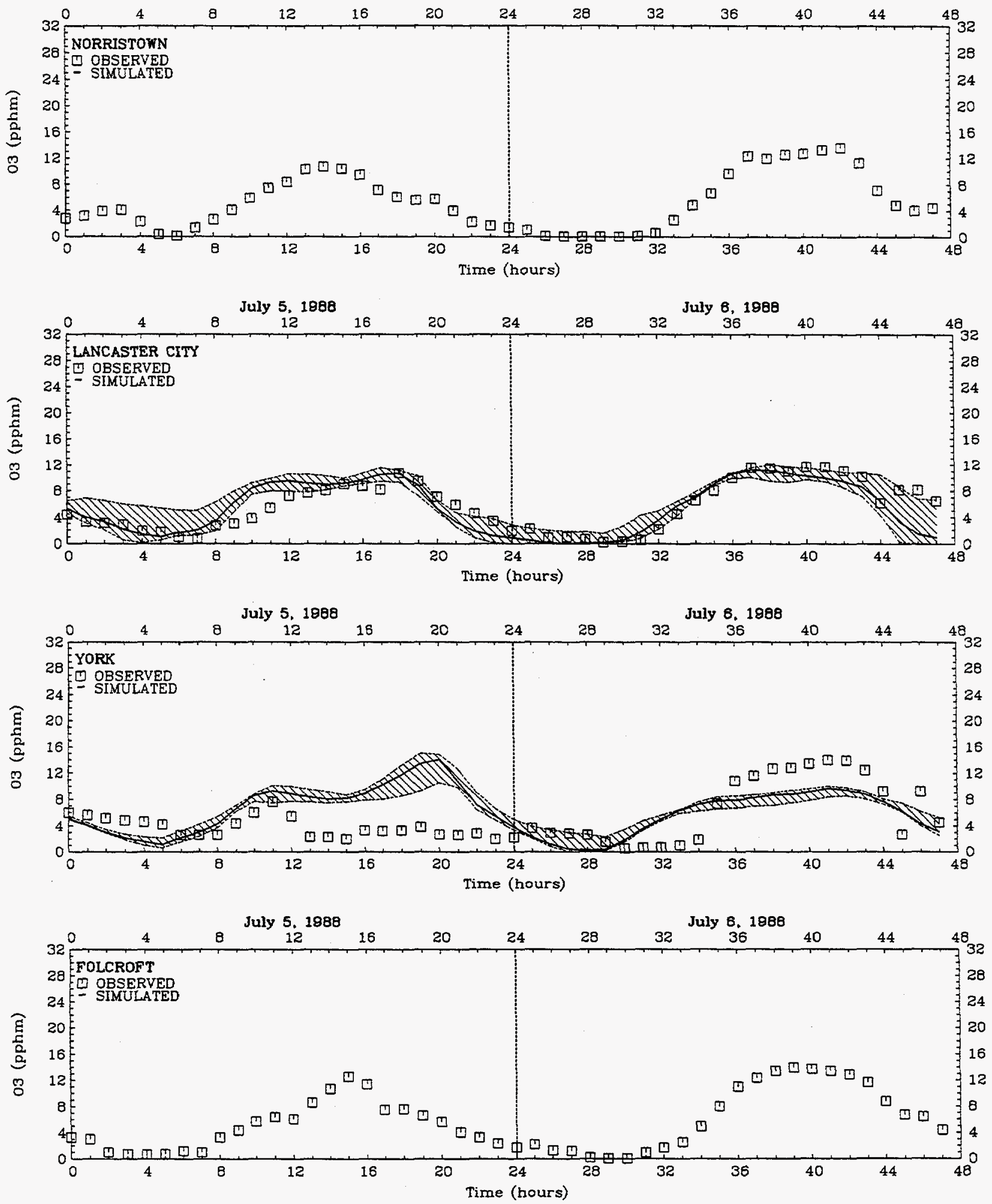

FIGURE 3-7. Continued. 

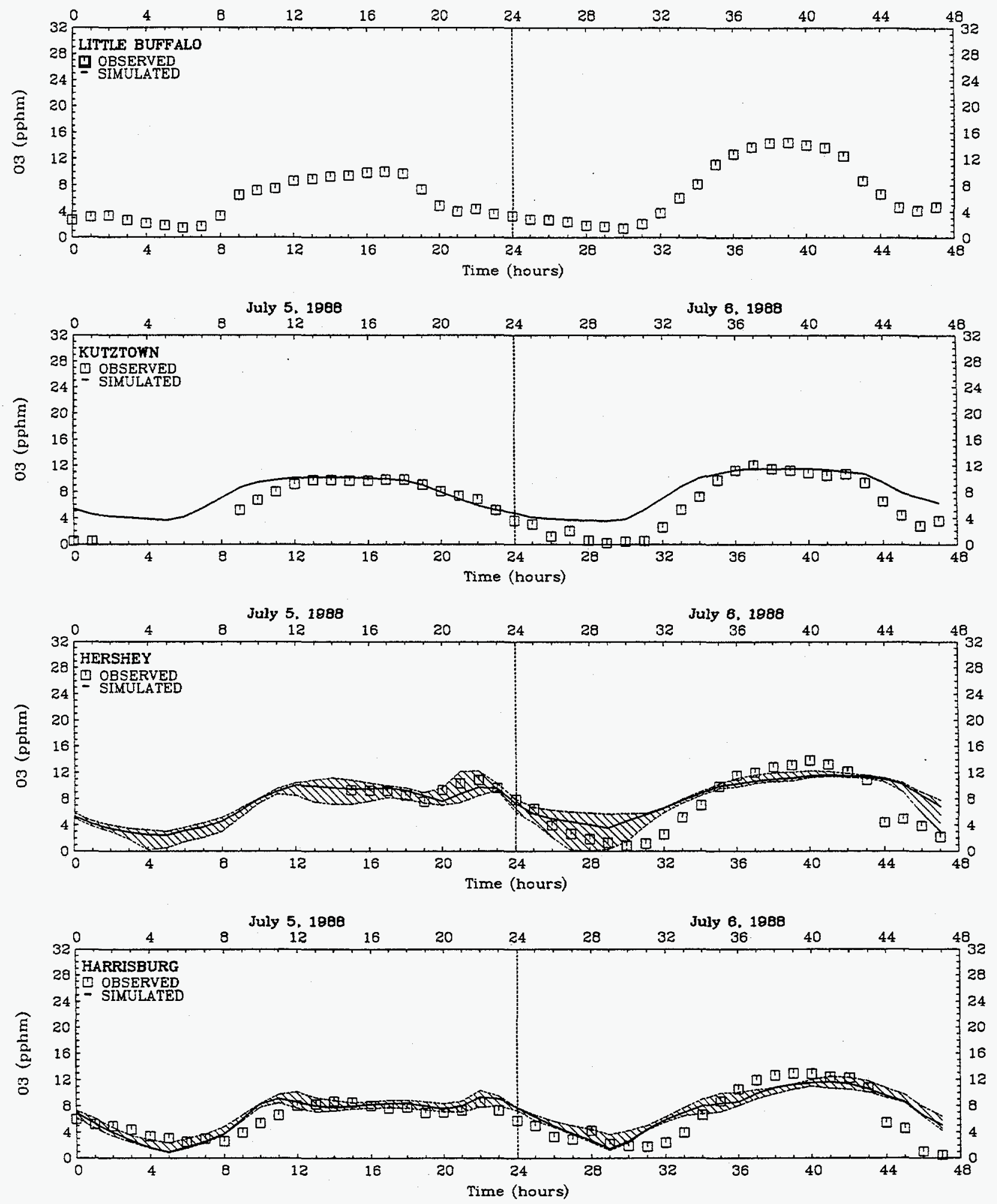

FIGURE 3-7. Concluded. 

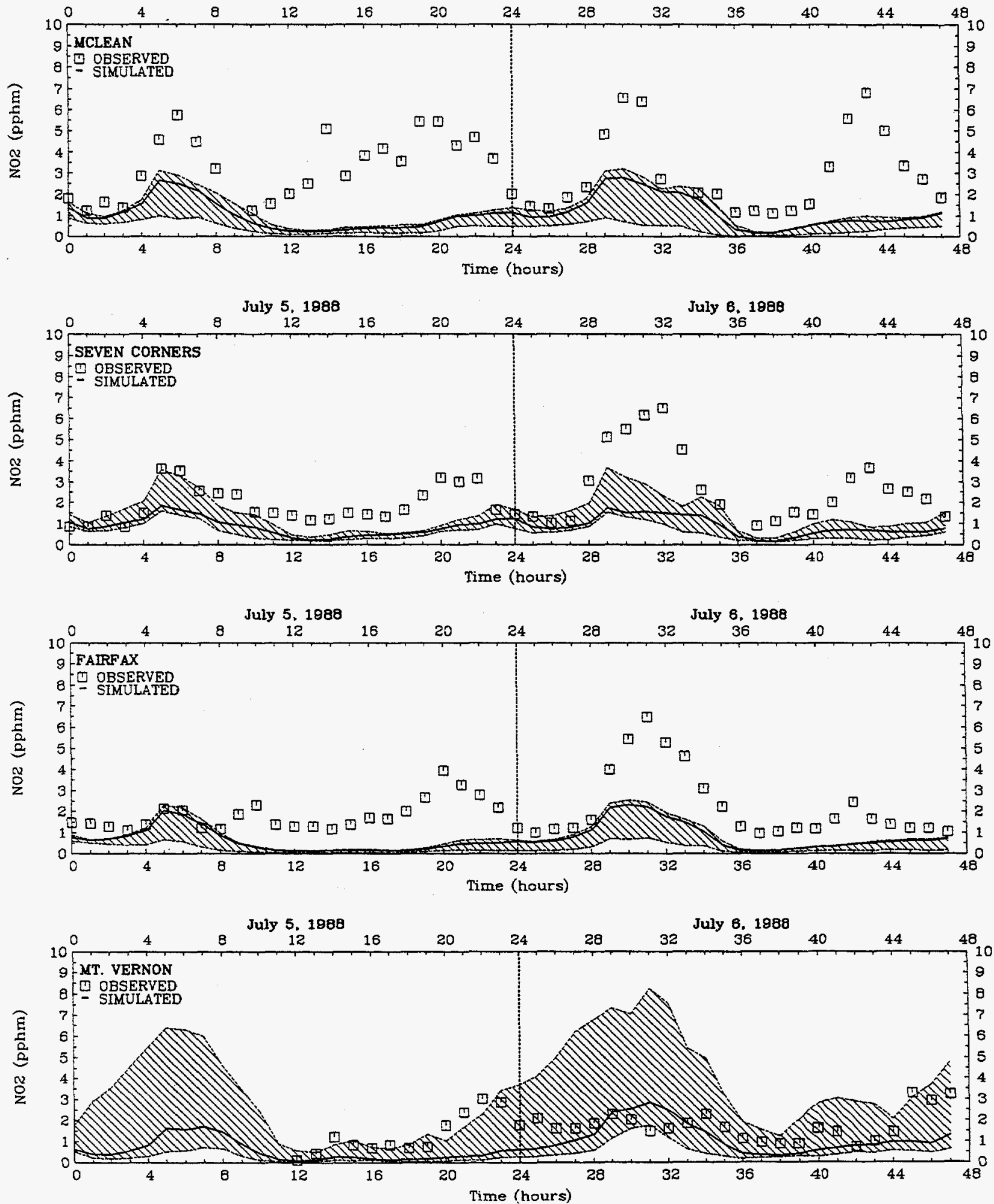

FIGURE 3-8. Simulated and observed $\mathrm{NO}_{2}$ concentrations (pphm) at monitoring sites in the Baltimore domain for the July 5-6, 1988 base episode. 

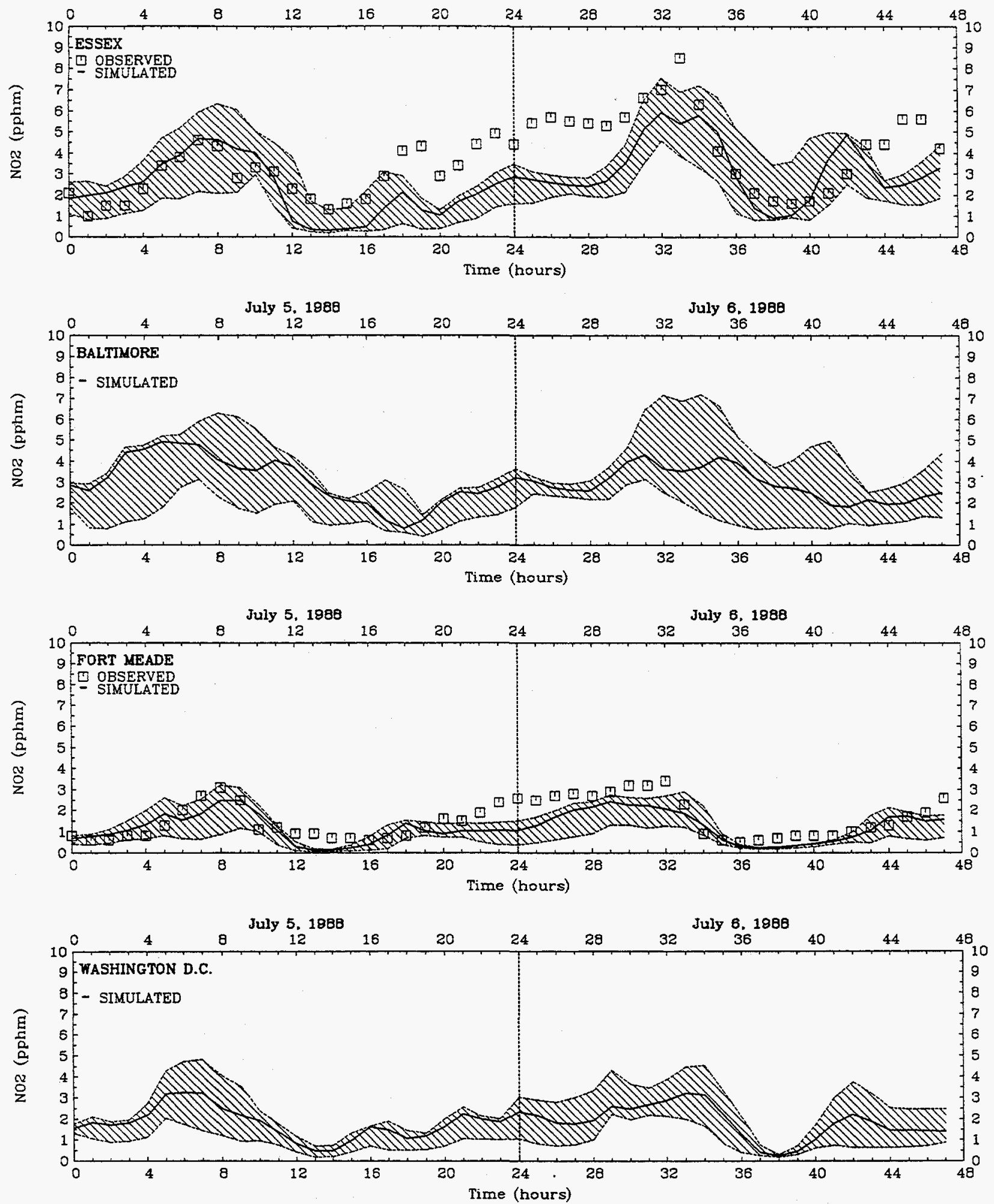

FIGURE 3-8. Continued. 

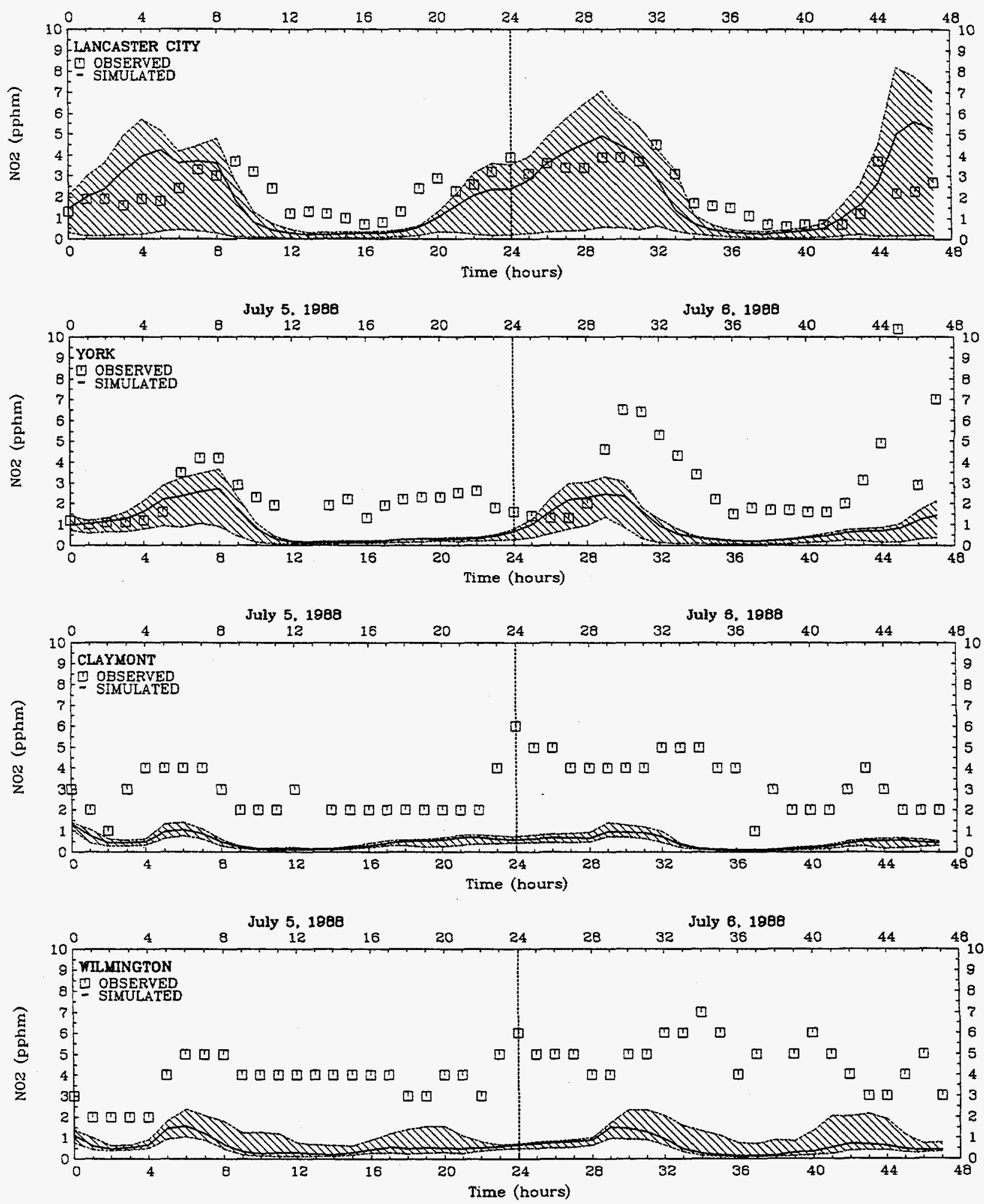

FIGURE 3-8. Continued. 

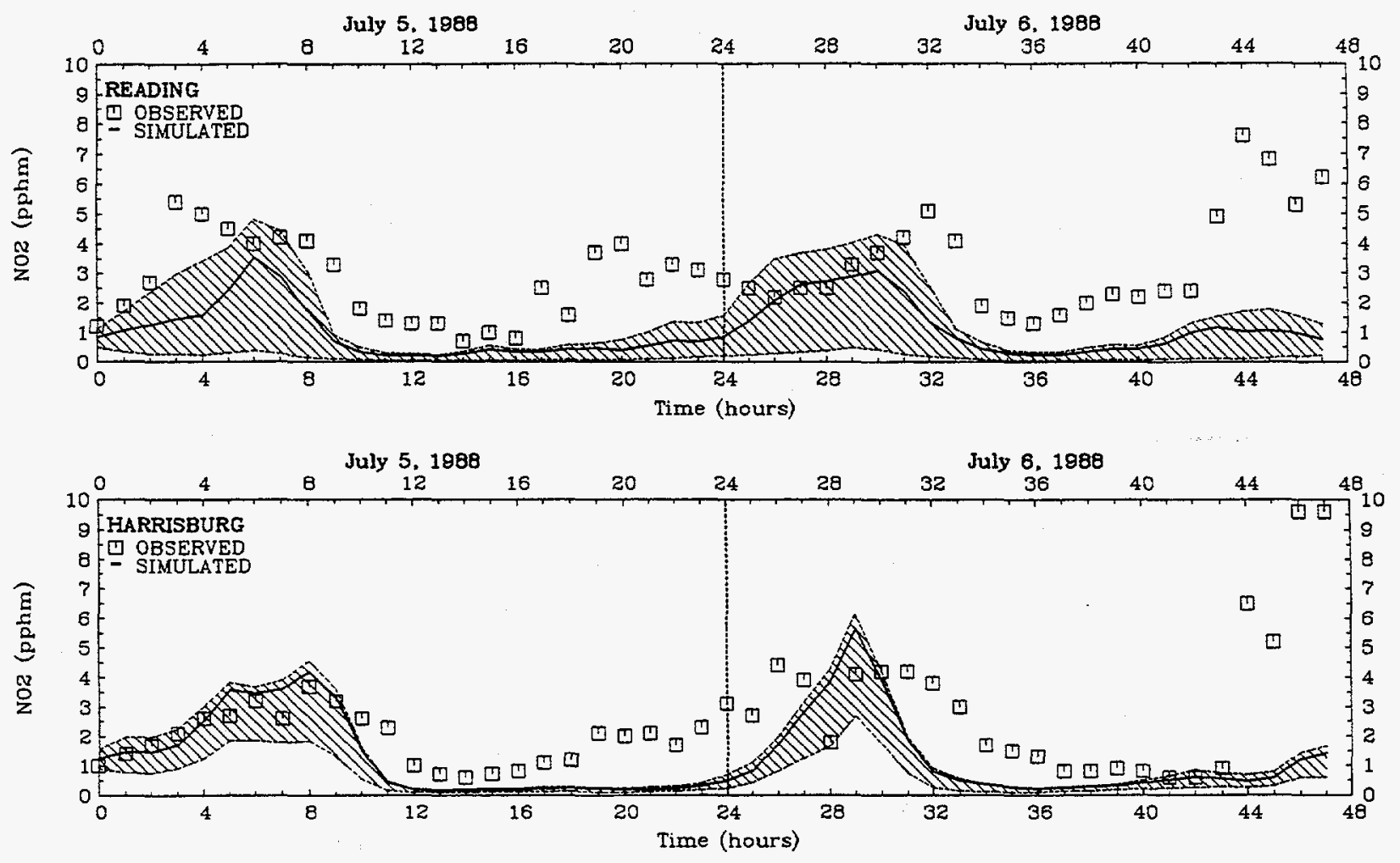

FIGURE 3-8. Concluded. 
LEVEL 1 RHC (pphmC)

Time: $0-2400$ July 6.1988
+ MAXIMUM $=211.7 \mathrm{pphmC}$

- MINIMUM $=2.2 \mathrm{pphmC}$

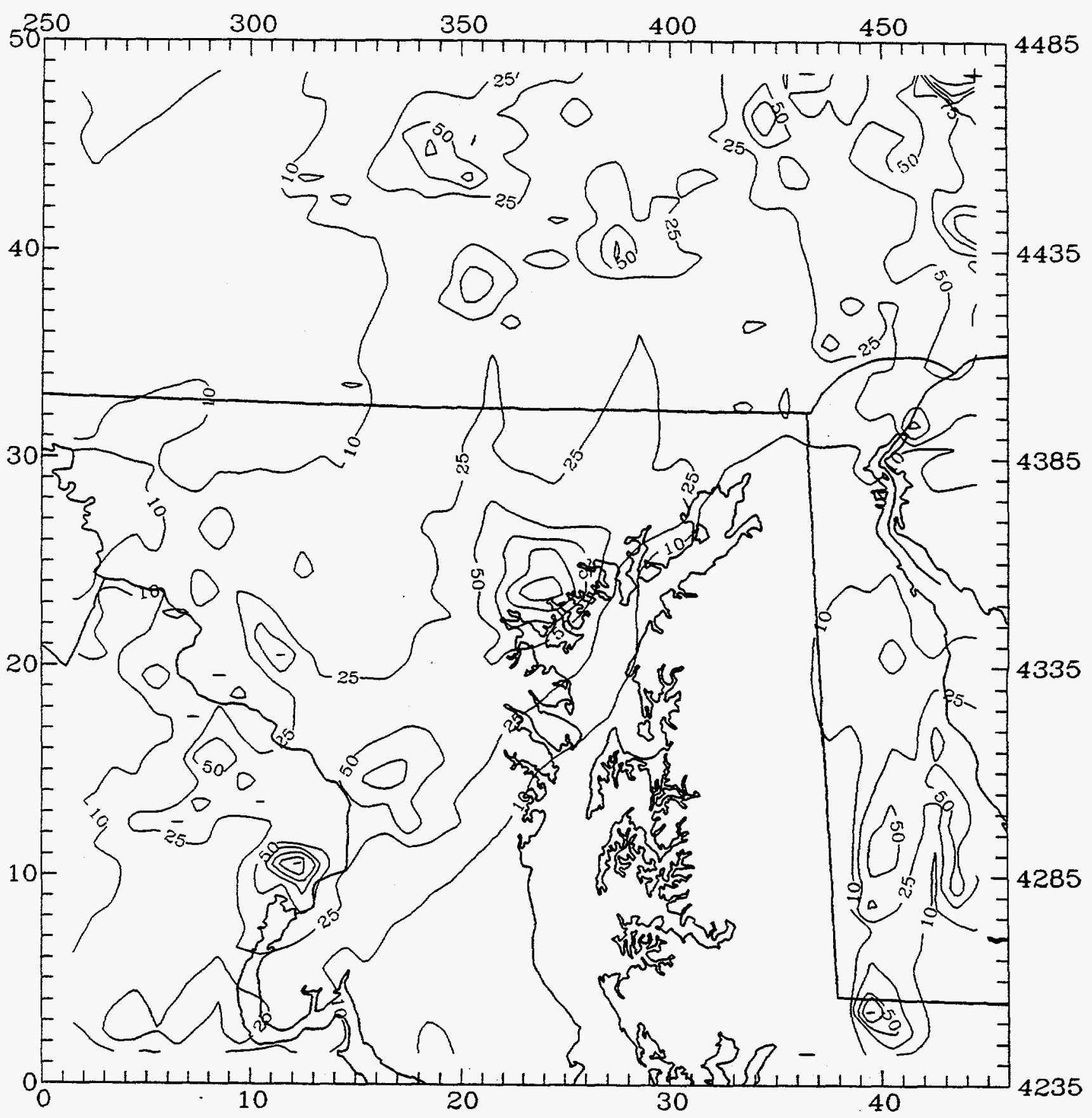

FIGURE 3-9. Maximum simulated RHC concentrations (pphmC) in the Baltimore modeling domain: UAM-Tox predictions for the July 5-6, 1988 base episode. 
LEVEL 1 RHC 'NOX

Time 500-600 July 6, 1988
+ MANIMTIM $=98.8$

- MINIMUM $=0.9$

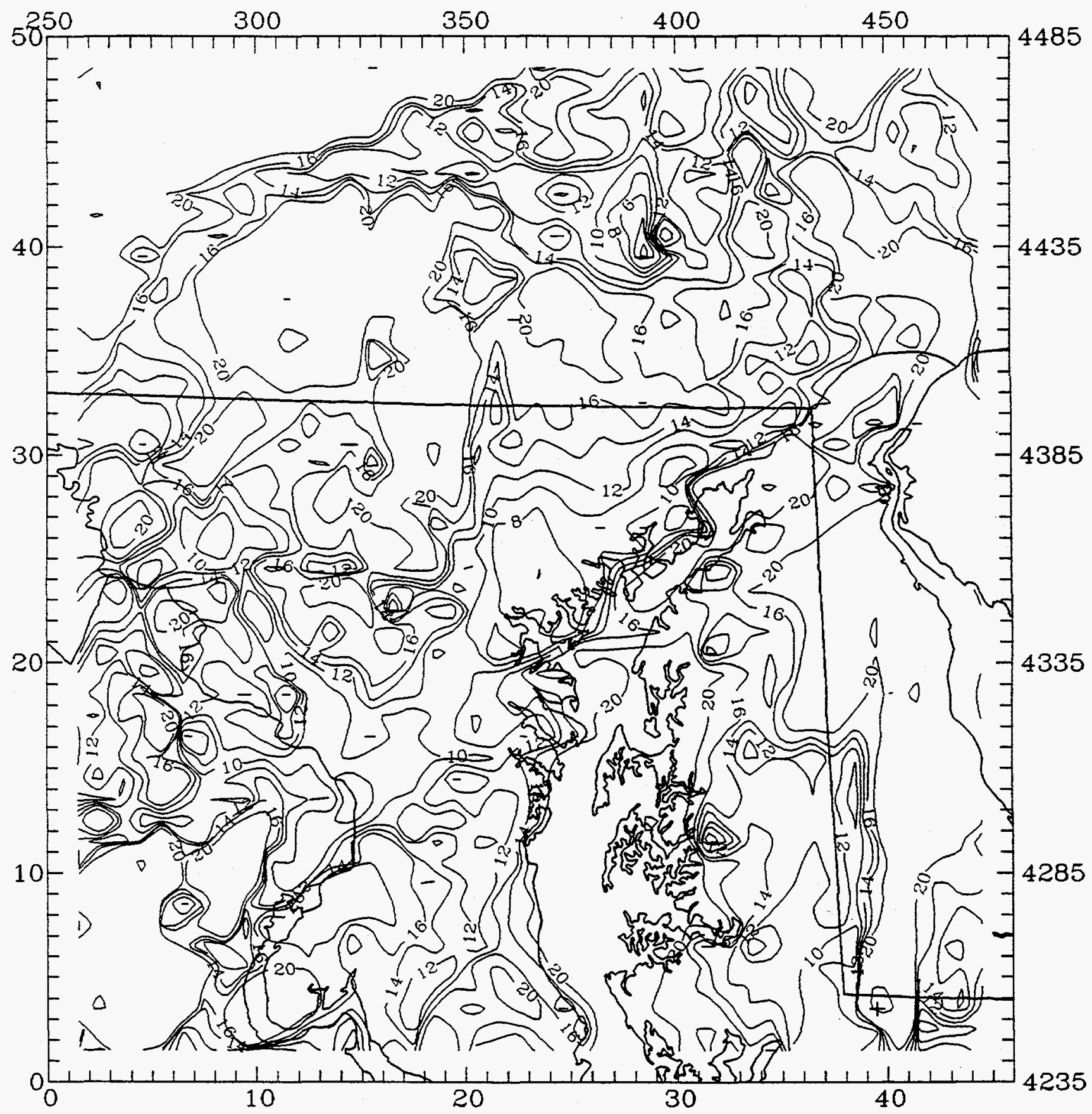

FIGURE 3-10a. Hourly simulated $\mathrm{RHC} / \mathrm{NO}_{\mathrm{x}}(\mathrm{ppbC} / \mathrm{ppb})$ in the Baltimore domain: UAM-Tox predictions for the July 5-6, 1988 base episode, 0500-0600 July 6. 
LEVEL 1 RHC: NOX

Time: 600-700 July 6, 1988
- MALIMUM $=778$

- MINIMUM $=1.4$

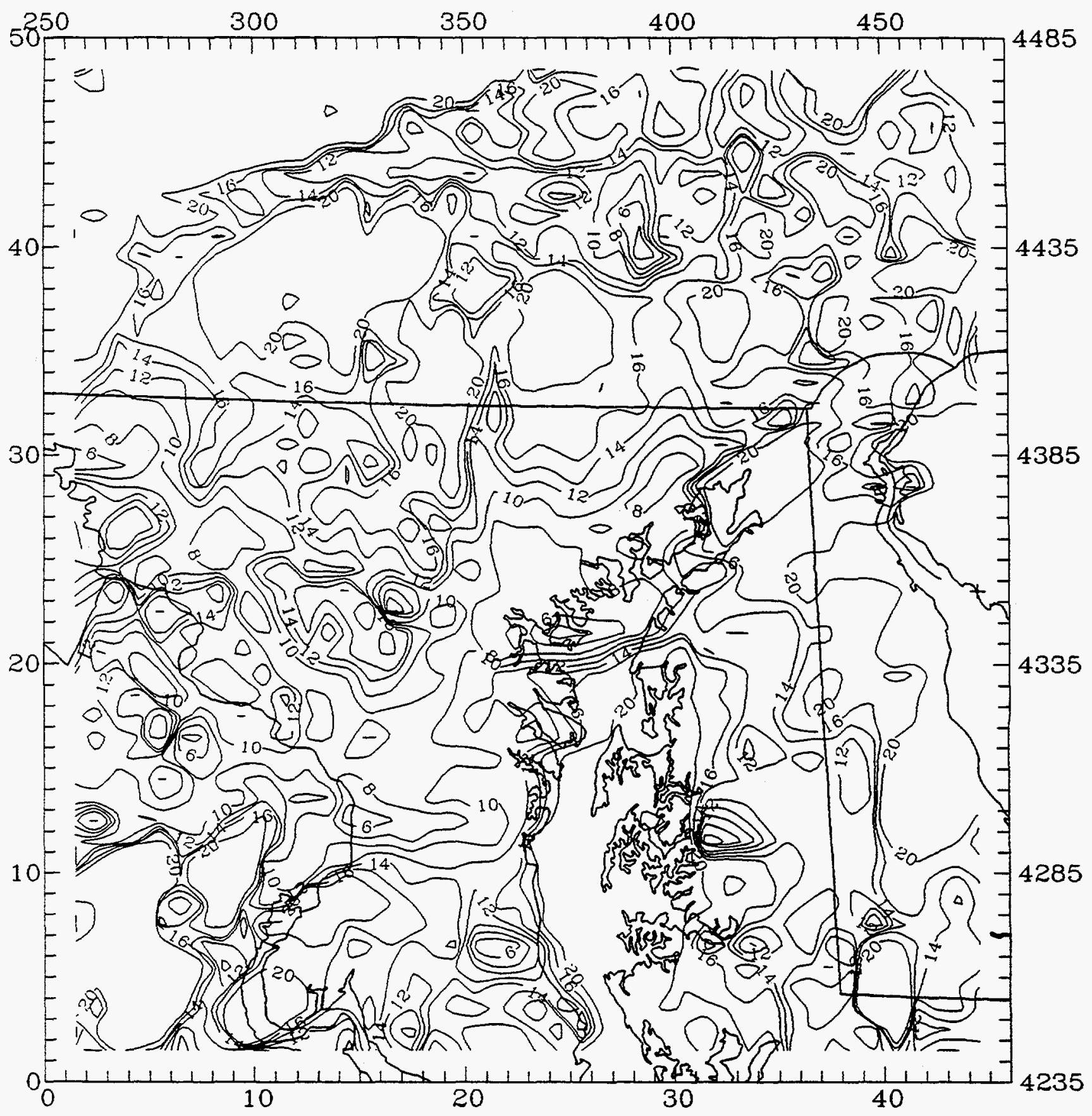

FIGURE 3-10b. Hourly simulated $\mathrm{RHC} / \mathrm{NO}_{\mathrm{x}}(\mathrm{ppbC} / \mathrm{ppb})$ in the Baltimore domain: UAM-Tox predictions for the July 5-6, 1988 base episode, 0600-0700 July 6. 
LEVEL 1 RHC NOA

Time: T00-800 July 6,1988
+ MAXIMUIM $=82.4$

- MINIMUM $=1 . \tau$

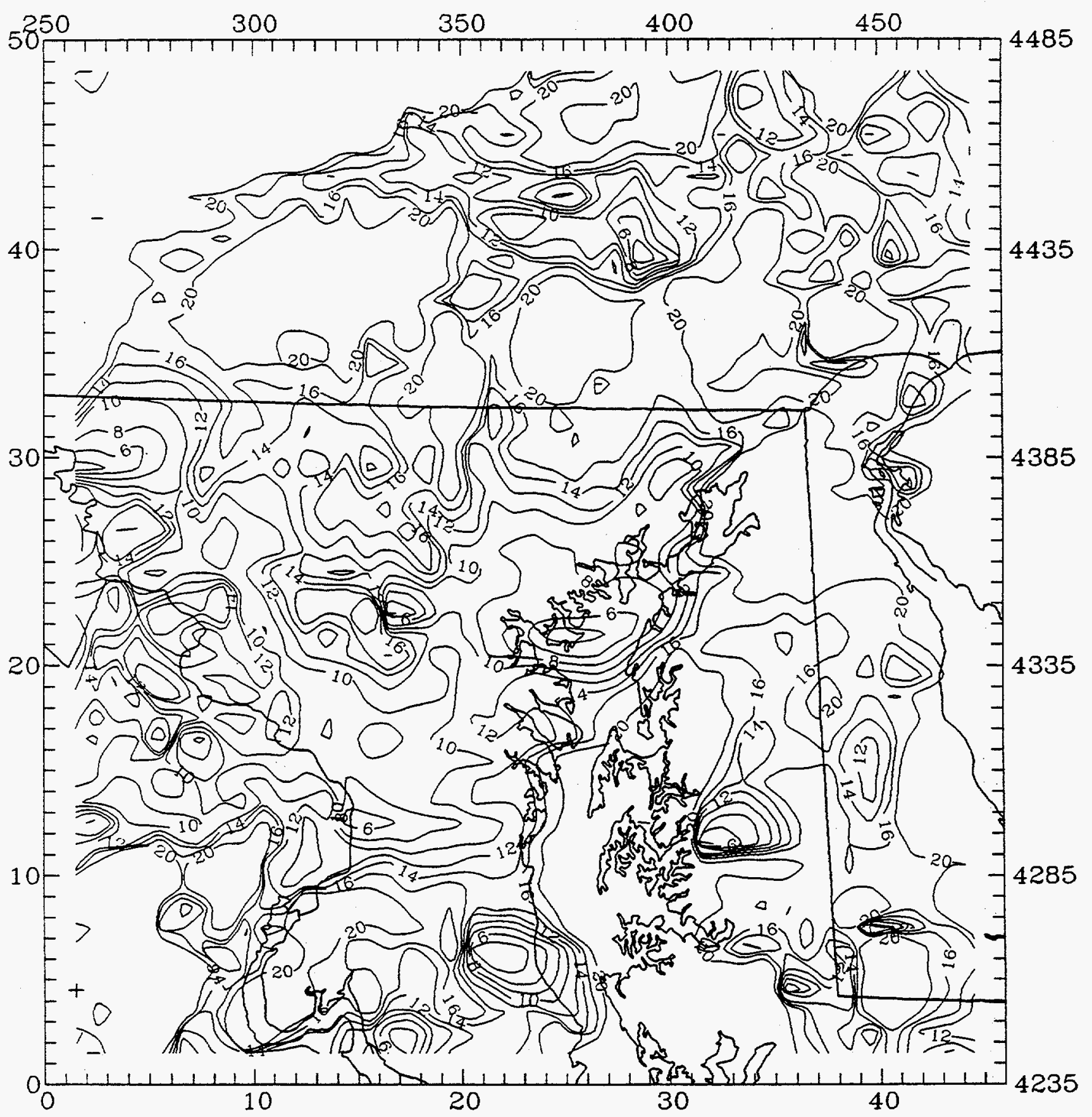

FIGURE 3-10c. Hourly simulated $\mathrm{RHC} / \mathrm{NO}_{\mathrm{x}}(\mathrm{ppbC} / \mathrm{ppb})$ in the Baltimore domain: UAM-Tox predictions for the July 5-6, 1988 base episode, 0700-0800 July 6. 
LEVEL 1 RHC NOX

Time: 800-900 July 6, 1988
+ MANIMLM $=1536$

- MINIMUM $=1.6$

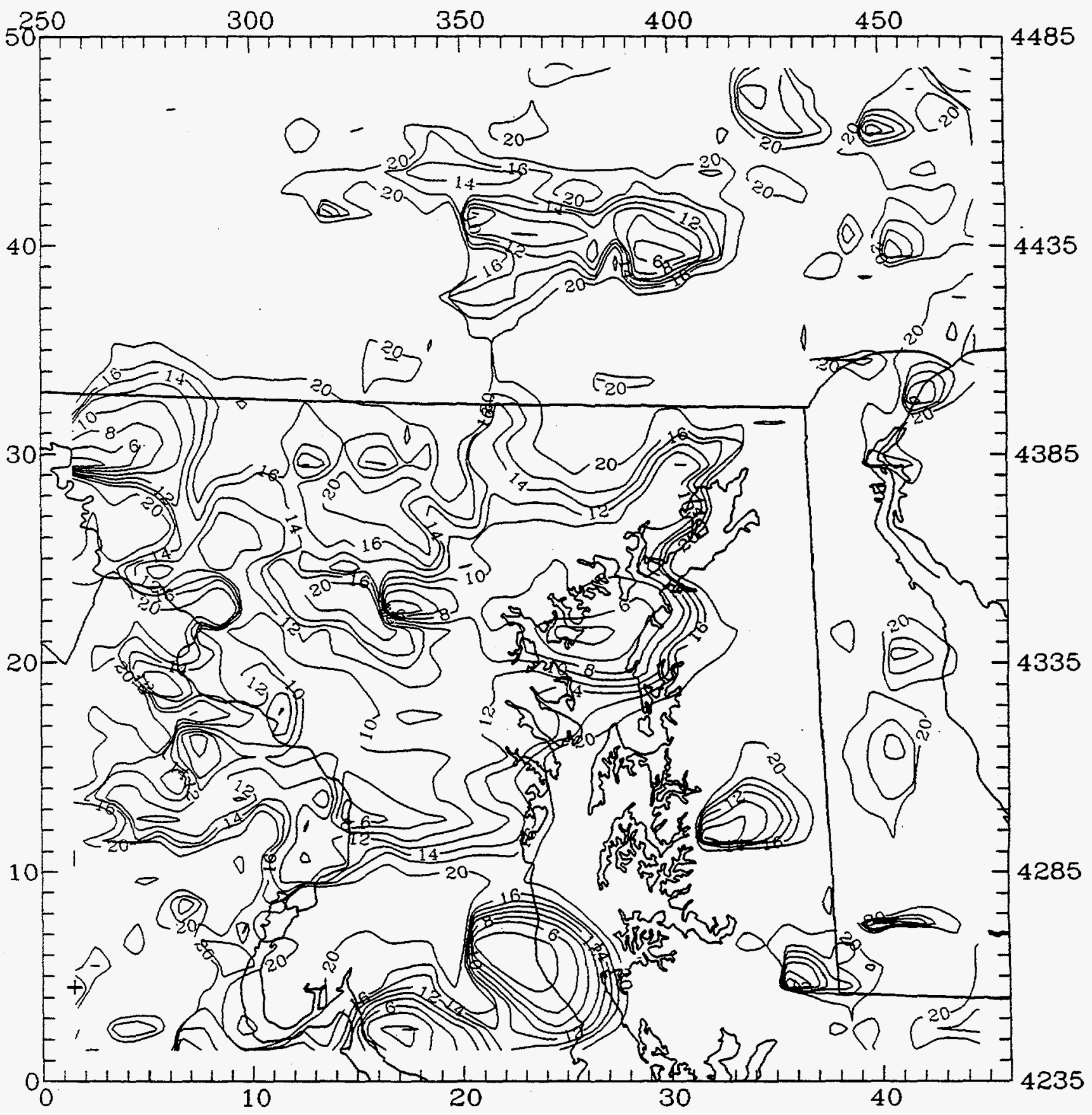

FIGURE 3-10d. Hourly simulated $\mathrm{RHC}_{\mathrm{NO}}(\mathrm{ppbC} / \mathrm{ppb})$ in the Baltimore domain: UAM-Tox predictions for the July 5-6, 1988 base episode, 0800-0900 July 6. 
LEVEL 1 BENZ (ppb)

Time: $0-2400$ July 6, 1988
+ MAXIMUM $=6.9 \mathrm{ppb}$

- MINIMUM $=0.2 \mathrm{ppb}$

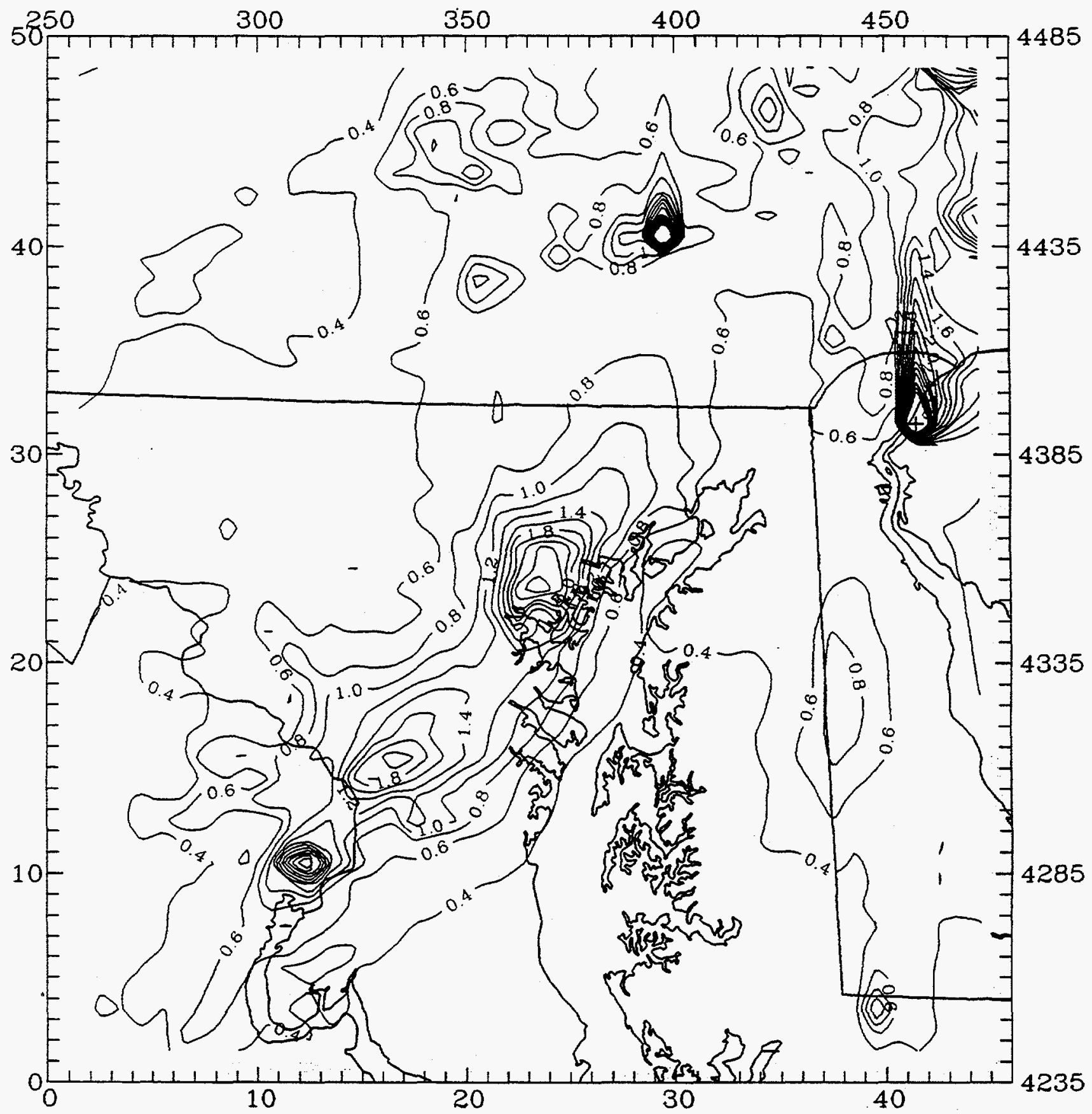

FIGURE 3-11a. Daily average simulated benzene concentrations (ppb) in the Baltimore domain: UAM-Tox predictions for July 6, 1988. 
LEVEL 1 BUTA (ppb)

Time: 0-2400 July 6,1988
+ MAXIMUM $=7.70 \mathrm{ppb}$

- MINIMUM $=0.00 \mathrm{ppb}$

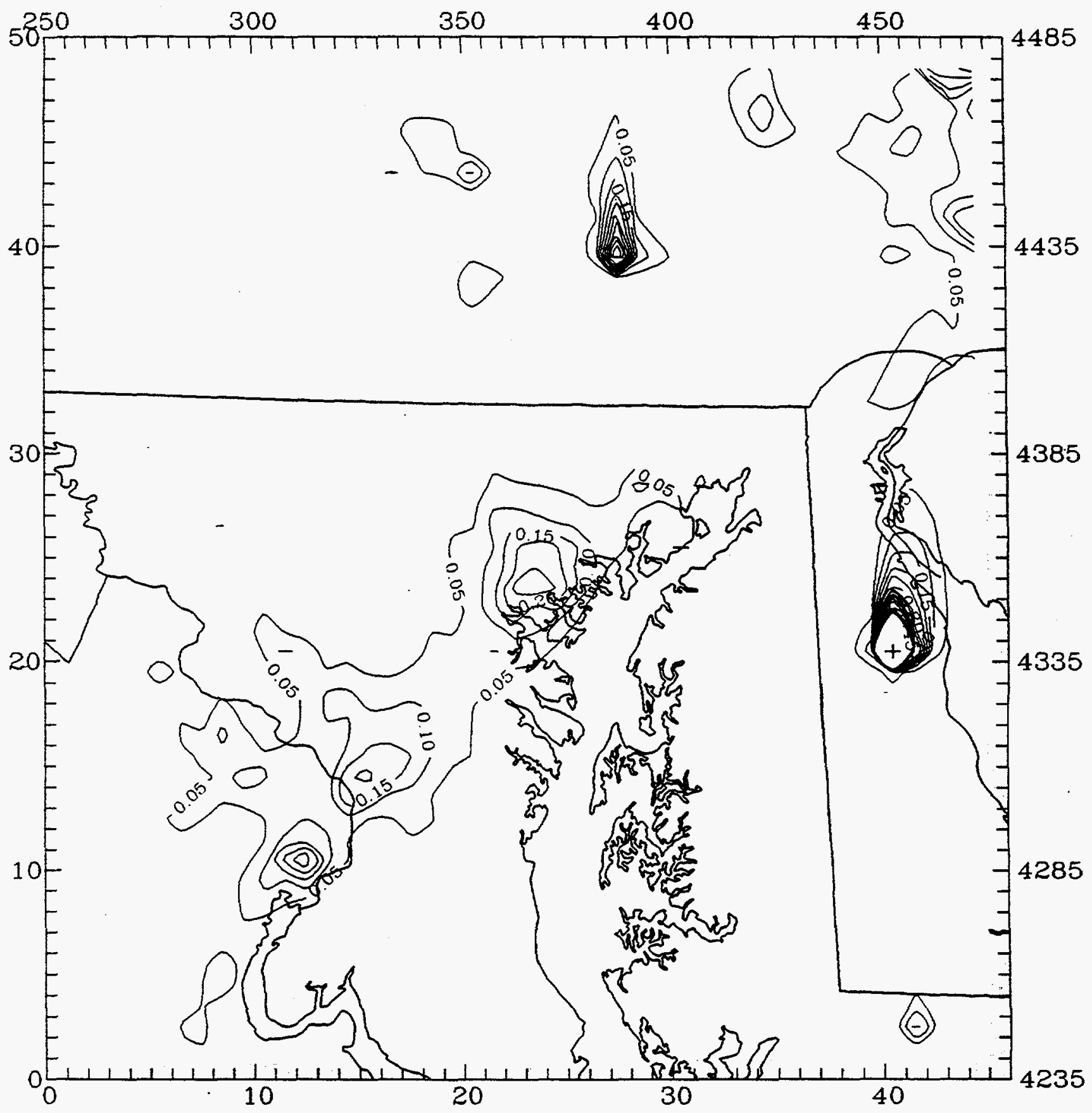

FIGURE 3-11b. Daily average simulated 1,3-butadiene concentrations (ppb) in the Baltimore domain: UAM-Tox predictions for July 6, 1988. 
LEVEL 1 PHCHO (ppb)

Time: $0-2400$ July 6,1988
- MANIMUM $=40 \mathrm{ppb}$

- MINIMUM $=0.0 \mathrm{ppb}$

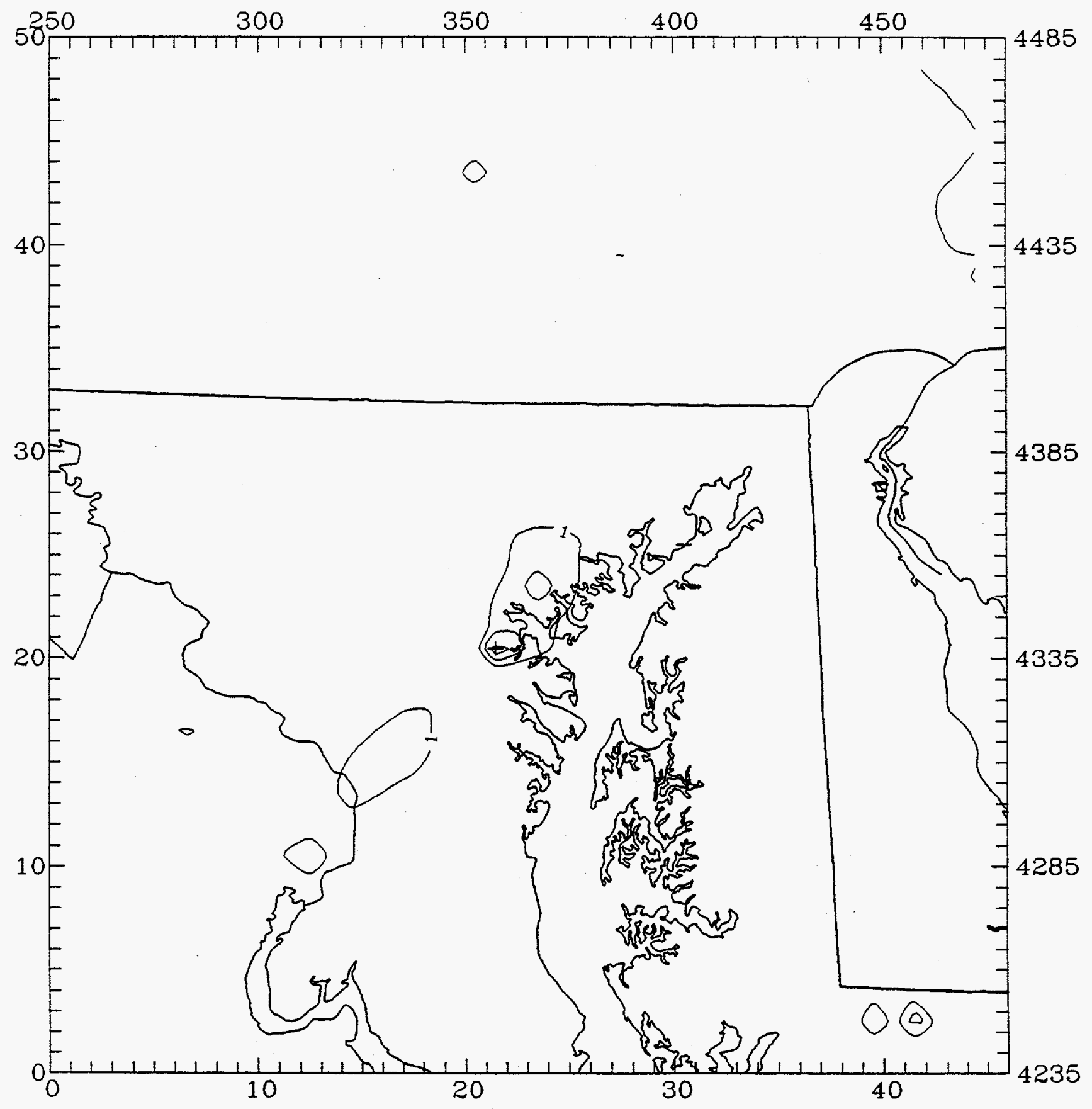

FIGURE 3-11c. Daily average simulated primary formaldehyde concentrations (ppb) in the Baltimore domain: UAM-Tox predictions for July 6, 1988. 
LEVEL 1 FORM (ppb)

Time: $0-2400$ July 6, 1988
- MAXIMUM $=17 \approx \mathrm{ppb}$

- MINIMUM $=1.3 \mathrm{ppb}$

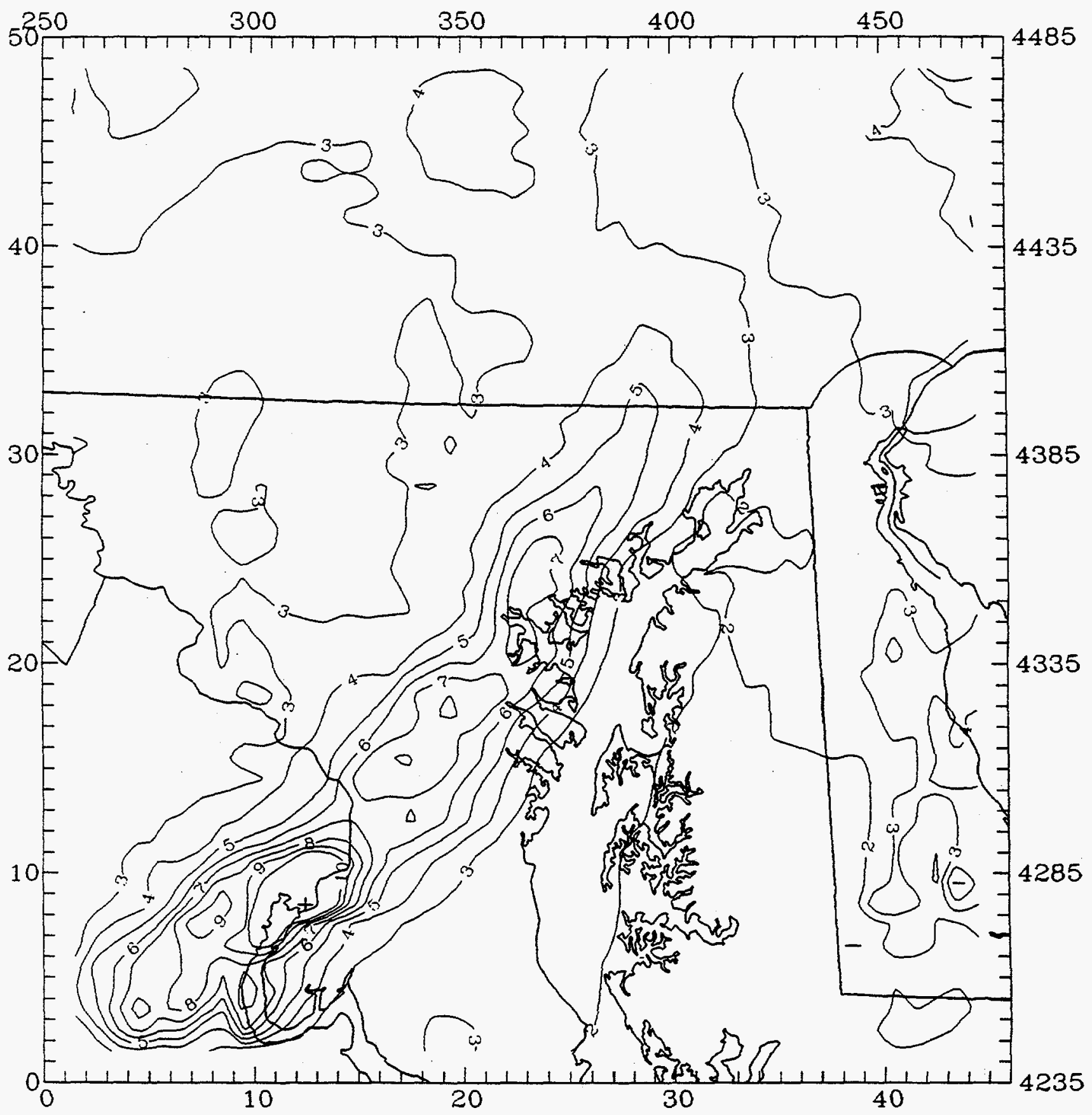

FIGURE 3-11d. Daily average simulated secondary formaldehyde concentrations (ppb) in the Baltimore domain: UAM-Tox predictions for July 6, 1988. 
LEVEL 1 TFORM (ppb)

- MALIMUM $=175 \mathrm{ppb}$

Time: $0-2400$ July 6,1988

- MINIMUM $=1.4 \mathrm{ppb}$

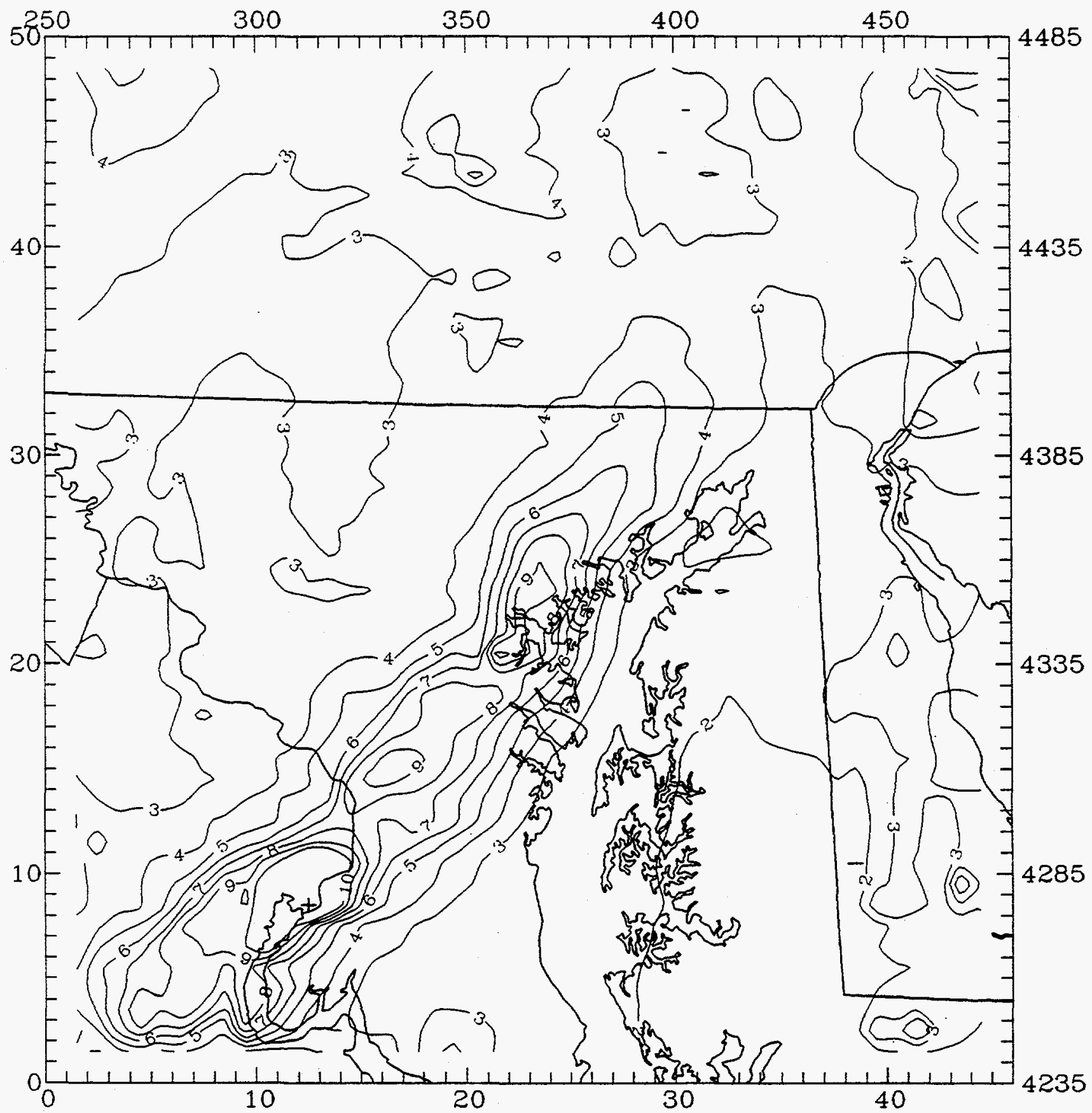

FIGURE 3-11e. Daily average simulated total formaldehyde concentrations (ppb) in the Baltimore domain: UAM-Tox predictions for July 6, 1988. 
LEVEL 1 PACET ( $\mathrm{ppb}$ )

Time: $0-2400$ July 6,1988

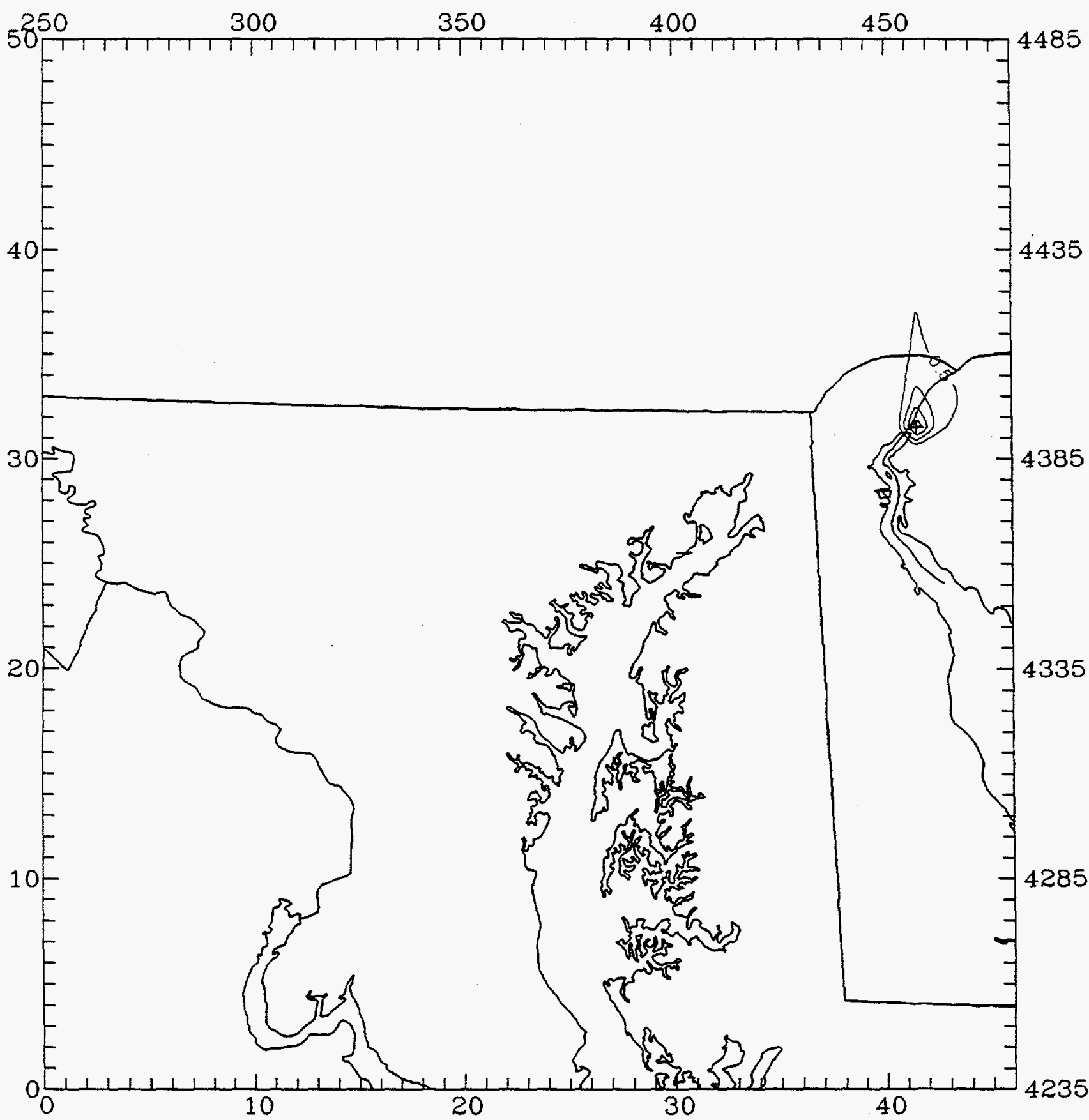

FIGURE 3-11f. Daily average simulated primary acetaldehyde concentrations (ppb) in the Baltimore domain: UAM-Tox predictions for July 6, 1988.

- MANIMUM $=2+\mathrm{ppb}$

- MINIMUM $=0.0 \mathrm{ppb}$ 
LEVEL 1 ACET (ppb)

Time: $0-2400$ July 6, 1988
- MAXIMUM $=6.5 \mathrm{ppb}$

- MINIMUM $=0.4 \mathrm{ppb}$

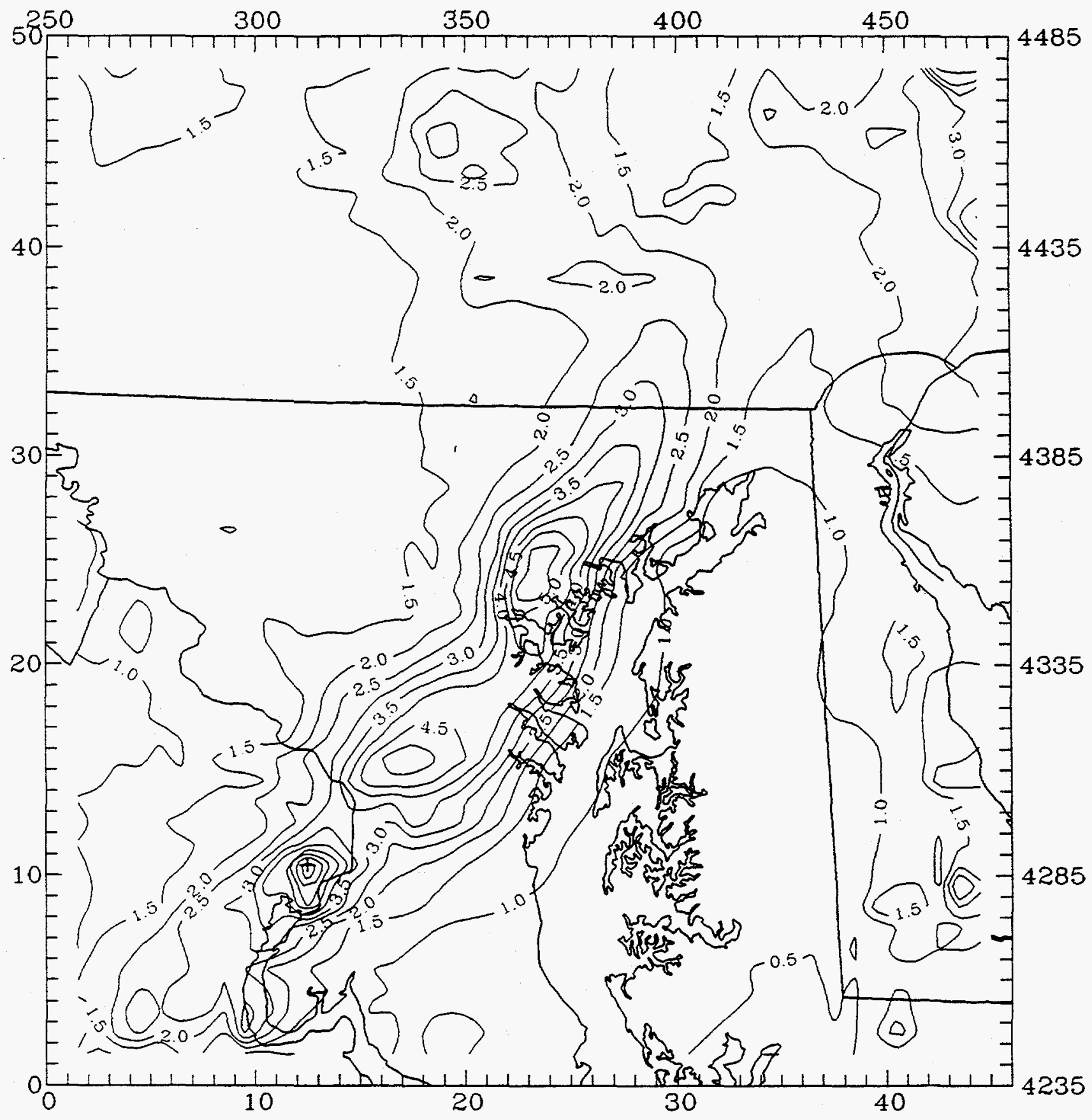

FIGURE 3-11g. Daily average simulated secondary acetaldehyde concentrations (ppb) in the Baltimore domain: UAM-Tox predictions for July 6, 1988. 


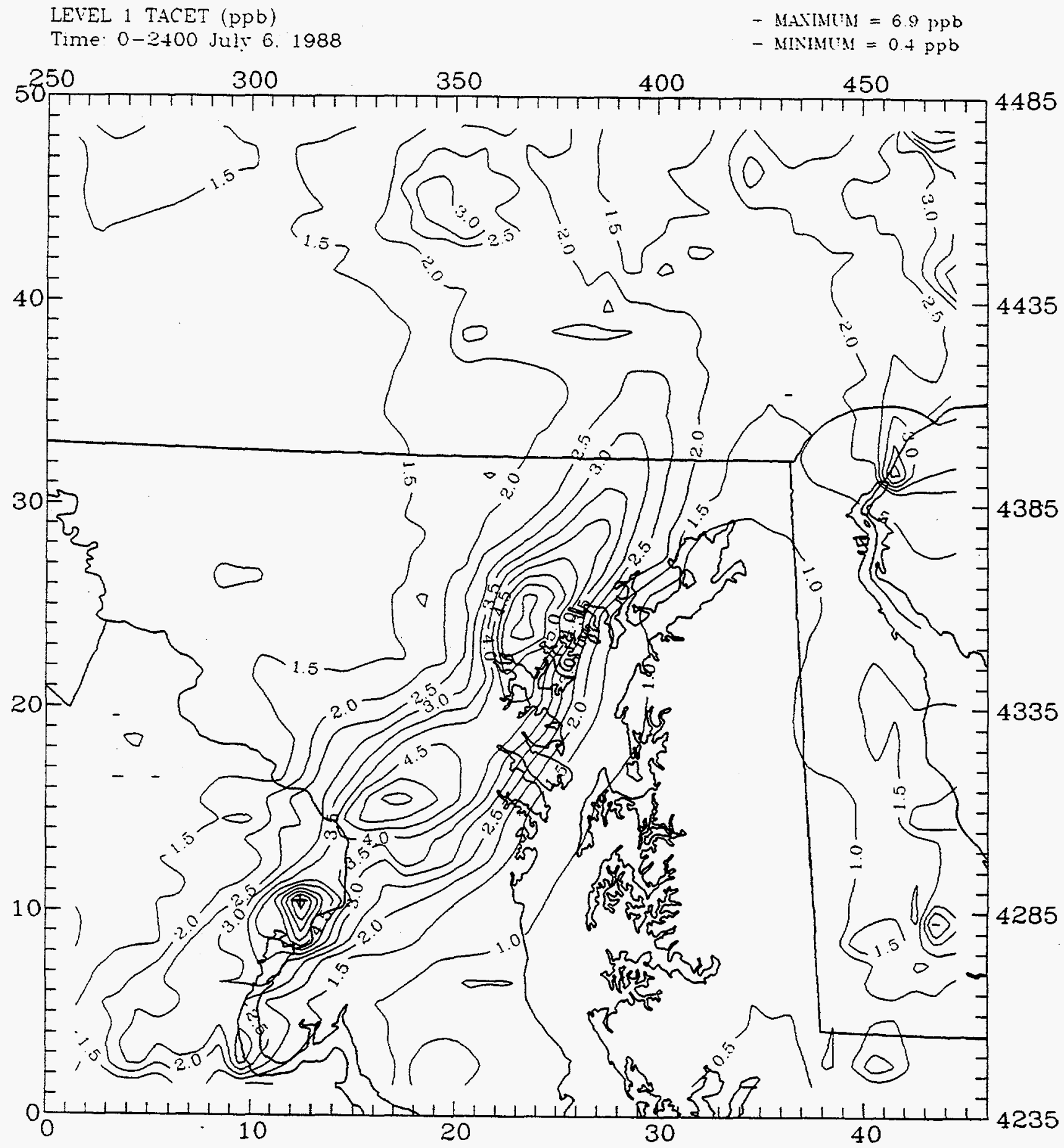

FIGURE 3-11h. Daily average simulated total acetaldehyde concentrations (ppb) in the Baltimore domain: UAM-Tox predictions for July 6, 1988. 

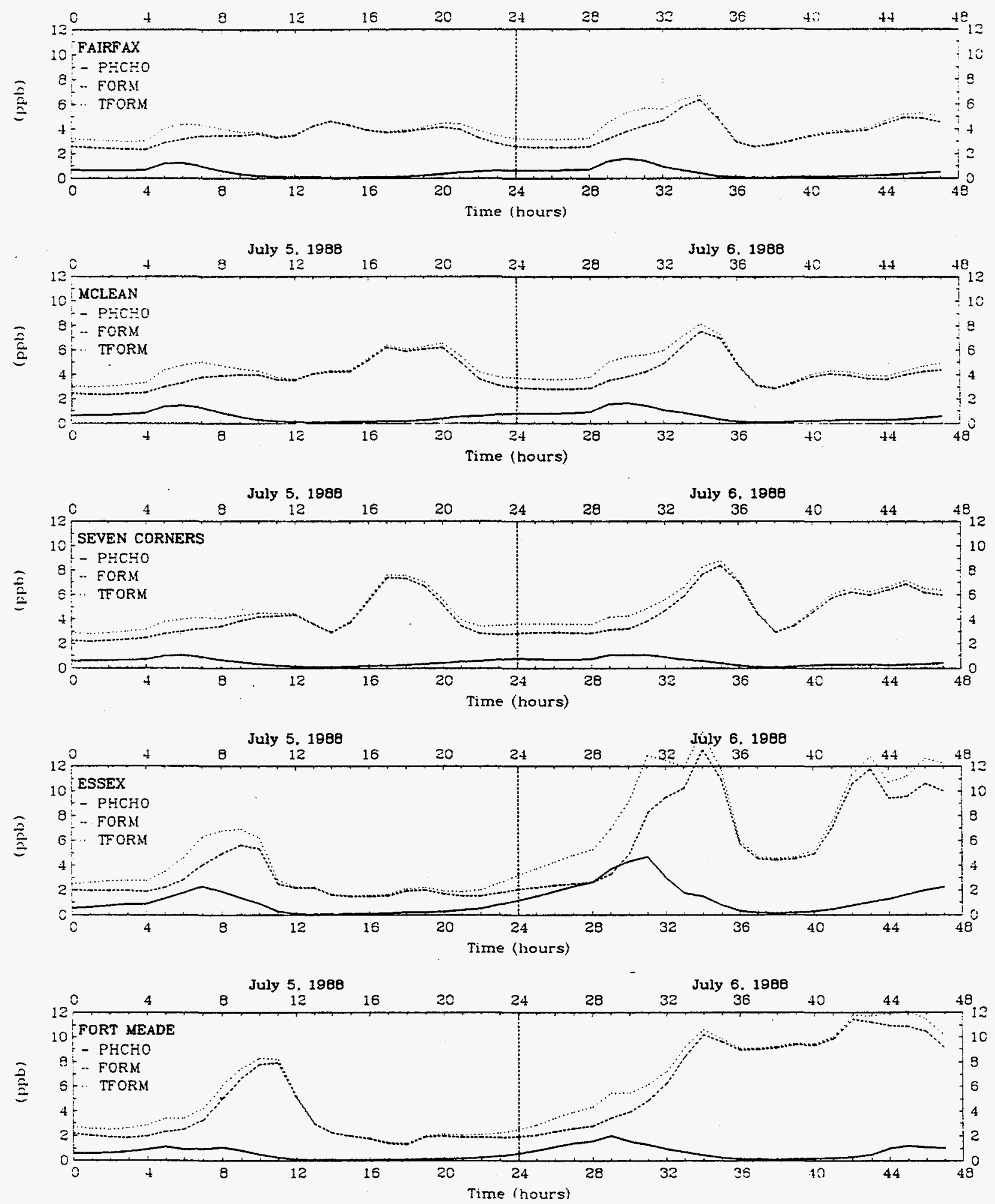

FIGURE 3-12a. Simulated primary (PHCHO), secondary (FORM), and total (TFORM) formaldehyde concentrations ( $\mathrm{ppb}$ ) in the Baltimore domain: UAM-Tox predictions for the July 5-6, 1988 base episode. 

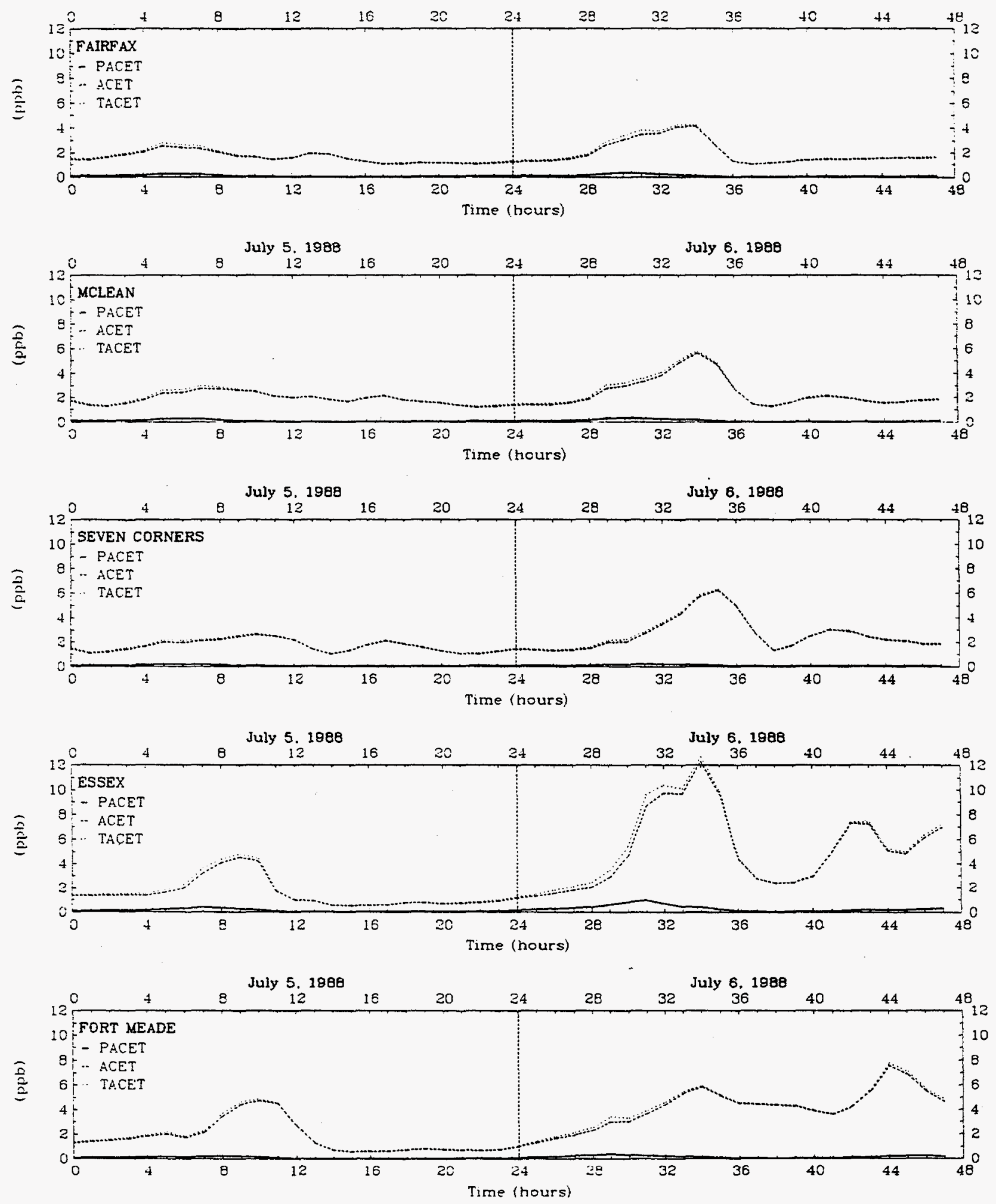

FIGURE 3-12b. Simulated primary (PACET), secondary (ACET), and total (TACET) acetaldehyde concentrations ( $\mathrm{ppb}$ ) in the Baltimore domain: UAM-Tox predictions for the July 5-6, 1988 base episode. 


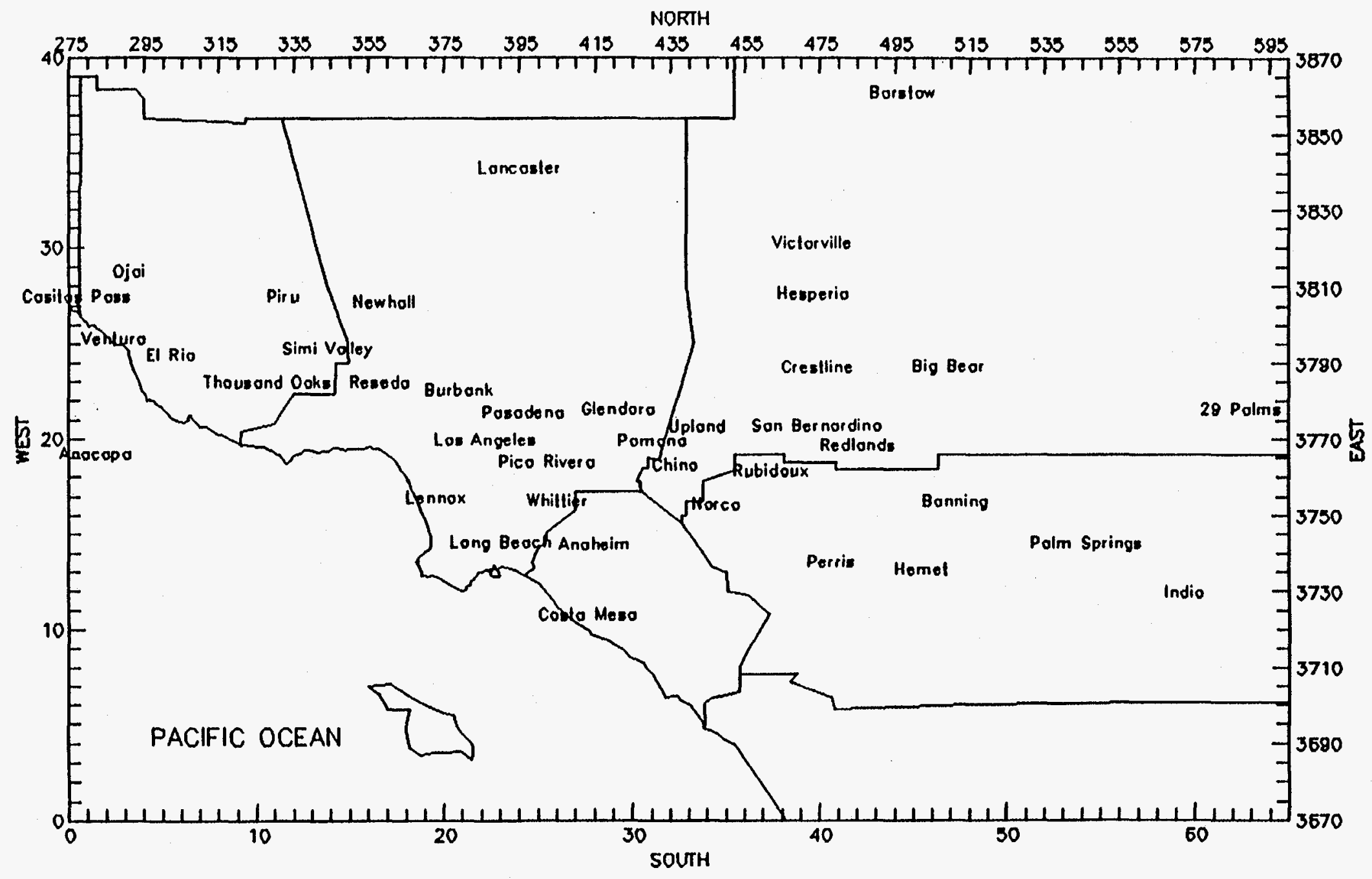

FIGURE 3-13. Los Angeles modeling domain. 


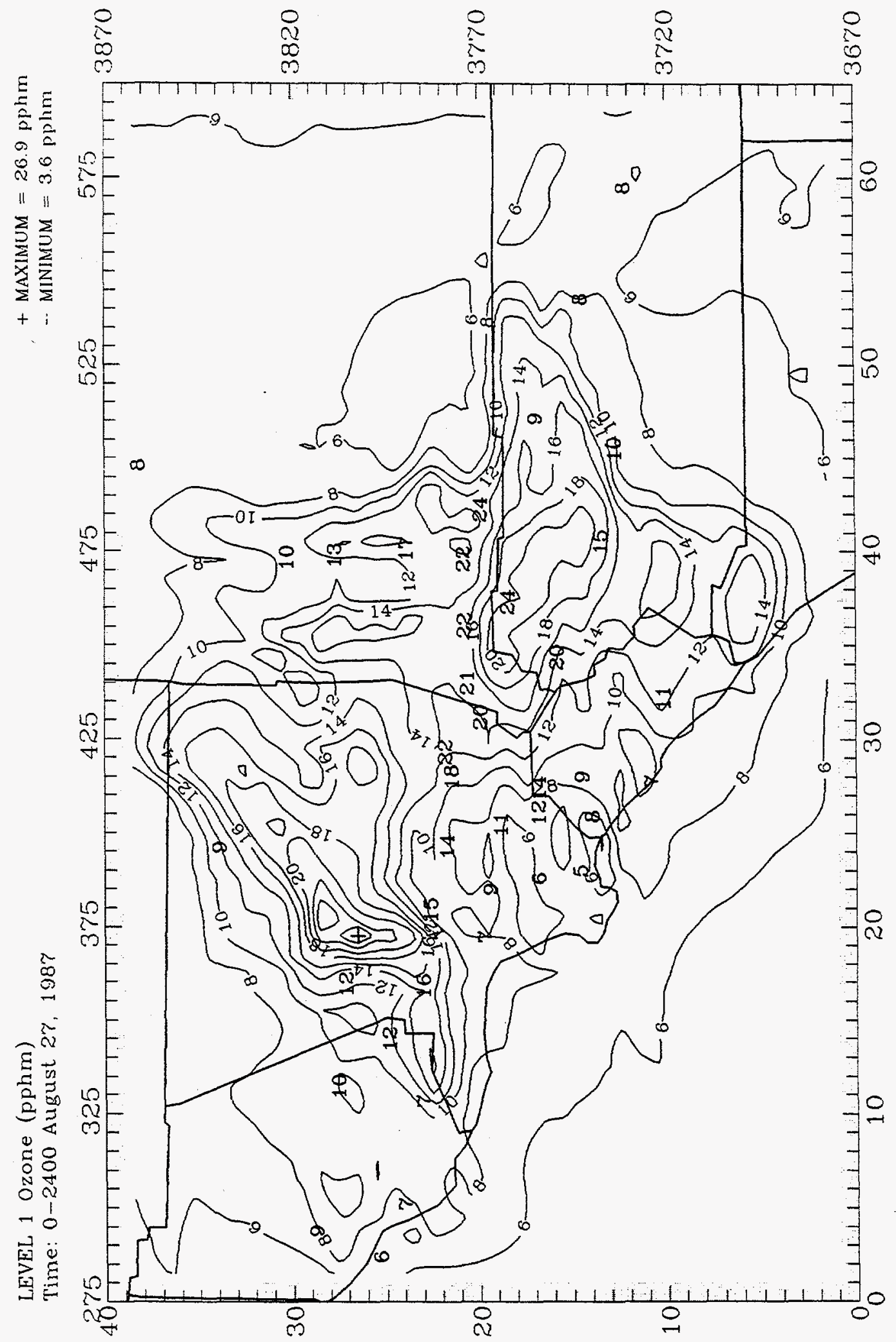

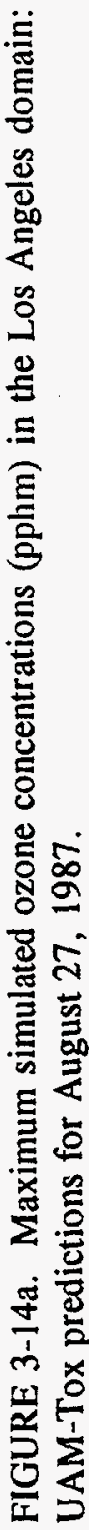




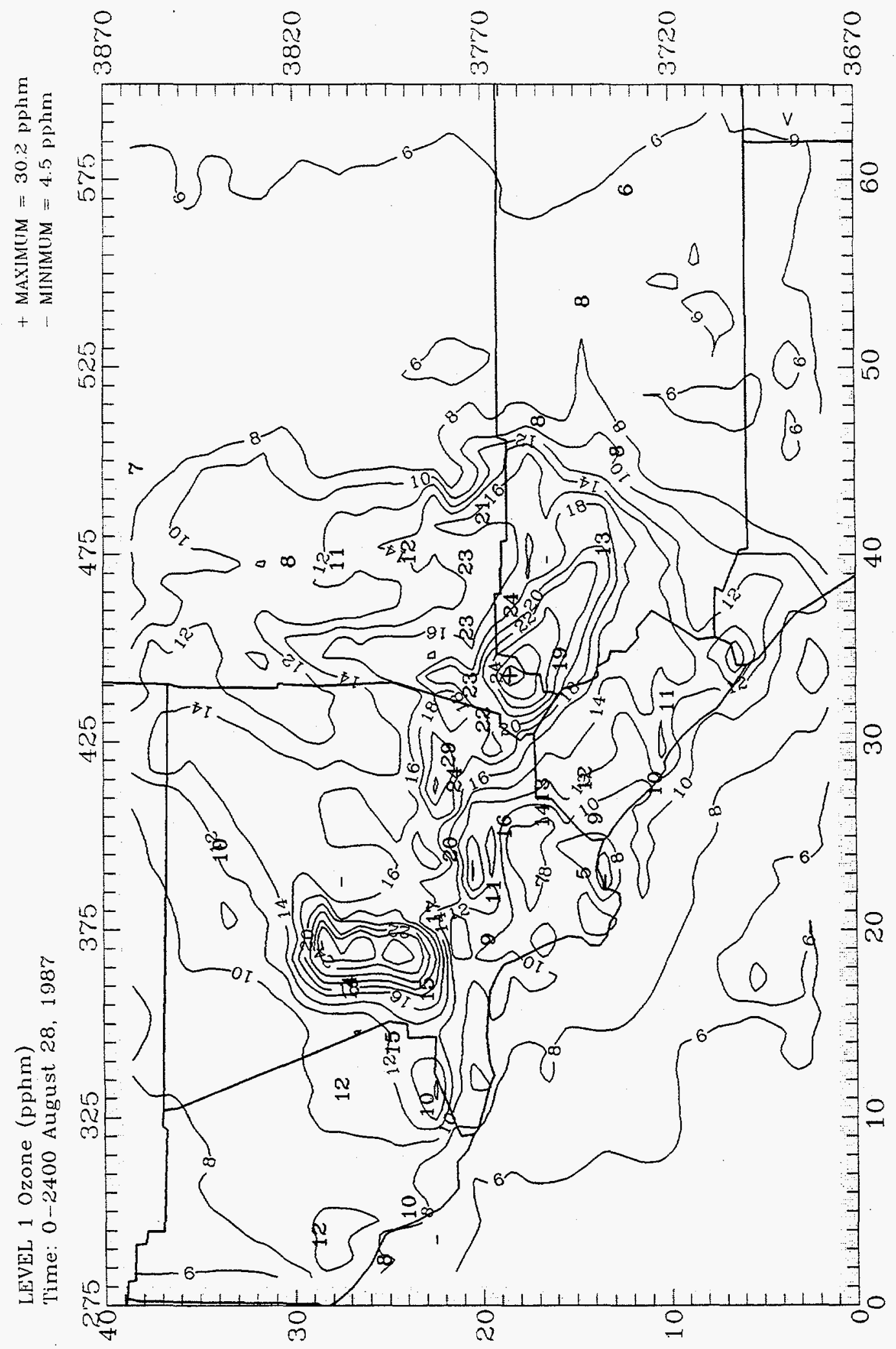

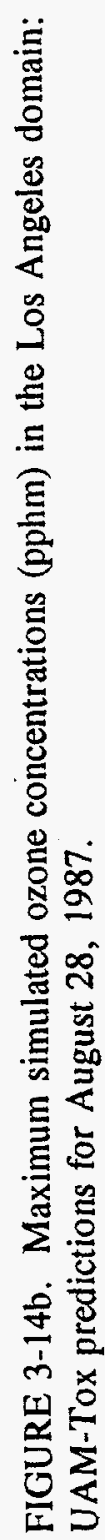



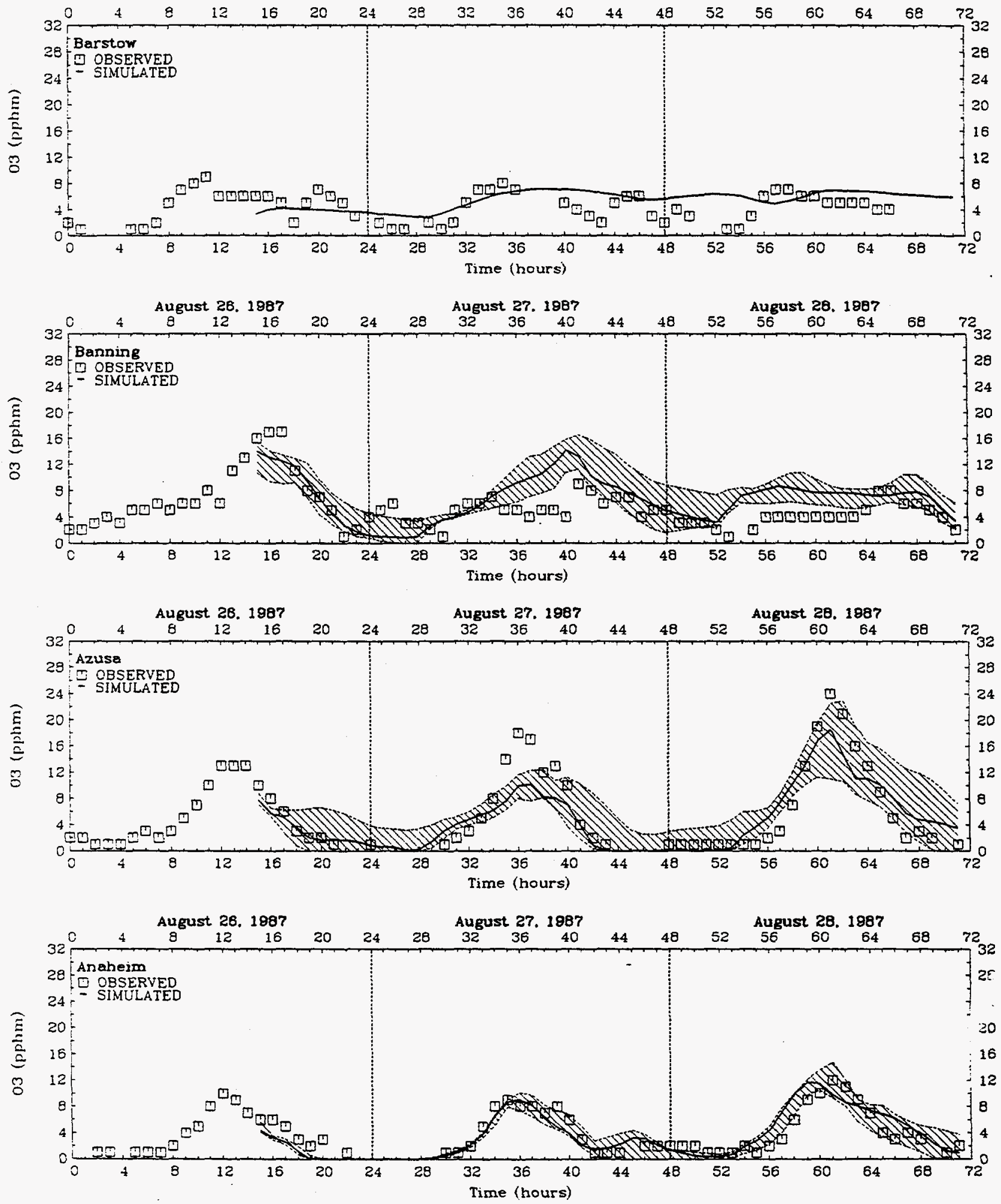

FIGURE 3-15. Simulated and observed ozone concentrations (pphm) at monitoring sites in the Los Angeles domain for the August 26-28, 1987 base episode. 

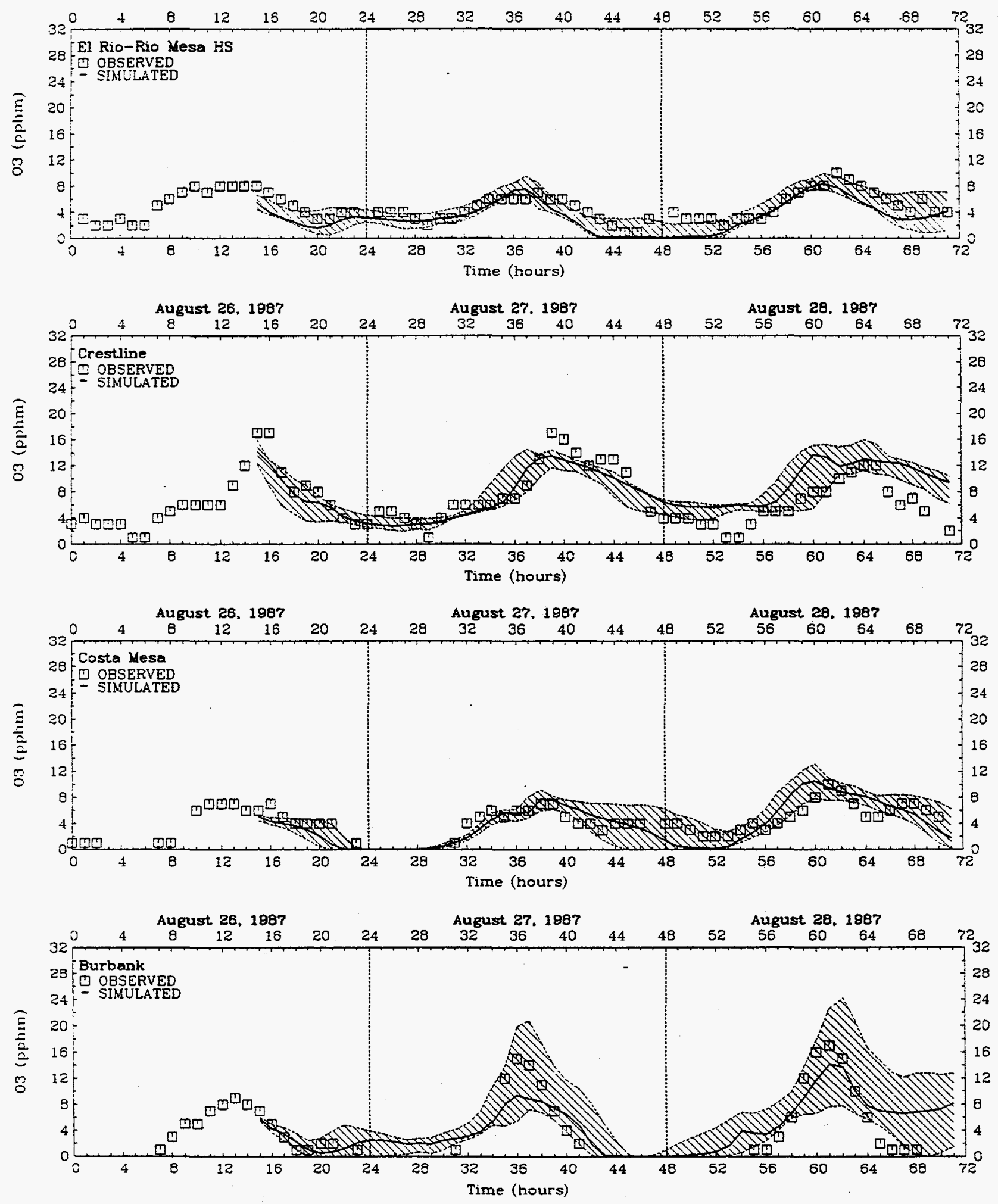

FIGURE 3-15. Continued. 

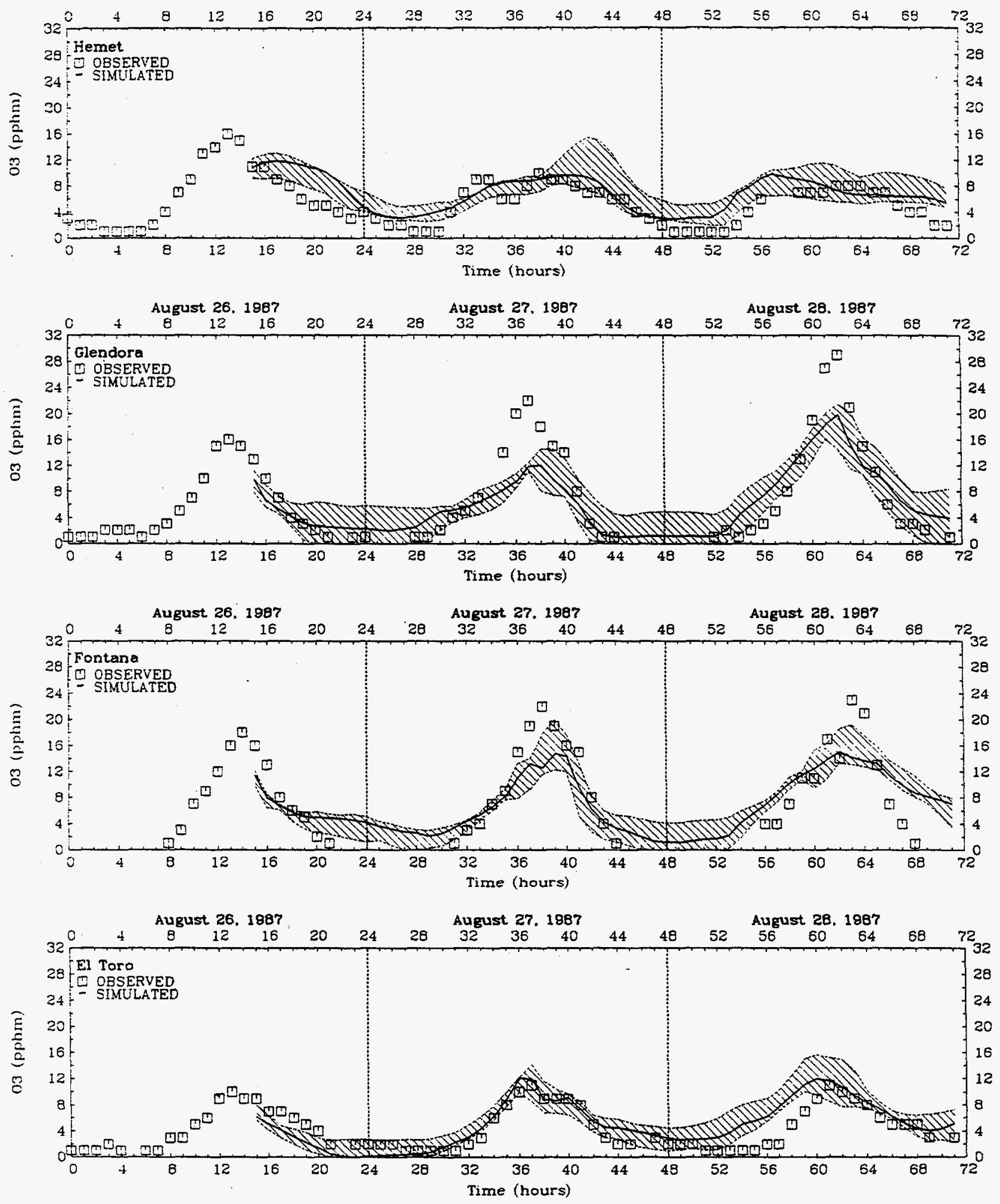

FIGURE 3-15. Continued. 

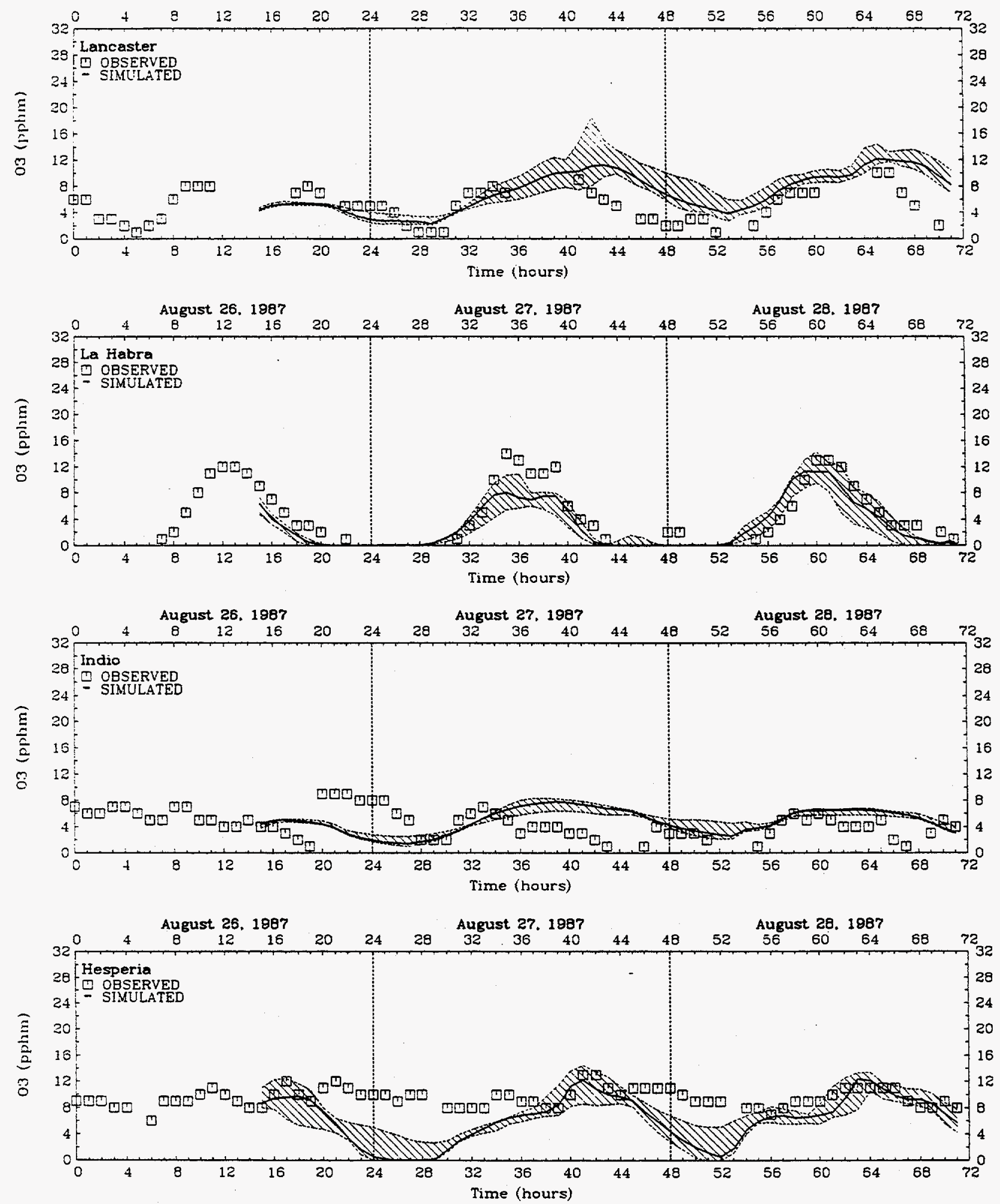

FIGURE 3-15. Continued. 

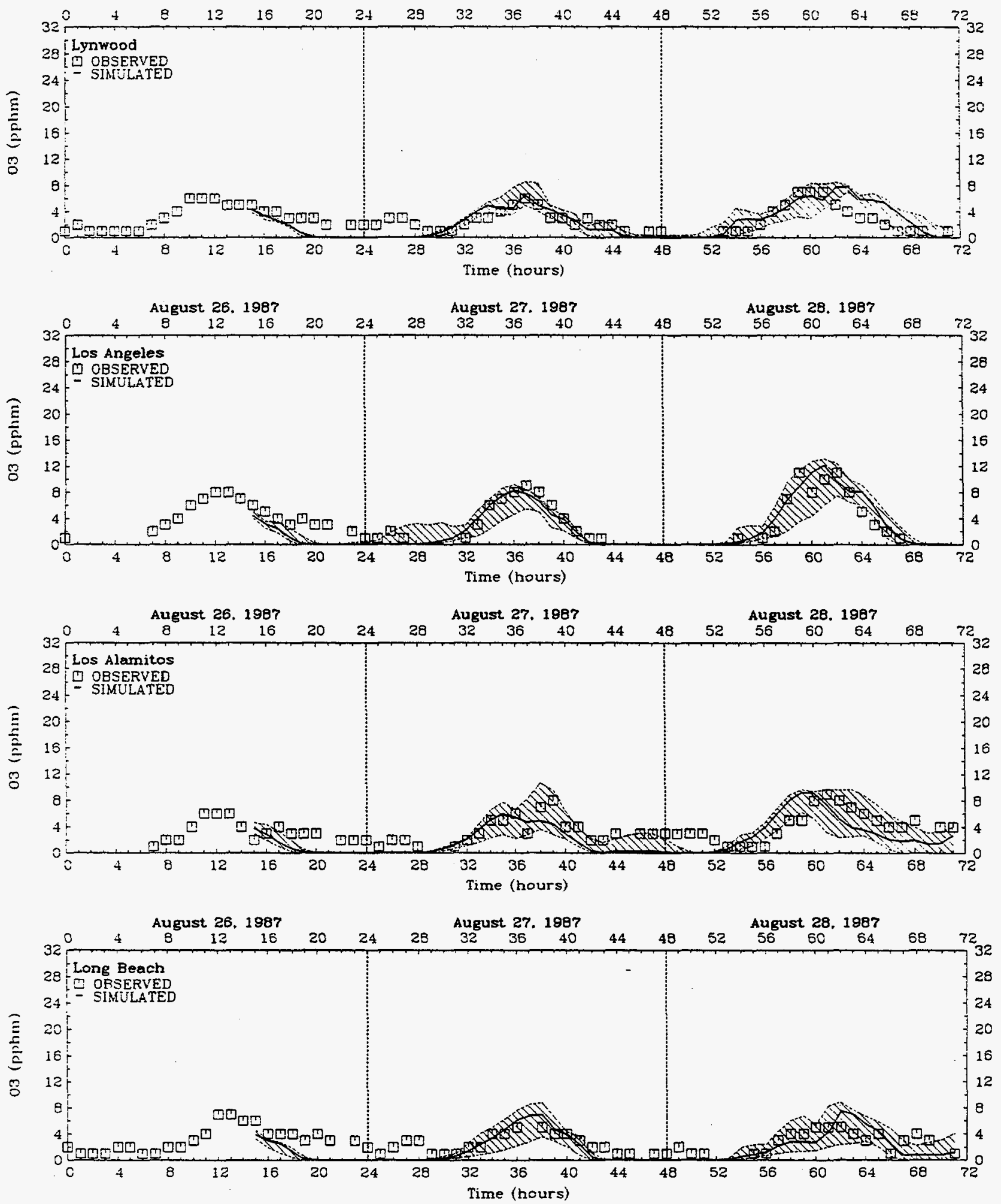

FIGURE 3-15. Continued. 

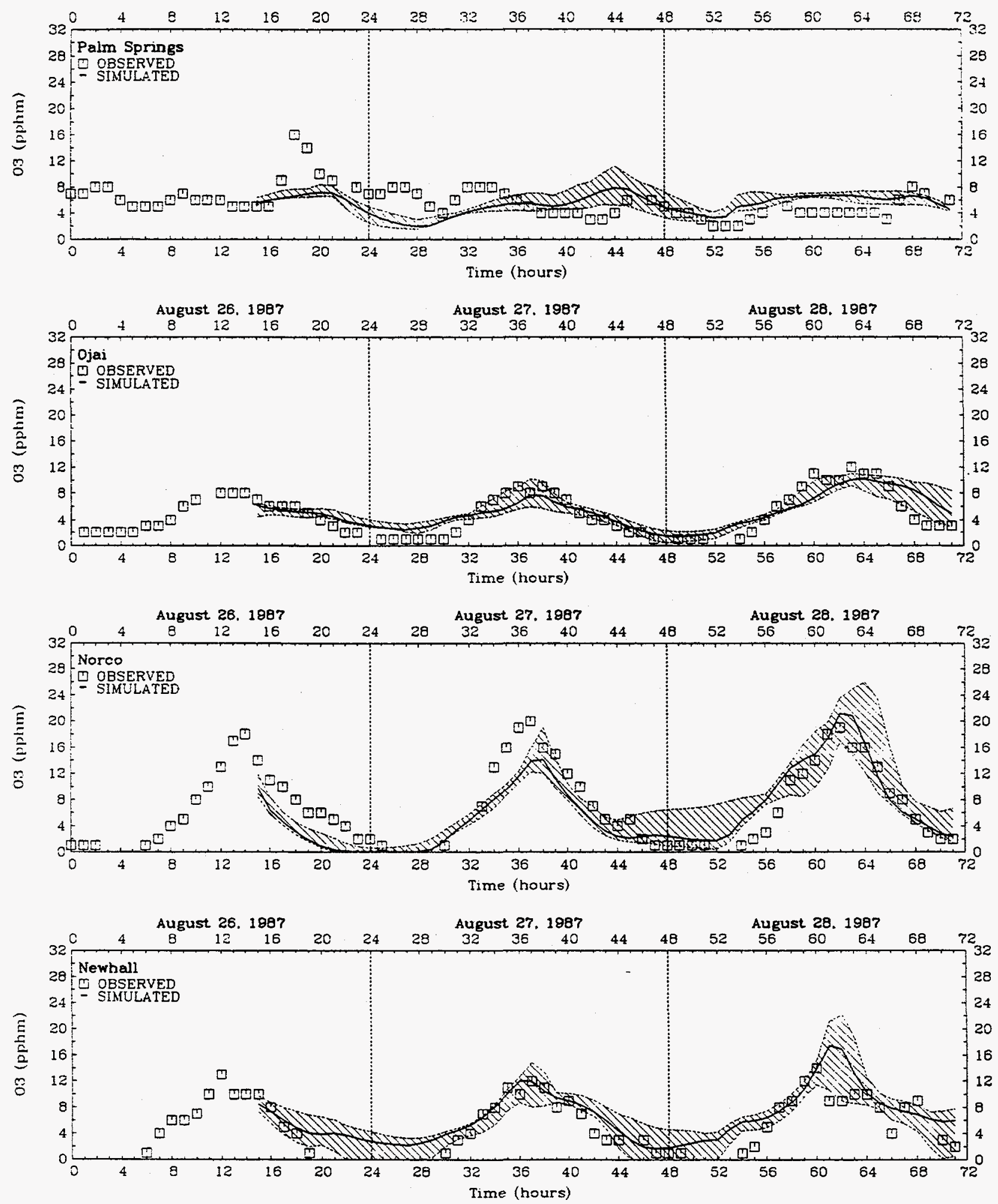

FIGURE 3-15. Continued. 

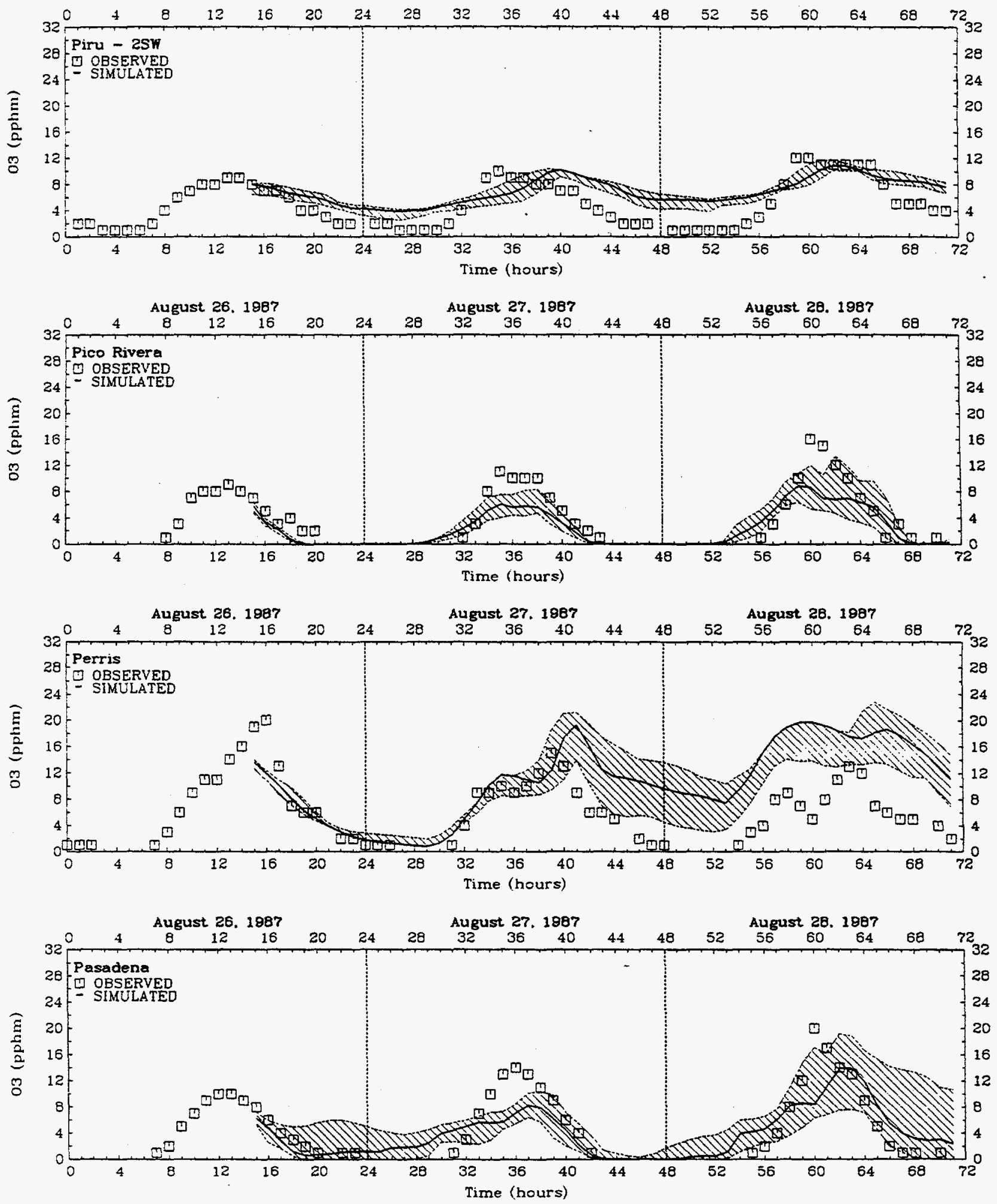

FIGURE 3-15. Continued. 

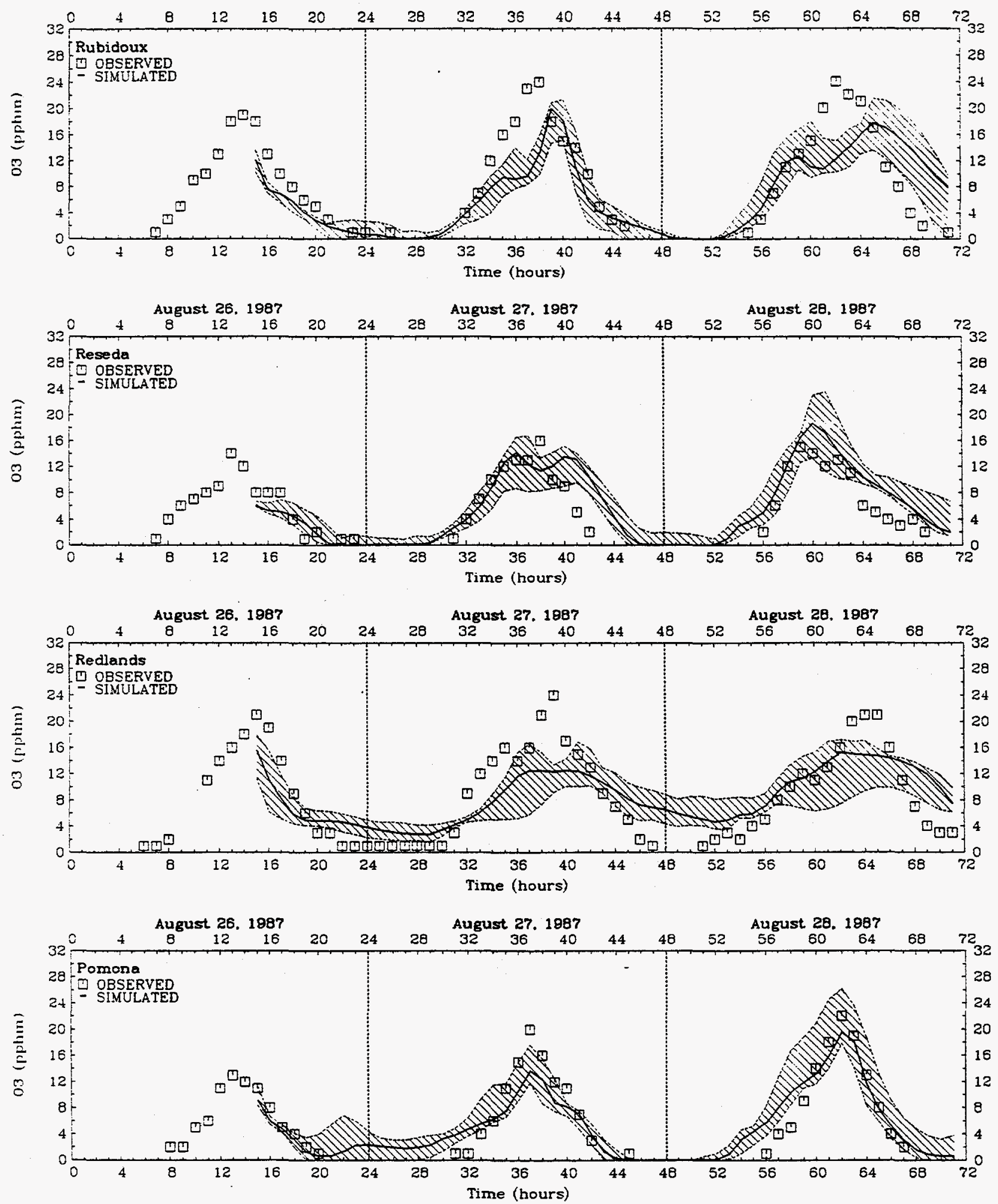

FIGURE 3-15. Continued. 

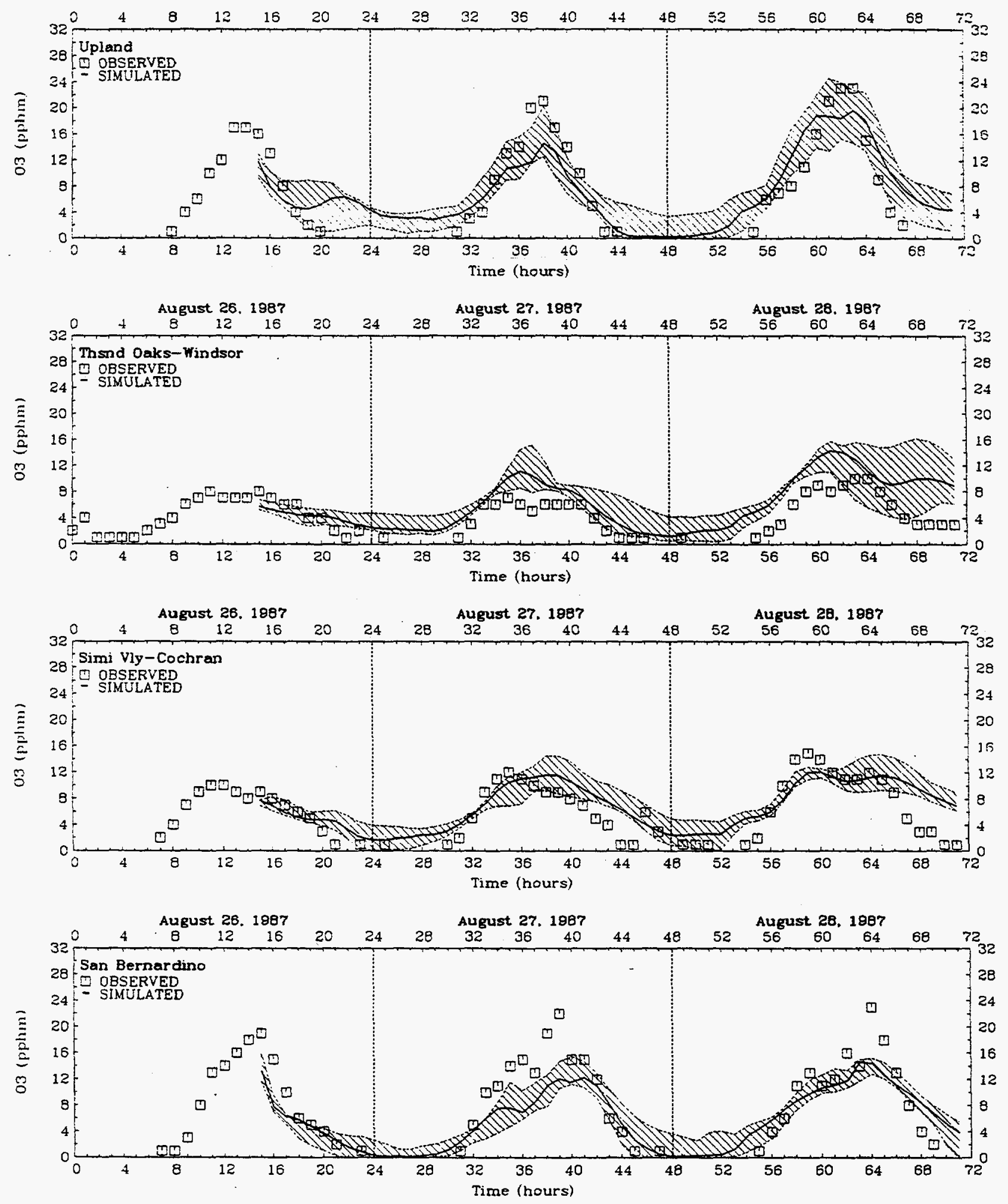

FIGURE 3-15. Continued. 

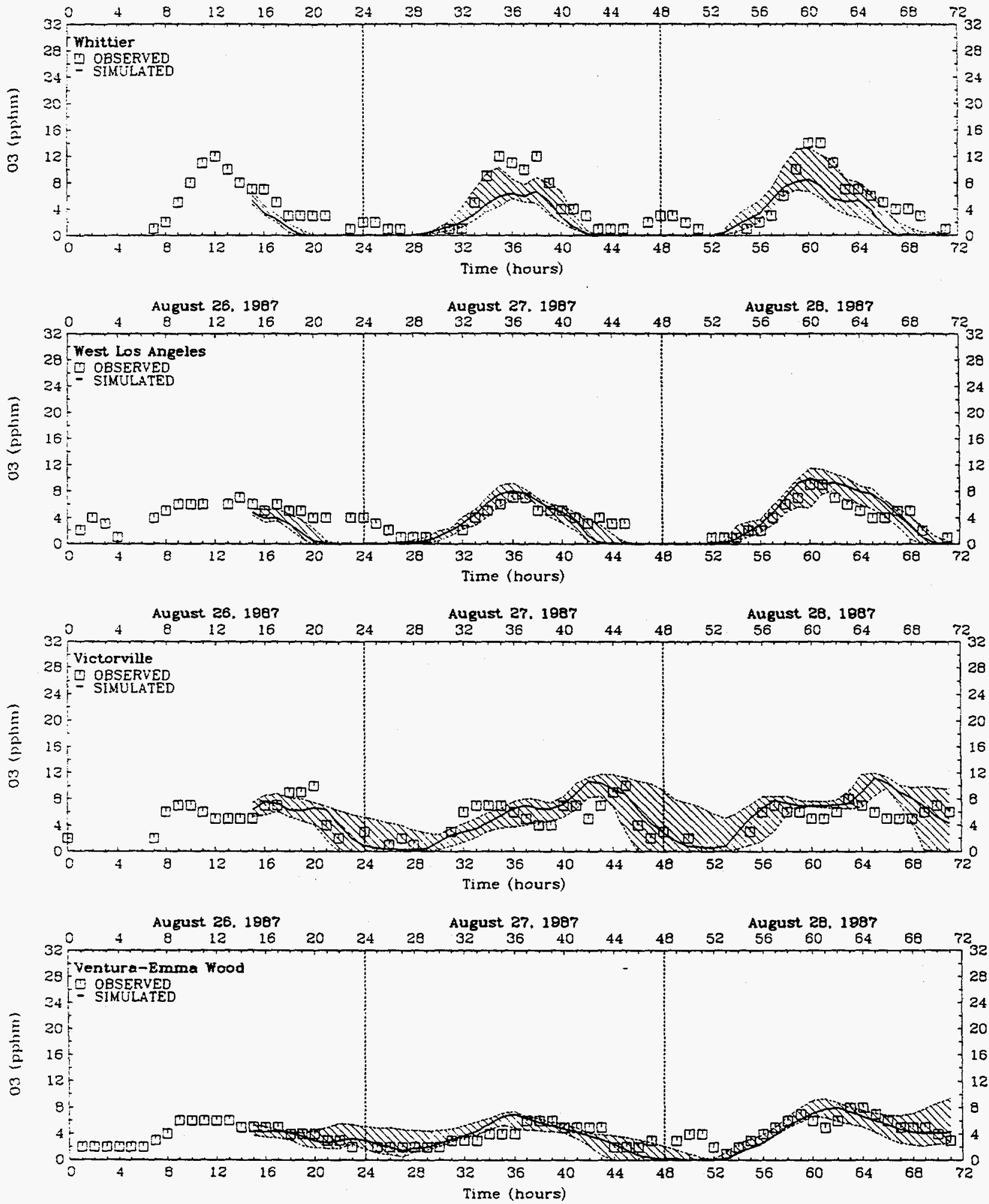

FIGURE 3-15. Concluded. 

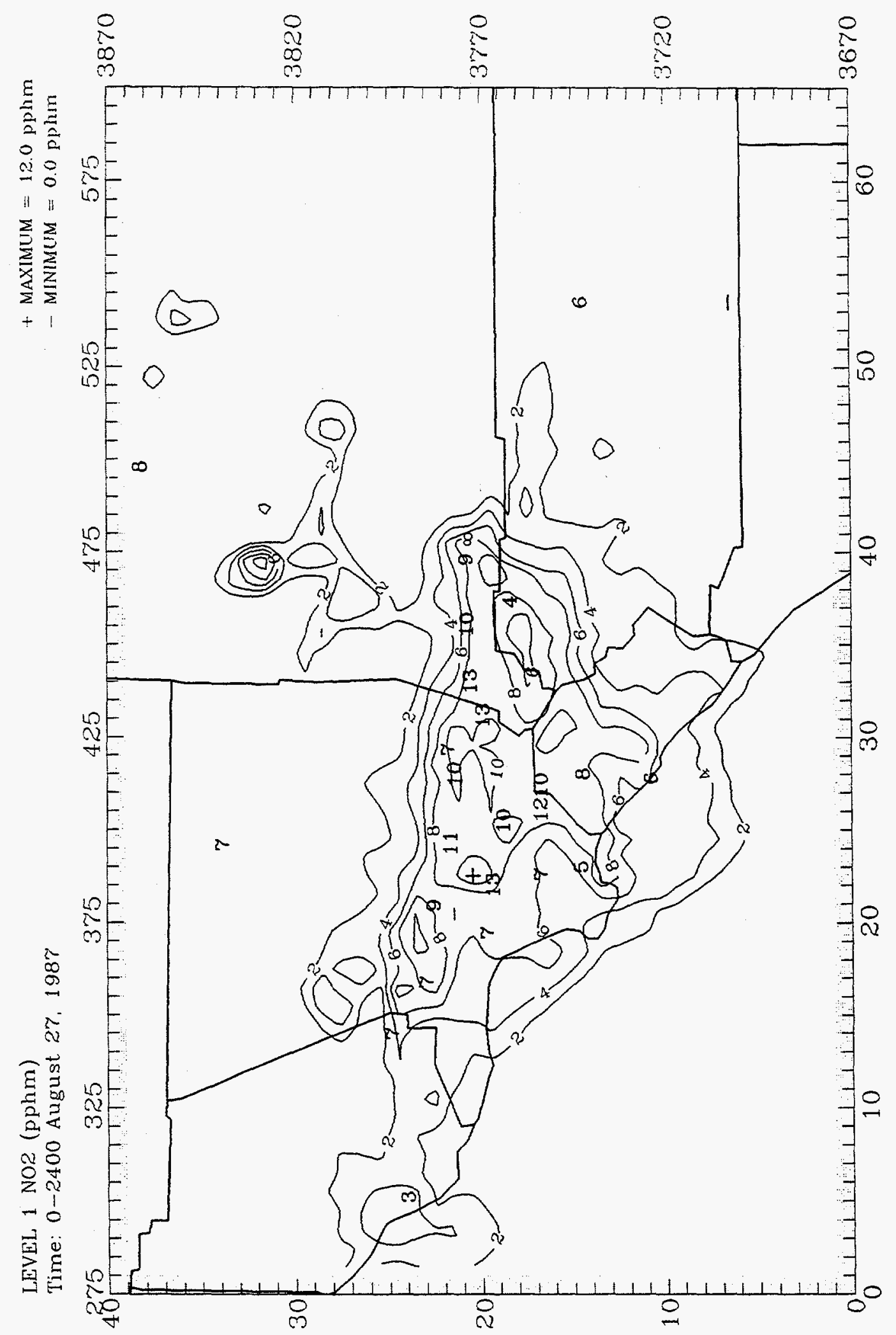

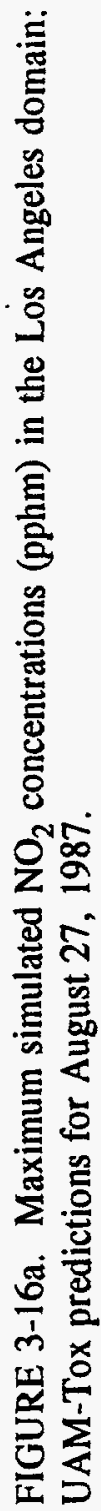



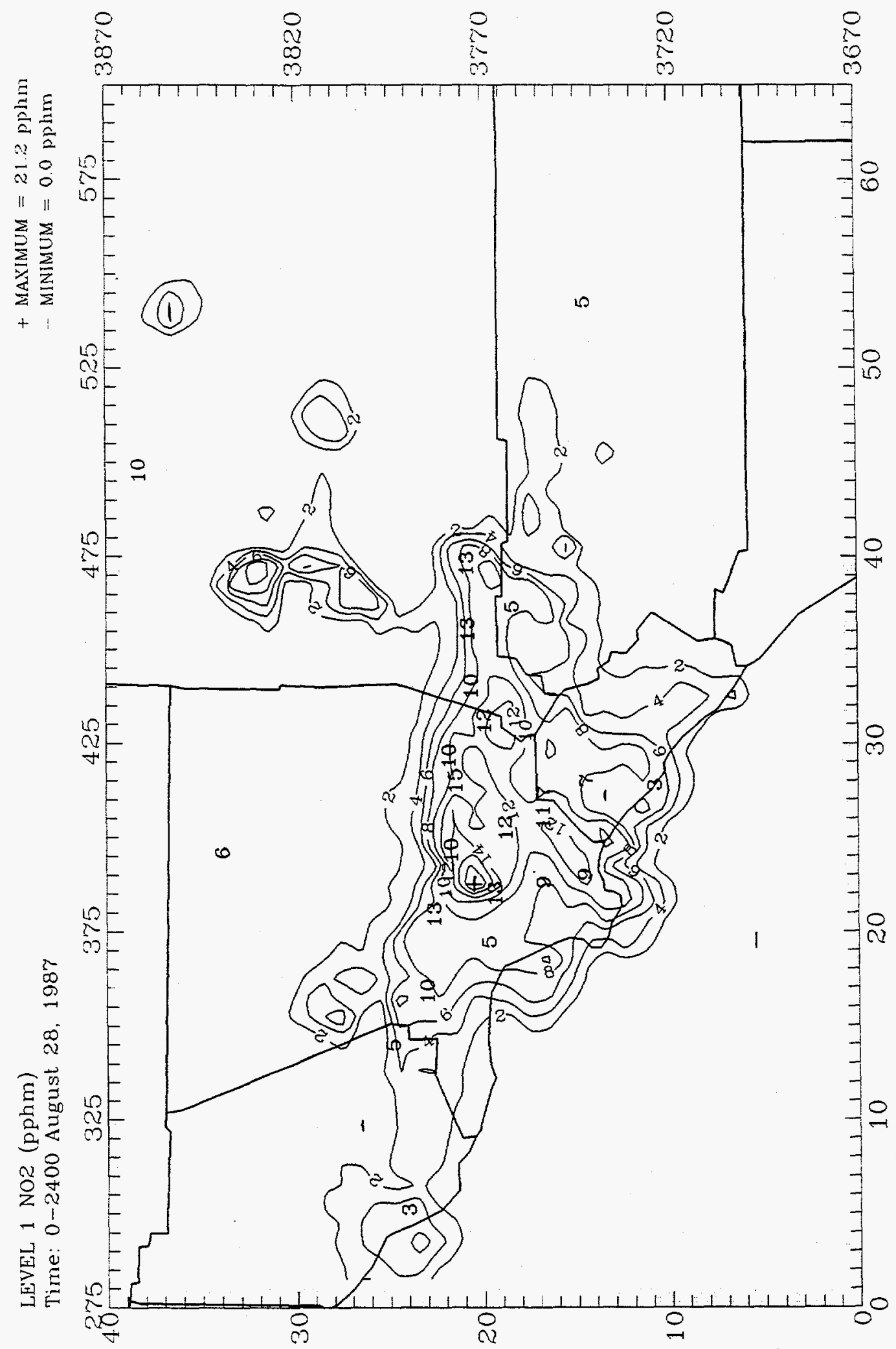

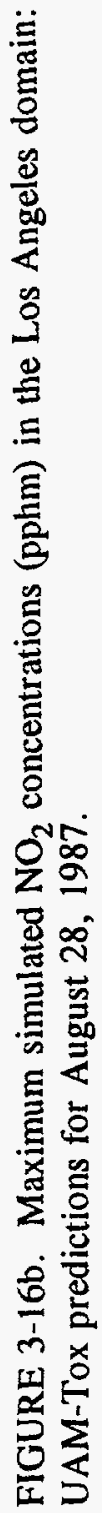



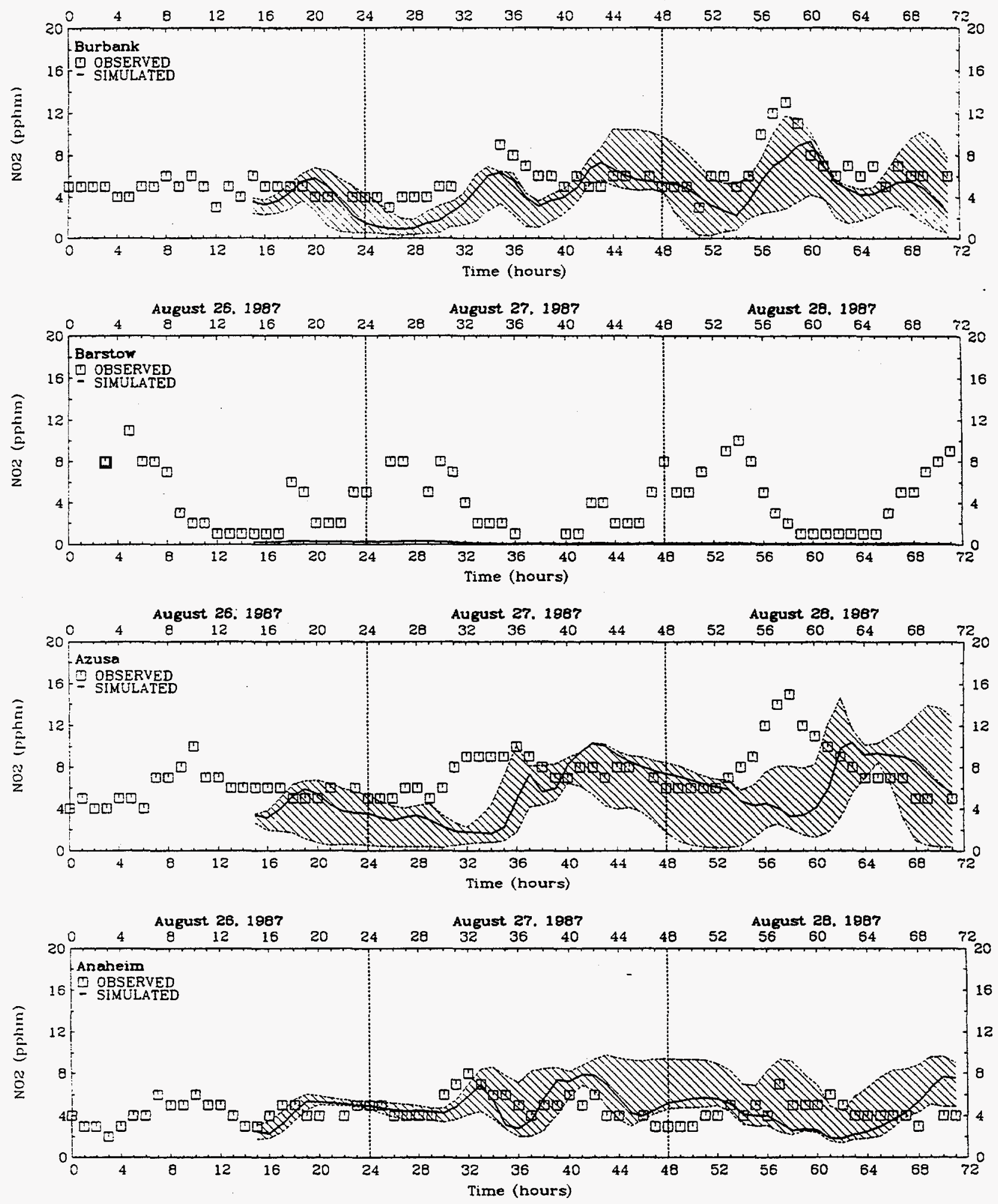

FIGURE 3-17. Simulated and observed $\mathrm{NO}_{2}$ concentrations (pphm) at monitoring sites in the Los Angeles domain for the August 26-28, 1987 base episode. 

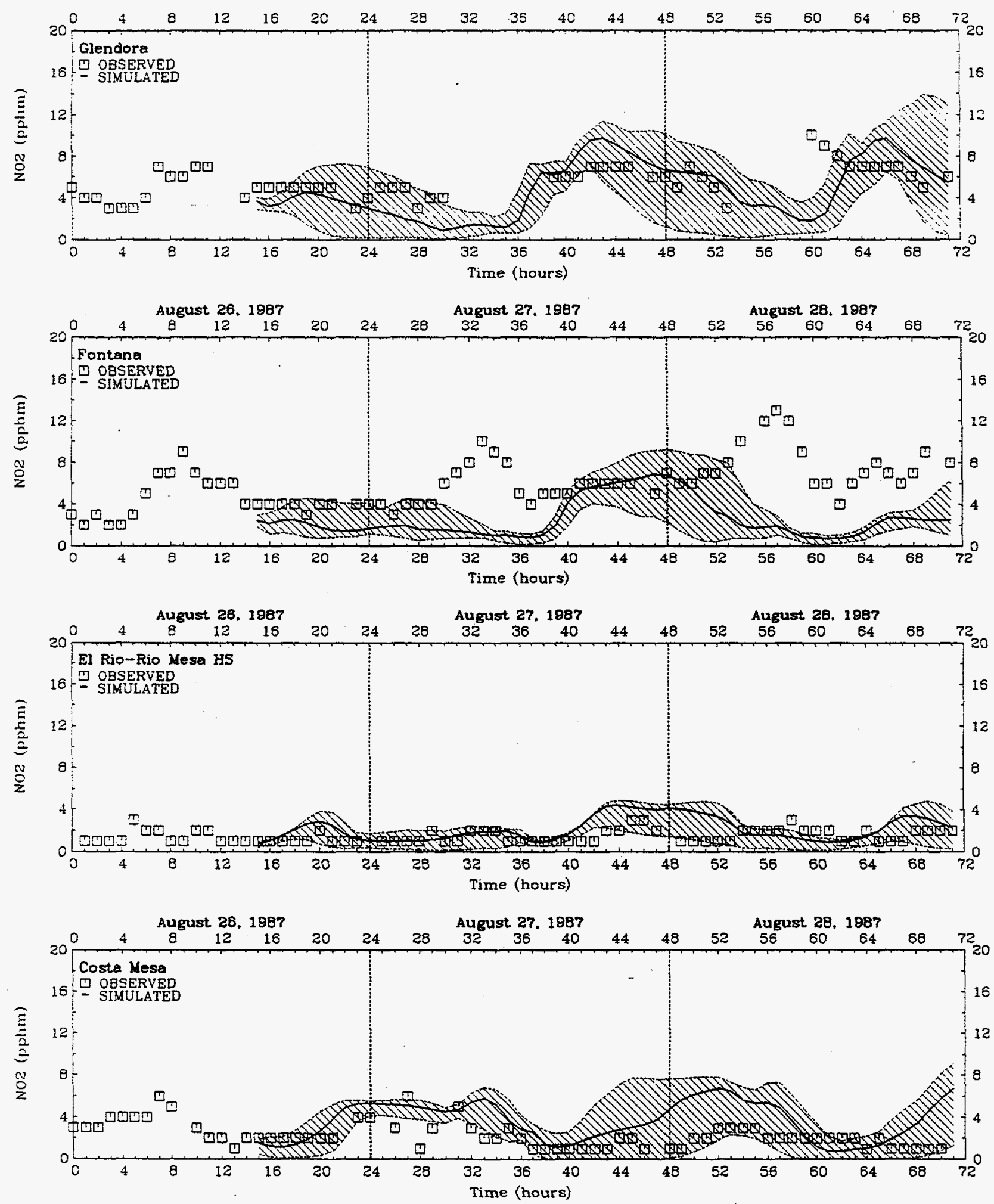

FIGURE 3-17. Continued. 

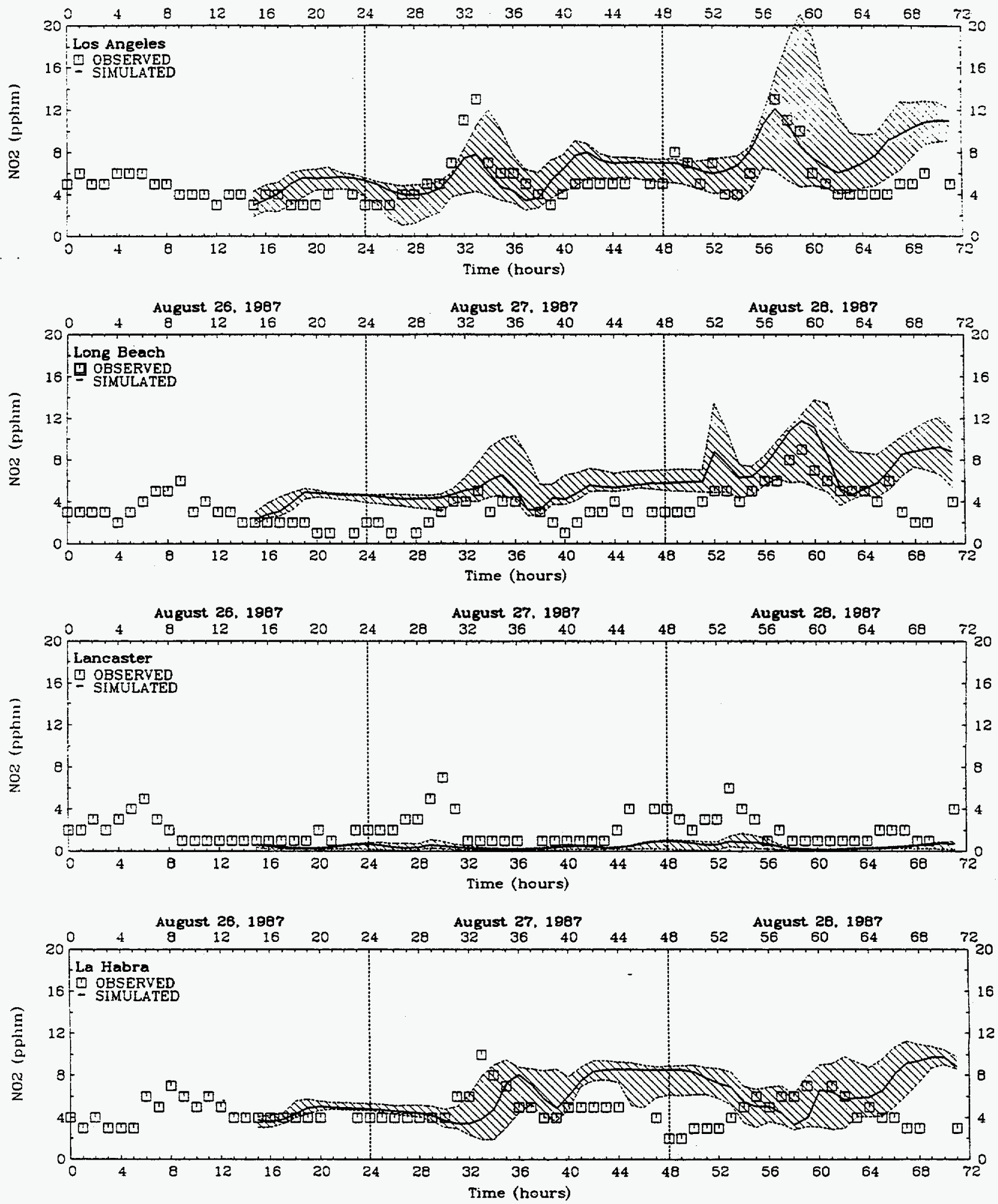

FIGURE 3-17. Continued. 

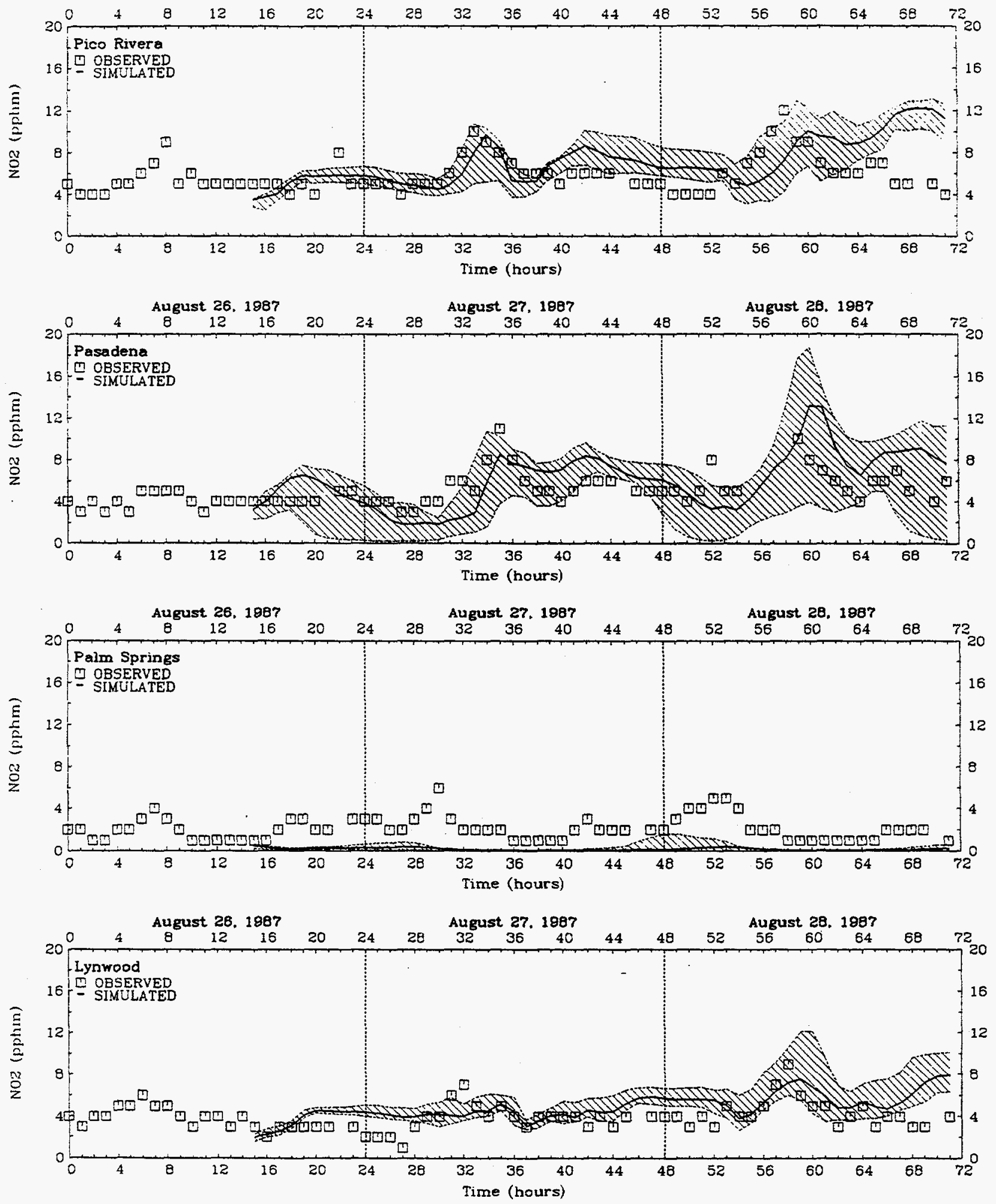

FIGURE 3-17. Continued. 

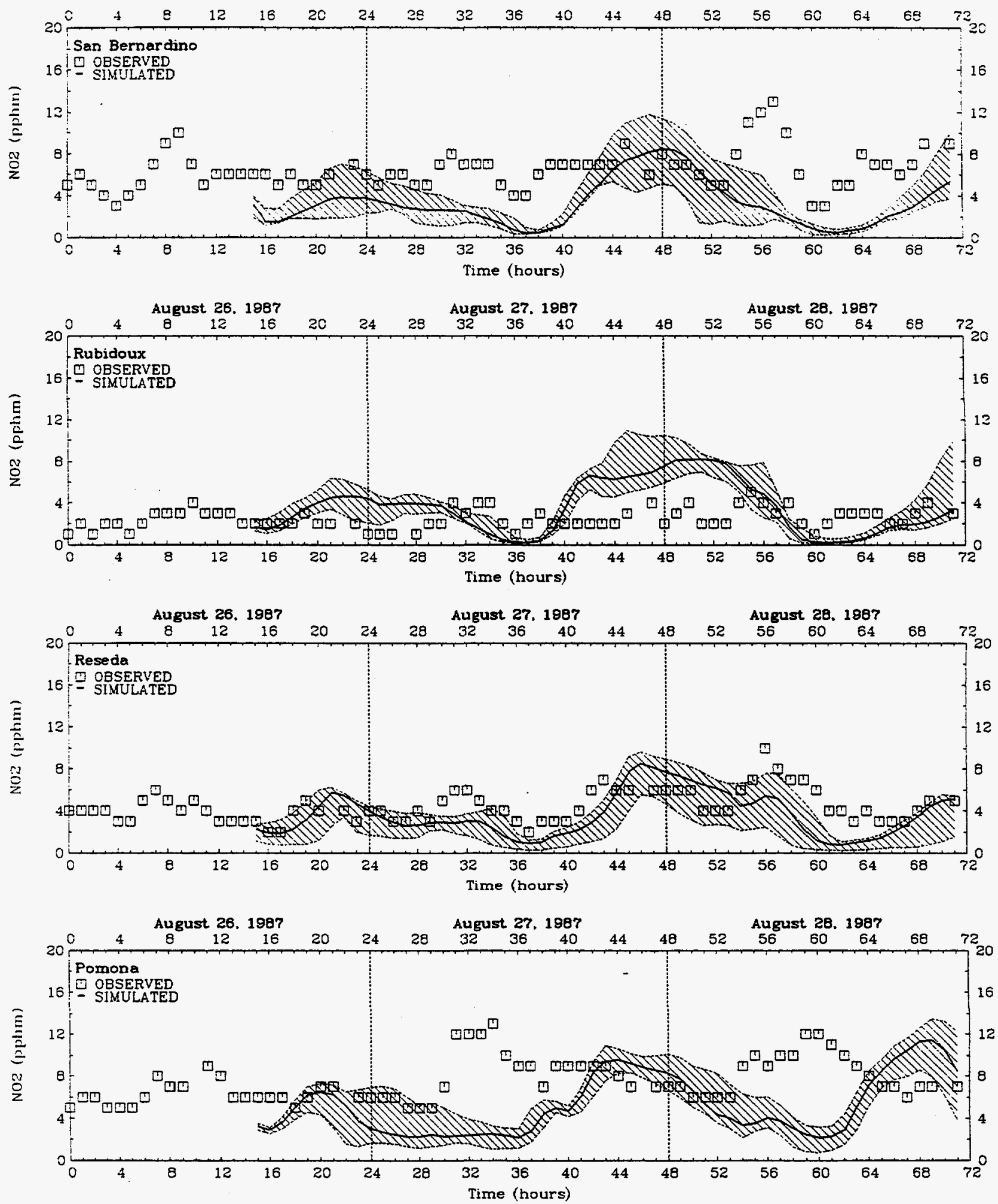

FIGURE 3-17. Continued. 

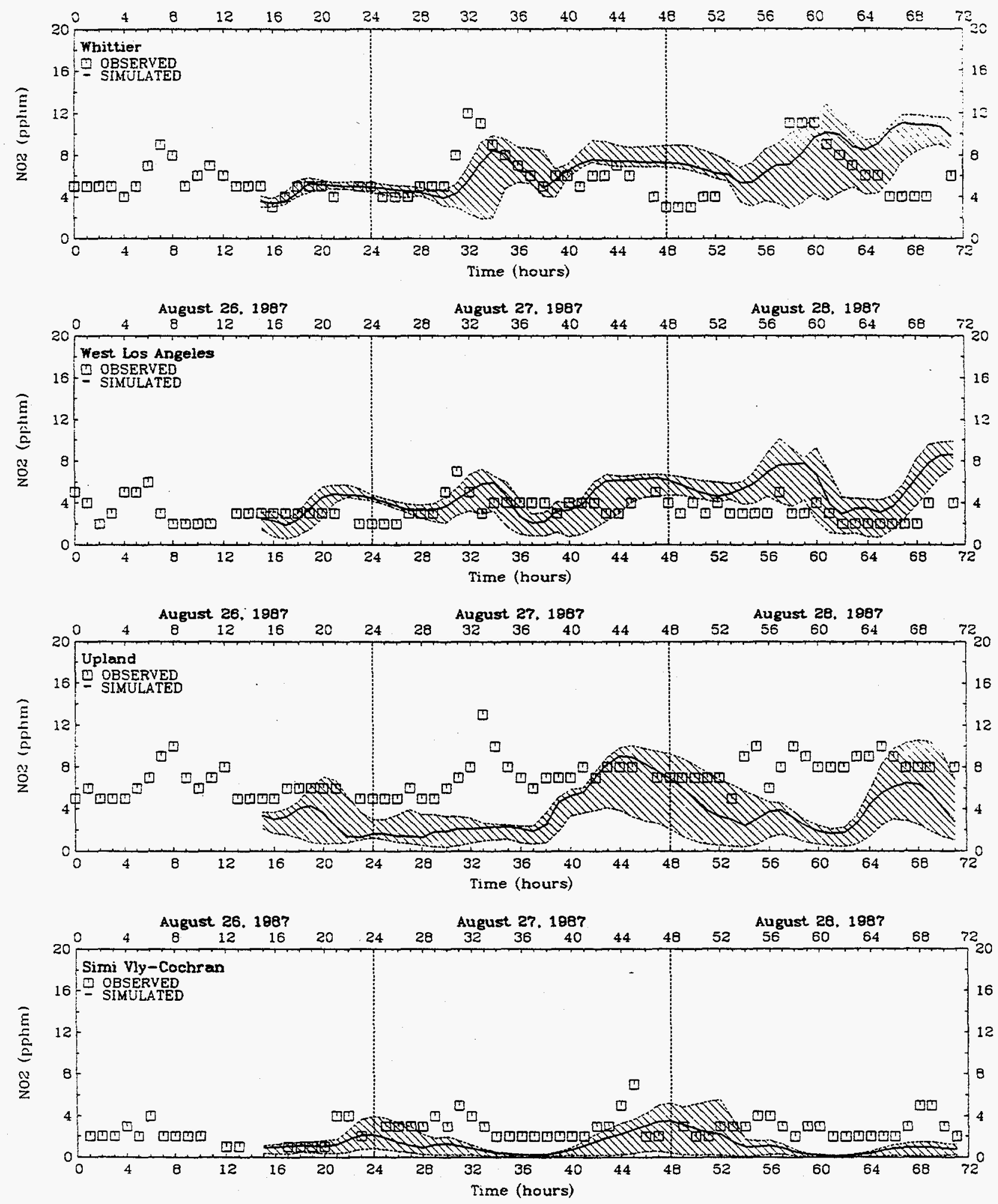

FIGURE 3-17. Concluded. 

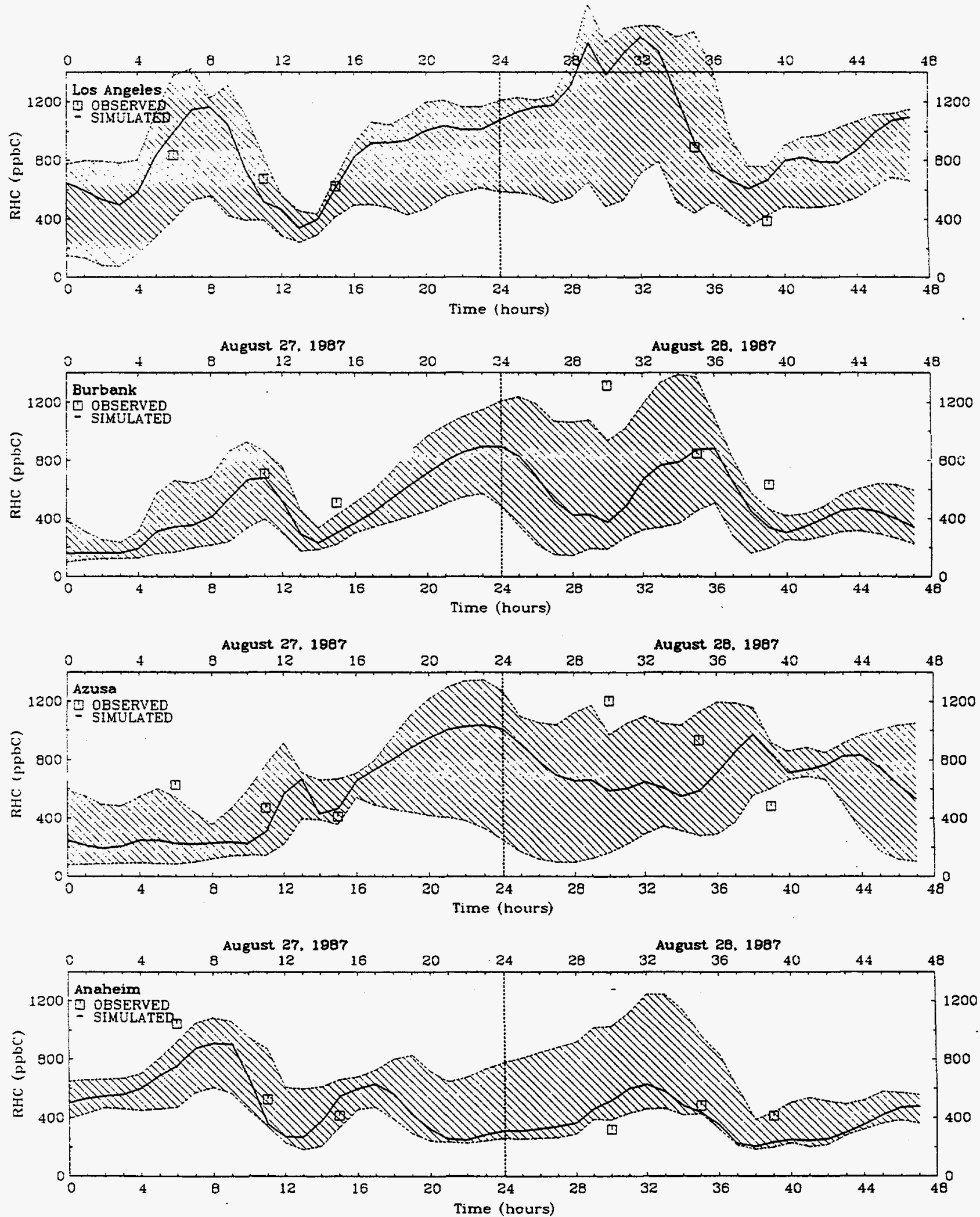

FIGURE 3-18. Simulated and observed RHC concentrations (ppbC) at monitoring sites in the Los Angeles domain for the August 27-28, 1987 base episode. 

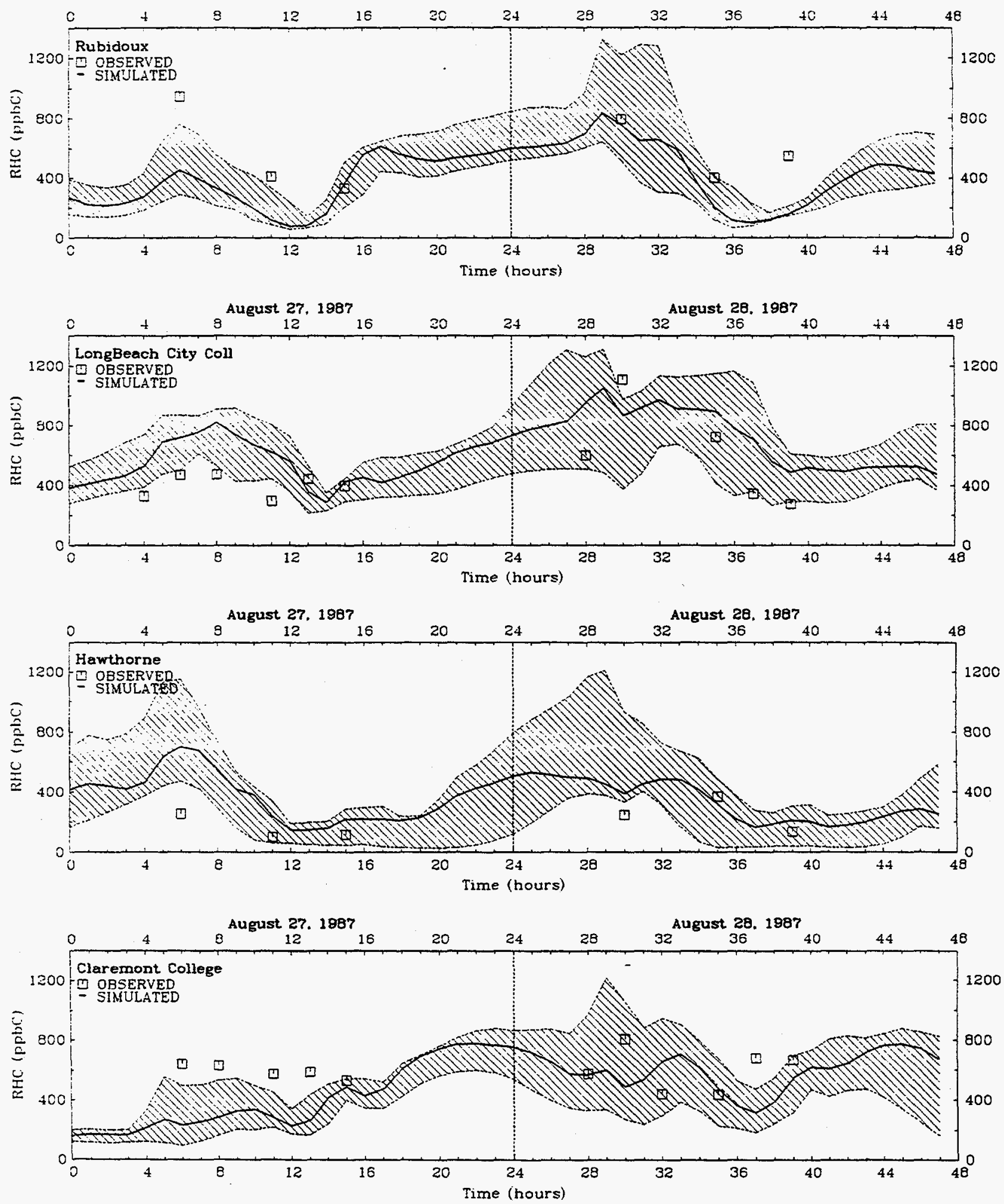

FIGURE 3-18. Concluded. 

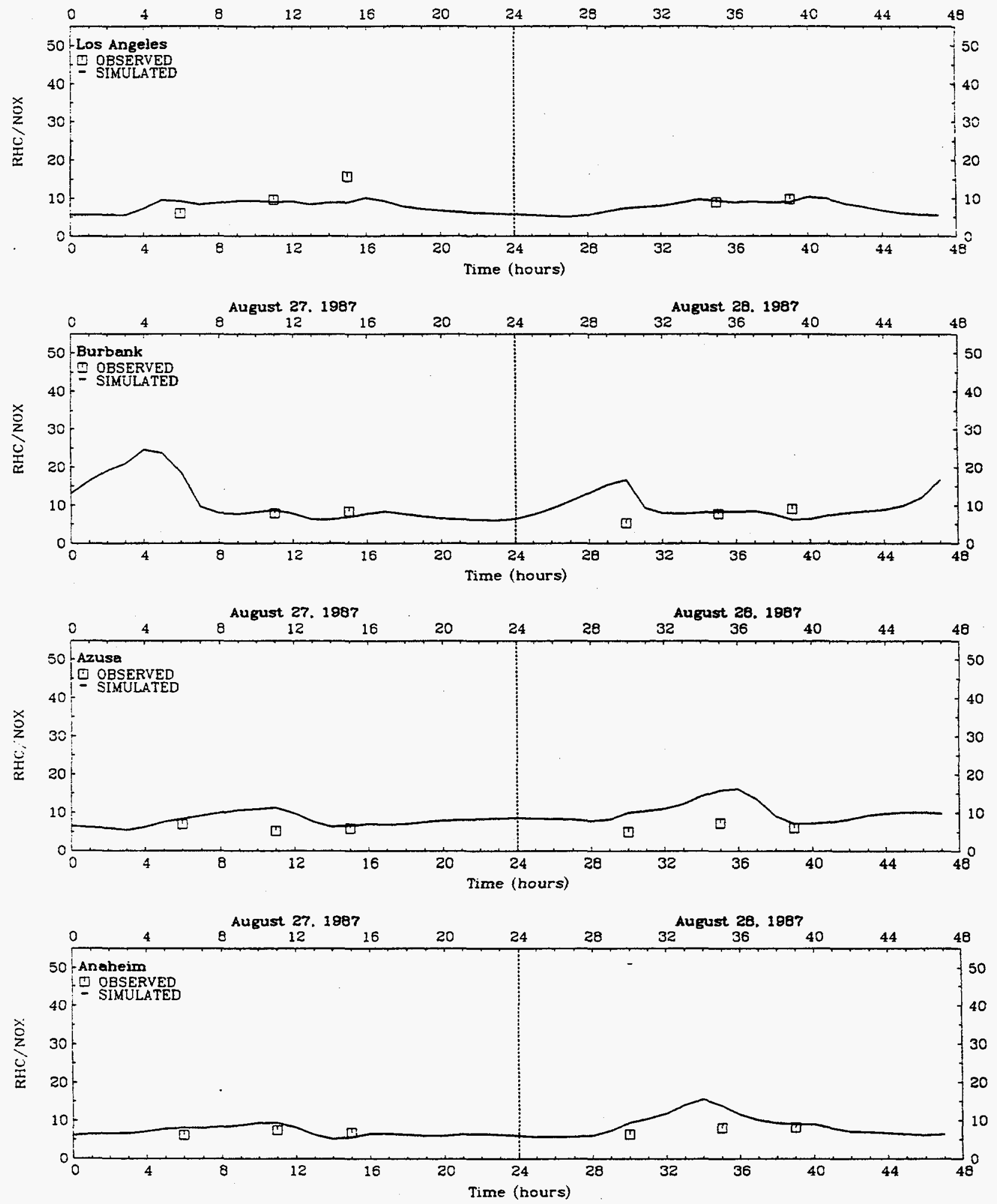

FIGURE 3-19. Simulated and observed $\mathrm{RHC} / \mathrm{NO}_{\mathrm{x}}(\mathrm{ppbC} / \mathrm{ppb})$ at monitoring sites in the Los Angeles domain for the August 27-28, 1987 base episode. 

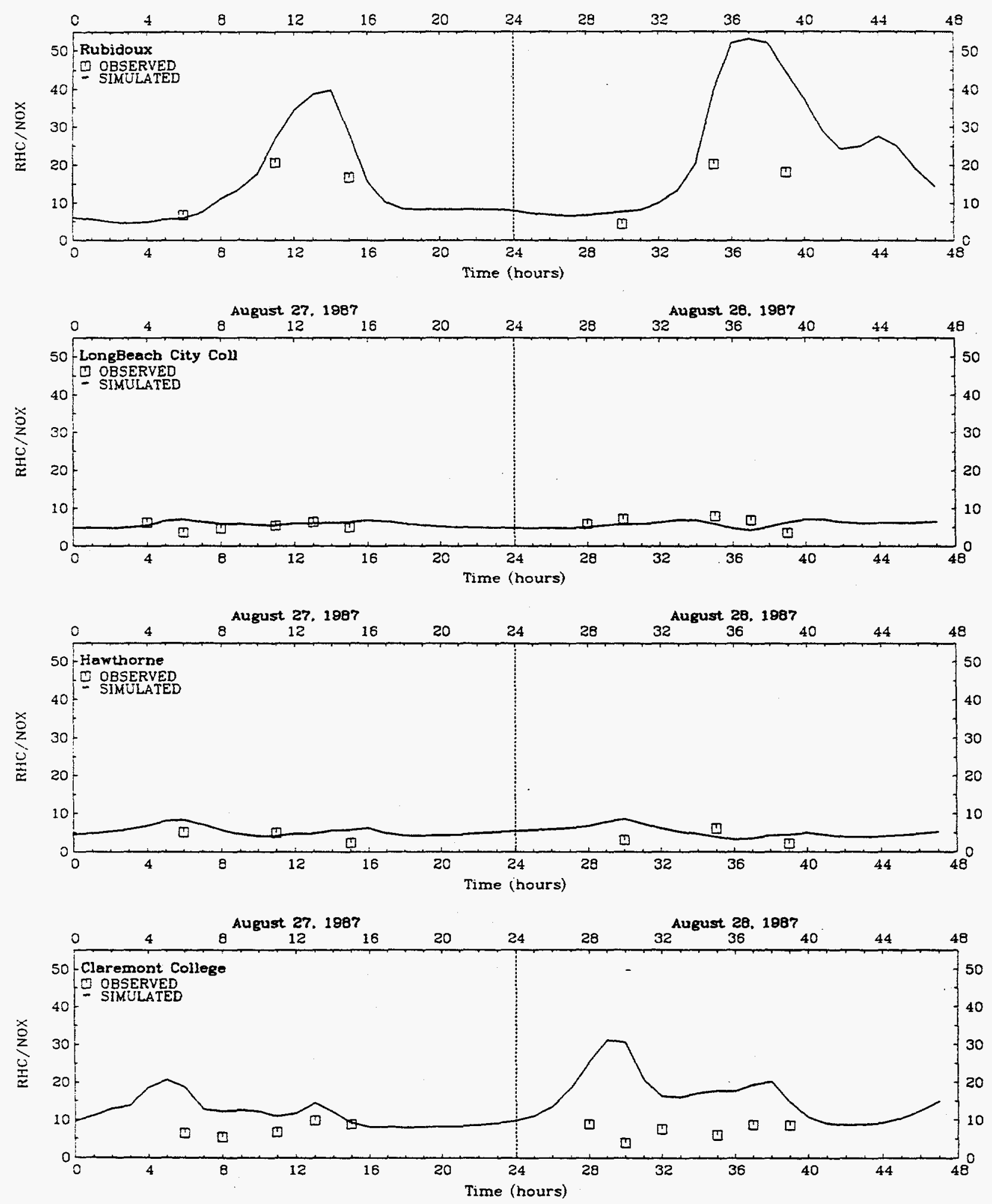

FIGURE 3-19. Concluded. 

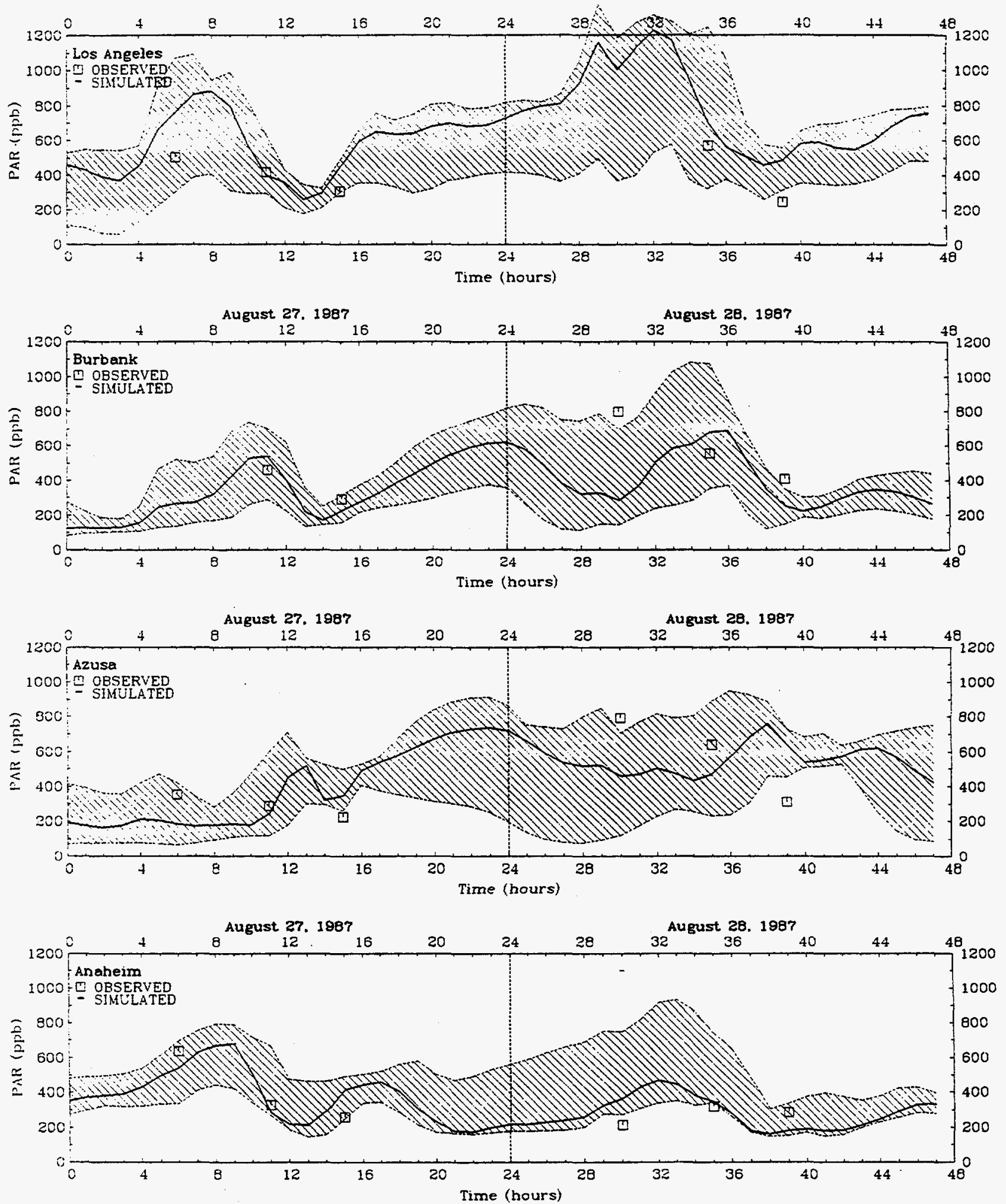

FIGURE 3-20. Simulated and observed PAR concentrations (ppb) at monitoring sites in the Los Angeles domain for the August 27-28, 1987 base episode. 

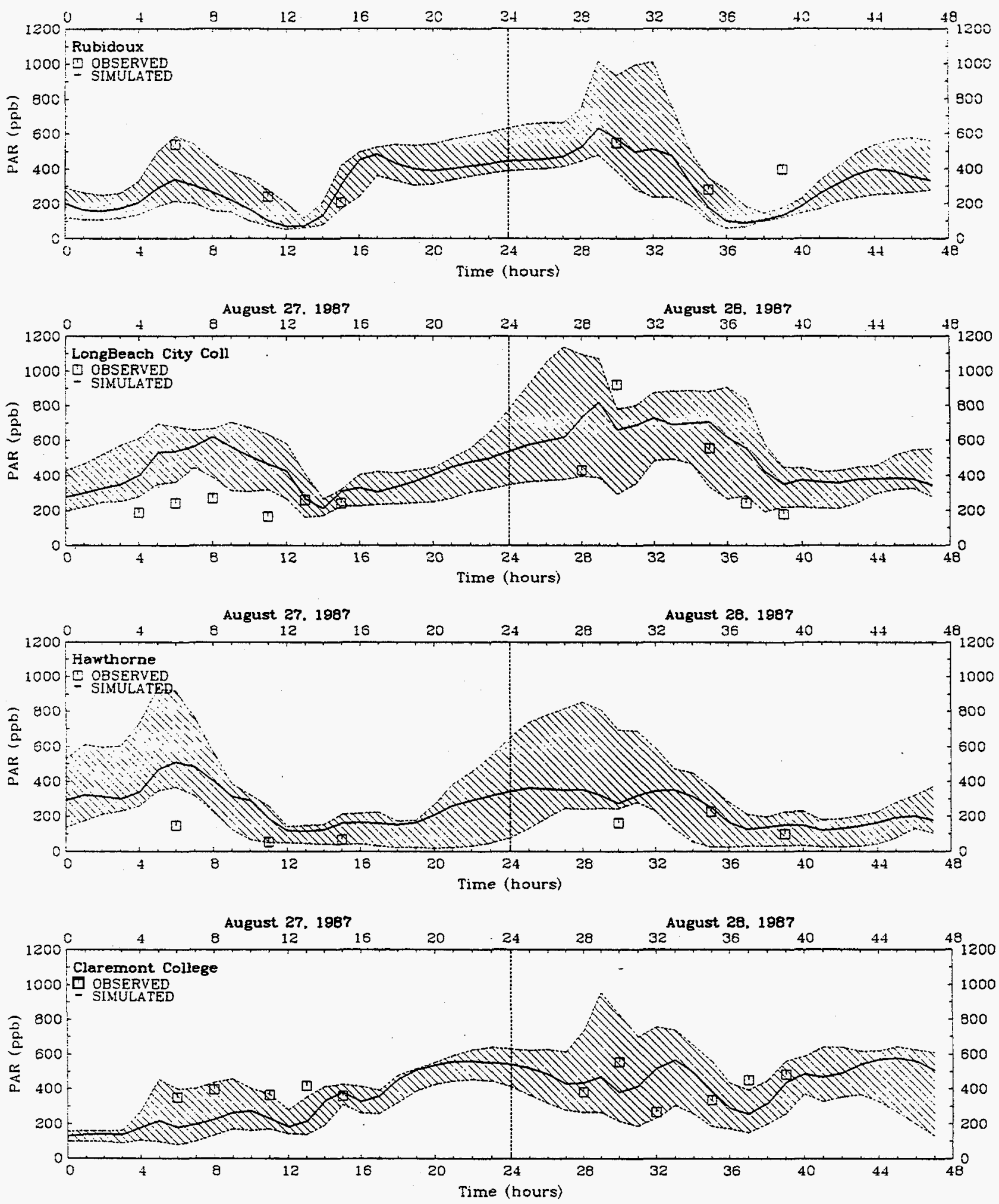

FIGURE 3-20. Concluded. 

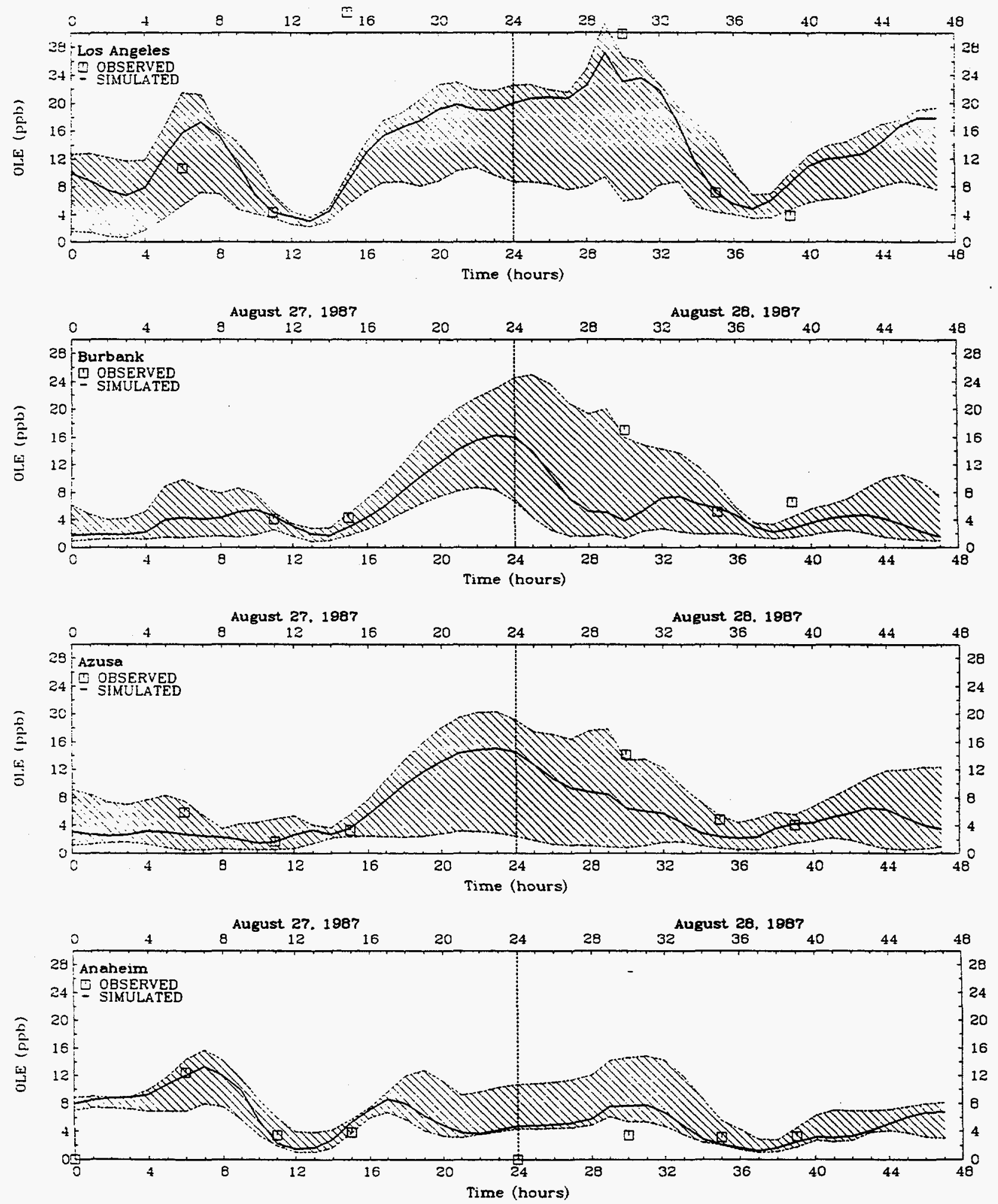

FIGURE 3-21. Simulated and observed OLE concentrations (ppb) at monitoring sites in the Los Angeles domain for the August 27-28, 1987 base episode. 

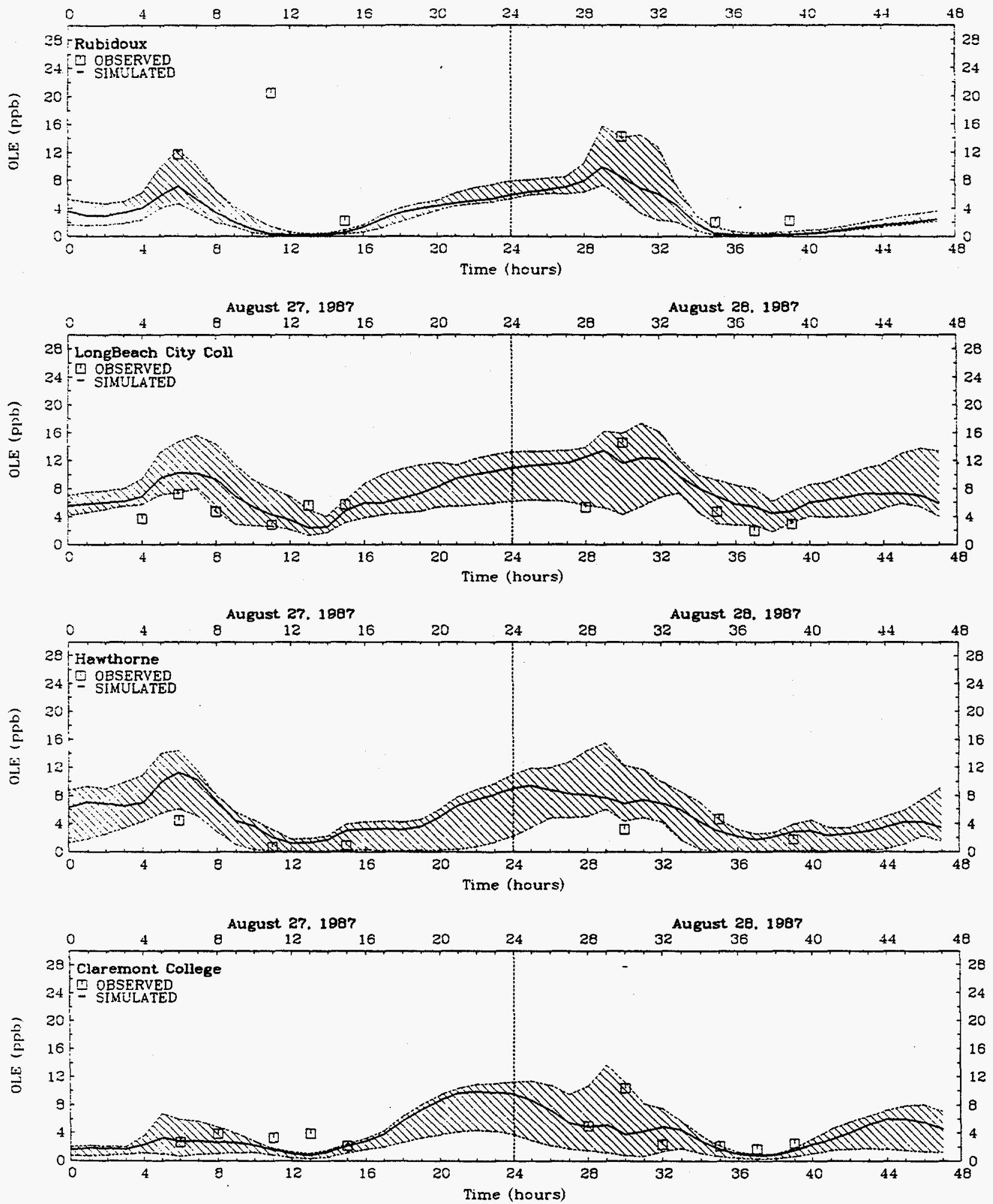

FIGURE 3-21. Concluded. 

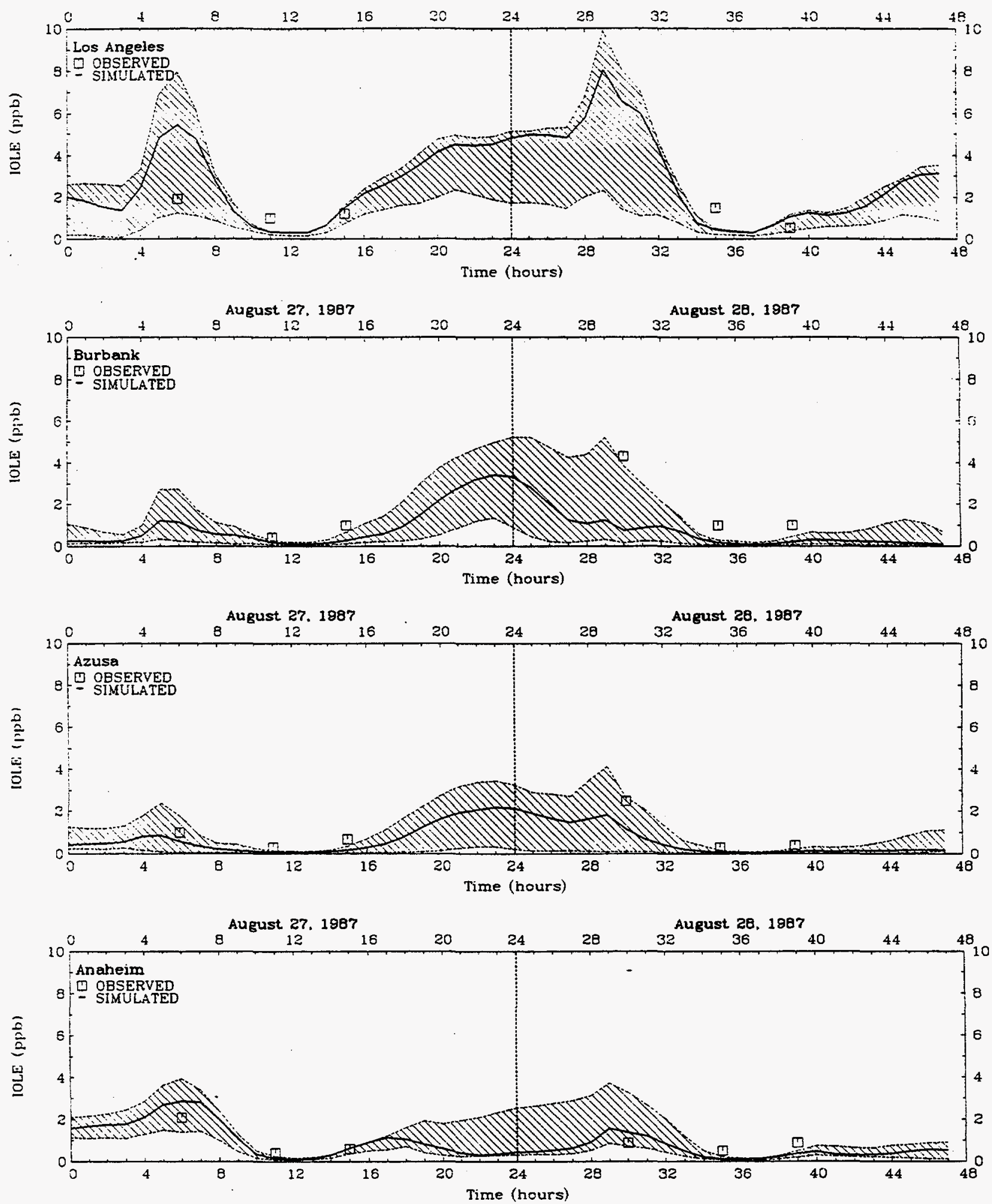

FIGURE 3-22. Simulated and observed IOLE concentrations (ppb) at monitoring sites in the Los Angeles domain for the August 27-28, 1987 base episode. 

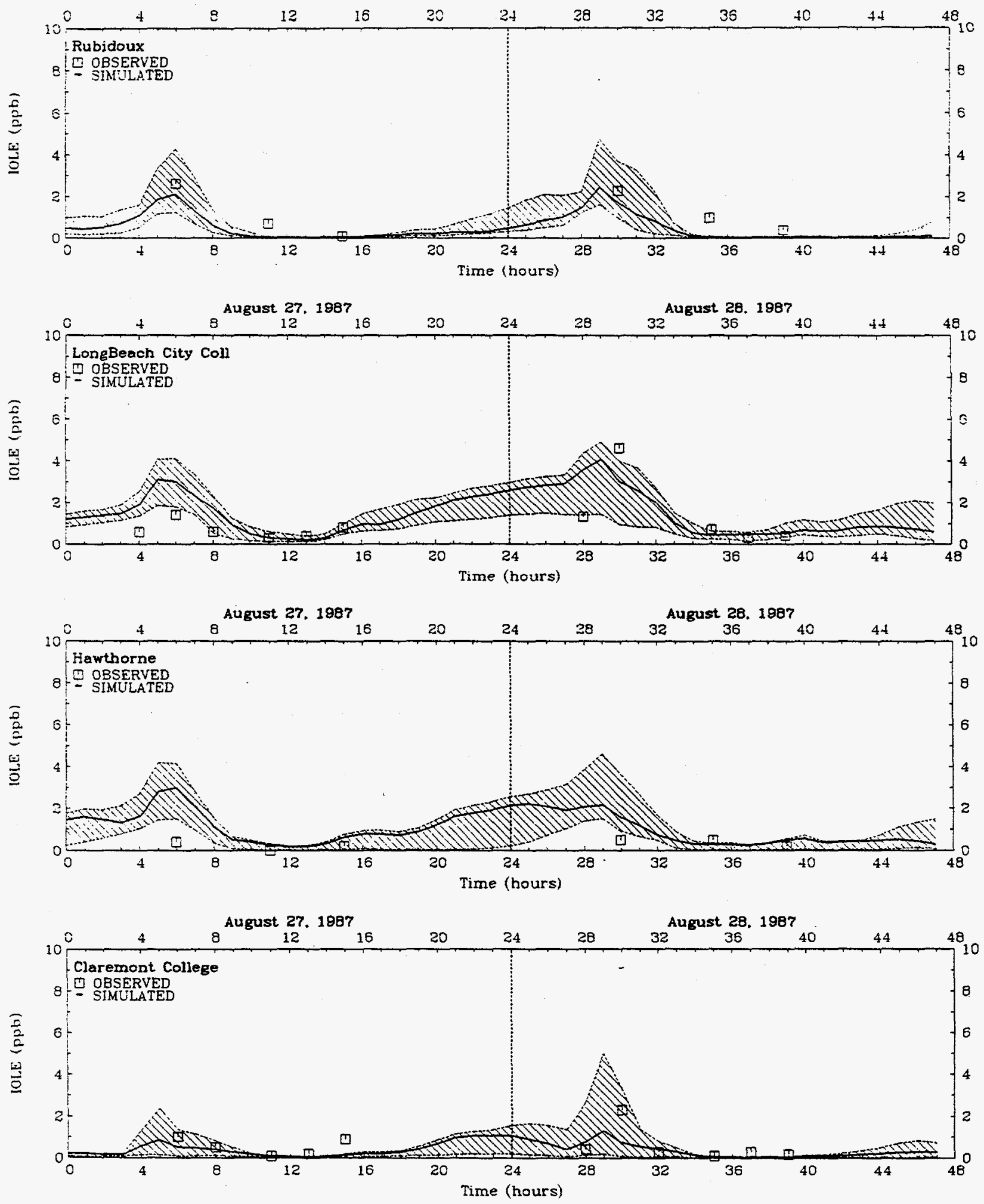

FIGURE 3-22. Concluded. 

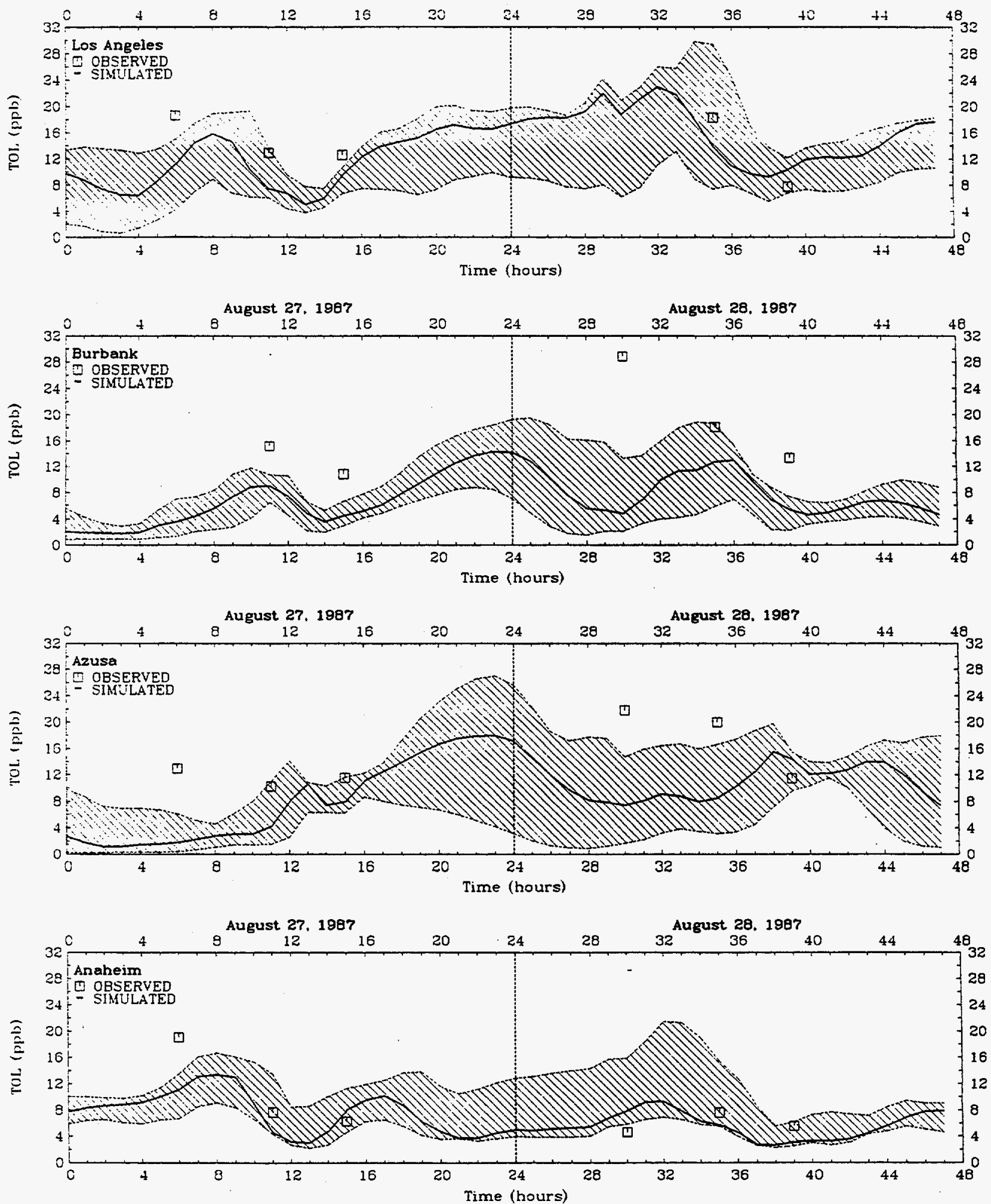

FIGURE 3-23. Simulated and observed TOL concentrations (ppb) at monitoring sites in the Los Angeles domain for the August 27-28, 1987 base episode. 

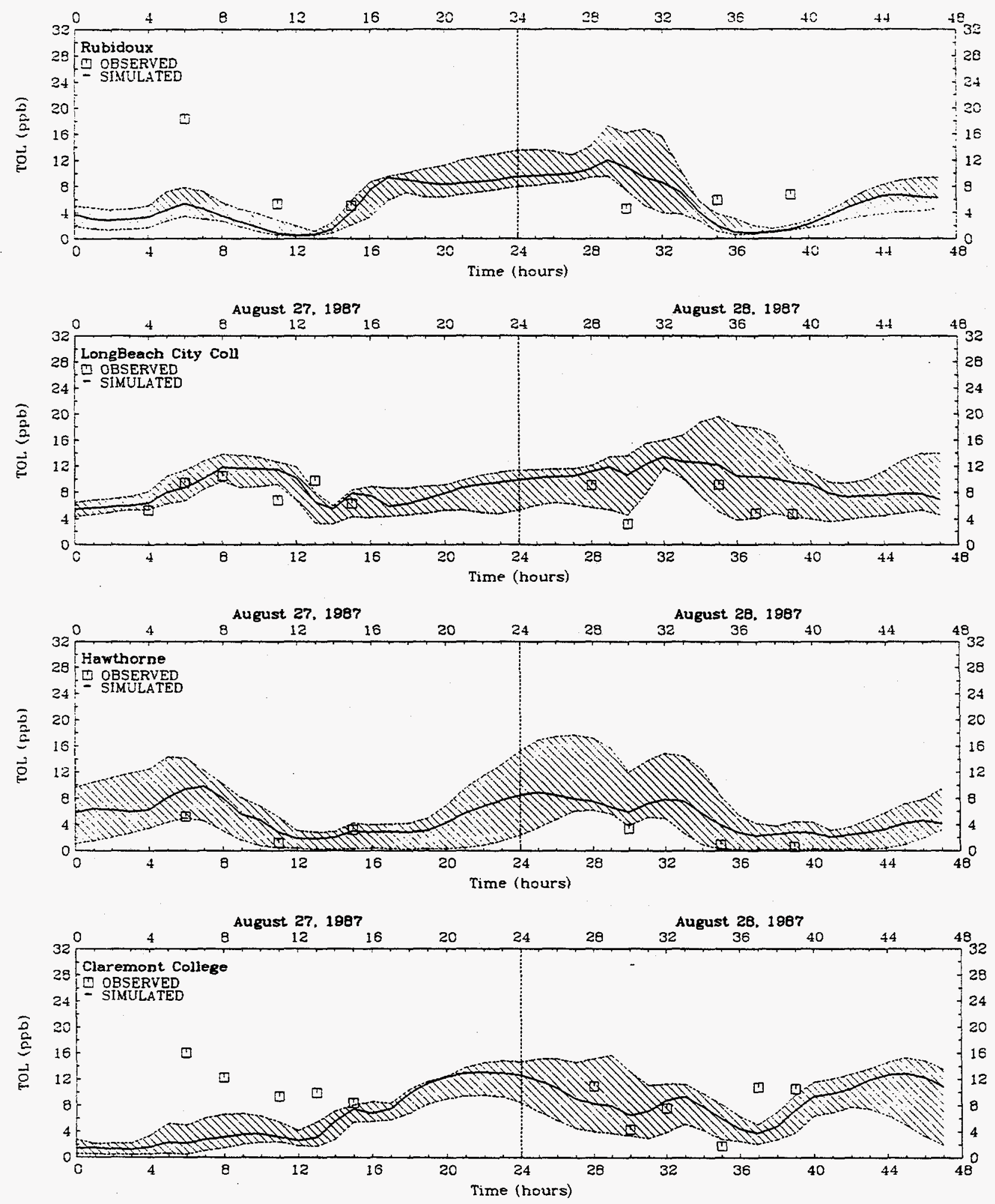

FIGURE 3-23. Concluded. 

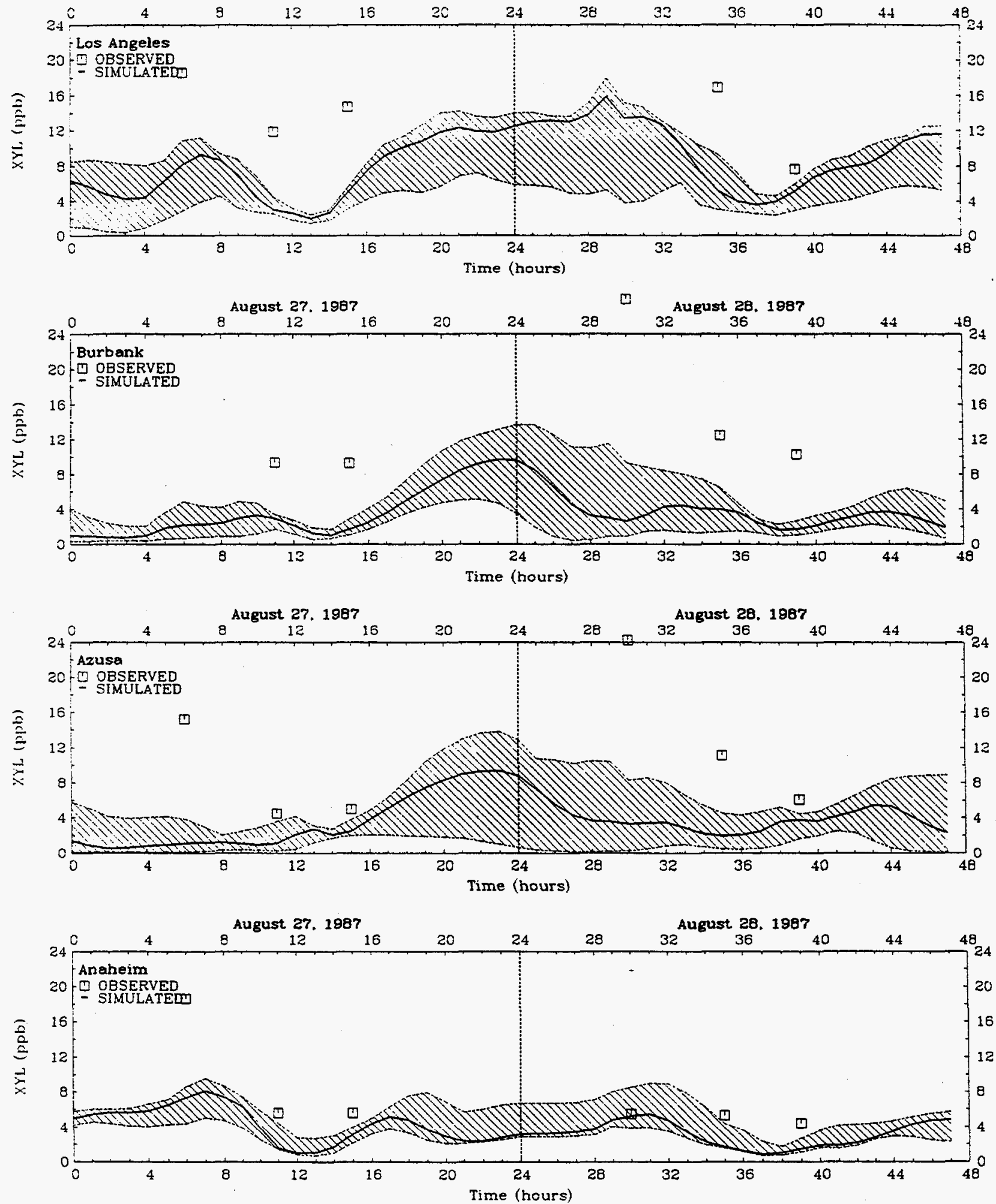

FIGURE 3-24. Simulated and observed XYL concentrations (ppb) at monitoring sites in the Los Angeles domain for the August 27-28, 1987 base episode. 

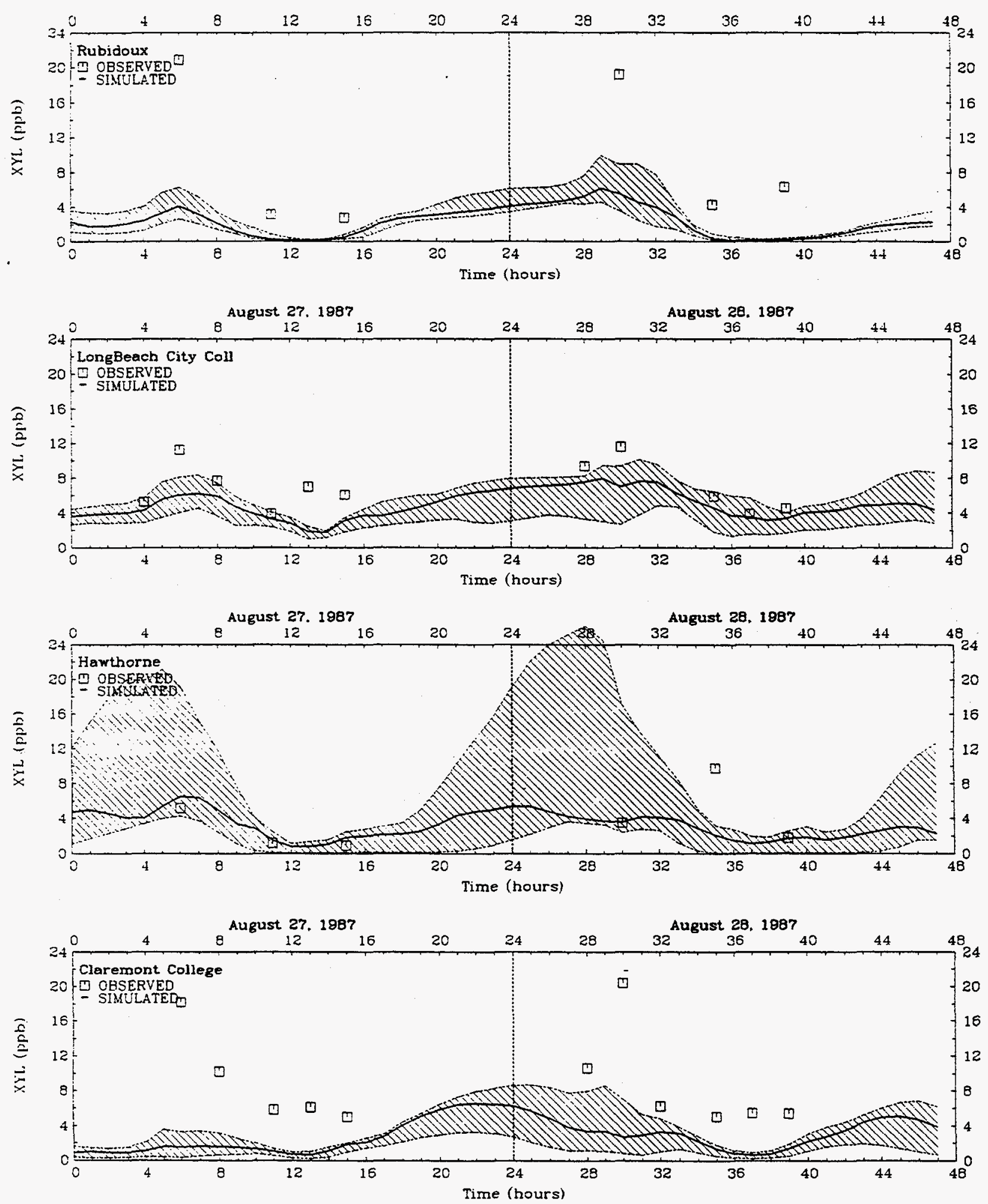

FIGURE 3-24. Concluded. 

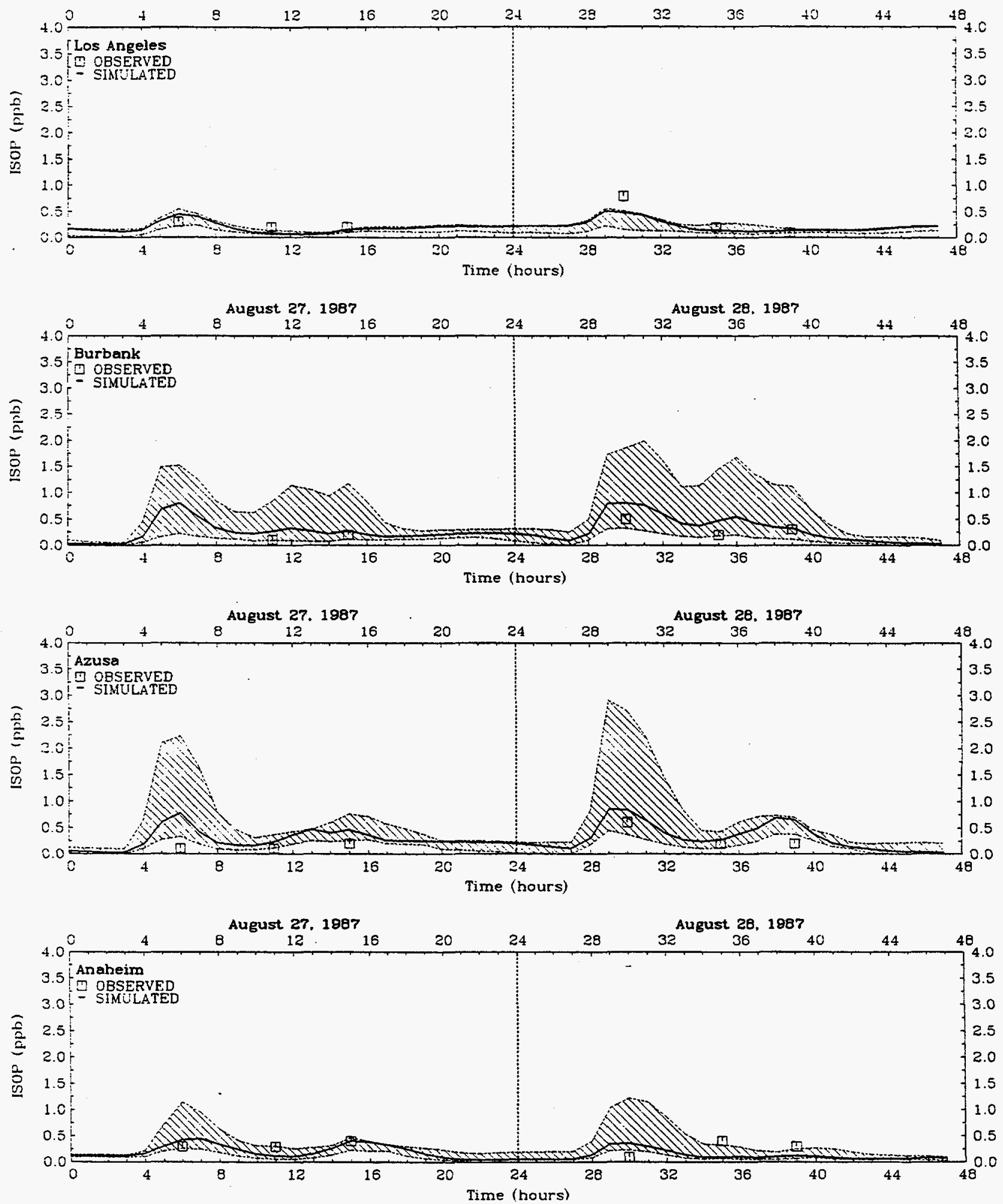

FIGURE 3-25. Simulated and observed ISOP concentrations (ppb) at monitoring sites in the Los Angeles domain for the August 27-28, 1987 base episode. 

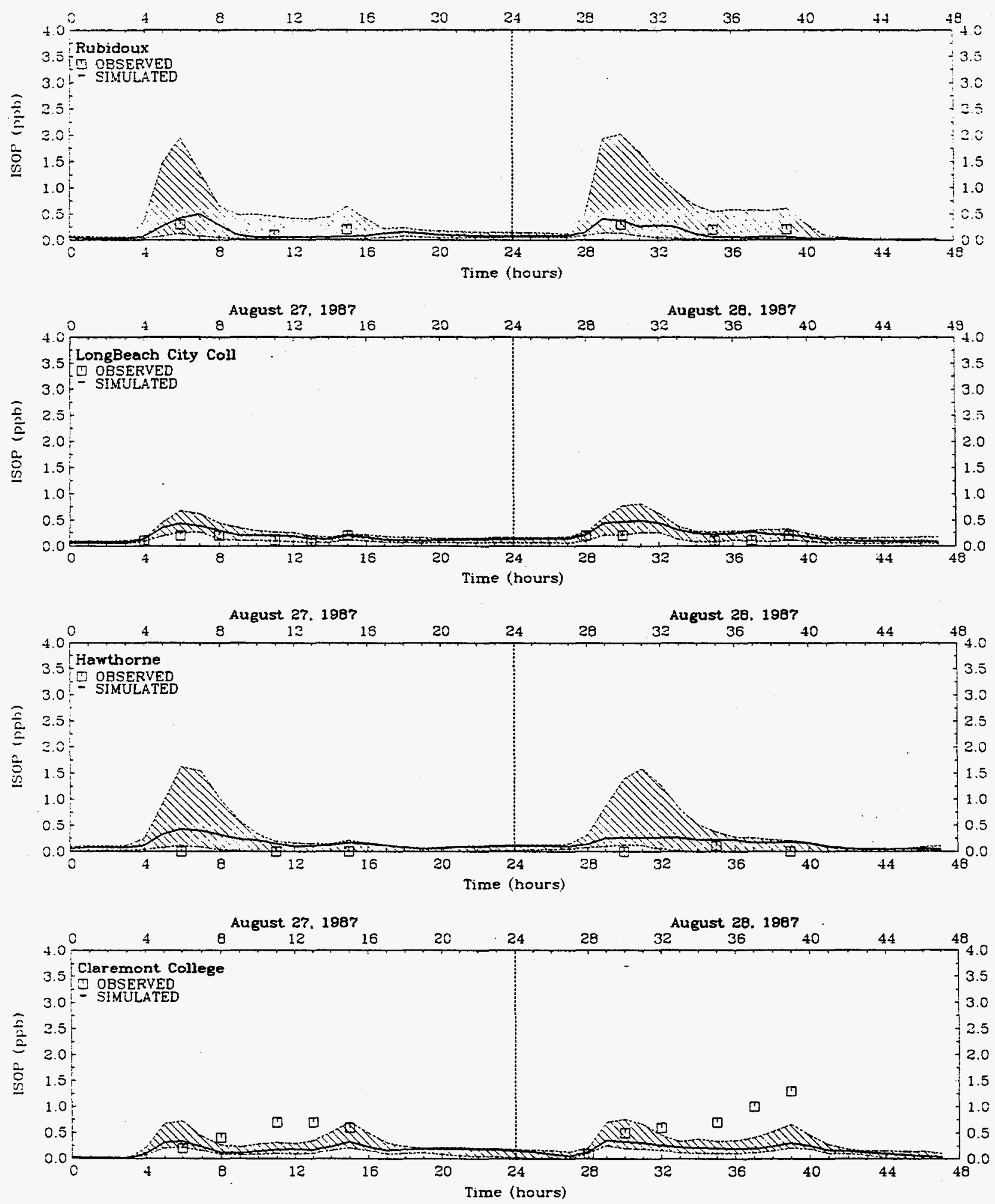

FIGURE 3-25. Concluded. 


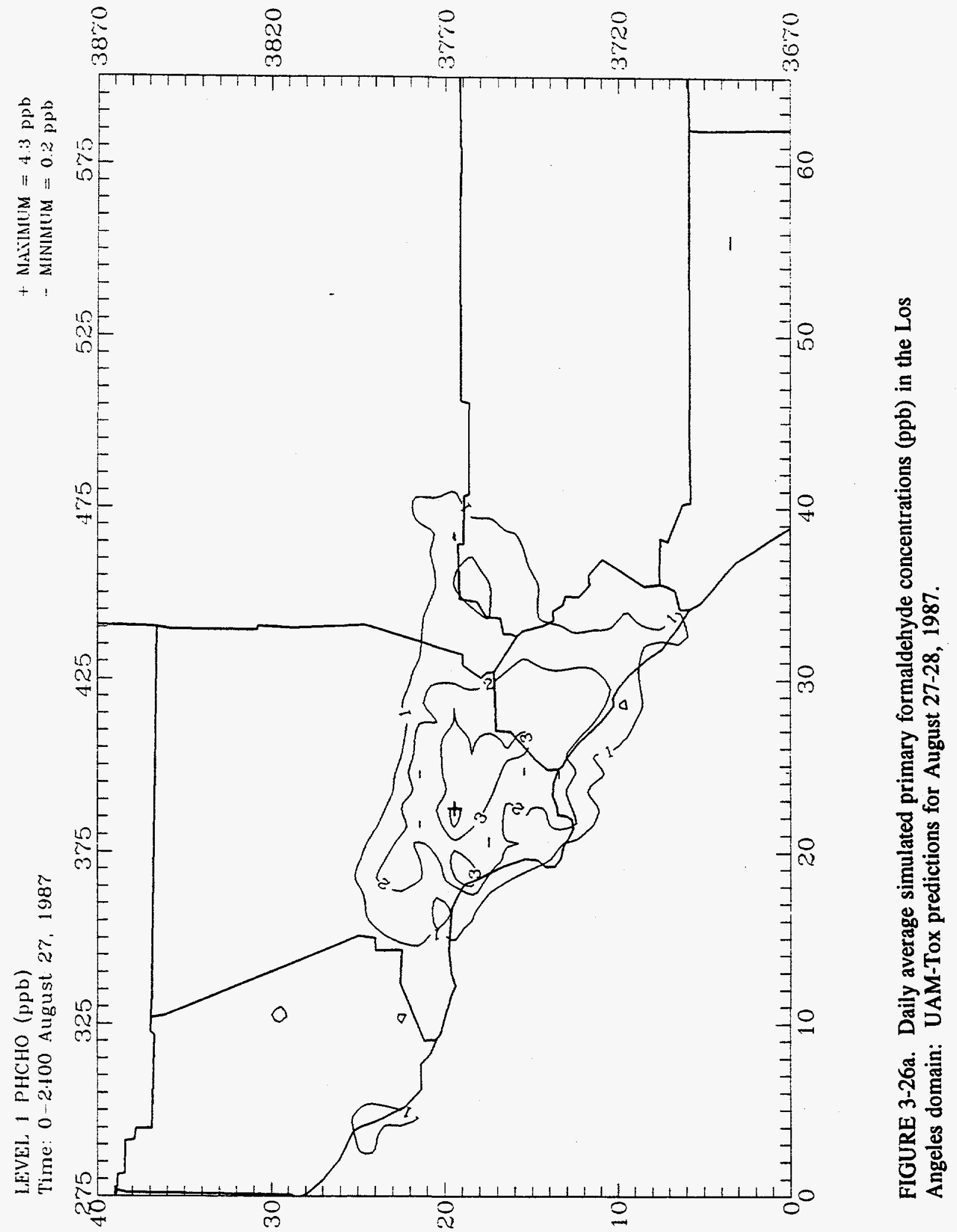




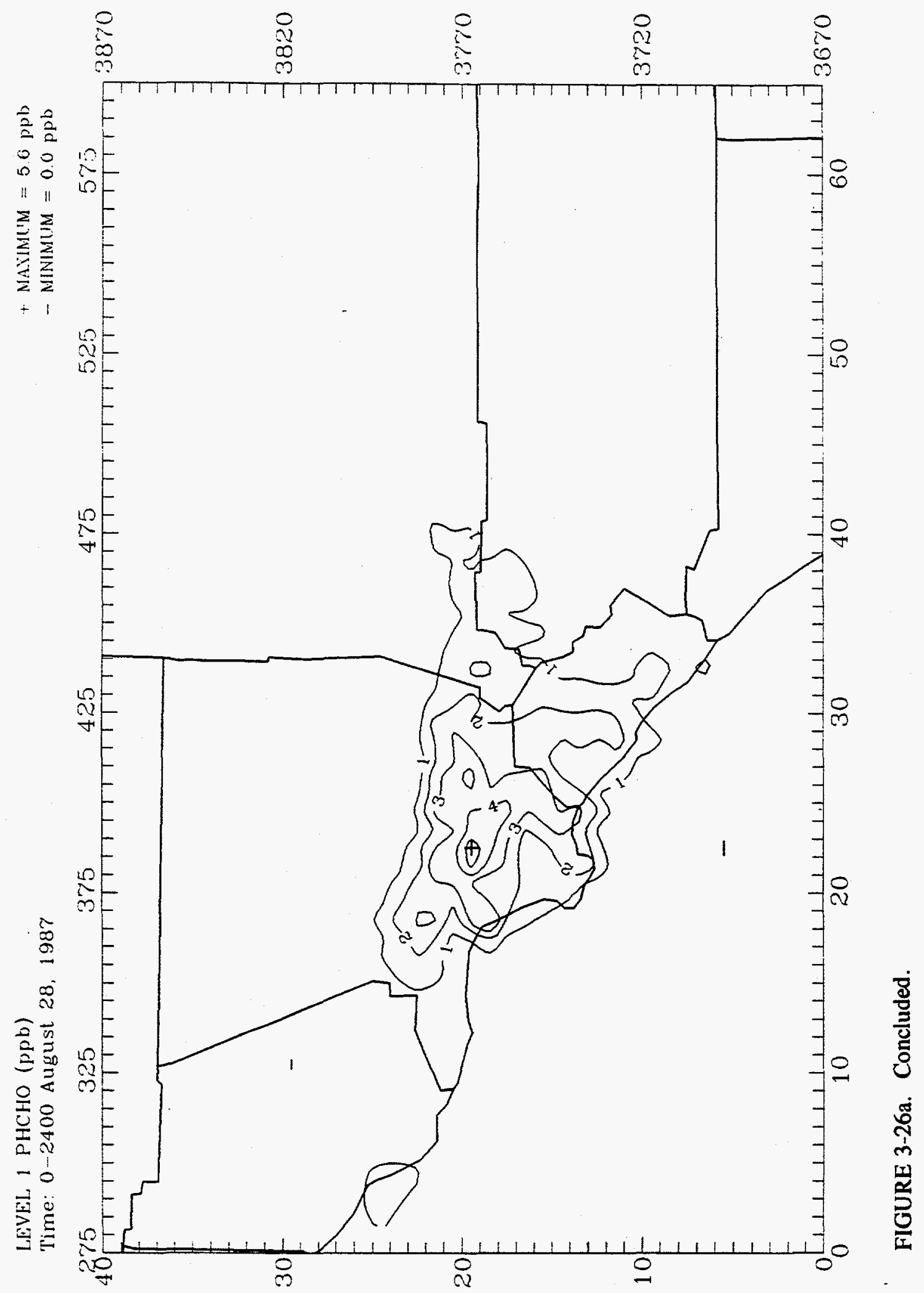




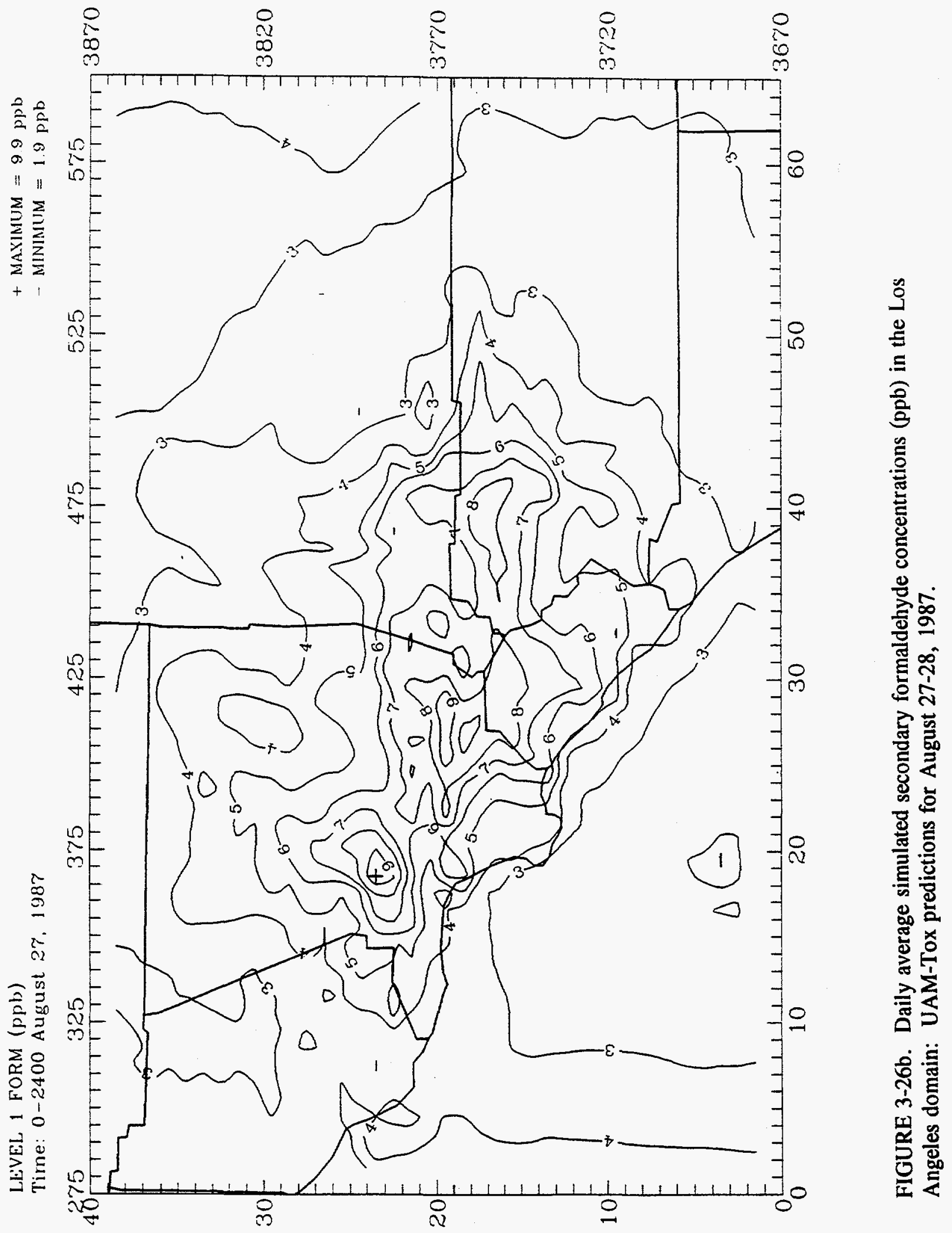




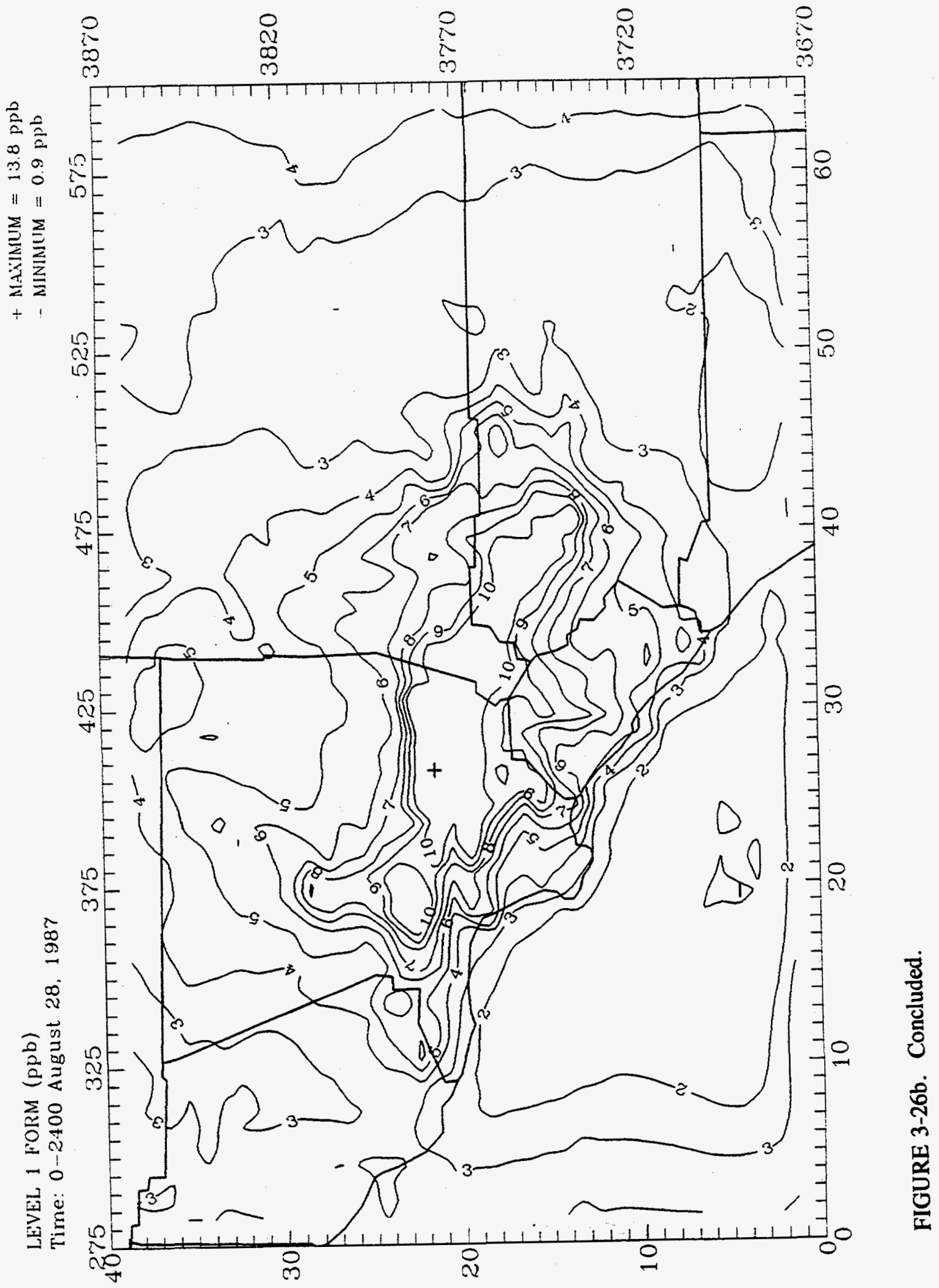




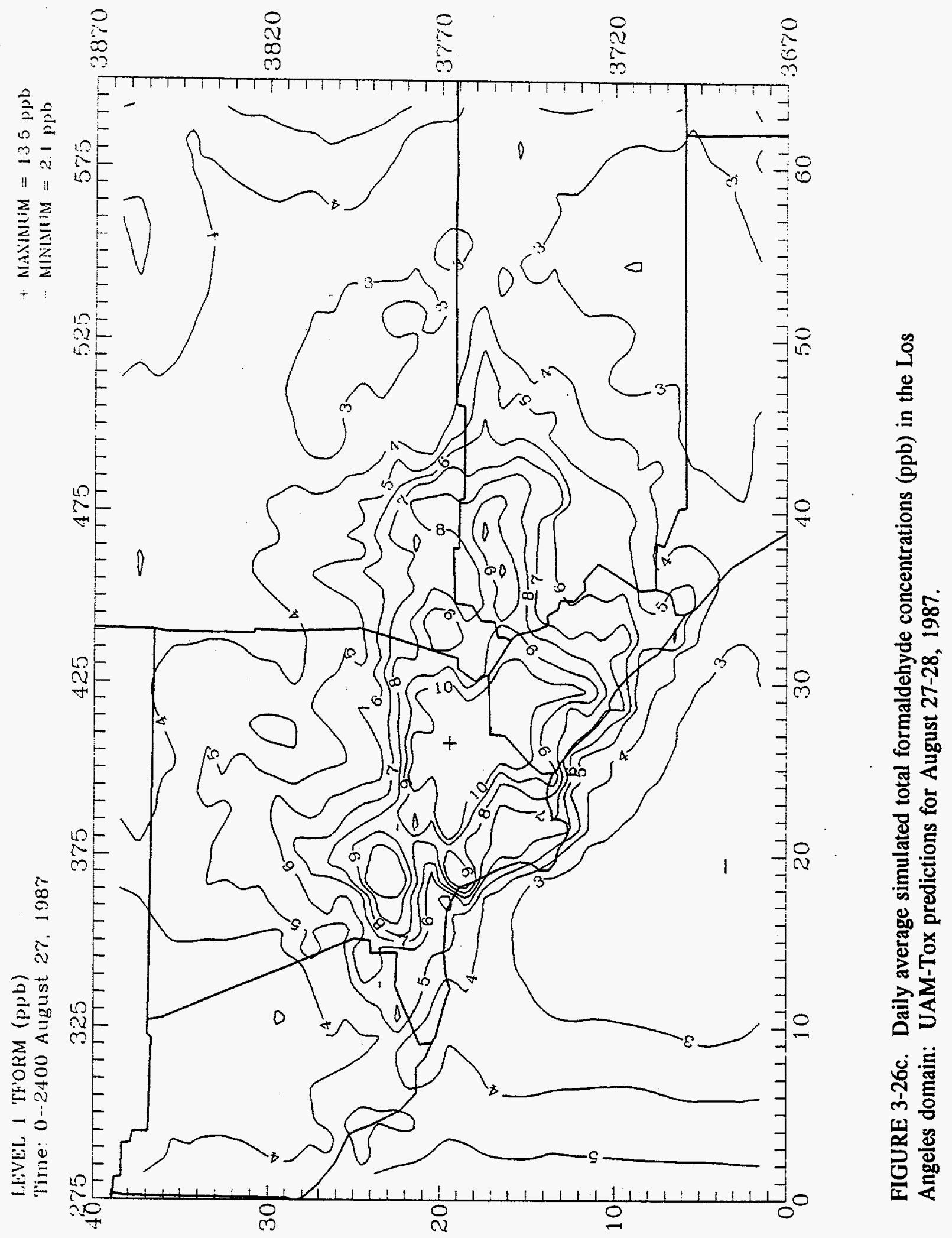




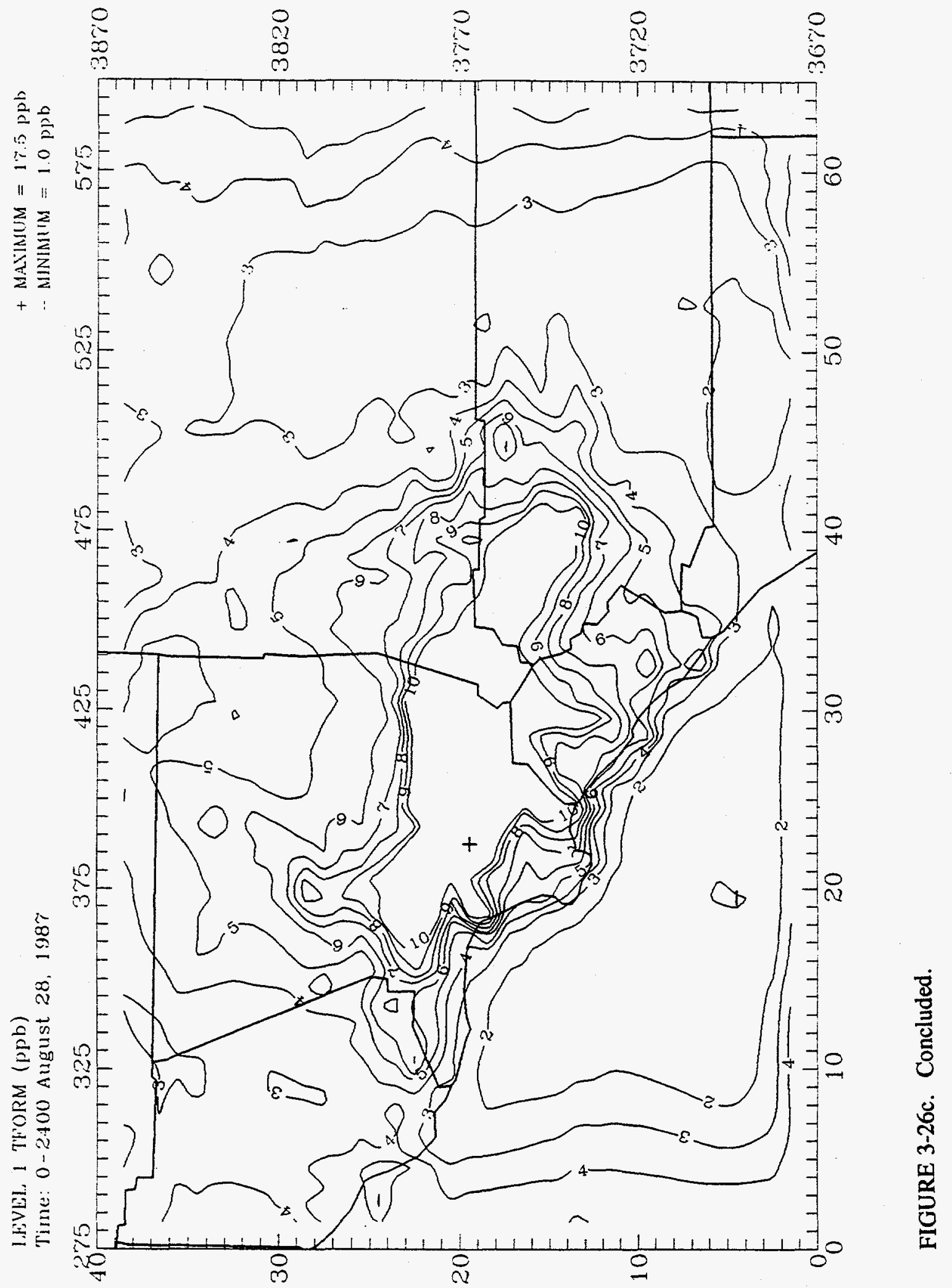


LEVEL 1 PACET (ppb)

Time: $0-2400$ August 27, 1987

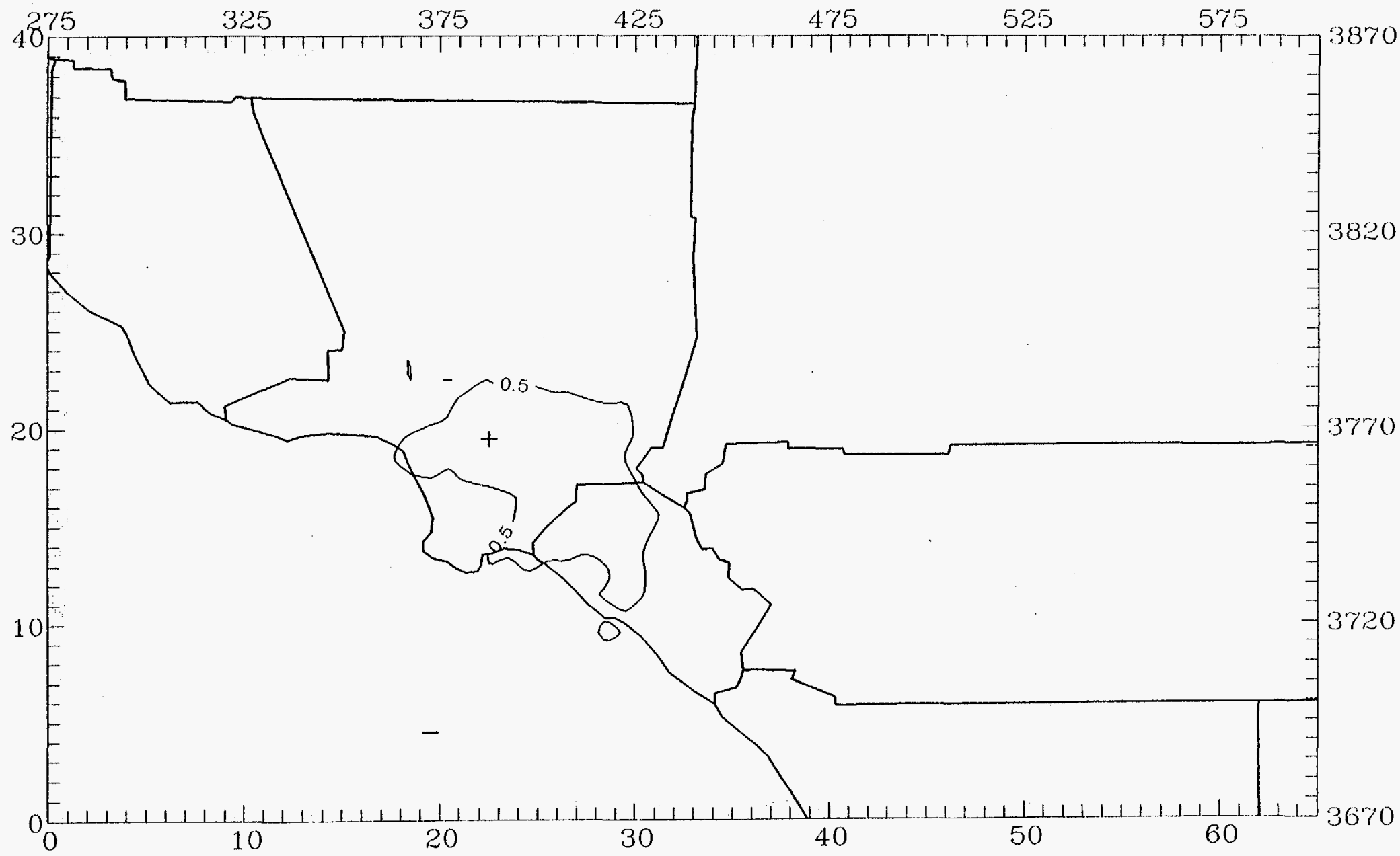

FIGURE 3-27a. Daily average simulated primary acetaldehyde concentrations (ppb) in the Los Angeles domain: UAM-Tox predictions for August 27, 1987. 


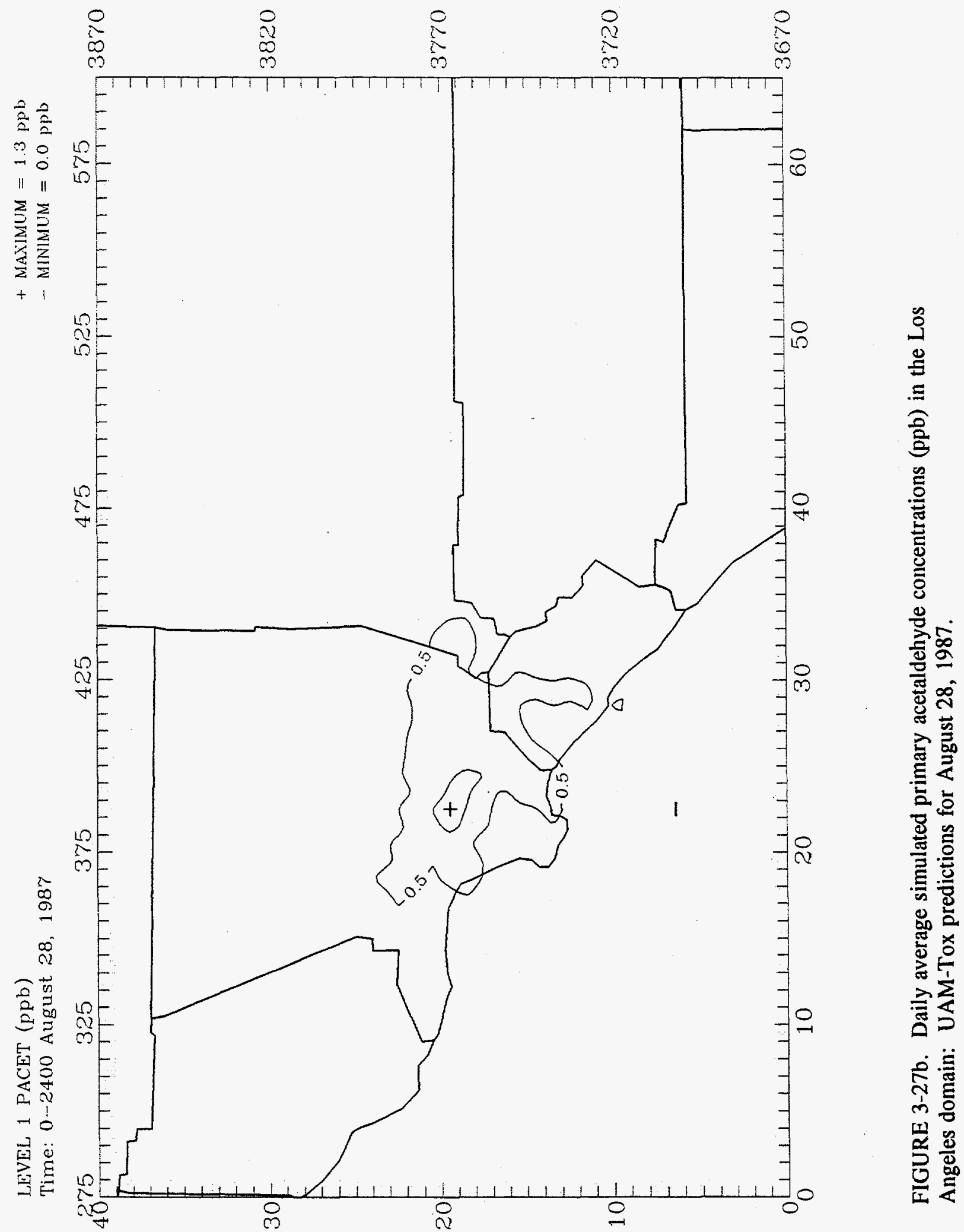




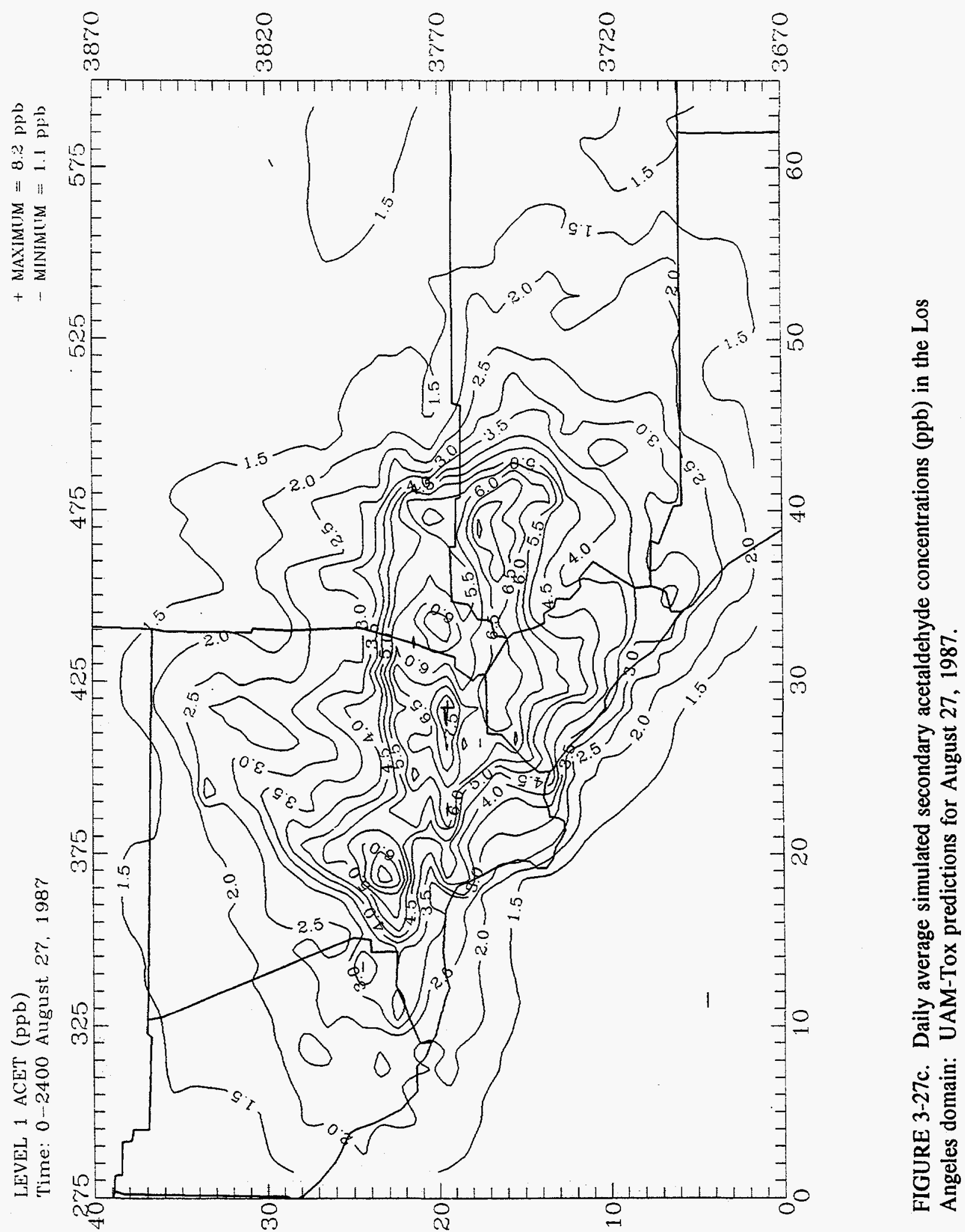




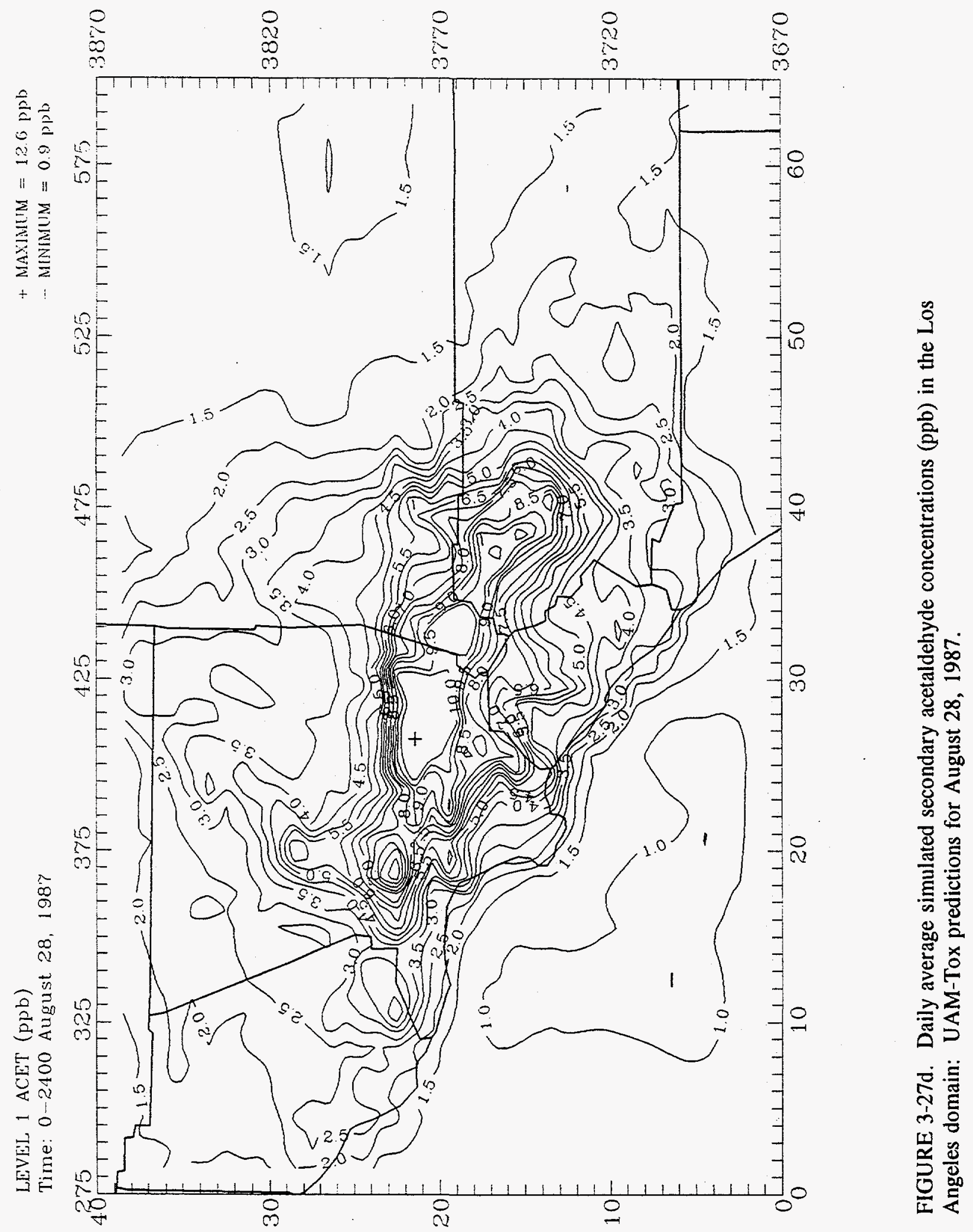




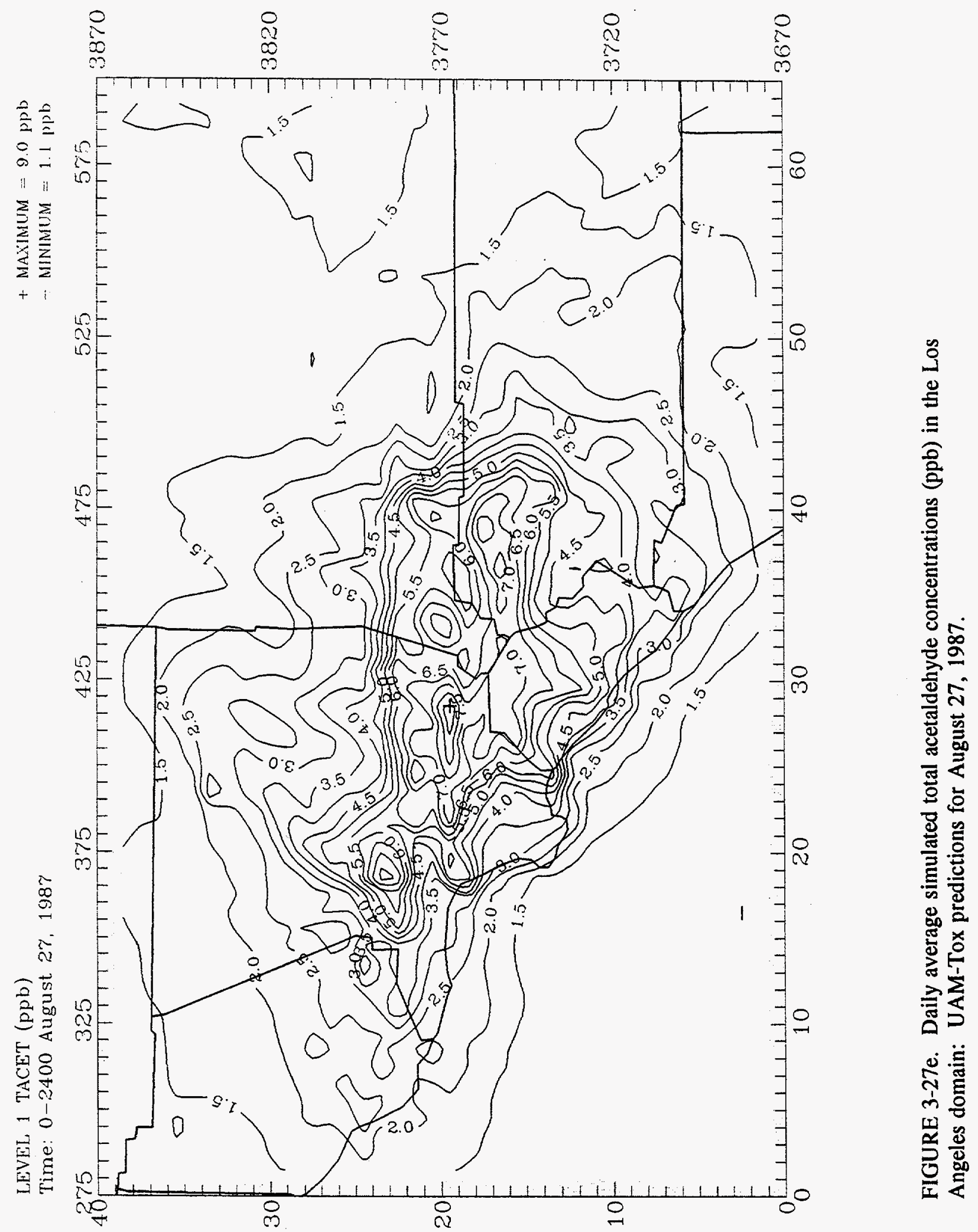


LEVEL 1 TACET (ppb)

Time: $0-2400$ August 28, $198 \%$

+ MAXIMUM $=13.3 \mathrm{ppb}$

- MINIMUM $=0.9 \mathrm{ppb}$

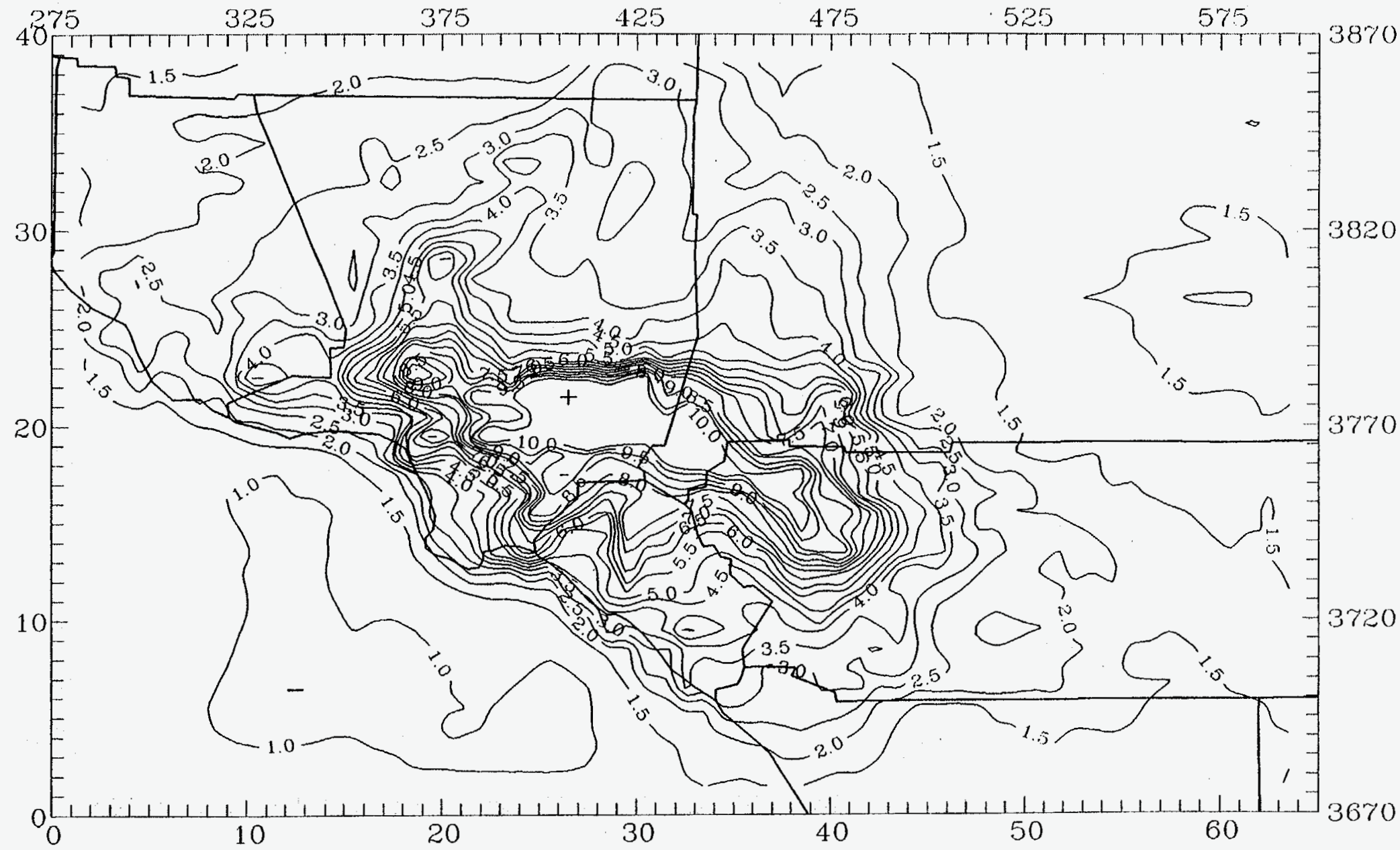

FIGURE 3-27f. Daily average simulated total acetaldehyde concentrations (ppb) in the Los 


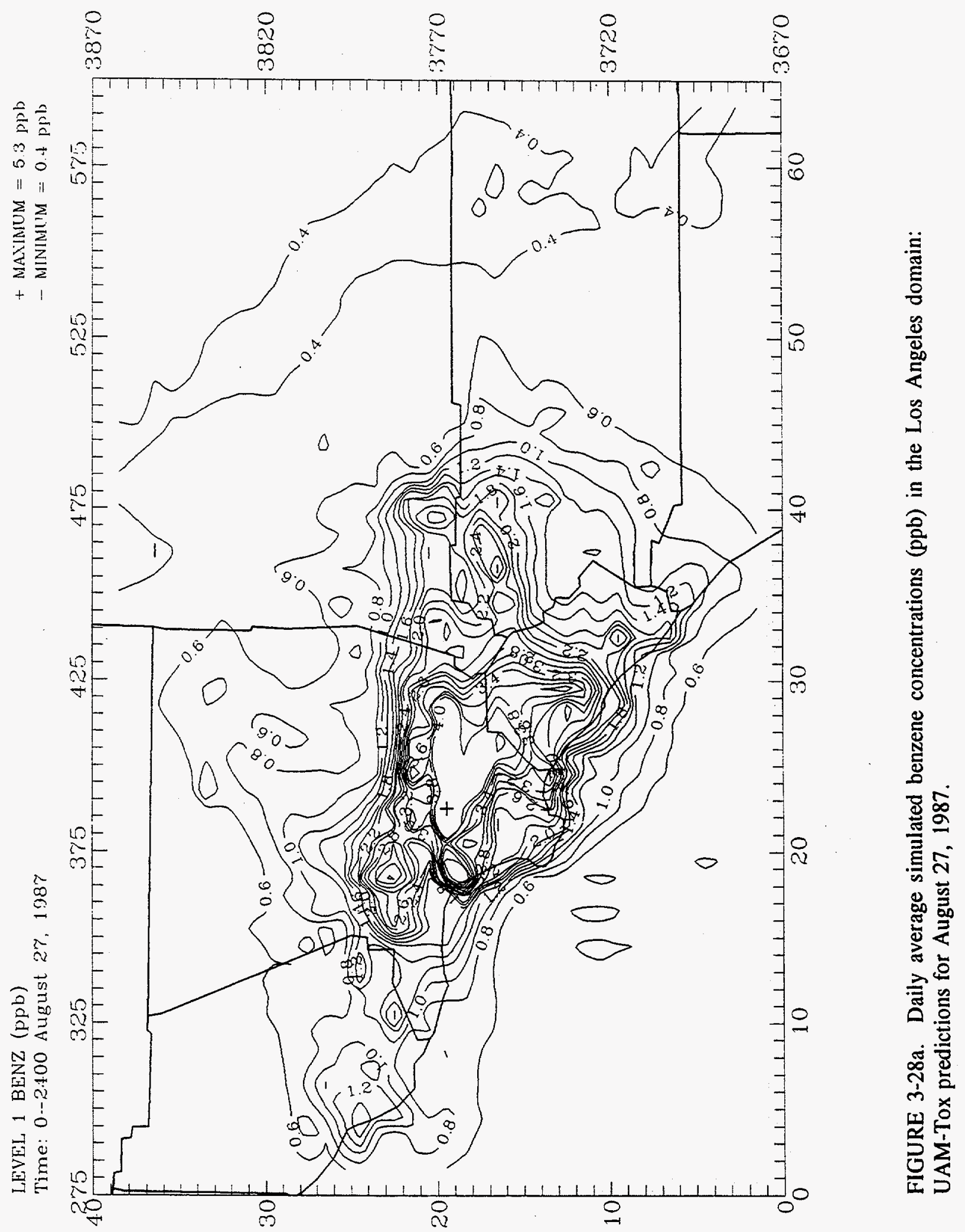




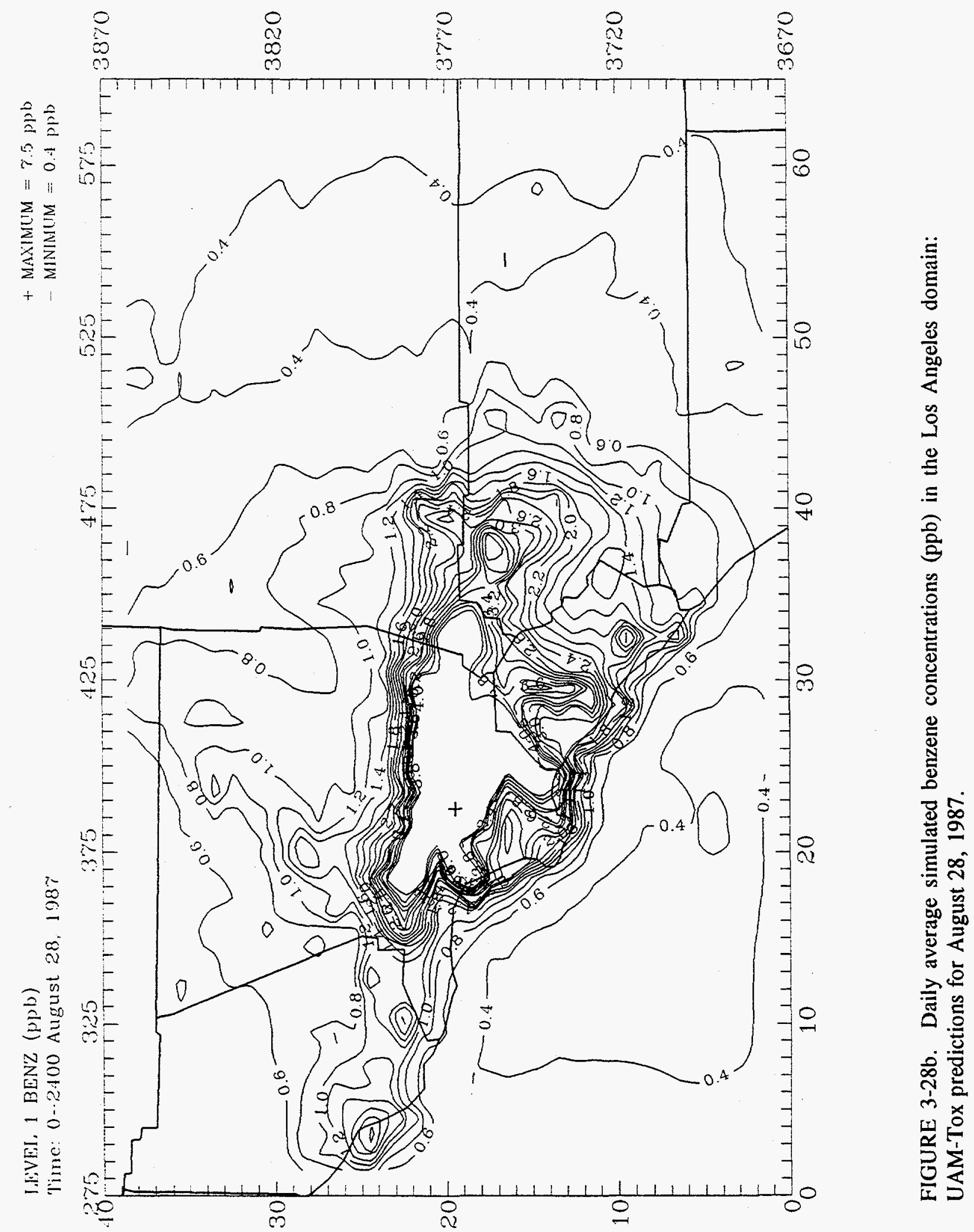




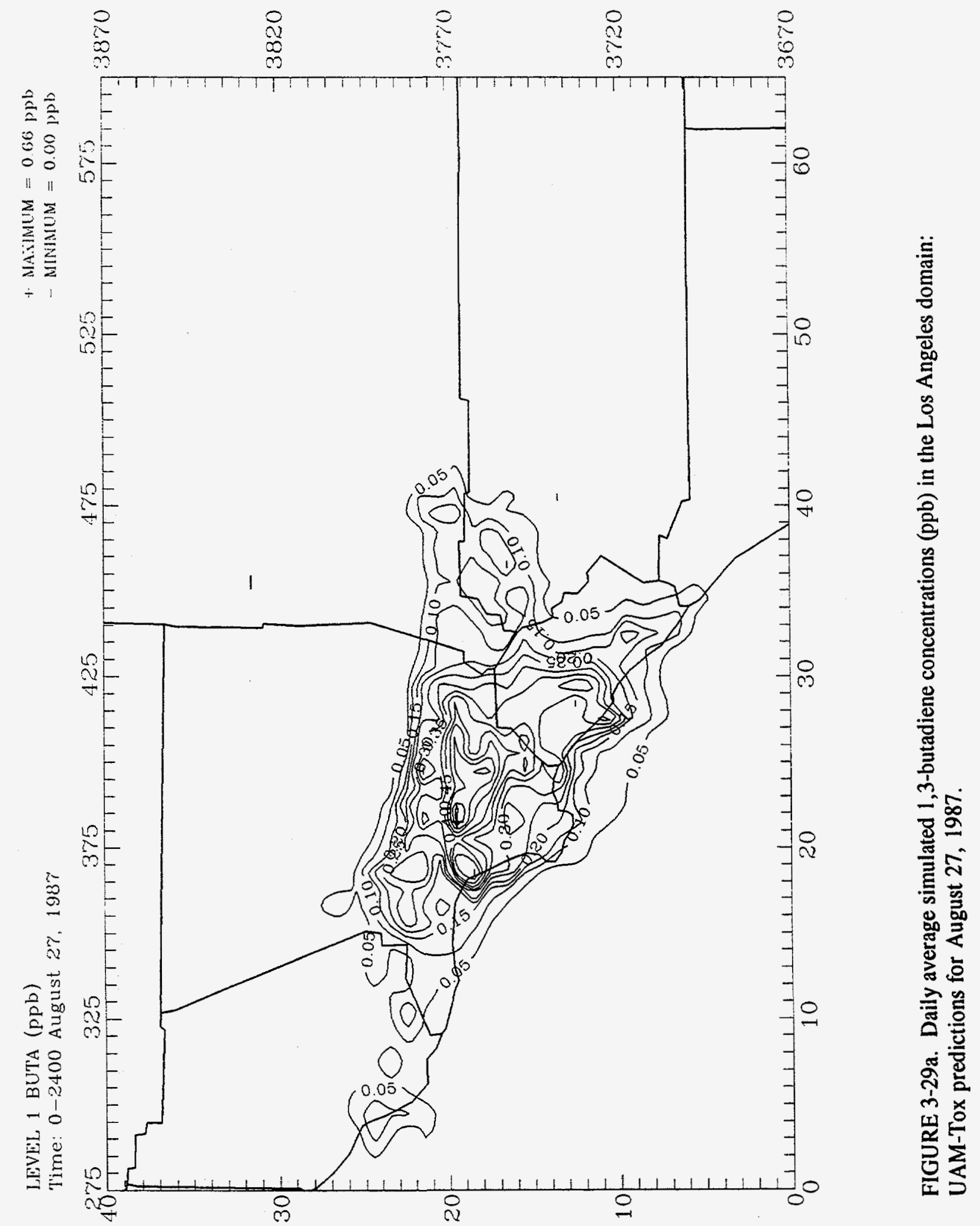


LEVEL 1 BUTA (ppb)

Time: $0-2400$ August 28, 1987
+ MASINUM $=0.88 \mathrm{ppl}$

- MINIMUM $=0.00 \mathrm{ppb}$

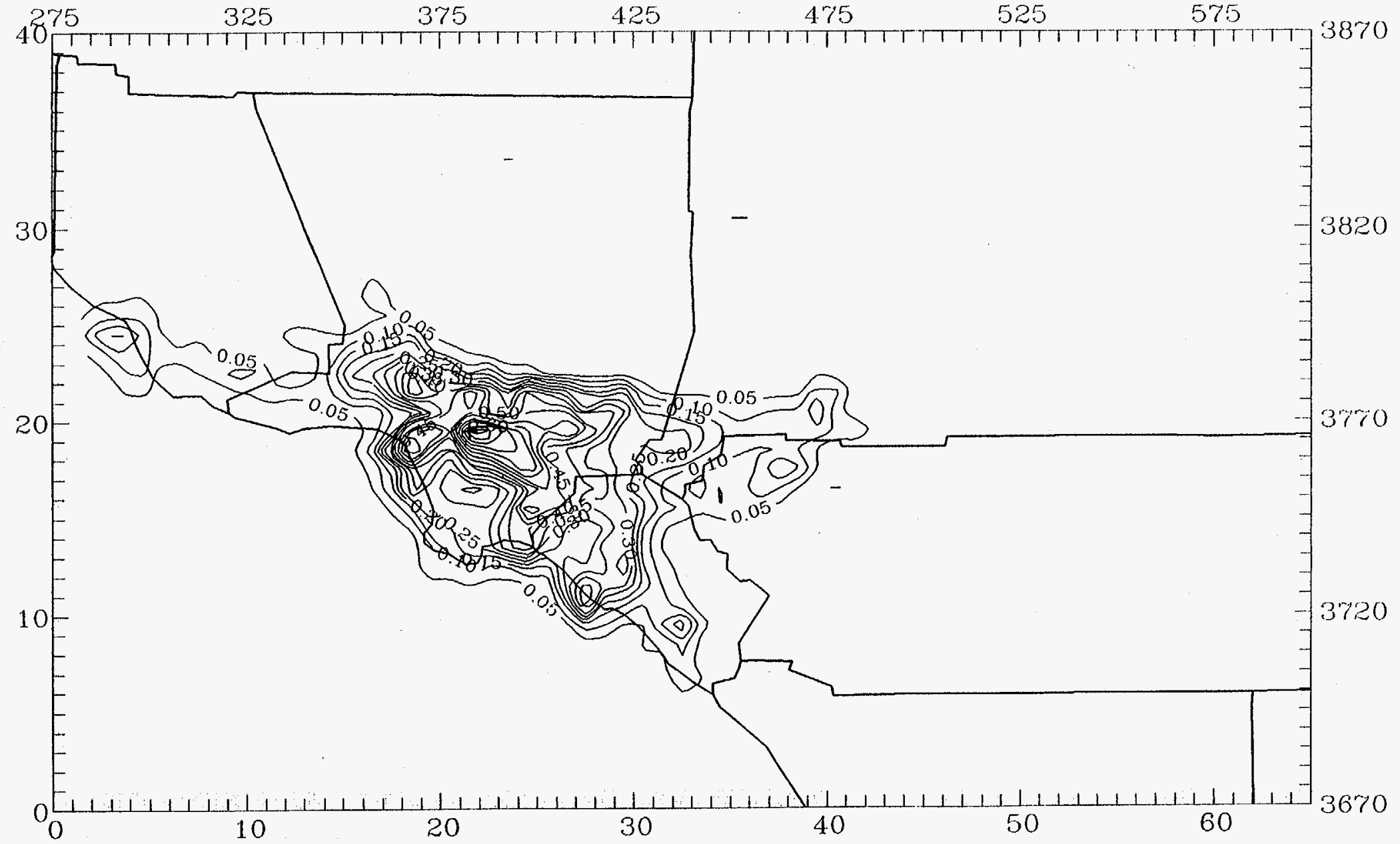

FIGURE 3-29b. Daily average simulated 1,3-butadiene concentrations ( $\mathrm{ppb}$ ) in the Los Angeles domain: UAM-Tox predictions for August 28, 1987. 

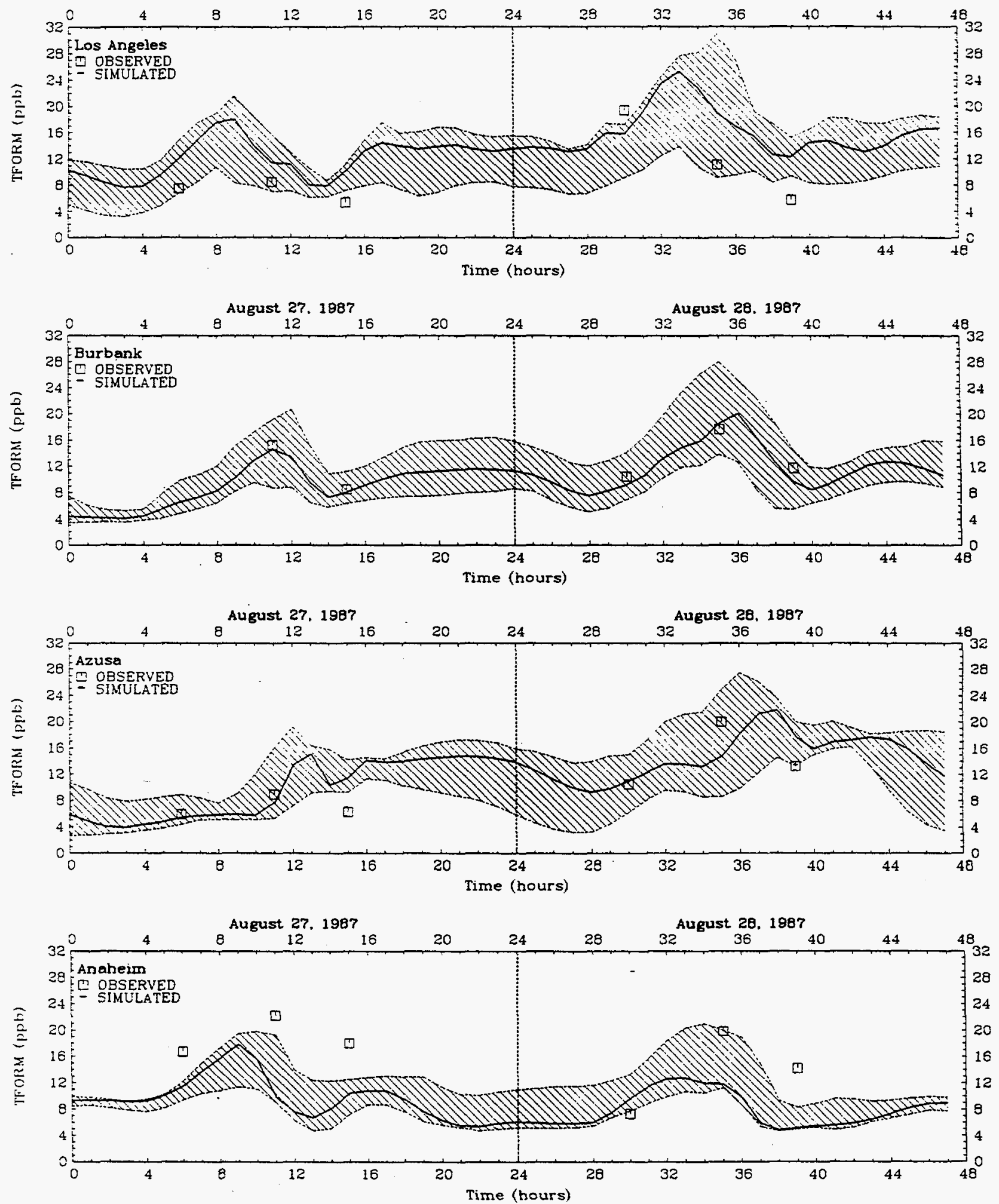

FIGURE 3-30. Simulated and observed formaldehyde concentrations (ppb) at monitoring sites in the Los Angeles domain for August 27-28, 1987. 

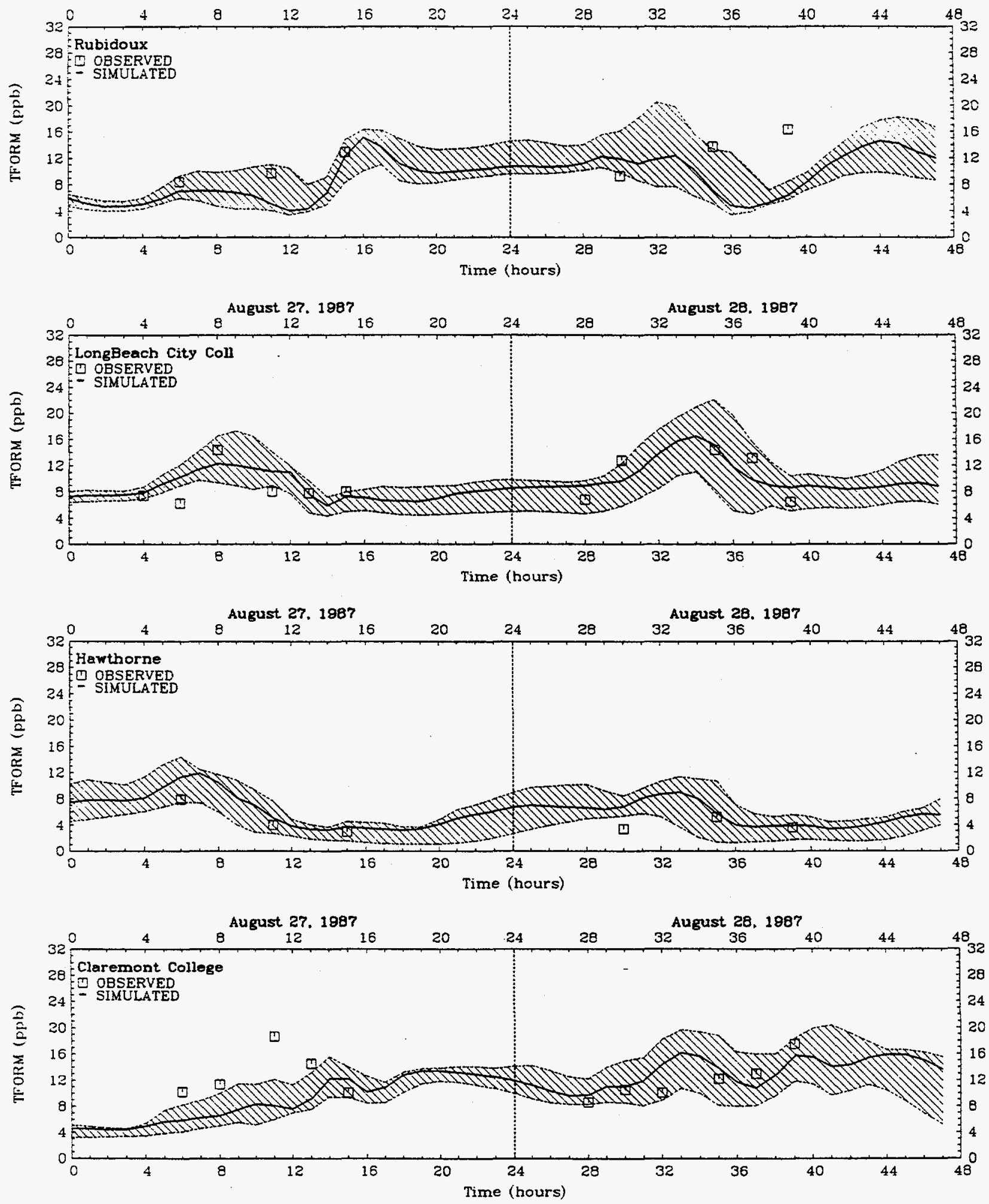

FIGURE 3-30. Concluded. 

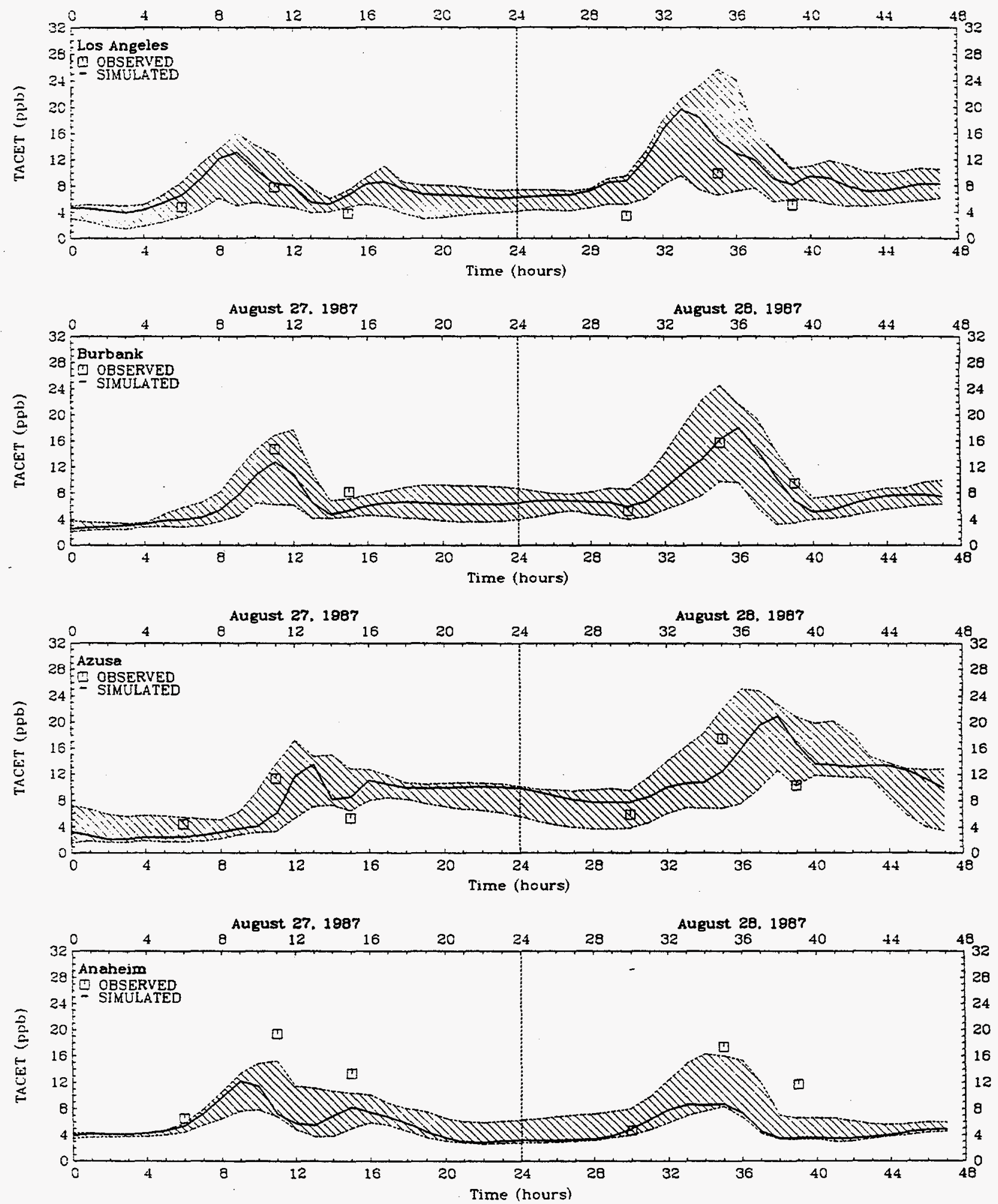

FIGURE 3-31. Simulated and observed acetaldehyde concentrations (ppb) at monitoring sites in the Los Angeles domain for August 27-28, 1987. 

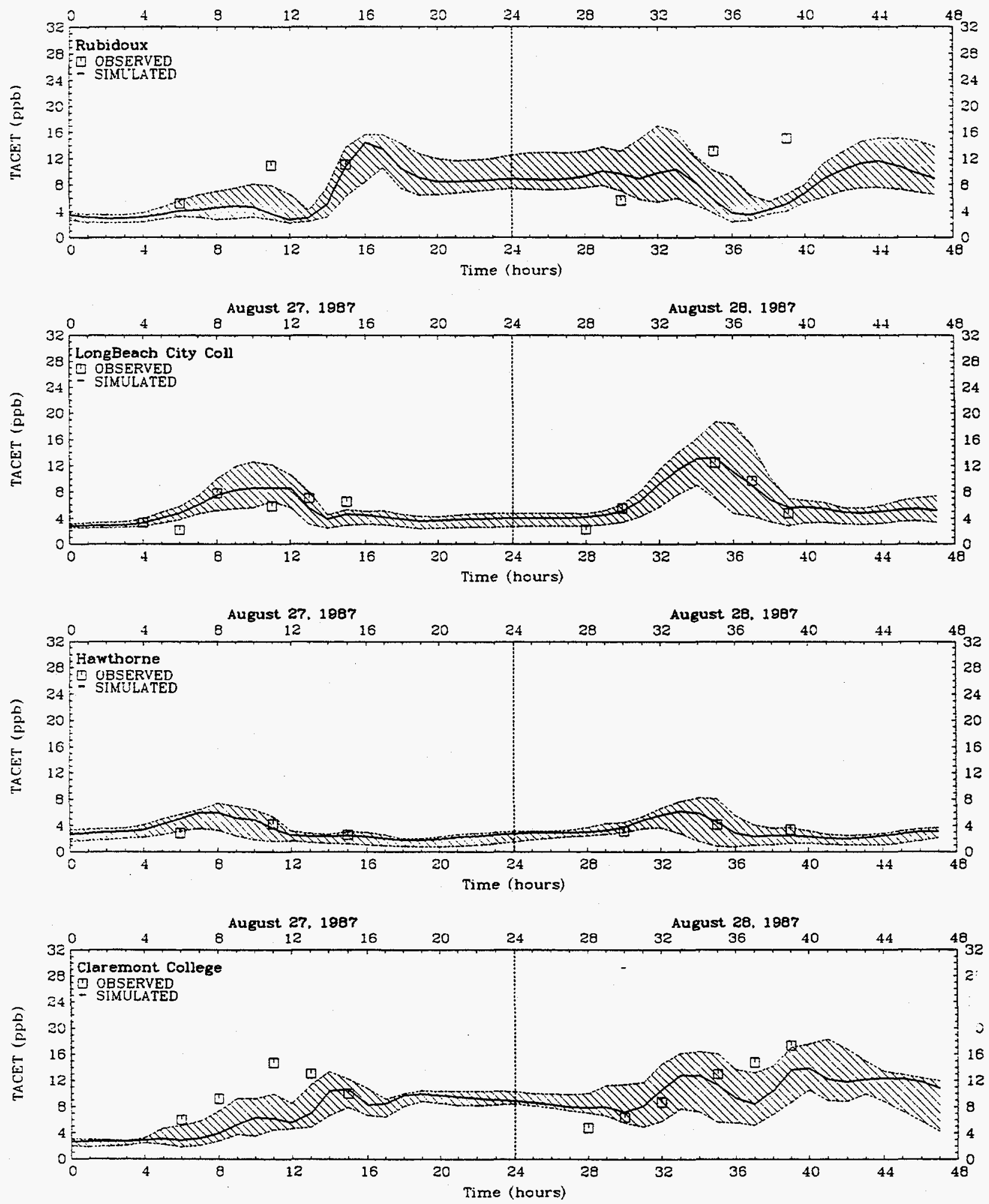

FIGURE 3-31. Concluded. 

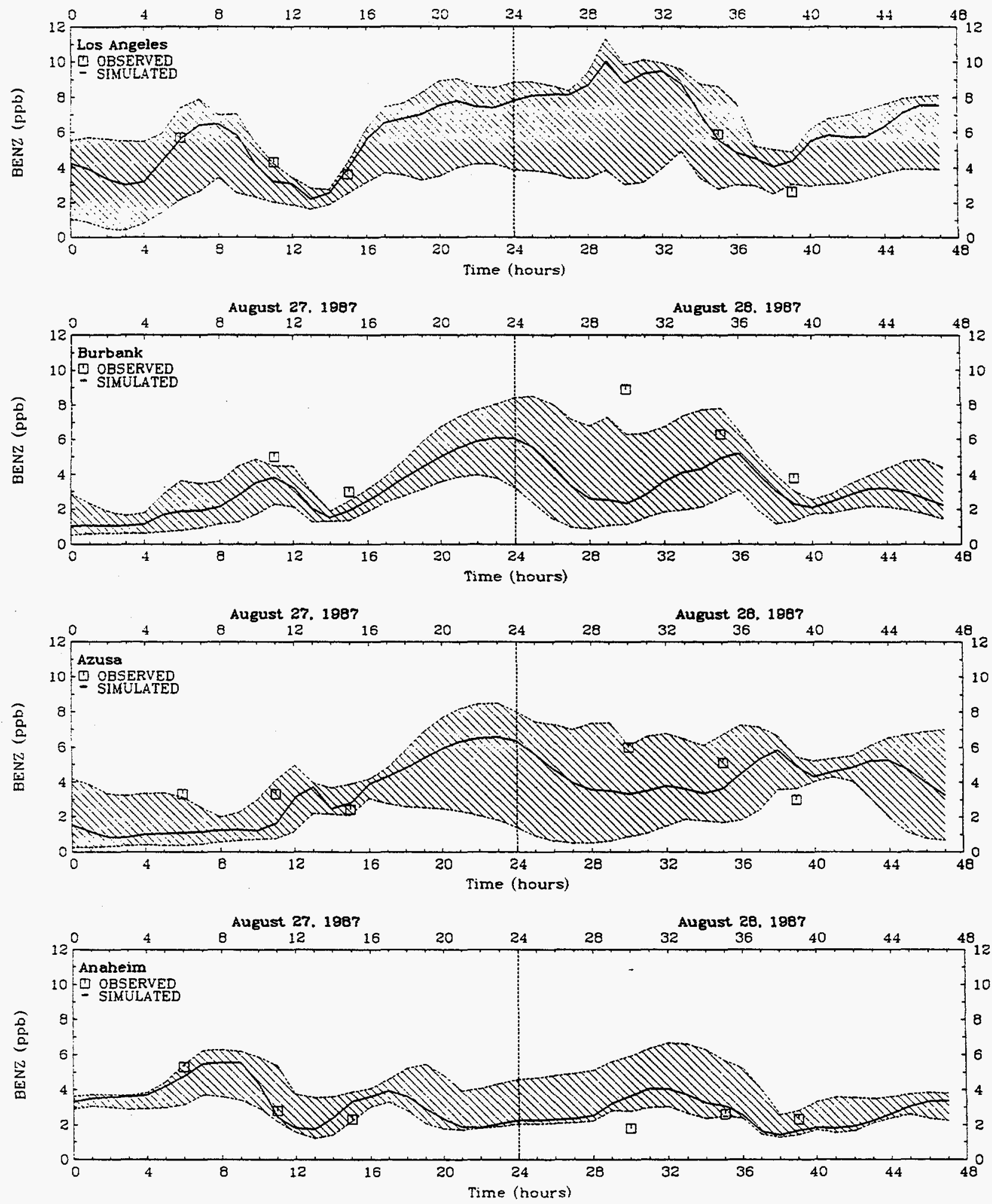

FIGURE 3-32. Simulated and observed benzene concentrations (ppb) at monitoring sites in the Los Angeles domain for August 27-28, 1987. 

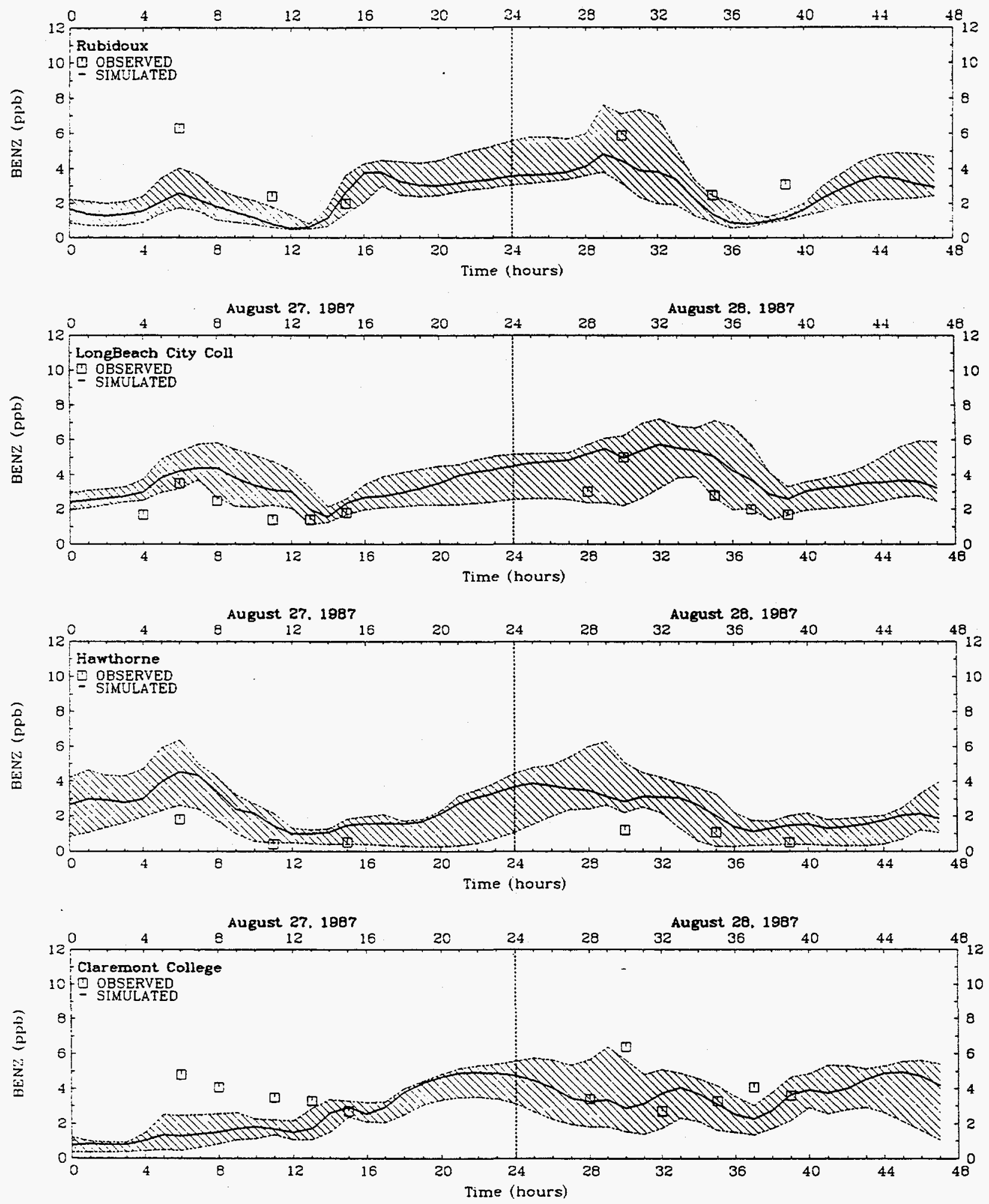

FIGURE 3-32. Concluded. 

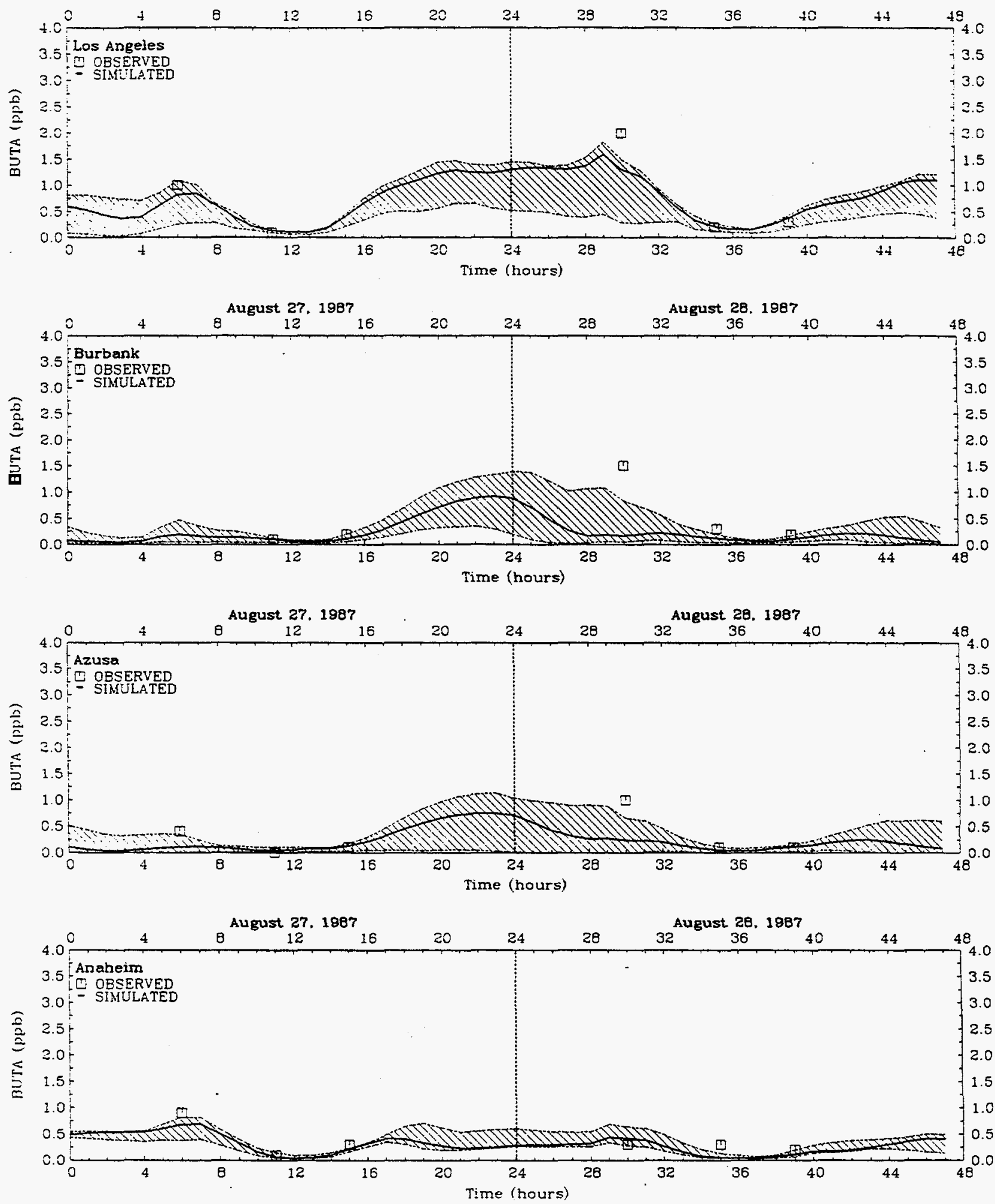

FIGURE 3-33. Simulated and observed 1,3-butadiene concentrations (ppb) at monitoring sites in the Los Angeles domain for the August 26-28, 1987 base episode. 

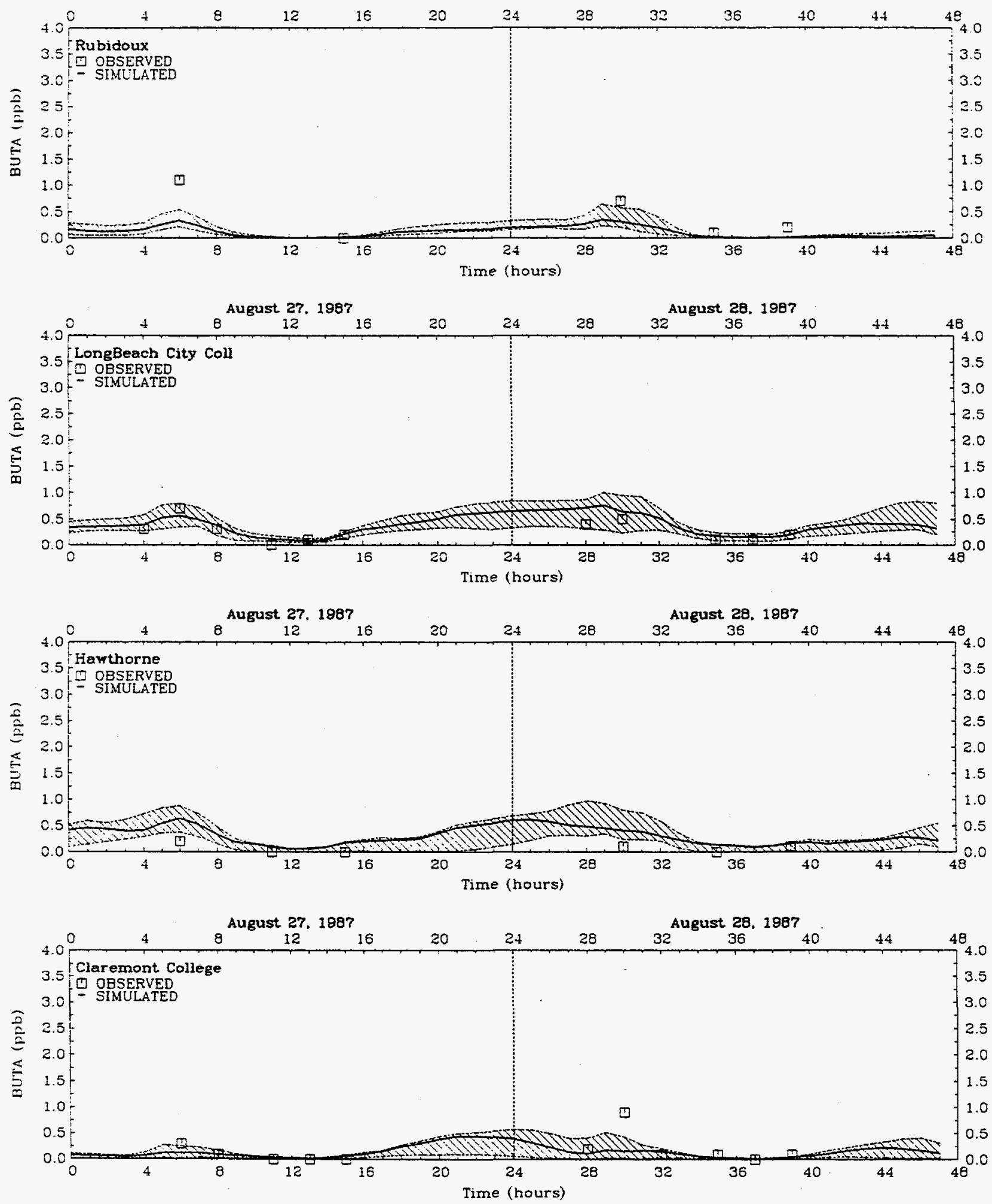

FIGURE 3-33. Concluded. 


\section{FUTURE-YEAR INVENTORY PREPARATION}

This section describes the methodologies used to project the selected base years to 2020 and to develop inventories corresponding to each fuel. Three 2020 inventories were prepared for each city. The 2020 base cases assumed the exclusive use of reformulated gasoline (RFG) in the light-duty gasoline fleet in each city. A hypothetical Federal Phase 2 RFG, based on available EPA guidance (EPA, 1994), was assumed for Baltimore, while actual California Phase II RFG was assumed for Los Angeles. From the standpoint of this study the major difference between California and Federal RFGs is the Reid Vapor Pressure (RVP) which is assumed. For California RFG, the RVP is 7.0, while the Federal RFG specification permits variation in the RVP. The default specification of 7.5, contained in the EPA's MOBILE5 model, was used here. The difference in RVP leads to higher evaporative emissions for Federal RFG than for California RFG. Additional inventories were prepared assuming complete conversion of the light-duty gasoline vehicle fleet to an 85 percent methanol (M85) fuel and to compressed natural gas (CNG) and included adjustments to emissions from refueling and bulk fuel storage sites. The M85 fuels were assumed to be blended with California Phase II RFG. No fuel changes were assumed for nonroad mobile sources, heavyduty vehicles, or diesel vehicles. Possible changes in refinery operation due to the hypothesized switch to the alternative fuel were not considered. The assumption of doubled RHC emissions from onroad gasoline vehicles was applied to the future-year inventories for all three fuels.

\section{INVENTORY PROJECTIONS}

\section{Baltimore}

The stationary source portion of the Baltimore inventory was projected to 2020 using a combination of Bureau of Economic Analysis growth factors (BEA, 1990) and future-year control measure assumptions developed under a separate project. The control measures included in this inventory include all controls required by the 1990 Clean Air Act Amendments (CAAA), such as Reasonably Available Control Technology (RACT) and emission offsets for stationary sources, and Stage II refueling controls and enhanced inspection/maintenance programs (I/M) for mobile sources. The 15 percent VOC emission reduction required by 1996 to demonstrate reasonable further progress (RFP) is included. However, this inventory does not include sufficient control measures to demonstrate attainment of the ozone standard by the attainment deadlines of 1999 for Washington, D.C. or 2005 for Baltimore. The dayspecific biogenic inventories from the base-year inventory were assumed to apply to 2020 .

\section{Projecting Area Sources}

$\mathrm{NO}_{\mathrm{x}}$ emission offsets for industrial sources were simulated by assuming no growth (EPA, 1992b) after the year 1996. The industrial sources subject to no-growth were separated from the nonindustrial sources prior to loading into EPS. The offset sources were grown from the 1990 levels to 1996 using the BEA growth projection data. The sources not subject to offset were grown from 1990 to 2020 . Future-year controls for 2005 including those mandated by 
the 1990 CAAA were implemented for all area sources, i.e., both the industrial and nonindustrial sources.

\section{Projecting Point Sources}

The point source input emissions were separated first into utility and nonutility data to facilitate the application of controls specific to this industry. The nonutility sources were further separated into those sources subject and not subject to the $\mathrm{NO}_{\mathrm{x}}$ offset requirements. Each of the three sets of data for the point sources (i.e., utility, nomutility offset, and remaining nonutility) were loaded into EPS separately. Distinct sets of projection factors were applied for each set of point sources. The controls applied were developed under separate work and address applicable controls for both 2005 and 2015. BEA growth factors from 1990 to 2020 were also applied. Utility point sources were projected assuming 2015 control requirements including the Title I NO $\mathrm{NACT}_{\mathrm{x}}$ and the Title IV, Phase II controls. Industrial point sources subject to offset requirements were grown from 1990 to 1996. For these sources, 2005 VOC and $\mathrm{NO}_{\mathrm{x}} \mathrm{RACT}$ controls were also applied. For the remaining industrial sources not subject to offset, the emissions were grown from 1990 to 2020 . VOC and $\mathrm{NO}_{\mathrm{x}} \mathrm{RACT}$ controls for 2015 were also used to project these sources.

\section{Projecting Mobile Sources}

Onroad mobile emissions were projected using VMT growth rates developed previously (Morris et al., 1994). Control measures for mobile sources include Federal Tier 1 tailpipe standards, RFG, and enhanced IM. When the RFG option is selected in MOBLE5, the model assumes a fuel RVP. Because MOBILE5 was developed prior to the promulgation of the final RFG rule, MOBILE5 does not give credit for the 7 percent $\mathrm{NO}_{\mathrm{x}}$ reduction that is required of Federal Phase II RFG by the final rule (EPA, 1994). Therefore, this 7 percent $\mathrm{NO}_{\mathrm{x}}$ reduction was applied manually to the inventory.

\section{Los Angeles}

The basis of the 2020 emission inventory for the Los Angeles domain was the 2010 inventory provided by the South Coast Air Quality Management District. The biogenic component of the inventory was also provided and differs from the 1987 biogenic inventory. This inventory includes a level of emission control sufficient to bring the region into attainment with the Federal ozone standard. In most cases, the control factors represent the level of emission reduction deemed necessary for attainment, rather than the level of control that would be achieved through the application of specific measures. In other words, the control measures include levels of emission reductions that are not achievable with current technology.

\section{Projecting Point and Area Sources}

The 2010 inventory was projected to 2020 using socioeconomic growth predictions. No additional regulatory controls were applied. Population and employment by county were calculated using the information provided in Table 1 and Table 4 of the document Southern California 2020-A preliminary Growth Forecast-Regional Overview (SCAG, 1995). A "best match" assignment of population and employment projections to area and point sources was made based on current California Air Resource Board methodology and engineering judgment. Biogenic emissions were retained at the 2010 level. 


\section{Projecting Mobile Sources}

Onroad mobile emissions for 2010 were obtained from the SCAQMD and were projected to 2020 assuming no additional controls. The 2020 inventory includes the California Low Emission Vehicle (LEV) program, reformulated gasoline, and other unspecified mobile source controls measures that bring the total level of emission reduction to approximately 80 percent. Since these control measures are not specified, it is impossible to assess whether they would be likely to have equal impacts on M85 or CNG vehicles.

The Los Angeles and Baltimore 2020 inventories are based on strongly dissimilar assumptions as to future controls on sources of both $\mathrm{VOC}$ and $\mathrm{NO}_{\mathrm{x}}$. The Los Angeles inventory is based on data provided by the South Coast Air Quality Management District, as part of its 1994 Air Quality Management Plan, and assumes sufficient controls will be in place to bring Los Angeles into attainment of the ozone standard. Some of these controls include assumptions as to future technologies that are not yet demonstrated. The Baltimore 2020 inventory includes only those controls specifically mandated by CAAA provisions and does not reduce emissions to the level needed for attainment.

\section{FUEL-SPECIFIC INVENTORY COMPONENTS}

The alternative fuel scenarios required adjustments to onroad mobile emission rates and speciation, and to emissions and speciation for refueling/bulk storage. Although MOBILE5 does provide emission factors for M85, we did not use them. Instead, emissions for M85 were estimated from vehicle test data. Emission ratios (MERs) were calculated for TOG, $\mathrm{NO}_{\mathrm{x}}$, and $\mathrm{CO}$, and applied to the RFG base case emissions.

\section{Using the Alternative Fuels Database}

This section provides a brief overview of the collection of vehicle demonstration data at the Alternative Fuels Data Center (AFDC) of the National Renewable Energy Laboratory (NREL). This is not intended as an exhaustive guide or description of the database. Rather, it illustrates some of the information used to develop source emissions inputs for air quality modeling. There is much more information in the database than has been used in this study, and very sophisticated queries can be performed. NREL has produced a document entitled, "Data Query at the AFDC' which explains the content of the database in great detail as well as methods of access, numerous sample queries, and explanations of coding of certain key fields of the database. This document is essential for individuals wishing to explore the vehicle demonstration data in great detail.

The AFDC collects operating data from alternative-fueled vehicles. These vehicles include passenger sedans, light-duty trucks, heavy-duty trucks, and light-duty vehicles. A wide variety of information from these vehicles is collected by various testing laboratories across the country. These data include fuel usage, mileage, results of emissions testing, analysis of used lube oil, maintenance reports, and speciation of vehicle emissions. The data are collected in tables which can be linked together through fields common to both tables. For example, if one table contains the results of emissions tests performed on a set of vehicles along with the decal ID of the vehicle, and another table contains information about the make and model of such vehicles along with the decal ID, the information in these two tables can be linked together through the decal ID field. The database structure linking these tables through common fields is fully relational. In the procedures described below for comparing 
emissions from vehicles using alternative fuels, extensive use of these relational query features was made in order to match appropriate vehicles.

\section{Methodologies and Results for Calculating Measured Emission Ratios (MERs) and Speciation Profiles}

MERs are pollutant (hydrocarbons, $\mathrm{CO}$, and $\mathrm{NO}_{\mathrm{x}}$ ) emission rates for a given fuel $\mathrm{X}$ divided by pollutant emission rates for a base fuel. By applying these MERs to the pollutant emission rates in the base fuel emissions inventory, one can generate an estimate for an emission inventory for the fuel $\mathrm{X}$ assuming that the entire fleet of vehicles in the base inventory was fueled with fuel $X$. Speciation profiles consist of weight fractions of species which make up the mass of the total organic gases (TOG) emissions for a given fuel and emissions mode (i.e., FTP exhaust, hot soak evaporative, and diurnal evaporative). These are used to allocate the total TOG from the emission inventory to particular chemical species used in photochemical modeling.

The rest of this section describes the methodologies employed to calculate MERs and speciation profiles using data from the alternative fuels database at NREL along with the results obtained. MERs were computed for the fuel pairs CNG-RFG and M85-RFG. Speciation profiles were computed for the CNG, M85, and RFG fuels.

Procedures and results from sensitivity analyses performed both for the MERs and speciation profiles are available in the supplement to this report. Emissions and speciation data for each vehicle used in the calculations of the MERs and speciation profiles will be made available in electronic format upon request.

The AFDC database is continually being updated. One set of updates during the course of this project led us to re-evaluate the emissions from CNG vehicles. The updated evaluation indicated significantly lower MER's than had been developed earlier. However, the modeling for CNG had already been completed when this re-evaluation was conducted. It was thus decided that the differences between the two sets of CNG MERs would be reported along with the Phase 1 results, but that the modeling of the impacts of these differences would be deferred until the Phase 2 sensitivity studies were undertaken. The differences in the CNG emissions are described in the Supplement to this report.

\section{Calculation of CNG-RFG MERs}

We computed CNG-RFG measured emission ratios (MERs) for $\mathrm{CO}, \mathrm{NO}_{\mathrm{x}}$ and $\mathrm{TOG}$ for the exhaust mode (composite FTP) and for TOG for the evaporative modes (hot soak and diurnal). TOG is defined as the sum of total hydrocarbons (THC) and aldehydes from the "panel" (nonspeciated) portion of the alternative fuels emissions database.

Due to the fact that CNG tests cannot be performed on the same fleet of vehicles for which RFG tests are performed, we chose to consider only tests on Chrysler-Dodge B250s and GMC-Chevy C2500 pickups for computing the CNG-RFG MERs. These were the only make/model combinations for which both CNG and RFG tests meeting our validity and inclusion criteria were performed. Of course, the tests for the two fuels were not performed on the same fleet of vehicles because the engine construction of a CNG vehicle is markedly different from that of a vehicle which runs on gasoline, and, thus, the same vehicle cannot use both fuels. Average emission rates were computed separately for the B250s and C2500s first

Final Report - October 1997 
by averaging total mass emission rates within and then across all selected vehicles for each particular operating mode and fuel. Then, a MER for a given pollutant and operating mode is calculated as the ratio of the average emission rate from the CNG tests to the average emission rate from the RFG tests. Finally, the resultant MERs calculated from B250 data and C2500 data were averaged. The results of these calculations are shown in Table 4-1.

TABLE 4-1. MERs for CNG-RFG

\begin{tabular}{|lccc|}
\hline \multicolumn{1}{c}{$\begin{array}{c}\text { Operating } \\
\text { Mode }\end{array}$} & Pollutant & $\begin{array}{c}\text { Number of } \\
\text { Vehicles } \\
\text { CNG/RFG }\end{array}$ & MER \\
\hline FTP compos. & CO & $44 / 42$ & 0.79 \\
FTP compos. & TOG & $44 / 42$ & 2.46 \\
FTP compos. & NO & $44 / 42$ & 0.58 \\
Shed-diurnal & TOG & $29 / 40$ & 0.42 \\
Shed-hot soak & TOG & $29 / 40$ & 0.47 \\
\hline
\end{tabular}

Emission rates for evaporative mode tests given in grams per test.

\section{Calculation of M85-RFG MERs}

Prior to performing any calculations, tests on certain types of vehicles were excluded:

- Vehicles not tested on both RFG and M85

- Vehicles vintage 1991 or older

- M85 tests missing methanol in panel portion of database

MERs were computed for $\mathrm{CO}, \mathrm{NO}_{\mathrm{x}}$, and TOG for the exhaust mode, and MERs for TOG were computed for the evaporative modes. The methodology for computing the M85-RFG MERs is similar to that stated above for CNG-RFG, but it was possible to make use of a "matched fleet" of flexible-fueled vehicles for the calculation of average total mass emission rates. Therefore, the M85-RFG MER for a given pollutant and operating mode is the average total mass emission rate for a particular pollutant from M85 tests performed on a certain set of vehicles divided by the average total mass emission rate for a particular pollutant from RFG tests performed on the identical set of vehicles. These results are shown in Table 4-2.

TABLE 4-2. Emission rates, MERs, and standard deviations of MERs for M85-RFG.

\begin{tabular}{|llccccc|}
\hline $\begin{array}{c}\text { Operating } \\
\text { Mode }\end{array}$ & Pollutant & $\begin{array}{c}\text { Number of } \\
\text { Vehicles }\end{array}$ & $\begin{array}{c}\text { Avg. Emiss } \\
\text { from M85 } \\
(\mathrm{g} / \mathrm{mi})^{*}\end{array}$ & $\begin{array}{c}\text { Avg. Emiss } \\
\text { from RFG } \\
(\mathrm{g} / \mathrm{mi})^{*}\end{array}$ & $\begin{array}{c}\text { MER } \\
\text { of MER }\end{array}$ \\
\hline FTP compos. & CO & 111 & 1.60 & 1.80 & 0.89 & 0.038 \\
FTP compos. & TOG & 111 & 0.23 & 0.19 & 1.26 & 0.046 \\
FTP compos. & NO & 111 & 0.31 & 0.29 & 1.10 & 0.047 \\
Shed-diumal & TOG & 107 & 0.32 & 0.23 & 1.41 & 0.146 \\
Shed-hot soak & TOG & 107 & 0.55 & 0.38 & 1.44 & 0.074 \\
\hline
\end{tabular}

Emission rates for evaporative mode tests are given in grams per test.

Table 4-2 also includes estimates of the standard deviation of the MER for M85. The standard deviation of the MER for M85 was estimated by applying well known results from sampling theory for ratio estimators where the numerator and denominator are not independent. Assume that $y_{i}$ and $x_{i}$ denote the mean emissions for vehicle $i$ on the test fuel and base fuel, respectively and that the same $n$ vehicles were tested on both fuels. The MER 
is defined as the ratio of the sample means $\bar{y} / \bar{x}=\Sigma y_{i} / \Sigma x_{i}$. This is a consistent estimate of the national fleet MER assuming the test fleet can be viewed as a simple random sample from the national fleet. Various approximate formulae for the standard deviation of the test fleet MER are given in Cochran's 1977 textbook Sampling Techniques, Chapter 2. Using his equation 2.46 we obtain the estimate:

$$
\text { Standard Deviation }(M E R) \approx \frac{1}{\bar{x} \sqrt{n}} \times \sqrt{\frac{\sum\left(y_{i}-M E R \times x_{i}\right)^{2}}{n-1}}
$$

By the central limit theorem, the probability is about 95 percent that the true MER is within two standard deviations of the estimated MER. (The standard deviation calculation was an element added to this analysis late in the project, after the database used for the development of the MERs for M85 was revised. We have not gone back and reconstructed a similar calculation for the CNG MERs.)

\section{Definition of TOG Applied}

Due to differences among testing laboratories in the way THC is reported in the database, it was necessary to employ laboratory- and operating mode-specific procedures for calculating consistent values for TOG. For vehicles tested at the MANTECH laboratory both for exhaust and evaporative modes, we used the OMHCE data reported in the database to compute NOHC through use of the appropriate definitions in the Federal Register. NOHC is defined as non-oxygenated hydrocarbons, that is, excluding aldehydes, ketones, and alcohols. When OMHCE was not available for MANTECH tests, we used THC from the database and interpreted it as NOHC. We then added this NOHC (however obtained) to alcohols and aldehydes (both taken from the panel portion of the database) to obtain TOG.

For exhaust tests on vehicles tested by laboratories other than MANTECH, we used reported OMHCE to compute NOHC and then TOG as described above. For evaporative tests on vehicles tested by a laboratory other than MANTECH, we used THC from the database interpreted as OMHCE along with the appropriate definition from the Federal Register to compute NOHC and then TOG in the same manner as above.

\section{CALCULATION OF SPECIATION PROFILES}

The general procedure for computing the speciation profiles was the same for all three fuels. The only differences resulted from the criteria used to select the vehicles for the calculation and some special data treatments. The procedure consisted of the following steps:

- Average species emission rates from multiple tests in the same operating mode performed on the same selected vehicle.

- Average species emission rates across all selected vehicles within a particular operating mode.

- Normalize the emission rates to unity such that the value for each species represents its weight fraction in the speciation profile.

Prior to performing these operations, there were some exclusion rules and special treatments applied. For $\mathrm{CNG}$, we applied the following special treatments to the data during processing: 
- We multiplied data from evaporative tests from MANTECH by 1000 (converts grams to $\mathrm{mg}$ ).

- We used alcohol and aldehyde data from panel tests instead of speciated tests.

The latter treatment was applied because emission rates for aldehydes and alcohols were not always reported in the speciated portion of the database although there were non-zero emissions of these compounds for the panel test. Thus, we took these data from the panel portion where they were reported in a more consistent fashion.

For RFG and M85 speciation profiles, we excluded the following vehicles from the calculation:

- Vehicles not having speciated tests both on RFG and M85

- Vehicles vintage 1991 or older

For RFG and M85 speciation, we applied the following special data treatments:

- We multiplied data from evaporative tests from MANTECH by 1000 (converts grams to $\mathrm{mg}$ ).

- We used alcohol and aldehyde data from panel tests instead of speciated tests.

- For evaporative tests from MANTECH, we used methanol from speciated tests because we were informed that these data were more reliable than methanol data in the panel portion.

The results of the speciation profile calculations are shown in two ways. Tables 4-3 through 4-5 show the number of vehicles selected for the calculation and the most prevalent species of each speciation profile in terms of weight fraction. These tables allow a quick assessment of how the mass distribution varies between the speciation profiles in different operating modes within a fuel and allow for a comparison across fuels. Tables 4-6 through 4-8 show the molar fractions of modeled CB4 species for each profile after allocating the species in the NREL database to their appropriate CB4 classes. Also shown on Tables 4-6 through 4-8 is an approximate indication of the reactivity of the profile in terms of potential ozone production. This reactivity was computed through use of maximum incremental reactivity (MIR) factors obtained from an Auto/Oil Program report from July 1994 entitled "Calculation of Reactivity Scales Using an Updated Carbon Bond IV Mechanism."

As a general comment about the overall profile reactivities shown in Tables 4-6 through 4-8, we notice that, for all operating modes, RFG is most reactive, followed by M85 and then by CNG. CNG is relatively unreactive because it is largely composed of unreactive methane. The slightly higher reactivity of RFG compared to M85 appears to be due to a greater proportion of reactive species at the expense of less reactive species. It appears that the relatively large weight fraction of xylene is a significant contributing factor to the reactivity of RFG.

\section{Gasoline Marketing/Bulk Storage Sources}

For simulation of the alternative fuels, mass adjustment factors were applied to point and area sources pertaining to gasoline bulk storage and marketing categories in order to account for differences in fuel RVP and other factors. Affected point source categories included bulk 
storage, bulk terminals, bulk storage plants, and marketing transport. Area sources included storage tank breathing losses, gasoline station storage, and working activities.

TABLE 4-3. Most prevalent species in terms of weight fraction for CNG speciation profiles.

\begin{tabular}{|c|c|c|c|c|}
\hline \multirow[b]{2}{*}{ Species } & \multirow[b]{2}{*}{$\begin{array}{l}\text { No. of } \\
\text { Vehicles }\end{array}$} & \multicolumn{3}{|c|}{ Weight Fraction } \\
\hline & & $\begin{array}{c}\text { FTP } \\
\text { Composite }\end{array}$ & $\begin{array}{l}\text { Shed- } \\
\text { Diurnal }\end{array}$ & $\begin{array}{l}\text { Shed-Hot } \\
\text { Soak }\end{array}$ \\
\hline Methane & 2 & 0.894670 & 0.824157 & 0.780284 \\
\hline Ethane & 2 & 0.047499 & 0.079238 & 0.079666 \\
\hline Ethylene & 2 & 0.016573 & 0.000000 & 0.000000 \\
\hline Propane & 2 & 0.010031 & 0.020967 & 0.035440 \\
\hline Formaldehyde & 2 & 0.004996 & 0.000000 & 0.000000 \\
\hline iso-Pentane & 2 & 0.003291 & 0.006046 & 0.002234 \\
\hline Acetone & 2 & 0.003085 & 0.000000 & 0.000000 \\
\hline n-Butane & 2 & 0.003053 & 0.006046 & 0.003574 \\
\hline iso-Butane & 2 & 0.002458 & 0.005274 & 0.003276 \\
\hline n-Pentane & 2 & 0.001824 & 0.003087 & 0.001787 \\
\hline Propylene & 2 & 0.001784 & 0.001415 & 0.000000 \\
\hline Acetylene & 2 & 0.001507 & 0.000000 & 0.000000 \\
\hline Toluene & 2 & 0.001427 & 0.009776 & 0.008488 \\
\hline n-Hexane & 2 & 0.000912 & 0.001158 & 0.000745 \\
\hline Benzene & 2 & 0.000555 & 0.001029 & 0.000745 \\
\hline iso-Octane & 2 & 0.000595 & 0.002315 & 0.002383 \\
\hline $\mathrm{C}_{10} \mathrm{H}_{20}$ & 2 & 0.000555 & 0.000515 & 0.001192 \\
\hline iso-Butylene & 2 & 0.000476 & 0.001158 & 0.000447 \\
\hline Acetaldehyde & 2 & 0.000317 & 0.000000 & 0.000000 \\
\hline 1-Butene & 2 & 0.000317 & 0.000000 & 0.000298 \\
\hline 2-Methylpentane & 2 & 0.000238 & 0.001286 & 0.001042 \\
\hline Naphthalene & 2 & 0.000119 & 0.001286 & 0.002978 \\
\hline 1,2,4-Trimethylbenzene & 2 & 0.000119 & 0.002701 & 0.003872 \\
\hline m\&p-Xylene & 2 & 0.000159 & 0.002830 & 0.003425 \\
\hline 1-Methyl-3-Ethylbenzene & 2 & 0.000079 & 0.001544 & 0.002234 \\
\hline 1,1,3-Trimethylcyclopentan & 2 & 0.000040 & 0.000129 & 0.001043 \\
\hline 1-Methyl-1h-Indene & 2 & 0.000000 & 0.000386 & 0.001191 \\
\hline 3,3-Dimethylpentane & 2 & 0.000040 & 0.000000 & 0.005063 \\
\hline 1,2,3,5-Tetramethylbenzene & 2 & 0.000000 & 0.000901 & 0.002829 \\
\hline 1,3-Dimethyl-2-Ethylbenzene & 2 & 0.000000 & 0.000644 & 0.003425 \\
\hline 1-Methyl-4-Ethylbenzene & 2 & 0.000079 & 0.000900 & 0.001191 \\
\hline 1,3,5-Trimethylbenzene & 2 & 0.000040 & 0.000900 & 0.001340 \\
\hline Metyhlcyclohexane & 2 & 0.000079 & 0.001930 & 0.005063 \\
\hline Cyclohexane & 2 & 0.000040 & 0.000386 & 0.000447 \\
\hline n-Undecane & 2 & 0.000000 & 0.002573 & 0.006105 \\
\hline
\end{tabular}

Factors were applied for RFG, M85, and CNG. For RFG, the factor (0.9375) represents only the effect of the lower RVP of RFG as compared to baseline gasoline. For M85, the factor $(0.9375 \times 1.67)$ also represents the difference in miles per gallon between M85 and RFG. Since M85 vehicles will have lower miles per gallon, more fuel would be transported, stored, and pumped, resulting in higher emission rates. No other adjustments were applied for M85. 
TABLE 4-4. Most prevalent species in terms of weight fraction for M85 speciation profiles.

\begin{tabular}{|lcccc|}
\hline & & \multicolumn{3}{c|}{ Weight Fraction } \\
\cline { 3 - 5 } \multicolumn{1}{r}{ Species } & No. of & FTP & Shed- & Shed-Hot \\
Vehicles & Composite & Diurnal & Soak \\
\hline Methanol & 16 & 0.712014 & 0.283196 & 0.574431 \\
Methane & 16 & 0.075296 & 0.000685 & 0.001218 \\
Formaldehyde & 16 & 0.050381 & 0.000000 & 0.000000 \\
Toluene & 16 & 0.012391 & 0.041191 & 0.046997 \\
iso-Octane & 16 & 0.010912 & 0.009078 & 0.013541 \\
iso-Pentane & 16 & 0.010459 & 0.155678 & 0.037713 \\
m\&p-Xylene & 16 & 0.009605 & 0.023868 & 0.029443 \\
Ethylene & 16 & 0.008061 & 0.000124 & 0.000000 \\
MTBE & 16 & 0.006647 & 0.008263 & 0.016702 \\
Benzene & 16 & 0.006152 & 0.012141 & 0.011341 \\
n-Butane & 16 & 0.005566 & 0.154214 & 0.023986 \\
iso-Butylene & 16 & 0.005058 & 0.001359 & 0.000530 \\
Propylene & 16 & 0.005063 & 0.000025 & 0.000148 \\
2,3-Dimethylpentane & 16 & 0.004300 & 0.005533 & 0.008049 \\
Acetylene & 16 & 0.004385 & 0.000037 & 0.000009 \\
Ethylbenzene & 16 & 0.003650 & 0.006775 & 0.009527 \\
o-Xylene & 16 & 0.003570 & 0.007689 & 0.009471 \\
2-Methylpentane & 16 & 0.003542 & 0.018909 & 0.014276 \\
Ethane & 16 & 0.003268 & 0.000296 & 0.000017 \\
1,2,4-Trimethylbenzene & 16 & 0.003019 & 0.009195 & 0.008923 \\
1-Methyl-3-ethylbenzene & 16 & 0.002319 & 0.005780 & 0.006183 \\
n-Pentane & 16 & 0.001682 & 0.029834 & 0.018228 \\
3-Methylpentane & 16 & 0.001433 & 0.010708 & 0.007544 \\
3-Methylhexane & 16 & 0.001286 & 0.007701 & 0.005614 \\
2-Methylhexane & 16 & 0.001164 & 0.007269 & 0.005518 \\
iso-Butane & 16 & 0.001057 & 0.020200 & 0.002044 \\
n-Hexane & 16 & 0.000946 & 0.015118 & 0.010984 \\
n-Heptane & 16 & 0.000878 & 0.007102 & 0.005862 \\
Methylcyclopentane & 16 & 0.000609 & 0.007713 & 0.005257 \\
2-Methyl-2-butene & 16 & 0.000627 & 0.009164 & 0.006796 \\
trans-2-Pentene & 16 & 0.000379 & 0.007293 & 0.005414 \\
\hline
\end{tabular}

For CNG, the transportation, storage and refueling systems would be quite different than those for the liquid fuels, and a different method was used to estimate the losses. A leakage rate of 0.5 percent was assumed, based on lower bound projections for the current natural gas distribution system (Resch, 1995). A lower bound value was used because the type of distribution system envisioned for CNG would not involve the last stage of distribution to homes and businesses in the current natural gas system. The total mass of CNG that would be required to support complete conversion of the gasoline fleet was calculated from the total VMT for the two domains and the reported miles per gallon-equivalent (mpg) from the NREL database. It should be noted that the FTP mpg for the test fleet does not necessarily reflect a fleet average mpg under actual driving conditions. However, it was the only data 
TABLE 4-5. Most prevalent species in terms of weight fraction for RFG speciation profiles.

\begin{tabular}{|c|c|c|c|c|}
\hline \multirow[b]{2}{*}{ Species } & \multirow[b]{2}{*}{$\begin{array}{c}\text { No. of } \\
\text { Vehicles }\end{array}$} & \multicolumn{3}{|c|}{ Weight Fraction } \\
\hline & & $\begin{array}{c}\text { FTP } \\
\text { Composite }\end{array}$ & $\begin{array}{l}\text { Shed- } \\
\text { Diurnal }\end{array}$ & $\begin{array}{l}\text { Shed-Hot } \\
\text { Soak }\end{array}$ \\
\hline Methane & 16 & 0.153701 & 0.000851 & 0.001749 \\
\hline iso-Octane & 16 & 0.069087 & 0.009717 & 0.029307 \\
\hline Toluene & 16 & 0.061496 & 0.040226 & 0.106601 \\
\hline iso-Pentane & 16 & 0.056801 & 0.244143 & 0.109332 \\
\hline m\&p-Xylene & 16 & 0.047123 & 0.021045 & 0.056560 \\
\hline iso-Butylene & 16 & 0.042041 & 0.003274 & 0.002168 \\
\hline Ethylene & 16 & 0.040905 & 0.000000 & 0.000198 \\
\hline 2,3-Dimethylpentane & 16 & 0.029996 & 0.005619 & 0.015334 \\
\hline Propylene & 16 & 0.028468 & 0.000091 & 0.000335 \\
\hline Benzene & 16 & 0.025182 & 0.011841 & 0.025618 \\
\hline Ethane & 16 & 0.022451 & 0.000377 & 0.000715 \\
\hline MTBE & 16 & 0.020713 & 0.020110 & 0.043089 \\
\hline Ethylbenzene & 16 & 0.018891 & 0.005878 & 0.018156 \\
\hline 2,3,4-Trimethylpentane & 16 & 0.018238 & 0.003235 & 0.010405 \\
\hline 2-Methylpentane & 16 & 0.018126 & 0.018486 & 0.031102 \\
\hline 2,4-Dimethylpentane & 16 & 0.016618 & 0.004177 & 0.009508 \\
\hline o-Xylene & 16 & 0.016534 & 0.007216 & 0.018559 \\
\hline 1,2,4-Trimethylbenzene & 16 & 0.014848 & 0.008412 & 0.017859 \\
\hline Acetylene & 16 & 0.014535 & 0.000351 & 0.000106 \\
\hline 1-Methyl-3-ethylbenzene & 16 & 0.011814 & 0.004631 & 0.011425 \\
\hline n-Butane & 16 & 0.011857 & 0.345180 & 0.111530 \\
\hline n-Pentane & 16 & 0.010059 & 0.035497 & 0.041157 \\
\hline 3-Methylpentane & 16 & 0.009273 & 0.009652 & 0.015859 \\
\hline 3-Methylhexane & 16 & 0.008126 & 0.006469 & 0.011425 \\
\hline 2-Methylhexane & 16 & 0.007385 & 0.006288 & 0.010732 \\
\hline $\mathrm{n}$-Hexane & 16 & 0.005628 & 0.012562 & 0.023016 \\
\hline n-Heptane & 16 & 0.005212 & 0.005885 & 0.011691 \\
\hline 2-Methyl-2-butene & 16 & 0.003643 & 0.009996 & 0.014825 \\
\hline Methylcyclopentane & 16 & 0.003383 & 0.006158 & 0.010824 \\
\hline 2-Methyl-1-butene & 16 & 0.002530 & 0.005917 & 0.006290 \\
\hline Unknown* & 16 & 0.002094 & 0.005378 & 0.015911 \\
\hline trans-2-Pentene & 16 & 0.001836 & 0.008886 & 0.012048 \\
\hline iso-Butane & 16 & 0.001432 & 0.024377 & 0.008215 \\
\hline
\end{tabular}

* The sum of all species for which no match was found in the list of named species from the alternative fuels database.

available. The 0.5 percent leakage rate was applied to the total CNG mass calculated from VMT and mpg to obtain the "refueling/bulk storage" emissions factor $(0.9375 \times 3.70)$ for the CNG case, relative to baseline gasoline.

Adjustment factors for RFG, M85, and CNG are summarized in Table 4-9. Refueling/bulk storage emissions were speciated according to the composite evaporative profiles for RFG and $\mathrm{M} 85$, and according to reported CNG composition for CNG. 
TABLE 4-6. Amounts of CB4 species and potential ozone production for CNG speciation profiles.

\begin{tabular}{|c|c|c|c|c|c|c|c|}
\hline \multirow[b]{2}{*}{ Species } & \multirow[b]{2}{*}{ MIR } & \multicolumn{2}{|c|}{ FTP Composite Mode } & \multicolumn{2}{|c|}{ Shed-Diurnal Mode } & \multicolumn{2}{|c|}{ Shed-Hot Soak Mode } \\
\hline & & $\begin{array}{l}\text { Mols } \\
\text { species per } \\
\text { mol emiss. }\end{array}$ & $\begin{array}{c}\mathrm{Mols}_{3} \\
\text { produced } \\
\text { from species }\end{array}$ & $\begin{array}{c}\text { Mols } \\
\text { species per } \\
\text { mol emiss }\end{array}$ & $\begin{array}{c}\mathrm{Mols}_{3} \\
\text { produced } \\
\text { from species }\end{array}$ & $\begin{array}{c}\text { Mols } \\
\text { species per } \\
\text { mol emiss. }\end{array}$ & $\begin{array}{c}\mathrm{Mols}_{3} \\
\text { produced } \\
\text { from species }\end{array}$ \\
\hline OLE & 9.9500 & 0.0010 & 0.0099 & 0.0011 & 0.0113 & 0.0009 & 0.0092 \\
\hline ETH & 4.9500 & 0.0101 & 0.0498 & 0.0000 & 0.0000 & 0.0000 & 0.0000 \\
\hline PAR & 0.9800 & 0.0392 & 0.0384 & 0.0845 & 0.0828 & 0.1062 & 0.1041 \\
\hline MTBE & 3.5700 & 0.0000 & 0.0000 & 0.0000 & 0.0000 & 0.0000 & 0.0000 \\
\hline IOLE & 3.9420 & 0.0001 & 0.0004 & 0.0005 & 0.0018 & 0.0001 & 0.0005 \\
\hline ALDX & 6.4400 & 0.0001 & 0.0003 & 0.0000 & 0.0000 & 0.0002 & 0.0010 \\
\hline MEOH & 3.3800 & 0.0000 & 0.0000 & 0.0000 & 0.0000 & 0.0000 & 0.0000 \\
\hline BUTA & 3.5760 & 0.0000 & 0.0001 & 0.0000 & 0.0000 & 0.0000 & 0.0000 \\
\hline CRES & 0.8370 & 0.0000 & 0.0000 & 0.0000 & 0.0000 & 0.0000 & 0.0000 \\
\hline PACET & 2.9010 & 0.0001 & 0.0004 & 0.0000 & 0.0000 & 0.0000 & 0.0000 \\
\hline METH & 0.0060 & 0.9491 & 0.0057 & 0.9280 & 0.0056 & 0.9163 & 0.0055 \\
\hline BENZ & 0.1630 & 0.0001 & 0.0000 & 0.0002 & 0.0000 & 0.0002 & 0.0000 \\
\hline TOL & 6.3000 & 0.0003 & 0.0018 & 0.0022 & 0.0137 & 0.0021 & 0.0135 \\
\hline ETOH & 3.6600 & 0.0000 & 0.0000 & 0.0000 & 0.0000 & 0.0000 & 0.0000 \\
\hline PHCHO & 0.0000 & 0.0028 & 0.0000 & 0.0000 & 0.0000 & 0.0000 & 0.0000 \\
\hline FORM & 6.5400 & 0.0001 & 0.0009 & 0.0004 & 0.0027 & 0.0001 & 0.0010 \\
\hline ISOP & 22.7000 & 0.0000 & 0.0011 & 0.0000 & 0.0000 & 0.0000 & 0.0009 \\
\hline ACET & 2.9010 & 0.0000 & 0.0000 & 0.0000 & 0.0001 & 0.0000 & 0.0000 \\
\hline XYL & 20.8000 & 0.0001 & 0.0024 & 0.0021 & 0.0445 & 0.0038 & 0.0788 \\
\hline Total & - & - & 0.1112 & & 0.1625 & & 0.2145 \\
\hline
\end{tabular}

TABLE 4-7. Amounts of CB4 species and potential ozone production for M85 speciation profiles.

\begin{tabular}{|c|c|c|c|c|c|c|c|}
\hline \multirow[b]{2}{*}{ Species } & \multirow[b]{2}{*}{ MIR } & \multicolumn{2}{|c|}{ FTP Composite Mode } & \multicolumn{2}{|c|}{ Shed-Diurnal Mode } & \multicolumn{2}{|c|}{ Shed-Hot Soak Mode } \\
\hline & & $\begin{array}{c}\text { Mols } \\
\text { species per } \\
\text { mol emiss. }\end{array}$ & $\begin{array}{c}\mathrm{Mols}_{3} \\
\text { produced } \\
\text { from species }\end{array}$ & $\begin{array}{c}\text { Mols } \\
\text { species per } \\
\text { mol emiss }\end{array}$ & $\begin{array}{c}\mathrm{Mols}_{3} \\
\text { produced } \\
\text { from species }\end{array}$ & $\begin{array}{c}\text { Mols } \\
\text { species per } \\
\text { mol emiss. }\end{array}$ & $\begin{array}{c}\text { Mols } \mathrm{O}_{3} \\
\text { produced } \\
\text { from species }\end{array}$ \\
\hline OLE & 9.9500 & 0.0059 & 0.0586 & 0.0113 & 0.1123 & 0.0070 & 0.0701 \\
\hline ETH & 4.9500 & 0.0093 & 0.0461 & 0.0002 & 0.0012 & 0.0000 & 0.0000 \\
\hline PAR & 0.9800 & 0.1729 & 0.1694 & 2.0061 & 1.9660 & 0.6991 & 0.6851 \\
\hline MTBE & 3.5700 & 0.0024 & 0.0087 & 0.0051 & 0.0183 & 0.0083 & 0.0296 \\
\hline IOLE & 3.9420 & 0.0012 & 0.0047 & 0.0211 & 0.0833 & 0.0111 & 0.0436 \\
\hline ALDX & 6.4400 & 0.0002 & 0.0014 & 0.0019 & 0.0121 & 0.0011 & 0.0071 \\
\hline MEOH & 3.3800 & 0.7201 & 2.4340 & 0.4826 & 1.6312 & 0.7854 & 2.6548 \\
\hline BUTA & 3.5760 & 0.0003 & 0.0012 & 0.0000 & 0.0000 & 0.0000 & 0.0000 \\
\hline CRES & 0.8370 & 0.0000 & 0.0000 & 0.0000 & 0.0000 & 0.0000 & 0.0000 \\
\hline PACET & 2.9010 & 0.0008 & 0.0023 & 0.0000 & 0.0000 & 0.0000 & 0.0000 \\
\hline METH & 0.0060 & 0.1521 & 0.0009 & 0.0023 & 0.0000 & 0.0033 & 0.0000 \\
\hline BENZ & 0.1630 & 0.0026 & 0.0004 & 0.0085 & 0.0014 & 0.0064 & 0.0010 \\
\hline TOL & 6.3000 & 0.0058 & 0.0367 & 0.0291 & 0.1832 & 0.0272 & 0.1714 \\
\hline ETOH & 3.6600 & 0.0000 & 0.0000 & 0.0000 & 0.0000 & 0.0000 & 0.0000 \\
\hline PHCHO & 0.0000 & 0.0544 & 0.0000 & 0.0000 & 0.0000 & 0.0000 & 0.0000 \\
\hline FORM & 6.5400 & 0.0032 & 0.0206 & 0.0058 & 0.0379 & 0.0028 & 0.0182 \\
\hline ISOP & 22.7000 & 0.0000 & 0.0000 & 0.0002 & 0.0040 & 0.0002 & 0.0036 \\
\hline ACET & 2.9010 & 0.0003 & 0.0010 & 0.0084 & 0.0243 & 0.0051 & 0.0147 \\
\hline XYL & 20.8000 & 0.0073 & 0.1516 & 0.0309 & 0.6432 & 0.0273 & 0.5680 \\
\hline Total & - & - & 2.9376 & - & 4.7184 & - & 4.2672 \\
\hline
\end{tabular}


TABLE 4-8. Amounts of CB4 species and potential ozone production for RFG speciation profiles.

\begin{tabular}{|c|c|c|c|c|c|c|c|}
\hline \multirow[b]{2}{*}{ Species } & \multirow[b]{2}{*}{ MIR } & \multicolumn{2}{|c|}{ FTP Composite Mode } & \multicolumn{2}{|c|}{ Shed-Diurnal Mode } & \multicolumn{2}{|c|}{ Shed-Hot Soak Mode } \\
\hline & & $\begin{array}{c}\text { Mols } \\
\text { species per } \\
\text { mol emiss. }\end{array}$ & $\begin{array}{c}\text { Mols } \mathrm{O}_{3} \\
\text { produced } \\
\text { from species }\end{array}$ & $\begin{array}{c}\text { Mols } \\
\text { species per } \\
\text { mol emiss }\end{array}$ & $\begin{array}{c}\mathrm{Mols}_{3} \mathrm{O}_{3} \\
\text { produced } \\
\text { from species }\end{array}$ & $\begin{array}{c}\text { Mols } \\
\text { species per } \\
\text { mol emiss. }\end{array}$ & $\begin{array}{c}\text { Mols } \mathrm{O}_{3} \\
\text { produced } \\
\text { from species }\end{array}$ \\
\hline OLE & 9.9500 & 0.0441 & 0.4388 & 0.0150 & 0.1490 & 0.0292 & 0.2908 \\
\hline ETH & 4.9500 & 0.0683 & 0.3380 & 0.0000 & 0.0000 & 0.0006 & 0.0029 \\
\hline PAR & 0.9800 & 1.3946 & 1.3667 & 3.9603 & 3.8811 & 3.3788 & 3.3112 \\
\hline MTBE & 3.5700 & 0.0110 & 0.0393 & 0.0161 & 0.0575 & 0.0407 & 0.1452 \\
\hline IOLE & 3.9420 & 0.0095 & 0.0376 & 0.0315 & 0.1242 & 0.0471 & 0.1856 \\
\hline ALDX & 6.4400 & 0.0029 & 0.0189 & 0.0021 & 0.0138 & 0.0043 & 0.0279 \\
\hline MEOH & 3.3800 & 0.0000 & 0.0000 & 0.0000 & 0.0000 & 0.0000 & 0.0000 \\
\hline BUTA & 3.5760 & 0.0003 & 0.0011 & 0.0000 & 0.0000 & 0.0000 & 0.0002 \\
\hline CRES & 0.8370 & 0.0000 & 0.0000 & 0.0000 & 0.0000 & 0.0000 & 0.0000 \\
\hline PACET & 2.9010 & 0.0024 & 0.0068 & 0.0000 & 0.0000 & 0.0000 & 0.0000 \\
\hline METH & 0.0060 & 0.4487 & 0.0027 & 0.0037 & 0.0000 & 0.0091 & 0.0001 \\
\hline BENZ & 0.1630 & 0.0151 & 0.0025 & 0.0107 & 0.0017 & 0.0273 & 0.0044 \\
\hline TOL & 6.3000 & 0.0423 & 0.2668 & 0.0360 & 0.2266 & 0.1143 & 0.7203 \\
\hline ETOH & 3.6600 & 0.0000 & 0.0000 & 0.0000 & 0.0000 & 0.0000 & 0.0000 \\
\hline PHCHO & 0.0000 & 0.0118 & 0.0000 & 0.0000 & 0.0000 & 0.0000 & 0.0000 \\
\hline FORM & 6.5400 & 0.0372 & 0.2433 & 0.0111 & 0.0728 & 0.0132 & 0.0861 \\
\hline ISOP & 22.7000 & 0.0002 & 0.0053 & 0.0002 & 0.0047 & 0.0005 & 0.0120 \\
\hline ACET & 2.9010 & 0.0029 & 0.0085 & 0.0114 & 0.0332 & 0.0211 & 0.0611 \\
\hline XYL & 20.8000 & 0.0505 & 1.0506 & 0.0341 & 0.7094 & 0.1006 & 2.0932 \\
\hline Total & - & - & 3.8269 & - & 5.2740 & - & 6.9410 \\
\hline
\end{tabular}

TABLE 4-9. Adjustment factors for alternative fuels applied to gasoline-related stationary sources for Baltimore and Los Angeles.

\begin{tabular}{|ll|}
\hline Fuel & Adjustment factor \\
\hline RFG & 0.9375 \\
M85 & $1.5656(0.9375 \times 1.67)$ \\
CNG & $3.4688(0.9375 \times 3.70)$ \\
\hline
\end{tabular}

\section{PROJECTED 2020 EMISSION TOTALS}

\section{Baltimore}

Table 4-10 summarizes the projected 2020 criteria pollutant emissions for the Baltimore domain for the three fuels. Comparison of Table 4-10a (the RFG base inventory for 2020) to Table 2-2 shows that hydrocarbon emissions are projected to decrease significantly between 1988 and 2020. By contrast, $\mathrm{NO}_{\mathrm{x}}$ emissions show very little net change in that time period. The projected decrease in hydrocarbon emissions is primarily due to onroad mobile sources, for which the decrease in RHC emissions is 70 percent. Much of the projected decrease is due to the reduction in RVP between the 1988 base case ( 10 psi) and the 2020 RFG case (7.2 psi). Other factors are fleet turnover, stricter tailpipe standards, and RFG use. The other components of the inventory show little change between 1988 and 2020, indicating that the level of emission control applied to the inventory was adequate to counteract projected growth rates, but not adequate to reduce net emissions significantly. 
TABLE 4-10a. Baltimore projected emissions (tpd) for July weekday, 2020. Fuel RFG.

\begin{tabular}{|lrrrr|}
\hline \multicolumn{1}{r}{ Source Type } & NO $_{x}$ & RHC & THC & \multicolumn{1}{c|}{ CO } \\
\hline Onroad MV & 760 & 679 & 783 & 3018 \\
GV & 585 & 643 & 745 & 2845 \\
HDV & 175 & 36 & 38 & 173 \\
Refuel/Bulk Storage & 0 & 173 & 180 & 0 \\
Area Other & 526 & 1725 & 2115 & 4194 \\
Points Other & & & & \\
Elevated & 669 & 204 & 222 & 410 \\
Low-level & 78 & 143 & 163 & 21 \\
Total anthropogenic & 2034 & 2925 & 3463 & 7643 \\
Biogenic & 17 & 1274 & 1274 & 0 \\
Total & 2050 & 4199 & 4737 & 7643 \\
\hline
\end{tabular}

TABLE 4-10b. Baltimore projected emissions (tpd) for July weekday, 2020. Fuel M85.

\begin{tabular}{|lrrrr|}
\hline \multicolumn{1}{r}{ Source Type } & $\mathrm{NO}_{\mathrm{x}}$ & $\mathrm{RHC}$ & $\mathrm{THC}$ & \multicolumn{1}{c|}{$\mathrm{CO}$} \\
\hline Onroad MV & 771 & 564 & 621 & 2705 \\
GV & 596 & 528 & 583 & 2532 \\
HDV & 175 & 36 & 38 & 173 \\
Refuel/Bulk Storage & 0 & 238 & 244 & 0 \\
Area Other & 526 & 1725 & 2115 & 4194 \\
Points Other & & & & \\
Elevated & 669 & 204 & 222 & 410 \\
Low-level & 78 & 143 & 163 & 21 \\
Total anthropogenic & 2045 & 2874 & 3365 & 7330 \\
Biogenic & 17 & 1274 & 1274 & 0 \\
Total & 2062 & 4148 & 4639 & 7330 \\
\hline
\end{tabular}

TABLE 4-10c. Baltimore projected emissions (tpd) for July weekday, 2020. Fuel CNG.

\begin{tabular}{|lrrrr|}
\hline \multicolumn{1}{c}{ Source Type } & NO $_{x}$ & RHC & THC & CO \\
\hline Onroad MV & 491 & 118 & 1214 & 2414 \\
GV & 316 & 82 & 1176 & 2241 \\
HDV & 175 & 36 & 38 & 173 \\
Refuel/Bulk Storage & 0 & 29 & 560 & 0 \\
Area Other & 526 & 1725 & 2115 & 4194 \\
Points Other & & & & \\
$\quad$ Elevated & 669 & 204 & 222 & 410 \\
Low-level & 78 & 143 & 163 & 21 \\
Total anthropogenic & 1764 & 2220 & 4273 & 7038 \\
Biogenic & 17 & 1274 & 1274 & 0 \\
Total & 1781 & 3494 & 5547 & 7038 \\
\hline
\end{tabular}


TABLE 4-11a. Speciated emissions (tpd), Baltimore, 5 July 1988 projected to 2020 . Fuel RFG.

\begin{tabular}{|lrrrr|}
\hline Species & $\begin{array}{c}\text { Area and } \\
\text { Low Level Point }\end{array}$ & $\begin{array}{r}\text { Onroad } \\
\text { Mobile }\end{array}$ & $\begin{array}{c}\text { Elevated } \\
\text { Point }\end{array}$ & $\begin{array}{c}\text { Total } \\
\text { Anthropogenic }\end{array}$ \\
\hline NO & 544.10 & 683.92 & 602.86 & 1830.88 \\
NO2 & 60.49 & 75.99 & 66.37 & 202.85 \\
NOx & 604.59 & 759.91 & 669.23 & 2033.73 \\
OLE & 143.07 & 28.05 & 2.12 & 173.24 \\
PAR & 1265.20 & 359.47 & 101.32 & 1725.99 \\
TOL & 243.48 & 92.02 & 72.90 & 408.40 \\
XYL & 186.65 & 123.21 & 23.26 & 333.12 \\
FORM & 0.70 & 6.01 & 0.00 & 6.71 \\
ALDX & 6.97 & 1.71 & 0.87 & 9.55 \\
ETH & 88.25 & 29.71 & 0.79 & 118.75 \\
MEOH & 0.73 & 0.00 & 0.48 & 1.21 \\
ETOH & 55.50 & 0.00 & 0.01 & 55.51 \\
ISOP & 2.28 & 1.42 & 0.00 & 3.70 \\
ACET & 3.51 & 2.62 & 0.00 & 6.13 \\
PACET & 4.41 & 1.32 & 0.83 & 6.56 \\
PHCHO & 9.55 & 3.03 & 0.57 & 13.15 \\
IOLE & 23.28 & 15.01 & 0.05 & 38.34 \\
CRES & 2.49 & 0.00 & 0.99 & 3.48 \\
MTBE & 5.81 & 15.51 & 0.00 & 21.32 \\
RHC & 2041.88 & 679.09 & 204.19 & 2925.16 \\
BENZ & 58.23 & 25.69 & 9.71 & 93.63 \\
BUTA & 12.12 & 3.93 & 0.78 & 16.83 \\
METH & 345.02 & 75.95 & 7.03 & 428.00 \\
THC & 2457.25 & 784.66 & 221.70 & 3463.61 \\
CO & 4214.55 & 3022.03 & 410.13 & 7646.71 \\
\hline
\end{tabular}

The M85 scenario has total anthropogenic $\mathrm{NO}_{\mathrm{x}}$ emissions that are 0.5 percent higher than the RFG base case. Total anthropogenic RHC emissions are 0.1 percent lower in the M85 scenario. In comparing the M85 RHC emissions to those from the RFG scenario, note that all UAM RHC species are reported on a methane-equivalent basis; thus mass emissions of methanol $(\mathrm{MEOH})$ are calculated using a molecular weight of 16 rather than 32. As MEOH constitutes a large fraction of the mobile RHC in the M85 case, the resulting methane-equivalent RHC emissions are considerably lower than the actual emissions would be. Consequently, the mobile RHC emissions in Table 4-10b are lower than those in Table 4-10a, despite the application of M85 MERs that were on the order of 1.3 to 1.4. On the other hand, the refueling/bulk storage RHC emissions increased in the M85 scenario, even on a methane-equivalent basis. The net effect was very little difference in total RHC emissions for the two fuels.

The CNG scenario has total anthropogenic $\mathrm{NO}_{\mathrm{x}}$ emissions that are 13 percent lower than in the RFG base case. The total anthropogenic RHC emissions are 24 percent lower than the RFG base case. However, THC emissions are 23 percent higher in the CNG case.

Speciated emissions are shown in Table 4-11 for each fuel. Onroad mobile emissions of the toxic species BENZ and BUTA decrease by 63 percent and 77 percent for M85 and 92 percent and 86 percent for CNG. These translate to 18 and 18 percent reductions in total BENZ and BUTA emissions for M85 and 32 and 20 percent for CNG. 
TABLE 4-11b. Speciated emissions (tpd), Baltimore, 5 July 1988 projected to 2020 . Fuel M85.

\begin{tabular}{|lrrrc|}
\hline Species & $\begin{array}{c}\text { Area and } \\
\text { Low Level Point }\end{array}$ & $\begin{array}{r}\text { Onroad } \\
\text { Mobile }\end{array}$ & $\begin{array}{c}\text { Elevated } \\
\text { Point }\end{array}$ & $\begin{array}{c}\text { Total } \\
\text { Anthropogenic }\end{array}$ \\
\hline NO & 544.10 & 694.18 & 602.86 & 1841.14 \\
NO2 & 60.49 & 77.00 & 66.37 & 203.86 \\
NO ${ }_{x}$ & 604.59 & 771.18 & 669.23 & 2045.00 \\
OLE & 143.45 & 9.25 & 2.12 & 154.82 \\
PAR & 1267.66 & 172.61 & 101.32 & 1541.47 \\
TOL & 243.36 & 31.29 & 72.90 & 347.55 \\
XYL & 193.28 & 44.33 & 23.26 & 260.87 \\
FORM & 0.64 & 1.27 & 0.00 & 1.91 \\
ALDX & 7.11 & 0.81 & 0.87 & 8.79 \\
ETH & 88.25 & 10.35 & 0.79 & 99.39 \\
MEOH & 56.94 & 261.27 & 0.48 & 318.69 \\
ETOH & 55.50 & 0.00 & 0.01 & 55.51 \\
ISOP & 2.29 & 0.39 & 0.00 & 2.68 \\
ACET & 3.42 & 1.24 & 0.00 & 4.66 \\
PACET & 4.41 & 0.80 & 0.83 & 6.04 \\
PHCHO & 9.55 & 16.56 & 0.57 & 26.68 \\
IOLE & 22.37 & 7.17 & 0.05 & 29.59 \\
CRES & 2.49 & 0.00 & 0.99 & 3.48 \\
MTBE & 5.87 & 6.33 & 0.00 & 12.2 \\
RHC & 2106.59 & 563.67 & 204.19 & 2874.45 \\
BENZ & 57.27 & 9.42 & 9.71 & 76.40 \\
BUTA & 12.12 & 0.89 & 0.78 & 13.79 \\
METH & 345.00 & 46.69 & 7.03 & 398.72 \\
THC & 2520.98 & 620.67 & 221.70 & 3363.35 \\
CO & 4214.55 & 2704.88 & 410.13 & 7329.56 \\
\hline
\end{tabular}

Onroad mobile emissions of formaldehyde (PHCHO) increase by 550 percent for M85 and by 30 percent for $\mathrm{CNG}$, resulting in overall formaldehyde increases of 136 percent for M85 and 7 percent for CNG. However, emissions of precursors for secondary formaldehyde (OLE and FORM) are lower in the M85 and CNG scenarios than in the RFG base case. Onroad mobile emissions of acetaldehyde (PACET) decrease by 40 percent for M85 and 54 percent for CNG. Emissions of precursors for secondary acetaldehyde (IOLE, OLE, ACET) also decrease in these two cases.

Interestingly, emissions of gasoline components are much higher in the M85 case than would be predicted from the fuel composition alone. For instance, levels of MTBE in M85 are presumably 15 percent of those in RFG, yet mobile emissions of MTBE from M85 are over a third those for RFG. The same is true for the aromatic species TOL and XYL.

\section{Los Angeles}

Table 4-12 summarizes projected criteria pollutant emissions for 2020 for the Los Angeles domain for the three fuels. Comparison of Table 4-12a (the RFG base inventory for 2020) to Table 2-4 shows a projected decrease in total anthropogenic $\mathrm{NO}_{\mathrm{x}}$ emissions of 73 percent; total anthropogenic RHC emissions show a projected decrease of 80 percent. All categories of emissions show large projected reductions from 1987 levels, ranging from 17 percent for 
TABLE 4-11c. Speciated emissions (tpd), Baltimore, 5 July 1988 projected to 2020 . Fuel CNG.

\begin{tabular}{|lrrrr|}
\hline Species & $\begin{array}{c}\text { Area and } \\
\text { Low Level Point }\end{array}$ & $\begin{array}{r}\text { Onroad } \\
\text { Mobile }\end{array}$ & $\begin{array}{r}\text { Elevated } \\
\text { Point }\end{array}$ & $\begin{array}{c}\text { Total } \\
\text { Anthropogenic }\end{array}$ \\
\hline NO & 544.58 & 441.64 & 602.86 & 1589.08 \\
NO2 & 60.54 & 48.98 & 66.37 & 175.89 \\
NO & 605.12 & 490.63 & 669.23 & 1764.97 \\
OLE & 141.66 & 5.04 & 2.12 & 148.82 \\
PAR & 1198.94 & 71.25 & 101.32 & 1371.52 \\
TOL & 214.44 & 5.30 & 72.90 & 292.64 \\
XYL & 154.78 & 3.95 & 23.26 & 181.99 \\
FORM & 0.23 & 0.20 & 0.00 & 0.44 \\
ALDX & 6.73 & 0.39 & 0.87 & 7.99 \\
ETH & 88.32 & 26.84 & 0.79 & 115.96 \\
MEOH & 0.73 & 0.00 & 0.48 & 1.21 \\
ETOH & 55.55 & 0.00 & 0.01 & 55.56 \\
ISOP & 2.22 & 0.28 & 0.00 & 2.50 \\
ACET & 1.94 & 0.00 & 0.00 & 1.95 \\
PACET & 4.42 & 0.61 & 0.83 & 5.86 \\
PHCHO & 9.56 & 3.92 & 0.57 & 14.05 \\
IOLE & 15.83 & 0.52 & 0.05 & 16.40 \\
CRES & 2.50 & 0.00 & 0.99 & 3.48 \\
MTBE & 1.42 & 0.00 & 0.00 & 1.42 \\
RHC & 1899.28 & 118.30 & 204.19 & 2221.78 \\
BENZ & 52.16 & 1.99 & 9.71 & 63.85 \\
BUTA & 12.13 & 0.56 & 0.78 & 13.46 \\
METH & 875.89 & 1093.47 & 7.03 & 1976.40 \\
THC & 2839.46 & 1214.33 & 221.70 & 4275.49 \\
CO & 4218.27 & 2413.58 & 410.13 & 7041.98 \\
\hline
\end{tabular}

low-level point source $\mathrm{NO}_{\mathrm{x}}$ emissions to 89 percent for onroad mobile $\mathrm{RHC}$. As discussed above, this inventory is derived from the 2010 attainment inventory that includes sufficient level of emission reduction to reduce modeled ozone levels below $120 \mathrm{ppb}$.

The M85 scenario has total anthropogenic $\mathrm{NO}_{\mathrm{x}}$ and $\mathrm{RHC}$ emissions that both are 1 percent higher than the RFG base case. In the CNG scenario, these $\mathrm{NO}_{\mathrm{x}}$ emissions are 4 percent lower and RHC emissions are 32 percent lower than the RFG base case.

The 2020 inventories for Baltimore and Los Angeles are very different. One striking difference is for refueling/bulk storage. The Los Angeles domain has emissions for this category that are only 8 percent of the Baltimore emissions, despite very similar projected 2020 VMT for the two domains.

Speciated emissions are shown in Table 4-13 for each fuel. Onroad mobile emissions of the toxic species BENZ and BUTA decrease by 51 percent and 62 percent for M85 and 92 percent and 70 percent for $\mathrm{CNG}$. These reductions translate to 28 and 55 percent reductions in total BENZ and BUTA emissions for M85, and 53 and 61 percent for CNG.

Onroad mobile emissions of primary formaldehyde (PHCHO) increase by 400 percent for M85 and by 17 percent for CNG, resulting in overall PHCHO increases of 64 percent for 
TABLE 4-12a. Los Angeles projected emissions (tpd) for August weekday, 2020. Fuel RFG.

\begin{tabular}{|lrrrr|}
\hline \multicolumn{1}{c}{ Source Type } & $\mathrm{NO}_{\mathrm{x}}$ & $\mathrm{RHC}$ & $\mathrm{THC}$ & $\mathrm{CO}$ \\
\hline Onroad MV & 94 & 186 & 203 & 1274 \\
GV & 41 & 175 & 191 & 1072 \\
HDV & 53 & 11 & 12 & 202 \\
Refuel/Bulk Storage & 0 & 10 & 10 & 0 \\
Area Other & 193 & 220 & 878 & 701 \\
Points Other & & & & \\
$\quad$ Elevated & 16 & 2 & 5 & 12 \\
Low-level & 126 & 110 & 157 & 162 \\
Total Anthropogenic & 429 & 528 & 1253 & 2149 \\
Biogenic & 0 & 257 & 257 & 0 \\
Total & 429 & 785 & 1510 & 2149 \\
\hline
\end{tabular}

TABLE 4-12b. Los Angeles projected emissions (tpd) for August weekday, 2020. Fuel M85.

\begin{tabular}{|lrrrr|}
\hline \multicolumn{1}{c}{ Source Type } & $\mathrm{NO}_{\mathrm{x}}$ & $\mathrm{RHC}$ & $\mathrm{THC}$ & $\mathrm{CO}$ \\
\hline Onroad MV & 98 & 190 & 200 & 1155 \\
GV & 45 & 179 & 188 & 953 \\
HDV & 53 & 11 & 12 & 202 \\
Refuel/Bulk Storage & 0 & 13 & 13 & 0 \\
Area Other & 193 & 220 & 878 & 701 \\
Points Other & & & & \\
$\quad$ Elevated & 16 & 2 & 5 & 12 \\
Low-level & 126 & 110 & 157 & 162 \\
Total Anthropogenic & 433 & 535 & 1253 & 2030 \\
Biogenic & 0 & 257 & 257 & 0 \\
Total & 433 & 792 & 1510 & 2030 \\
\hline
\end{tabular}

TABLE 4-12c. Los Angeles projected emissions (tpd) for August weekday, 2020. Fuel CNG.

\begin{tabular}{|lrrrr|}
\hline \multicolumn{1}{c}{ Source Type } & $\mathrm{NO}_{\mathrm{x}}$ & $\mathrm{RHC}$ & $\mathrm{THC}$ & $\mathrm{CO}$ \\
\hline Onroad MV & 77 & 27 & 204 & 1044 \\
GV & 24 & 16 & 192 & 842 \\
HDV & 53 & 11 & 12 & 202 \\
Refuel/Bulk Storage & 0 & 6 & 100 & 0 \\
Area Other & 193 & 220 & 878 & 701 \\
Points Other & & & & \\
$\quad$ Elevated & 16 & 2 & 5 & 12 \\
Low-level & 126 & 110 & 157 & 162 \\
Total Anthropogenic & 412 & 365 & 1344 & 1919 \\
Biogenic & 0 & 257 & 257 & 0 \\
Total & 412 & 622 & 1601 & 1919 \\
\hline
\end{tabular}

M85 and 3 percent for CNG. However, emissions of precursors for secondary formaldehyde (OLE and FORM) are lower in the M85 and CNG scenarios than in the RFG base case.

Onroad mobile emissions of primary acetaldehyde (PACET) decrease by 30 percent for M85 and 37 percent for CNG. Emissions of precursors for secondary acetaldehyde (IOLE, OLE, ACET) also decrease in these two cases. 
TABLE 4-13a. Speciated emissions (tpd), Los Angeles, 26 August 1987 , projected to 2020 , fuel RFG.

\begin{tabular}{|lrrrr|}
\hline Species & $\begin{array}{r}\text { Area and } \\
\text { Low Level Point }\end{array}$ & $\begin{array}{r}\text { Onroad } \\
\text { Mobile }\end{array}$ & $\begin{array}{c}\text { Elevated } \\
\text { Point }\end{array}$ & $\begin{array}{c}\text { Total } \\
\text { Anthropogenic }\end{array}$ \\
\hline NO & 303.52 & 84.54 & 14.74 & 402.79 \\
NO2 & 16.03 & 9.38 & 0.77 & 26.18 \\
NOx & 319.55 & 93.91 & 15.51 & 428.97 \\
OLE & 6.81 & 4.60 & 0.13 & 11.55 \\
PAR & 251.47 & 105.78 & 1.90 & 359.15 \\
TOL & 37.27 & 26.74 & 0.09 & 64.10 \\
XYL & 17.79 & 29.72 & 0.02 & 47.53 \\
FORM & 0.04 & 1.07 & 0.00 & 1.11 \\
ALDX & 1.01 & 0.36 & 0.00 & 1.37 \\
ETH & 13.67 & 4.88 & 0.02 & 18.57 \\
MEOH & 0.02 & 0.00 & 0.00 & 0.02 \\
ETOH & 8.04 & 0.00 & 0.00 & 8.04 \\
ISOP & 0.00 & 0.23 & 0.00 & 0.24 \\
ACET & 0.10 & 1.21 & 0.00 & 1.31 \\
PACET & 0.89 & 0.24 & 0.00 & 1.12 \\
PHCHO & 2.09 & 0.58 & 0.13 & 2.81 \\
IOLE & 0.58 & 5.92 & 0.01 & 6.51 \\
CRES & 0.03 & 0.00 & 0.00 & 0.03 \\
MTBE & 0.26 & 4.34 & 0.00 & 4.60 \\
RHC & 340.06 & 185.68 & 2.30 & 528.04 \\
BENZ & 5.03 & 6.55 & 0.11 & 11.69 \\
BUTA & 0.08 & 0.53 & 0.00 & 0.62 \\
METH & 699.86 & 10.67 & 2.15 & 712.69 \\
THC & 1045.04 & 203.44 & 4.56 & 1253.04 \\
CO & 862.64 & 1275.02 & 12.21 & 2149.87 \\
\hline
\end{tabular}

In contrast to Baltimore, the increase in methane (METH) emissions in the Los Angeles CNG case is only 36 percent. This is due in part to the higher METH emissions in the Los Angeles base case, and in part to the much smaller onroad mobile emissions.

The comparison of the Los Angeles and Baltimore 2020 inventories illustrates the divergence that can occur when uncertain parameters are projected to a far future year. The differences in onroad mobile and refueling emissions for the two cities for the M85 and CNG cases are very large, despite the use of the same M85 and CNG data for both cities and despite the roughly equal VMT in the two domains. These differences in inventory projection assumptions are likely to have a controlling effect on modeling conclusions for the two domains.

The relative changes in the emissions of toxics are summarized in Table 4-14. A rough scale of comparative toxicity relates the relative toxicities of these species to benzene as an arbitrary standard. Relative to benzene, 1,3-butadiene is roughly four times as toxic, while formaldehyde is only 8 percent as toxic and acetaldehyde is only 5 percent as toxic. 
TABLE 4-13b. Speciated emissions (tpd), Los Angeles, 26 August 1987 , projected to 2020 , fuel M85.

\begin{tabular}{|lrrrr|}
\hline Species & $\begin{array}{c}\text { Area and } \\
\text { Low Level Point }\end{array}$ & $\begin{array}{r}\text { Onroad } \\
\text { Mobile }\end{array}$ & $\begin{array}{c}\text { Elevated } \\
\text { Point }\end{array}$ & $\begin{array}{c}\text { Total } \\
\text { Anthropogenic }\end{array}$ \\
\hline NO & 303.52 & 88.09 & 14.74 & 406.35 \\
NO2 & 16.03 & 9.78 & 0.77 & 26.58 \\
NOx & 319.55 & 97.87 & 15.51 & 432.93 \\
OLE & 6.85 & 2.79 & 0.13 & 9.77 \\
PAR & 252.64 & 90.93 & 1.89 & 345.46 \\
TOL & 37.58 & 12.17 & 0.08 & 49.83 \\
XYL & 18.54 & 14.87 & 0.02 & 33.43 \\
FORM & 0.04 & 0.36 & 0.00 & 0.40 \\
ALDX & 1.02 & 0.27 & 0.00 & 1.29 \\
ETH & 13.67 & 2.34 & 0.02 & 16.03 \\
MEOH & 0.02 & 56.95 & 0.00 & 56.97 \\
ETOH & 8.04 & 0.00 & 0.00 & 8.04 \\
ISOP & 0.00 & 0.13 & 0.00 & 0.13 \\
ACET & 0.11 & 0.73 & 0.00 & 0.84 \\
PACET & 0.89 & 0.17 & 0.00 & 1.06 \\
PHCHO & 2.09 & 2.39 & 0.13 & 4.61 \\
IOLE & 0.60 & 3.80 & 0.00 & 4.40 \\
CRES & 0.03 & 0.00 & 0.00 & 0.03 \\
MTBE & 0.31 & 2.00 & 0.00 & 2.31 \\
RHC & 342.43 & 189.93 & 2.29 & 534.65 \\
BENZ & 5.14 & 3.21 & 0.11 & 8.46 \\
BUTA & 0.08 & 0.20 & 0.00 & 0.28 \\
METH & 699.87 & 6.88 & 2.15 & 708.90 \\
THC & 1047.52 & 200.21 & 4.55 & 1252.28 \\
CO & 862.64 & 1155.61 & 12.21 & 2030.46 \\
\hline
\end{tabular}

\section{Specification of Initial and Boundary Concentrations}

Base year initial and boundary concentration files were available for both cities for the episodes modeled. However, for the future year simulations, it was necessary to project the initial and boundary concentrations. Prior UAM model applications have typically used scaling factors based on the ratio of the future year anthropogenic $\mathrm{VOC}$ and $\mathrm{NO}_{\mathrm{x}}$ emissions to the base year anthropogenic VOC and $\mathrm{NO}_{\mathrm{x}}$ emissions (e.g., SCAQMD, 1994). Although evaluation of the effects of fuels is being done for only two cities, it is assumed that the scenarios represent nationwide fuel replacement. Therefore, an impact on the boundary concentrations in each city is expected from the fuel changeover in areas upwind of the modeling domains. For these applications, estimation of the future year boundary concentrations was made in a relatively detailed manner which projected the concentration of each species individually. For each species, the total anthropogenic emissions in the domain in the base and future years was calculated. The ratio of the future year to the base year was then calculated to determine a scaling factor for the concentration of each species. Since some portion of the concentration of a species is not expected to respond to changes in the anthropogenic emissions, a background concentration was subtracted from the boundary concentration prior to scaling. After scaling, the background value was added back in to obtain the final boundary concentration. The background concentrations used in this calculation are presented in Table 4-15. 
TABLE 4-13c. Speciated emissions (tpd), Los Angeles, 26 August 1987 , projected to 2020 , fuel CNG.

\begin{tabular}{|lrrrc|}
\hline Species & $\begin{array}{r}\text { Area and } \\
\text { Low Level Point }\end{array}$ & $\begin{array}{r}\text { Onroad } \\
\text { Mobile }\end{array}$ & $\begin{array}{c}\text { Elevated } \\
\text { Point }\end{array}$ & $\begin{array}{c}\text { Total } \\
\text { Anthropogenic }\end{array}$ \\
\hline NO & 303.52 & 69.16 & 14.74 & 387.42 \\
NO2 & 16.03 & 7.67 & 0.77 & 24.47 \\
NOx & 319.55 & 76.83 & 15.51 & 411.89 \\
OLE & 6.74 & 1.28 & 0.13 & 8.15 \\
PAR & 251.53 & 16.71 & 1.9 & 270.14 \\
TOL & 35.70 & 1.64 & 0.09 & 37.43 \\
XYL & 16.12 & 1.50 & 0.02 & 17.64 \\
FORM & 0.01 & 0.04 & 0 & 0.05 \\
ALDX & 1.00 & 0.10 & 0 & 1.10 \\
ETH & 13.69 & 4.52 & 0.02 & 18.23 \\
MEOH & 0.02 & 0.00 & 0 & 0.02 \\
ETOH & 8.04 & 0.00 & 0 & 8.04 \\
ISOP & 0.00 & 0.04 & 0 & 0.04 \\
ACET & 0.01 & 0.00 & 0 & 0.01 \\
PACET & 0.89 & 0.15 & 0 & 1.04 \\
PHCHO & 2.09 & 0.68 & 0.13 & 2.90 \\
IOLE & 0.18 & 0.12 & 0.01 & 0.31 \\
CRES & 0.03 & 0.00 & 0 & 0.03 \\
MTBE & 0.00 & 0.00 & 0 & 0 \\
RHC & 336.06 & 26.78 & 2.3 & 365.14 \\
BENZ & 4.81 & 0.52 & 0.11 & 5.44 \\
BUTA & 0.08 & 0.16 & 0 & 0.24 \\
METH & 793.62 & 176.27 & 2.15 & 972.04 \\
THC & 1134.58 & 203.74 & 4.56 & 1342.88 \\
CO & 862.64 & 1044.37 & 12.21 & 1919.22 \\
\hline
\end{tabular}

TABLE 4-14. Percent change in emissions of toxic species due to fuel substitution relative to RFG.

\begin{tabular}{|llllrlll|}
\hline & & & & & & Precursors to \\
& Fuel & BENZ & BUTA & PHCHO & PACET & Secondary & METH \\
\hline Baltimore & & & & & & & \\
Onroad Mobile & M85 & -55 & -77 & 600 & -31 & lower & \\
Total & CNG & -92 & -86 & 30 & -54 & lower & \\
& M85 & -16 & -18 & 136 & & & $360^{*}$ \\
Los Angeles & CNG & -32 & -20 & 7 & & & \\
Onroad Mobile & M85 & -37 & -62 & 400 & -21 & lower & \\
& CNG & -92 & -70 & 17 & -37 & lower & \\
Total & M85 & -20 & -55 & 86 & & & 36 \\
& CNG & -53 & -61 & 3 & & & \\
\hline
\end{tabular}

$2 / 3$ due to mobile sources, $1 / 3$ due to distribution.

Factors for non-emitted species were set to 1.0 with the exception of ozone. Since ozone is a product species resulting from the interaction of $\mathrm{VOC}$ and $\mathrm{NO}_{\mathrm{x}}$, the factor for ozone was calculated from the average $\mathrm{NO}_{\mathrm{x}}$ and VOC factors $\left(\mathrm{F}_{\mathrm{NOX}}\right.$ and $\left.\mathrm{F}_{\mathrm{VOC}}\right)$ as follows:

$$
\mathrm{F}_{\mathrm{O} 3}=\mathrm{SQRT}\left(\mathrm{F}_{\mathrm{NOX}} \cdot \mathrm{F}_{\mathrm{VOC}}\right)
$$


The individual factors used in the projection of initial and boundary concentrations for each species are shown in Table 4-15.

TABLE 4-15. Background concentrations and scaling factors for future year conditions for Los Angeles and Baltimore (concentrations in ppm)

\begin{tabular}{|c|c|c|c|c|c|c|c|c|}
\hline \multirow[b]{2}{*}{ Species } & \multicolumn{4}{|c|}{ Los Angeles } & \multicolumn{4}{|c|}{ Baltimore } \\
\hline & $\begin{array}{l}\text { Background } \\
\text { Concentration }\end{array}$ & $\begin{array}{c}\text { RFG } \\
\text { Factor }\end{array}$ & $\begin{array}{c}\text { M85 } \\
\text { Factor }\end{array}$ & $\begin{array}{c}\text { CNG } \\
\text { Factor }\end{array}$ & $\begin{array}{l}\text { Background } \\
\text { Concentration }\end{array}$ & $\begin{array}{l}\text { RFG } \\
\text { Factor }\end{array}$ & $\begin{array}{l}\text { M85 } \\
\text { Factor }\end{array}$ & $\begin{array}{l}\mathrm{CNG} \\
\text { Factor }\end{array}$ \\
\hline NO & 0.00025 & 0.29 & 0.29 & 0.28 & 0.0005 & 0.95 & 1.00 & 0.76 \\
\hline $\mathrm{NO} 2$ & 0.0005 & 0.23 & 0.24 & 0.22 & 0.0015 & 0.95 & 1.00 & 0.76 \\
\hline $\mathrm{O} 3$ & 0.04 & 0.24 & 0.25 & 0.21 & 0.04 & 0.81 & 0.81 & 0.61 \\
\hline OLE & 0.00055 & 0.13 & 0.1 & 0.09 & 0.0003 & 0.87 & 0.80 & 0.71 \\
\hline PAR & 0.0062 & 0.2 & 0.19 & 0.15 & 0.015 & 0.61 & 0.55 & 0.42 \\
\hline TOL & $9.14 \mathrm{E}-05$ & 0.21 & 0.19 & 0.12 & 0.0002 & 0.76 & 0.65 & 0.50 \\
\hline $\mathrm{XYL}$ & $4.00 \mathrm{E}-05$ & 0.23 & 0.21 & 0.09 & 0.0001 & 0.96 & 0.76 & 0.49 \\
\hline FORM & 0.0005 & 0.2 & 0.21 & 0.14 & 0.0005 & 0.67 & 0.66 & 0.05 \\
\hline ETH & 0.00011 & 0.14 & 0.12 & 0.14 & 0.0005 & 0.69 & 0.58 & 0.67 \\
\hline CRES & $1.00 \mathrm{E}-05$ & 1.00 & 1.00 & 1.00 & $1.00 \mathrm{E}-05$ & 1.00 & 1.00 & 1.00 \\
\hline MGLY & $1.00 \mathrm{E}-05$ & 1.00 & 1.00 & 1.00 & $1.00 \mathrm{E}-05$ & 1.00 & 1.00 & 1.00 \\
\hline OPEN & $1.00 \mathrm{E}-05$ & 1.00 & 1.00 & 1.00 & $1.00 \mathrm{E}-05$ & 1.00 & 1.00 & 1.00 \\
\hline PNA & $1.00 \mathrm{E}-05$ & 1.00 & 1.00 & 1.00 & $1.00 \mathrm{E}-05$ & 1.00 & 1.00 & 1.00 \\
\hline NXOY & $1.00 \mathrm{E}-05$ & 1.00 & 1.00 & 1.00 & $1.00 \mathrm{E}-05$ & 1.00 & 1.00 & 1.00 \\
\hline NO3 & $1.00 \mathrm{E}-05$ & 1.00 & 1.00 & 1.00 & $1.00 \mathrm{E}-05$ & 1.00 & 1.00 & 1.00 \\
\hline PAN & $1.00 \mathrm{E}-05$ & 1.00 & 1.00 & 1.00 & $1.00 \mathrm{E}-05$ & 1.00 & 1.00 & 1.00 \\
\hline $\mathrm{CO}$ & 0.2 & 0.2 & 0.29 & 0.26 & 0.12 & 0.64 & 0.62 & 0.58 \\
\hline HONO & $1.0 E-05$ & 1.00 & 1.00 & 1.00 & $1.00 \mathrm{E}-05$ & 1.00 & 1.00 & 1.00 \\
\hline $\mathrm{H} 2 \mathrm{O} 2$ & $1.0 \mathrm{E}-05$ & 1.00 & 1.00 & 1.00 & $1.00 \mathrm{E}-05$ & 1.00 & 1.00 & 1.00 \\
\hline HNO3 & $1.0 \mathrm{E}-05$ & 1.00 & 1.00 & 1.00 & $1.00 \mathrm{E}-05$ & 1.00 & 1.00 & 1.00 \\
\hline $\mathrm{MEOH}$ & $1.0 \mathrm{E}-05$ & 0.01 & 28.36 & 0.01 & $1.00 \mathrm{E}-05$ & 0.10 & 1.00 & 0.10 \\
\hline ETOH & $1.0 \mathrm{E}-05$ & 0.33 & 0.33 & 0.33 & $1.00 \mathrm{E}-05$ & 1.00 & 1.00 & 1.00 \\
\hline ISOP & 0.0001 & 0.12 & 0.04 & 0.04 & $1.00 \mathrm{E}-05$ & 1.00 & 1.00 & 0.49 \\
\hline BENZ & 0.0002 & 0.14 & 0.11 & 0.06 & 0.0002 & 0.64 & 0.52 & 0.41 \\
\hline IOLE & 0.0001 & 0.14 & 0.1 & 0.01 & 0.0001 & 0.68 & 0.59 & 0.19 \\
\hline BUTA & $1.00 \mathrm{E}-05$ & 0.07 & 0.03 & 0.03 & $1.00 \mathrm{E}-05$ & 0.93 & 0.76 & 0.74 \\
\hline PANX & $1.00 \mathrm{E}-05$ & 1.00 & 1.00 & 1.00 & $1.00 \mathrm{E}-05$ & 1.00 & 1.00 & 1.00 \\
\hline $\mathrm{PHCHO}$ & 0.0001 & 0.16 & 0.31 & 0.17 & 0.0001 & 0.63 & 1.59 & 0.67 \\
\hline ACET & 0.0005 & 0.2 & 0.21 & 0.14 & 0.0005 & 0.67 & 0.66 & 0.10 \\
\hline PACET & 0.0001 & 0.16 & 0.15 & 0.15 & 0.0001 & 0.66 & 0.59 & 0.58 \\
\hline ALDX & 0.0005 & 0.19 & 0.18 & 0.15 & 0.0005 & 0.62 & 0.56 & 0.51 \\
\hline METH & $1.00 \mathrm{E}-05$ & 1.38 & 1.38 & 1.38 & 1.75 & 1.38 & 1.00 & 1.38 \\
\hline
\end{tabular}




\section{MODELING RESULTS}

\section{DIFFERENCES BETWEEN AIR QUALITY IMPACTS OF FUELS}

The effects of the different fuels in the two cities in the simulated future year can be compared in terms of their impacts on the distributions of a variety of chemical species in the simulated atmosphere. For the purposes of this study we will concentrate on ozone and mobile source toxics most likely to be affected by alternative fuel use. We first compare the changes in atmospheric impacts among fuels for the two cities, and then summarize the overall impacts for each fuel. In the tables "NoGV" refers to the run with gasoline vehicle (GV) emissions removed.

\section{Ozone}

All three fuels contribute to substantial reductions in peak ozone concentrations for Los Angeles, although much of the reduction is undoubtedly due to the other emission reductions incorporated in the SCAQMD inventory. Table 5-1 compares the daily ozone maximum for the base and fuel runs.

TABLE 5-1. Simulated daily maximum ozone for Los Angeles (ppb).

\begin{tabular}{|lcc|}
\hline & 27 August & 28 August \\
\hline NoGV & 103 & 101 \\
RFG & 115 & 116 \\
M85 & 114 & 114 \\
CNG & 104 & 102 \\
\hline 1987 & 269 & 302 \\
\hline
\end{tabular}

The peak values for RFG and M85 are nearly identical; however, the M85 run has generally lower ozone maxima in the urban core, as shown on the difference plot in Figure 5-1 (figures begin on page 5-9). The difference here is between the M85 and RFG surface ozone maxima for 28 August. Dashed contours are negative, showing areas in which RFG produced higher ozone. The differences are approximately 2 to $3 \mathrm{ppb}$ at most. The CNG simulation has notably lower peak values on both days and has substantially lower ozone maxima throughout the domain, as may be seen in Figure 5-2. In the CNG case the differences with respect to the RFG case exceed $30 \mathrm{ppb}$ in the center of the basin.

In Baltimore the reduction of ozone for the M85 fuel below the concentrations seen with RFG is more clearly illustrated. The simulation of the Baltimore/Washington domain exhibits two peaks, one located near Baltimore and one further south near Washington, D.C.

Regardless of which location is examined, the peak values are nearly identical (Table 5-2), but on a broad areal basis the concentrations in the M85 run are clearly lower (Figure 5-3). 
TABLE 5-2. Simulated daily maximum ozone for

Baltimore $(\mathrm{ppb}){ }^{*}$

\begin{tabular}{|lll|}
\hline & 5 July & 6 July \\
\hline NoGV & $131(124)$ & $138(147)$ \\
RFG & $134(138)$ & $145(162)$ \\
M85 & $130(134)$ & $137(163)$ \\
CNG & $120(123)$ & $128(147)$ \\
\hline 1988 & $172(162)$ & $208(207)$ \\
\hline
\end{tabular}

* Baltimore (northern) peak followed by Washington (southern) peak in parentheses.

On 6 July, after a full day of spin-up, we see that ozone increases for the M85 case (relative to the RFG case) in the immediate metropolitan DC area and to the south. The increase is 1 $\mathrm{ppb}$ or less. Throughout the urban plume extending north and east, including all of Baltimore, rural Maryland, and the Chesapeake Bay region, ozone maxima decrease. The greatest decrease in the ozone maxima is $21.5 \mathrm{ppb}$.

Ozone in the CNG run is again substantially lower than in the RFG and M85 runs, both in terms of the peak value and in terms of the broad distribution (Figure 5-4). Note that the removal of the light-duty gasoline vehicle emissions includes $\mathrm{NO}_{\mathrm{x}}$ and $\mathrm{CO}$ emissions as well as hydrocarbons. As a consequence, the overall ozone formation potential for emissions from nonmobile sources may be altered. This is the reason that the 5 July peak ozone in Baltimore is higher with all GV emissions removed than with CNG fuel.

A reduction in ozone in the CNG simulation relative to the RFG simulation appears in the northwestern corner of the modeling domain in Figure 5-4. Although detailed analyses of this particular part of the domain have not been undertaken, this reduction is probably due to changes in the boundary concentrations between the RFG simulations and the CNG simulations. As described elsewhere, the boundary concentrations for each of the future year scenarios were derived by scaling from the base year concentrations based on the anthropogenic emissions present in the inventory for each of the scenarios. Since the CNG scenario includes lower levels of ozone precursors in the inventory than the RFG scenario, the scaling of the boundary concentrations will results in lower boundary concentrations for the CNG scenario than for the RFG scenario.

In general, then, CNG produces the greatest reduction in ozone of the three fuels in both Los Angeles and Baltimore. RFG and M85 show ozone decreases of about the same magnitude with respect to peak ozone maxima in the base case. On a broad scale, M85 appears to be slightly (Los Angeles) to significantly (Baltimore region) more effective than RFG in reducing ozone maxima, but substantially less effective than CNG.

While the peak value of the hourly ozone maxima is often used as a standard of comparison of ozone effects in air quality modeling, this single number does not capture any of the broadscale changes between model simulations. Other measures, which can quantify these larger scale differences in ozone distributions, are based on areal exposure and areal coverage above some threshold value. Areal exposure is defined as the product of the area in each cell times the surface ozone concentration in the cell summed over the day. Areal coverage above, say, $120 \mathrm{ppb}$ is the total area of all cells in each hour which experience a surface ozone 
concentration above $120 \mathrm{ppb}$ (hourly average) summed over the day. Table 5-3 shows a comparison of the values obtained for these measures for the three fuels and two cities. These results emphasize the dramatic difference in broad-scale ozone exposure between the CNG simulation and the other two fuels for ozone above a threshold value. In some sense the total ozone integrated over an entire domain is not very different among the three runs (and very similar for RFG and M85), but the extent of the area experiencing very high ozone concentrations is substantially less for the $\mathrm{CNG}$ simulation.

TABLE 5-3. Ozone areal exposure.

\begin{tabular}{|lrrrr|}
\hline & RFG & \multicolumn{1}{c}{ M85 } & \multicolumn{1}{c}{ CNG } & \multicolumn{1}{c|}{ NoGV } \\
\hline Baltimore (6 July) & & & & \\
Areal Exposure $\left(10^{4} \mathrm{ppm}-\mathrm{hr}-\mathrm{km}^{2}\right)$ & 7.45 & 7.41 & 6.90 & 7.21 \\
Area above $120 \mathrm{ppb}\left(10^{3} \mathrm{hr}-\mathrm{km}^{2}\right)$ & 12.48 & 10.50 & 5.30 & 5.45 \\
Los Angeles (28 August) & & & & \\
Areal Exposure $\left(10^{4} \mathrm{ppm}-\mathrm{hr}^{2} \mathrm{~km}^{2}\right)$ & 6.40 & 6.40 & 6.02 & 6.25 \\
Area above $90 \mathrm{ppb}\left(10^{3} \mathrm{hr}-\mathrm{km}^{2}\right)$ & 7.83 & 7.38 & 1.18 & 1.60 \\
\hline
\end{tabular}

$\mathrm{NO}_{2}$

Maximum surface concentrations of $\mathrm{NO}_{2}$ are not significantly different between $\mathrm{RFG}$ and M85 in either city. The $\mathrm{NO}_{2}$ values for Los Angeles are slightly higher for M85 than for $\mathrm{RFG}$, indicating a slightly longer $\mathrm{NO}_{\mathrm{x}}$ lifetime, but the effect does not appear to change the distribution significantly.

For CNG the response of $\mathrm{NO}_{2}$ is somewhat complex, as shown in Figures 5-5 and 5-6. These figures show the differences in peak $\mathrm{NO}_{2}$ concentrations between the $\mathrm{CNG}$ and $\mathrm{RFG}$ runs on the second day in each city. In general the $\mathrm{CNG}$ runs have lower $\mathrm{NO}_{2}$ values, but local effects near large point sources in the Los Angeles run can lead to $\mathrm{NO}_{2}$ increases. This illustrates the difficulty of predicting fuel effects on $\mathrm{NO}_{2}$ because of the competing photochemical influences on the balance between $\mathrm{NO}$ and $\mathrm{NO}_{2}$ and on the removal rate for $\mathrm{NO}_{2}$ by conversion to $\mathrm{HNO}_{3}$ and $\mathrm{PAN}$.

\section{Formaldehyde}

Use of M85 appears to generate slightly more formaldehyde than does use of RFG, while use of CNG generates slightly less. The model tracks both primary and secondary formaldehyde, and in both cities the secondary production greatly exceeds the primary. However, the comparison of the future year with the base case differs greatly between cities. Table 5-4 shows the maximum values obtained in the Los Angeles simulations, and Table 5-5 shows the maximum values obtained in the Baltimore simulations.

There is a large reduction between the base year and the future year for RFG, M85, and CNG in the Los Angeles simulation, whereas in Baltimore there is essentially no change from the base year to the future year for RFG and M85, and a relatively small change with CNG. This difference reflects the differing assumptions as to the efficacy of future-year emission controls applied in the two jurisdictions. These assumptions are built into the underlying inventories to which our fuel-specific modifications were applied. Note also that on 5 July in the 
TABLE 5-4. Simulated Los Angeles total formaldehyde concentrations (ppb).

\begin{tabular}{|lcc|}
\hline & 27 August & 28 August \\
\hline NoGV & 4.0 & 5.0 \\
RFG & 4.2 & 5.3 \\
M85 & 4.3 & 5.4 \\
CNG & 3.9 & 4.7 \\
\hline 1987 & 13.5 & 17.5 \\
\hline
\end{tabular}

TABLE 5-5. Simulated Baltimore total formaldehyde concentrations (ppb).

\begin{tabular}{|lcc|}
\hline & 5 July & 6 July \\
\hline NoGV & 7.4 & 15.7 \\
RFG & 7.5 & 17.3 \\
M85 & 7.6 & 17.5 \\
CNG & 7.3 & 16.2 \\
\hline 1988 & 7.6 & 17.5 \\
\hline
\end{tabular}

Baltimore runs the peak is associated with a strong point source just south of the Delaware border (Figure 5-7). The peaks on 6 July are in the DC metropolitan area and are clearly associated with secondary formaldehyde.

However, even though the base vs. future differences are very different in the two cities, the differences among fuels are consistent. The difference between RFG and M85 is small, with M85 leading to slightly higher formaldehyde maxima. CNG produces lower formaldehyde concentrations than either RFG or M85.

\section{Acetaldehyde}

In Los Angeles, acetaldehyde is almost entirely secondary. Table 5-6 shows the differences in peak levels of daily average total acetaldehyde. Overall the peak values are strongly reduced from the base year to the future year. The fuels produce similar results, but M85 produces slightly lower acetaldehyde peaks than does RFG while CNG produces lower values than does $\mathrm{M} 85$.

TABLE 5-6. Simulated Los Angeles maximum acetaldehyde concentrations (ppb).

\begin{tabular}{|lcc|}
\hline & 27 August & 28 August \\
\hline NoGV & 2.2 & 3.0 \\
RFG & 2.5 & 3.3 \\
M85 & 2.4 & 3.2 \\
CNG & 2.2 & 2.9 \\
\hline 1987 & 9.0 & 13.3 \\
\hline
\end{tabular}


In Baltimore the reduction from the base year to the future year is much less, and there is very little difference between RFG and M85, while CNG reduces acetaldehyde more than the other fuels. The peak values are shown in Table 5-7.

TABLE 5-7. Simulated Baltimore maximum acetaldehyde concentrations ( $\mathrm{ppb}$ ).

\begin{tabular}{|lcc|}
\hline & 5 July & 6 July \\
\hline NoGV & 2.8 & 4.3 \\
RFG & 3.3 & 4.7 \\
M85 & 3.3 & 4.7 \\
CNG & 2.9 & 4.4 \\
\hline 1988 & 4.8 & 6.9 \\
\hline
\end{tabular}

Comparison of panels $\mathrm{a}$ and $\mathrm{b}$ of Figure 5-8 shows that the identical peak values are occurring in the same location for the RFG and M85 fuel simulations. There are no significant primary acetaldehyde peaks near the concentration peak, so the fuels do appear to be identical by this measure. In the downplume region north and east of the peak, the maxima are slightly lower for M85 than for RFG. The CNG peak also occurs in the same location (panel c), and the reduction in downplume acetaldehyde is proportionally greater than that of the peak value as compared to the RFG run.

\section{Benzene}

As with formaldehyde and acetaldehyde, benzene maxima are much more strongly reduced in the future for the Los Angeles simulation than for the Baltimore simulation. Table 5-8 illustrates the peak values seen in the Los Angeles simulations.

TABLE 5-8. Simulated Los Angeles maximum benzene concentrations (ppb).

\begin{tabular}{|lcc|}
\hline & 27 August & 28 August \\
\hline NoGV & 0.3 & 0.3 \\
RFG & 0.4 & 0.6 \\
M85 & 0.3 & 0.4 \\
CNG & 0.5 & 0.6 \\
\hline I987 & 5.3 & 7.5 \\
\hline
\end{tabular}

The use of M85 appears slightly more effective than RFG in reducing benzene, but both fuels show substantial reductions compared to the base case. It is likely that the peak benzene values in the future-year fuel runs are indicative of weak nonmobile sources and the assumed boundary conditions, since the maxima are well removed from the core urban area, and the overall concentrations are lower in the center of the domain than along the boundaries (see Figure 5-9). 
In Baltimore the analysis is complicated by the presence of several large point sources of benzene. These point sources determine the maximum values in the simulations, which are thus not sensitive to fuel differences. Instead of domain-wide maximum values, then, Table 5-9 compares the highest concentrations seen in the DC and Baltimore metro areas on 6 July. These areas are dominated by motor vehicle emissions.

TABLE 5-9. Simulated Baltimore/DC urban area highest benzene concentrations (ppb).

\begin{tabular}{|lcc|}
\hline & D.C. & Baltimore \\
\hline NoGV & 0.7 & 1.0 \\
RFG & 1.6 & 1.3 \\
M85 & 1.0 & 1.1 \\
CNG & 0.5 & 0.8 \\
\hline 1988 & 3.0 & 2.6 \\
\hline
\end{tabular}

Thus in urban areas of the Baltimore domain, $\mathrm{CNG}$ reduces benzene concentrations more effectively than either M85 or RFG, and M85 leads to lower concentrations than does RFG by about 15-40 percent of the RFG-vs.-base differential. The relative effects of these fuels on benzene concentrations in a far future year appears to vary between the Los Angeles cases, and among cities within the Baltimore domain. They also may vary from day to day in the Baltimore domain, although we do not present results for the 5 July spinup day.

\section{1,3-Butadiene}

As in the case of benzene, 1,3-butadiene (butadiene hereafter) is much reduced for the future year compared to the base year in Los Angeles for all three fuels. Table 5-10 illustrates the reduction, which is more than a factor of 20 on 28 August.

TABLE 5-10. Simulated Los Angeles maximum butadiene concentrations (ppb).

\begin{tabular}{|lcc|}
\hline & 27 August & 28 August \\
\hline NoGV & 0.04 & 0.03 \\
RFG & 0.04 & 0.04 \\
M85 & 0.04 & 0.03 \\
CNG & 0.04 & 0.03 \\
\hline 1987 & 0.7 & 0.9 \\
\hline
\end{tabular}

Note that there may be essentially no butadiene from mobile sources in the future-year runs. There are no contours above 0.05 in any of these runs, and the peak is consistently in the same location off the coast near Santa Barbara. This may indicate that an offshore point source, possibly associated with petroleum operations, is the only remaining significant source in the inventories. 
In Baltimore the reduction in butadiene for the future year is much less than in Los Angeles. As in the case of benzene, there are large point sources in this domain, which determine the peak values of the maxima and are insensitive to fuel changes. We adopt the same alternative for Table 5-11 as was used for benzene, listing the maximum concentrations seen in the DC and Baltimore metropolitan areas on 6 July.

TABLE 5-11. Simulated Baltimore/DC urban area maximum butadiene concentrations (ppb).

\begin{tabular}{|lcc|}
\hline & D.C. & Baltimore \\
\hline NoGV & 0.1 & 0.2 \\
RFG & 0.2 & 0.2 \\
M85 & 0.1 & 0.2 \\
CNG & 0.1 & 0.1 \\
\hline 1988 & 0.3 & 0.3 \\
\hline
\end{tabular}

In the Baltimore domain $\mathrm{RFG}, \mathrm{M} 85$, and $\mathrm{CNG}$ all reduce butadiene maxima in the urban areas for the future year, but the fractional reductions with respect to the base year are much less than were observed in the Los Angeles simulations. The reductions obtained with M85 are greater than those obtained with RFG; the fuel differential is at least as great as the differential between the future-year RFG case and the base case in DC. The reduction for CNG is comparable to that with M85 in DC and greater than that with M85 in metropolitan Baltimore. Because of the imprecision of this comparison of urban areas and the day-to-day variability, the butadiene level in the CNG run is perhaps best described as being comparable to or less than that in the M85 run in core urban areas.

\section{SUMMARY OF FUEL EFFECTS}

The overall results of this study indicate that in both Los Angeles and Baltimore substitution of $\mathrm{CNG}$ for what is expected to be a typical reformulated gasoline (by the California and Federal definitions, respectively) in a far future year can be expected to reduce peak ozone levels and the average daily concentrations of the mobile source toxics formaldehyde, acetaldehyde, benzene, and 1,3-butadiene. The conclusion as to the likely reduction of benzene is weakened by the Los Angeles results, which show essentially no change with respect to a future RFG scenario (but see below).

Substitution of M85 for the reformulated gasolines can be expected to reduce ozone somewhat over broad areas, especially in suburban and outlying areas, but may have little effect on the magnitude of the highest ozone maxima in urban cores. Substitution of M85 for RFG can be expected to increase formaldehyde levels slightly, while lowering daily average concentrations of acetaldehyde very slightly, again primarily outside urban cores.

Substitution of M85 for RFG is likely to reduce daily average concentrations of both benzene and 1,3-butadiene, but this conclusion is based primarily on the Baltimore modeling results.

The Los Angeles control strategies assumed in the South Coast Air Quality Management District Air Quality Management Plan for 2010, as projected to 2020, reduce the overall levels of modeled mobile source air toxics to the point where the differentials between fuels may not be significant. The directions of the differentials in the mobile source toxics 
concentrations are consistent with the results of the Baltimore simulations, but the relative magnitudes of the fuel differentials are very small compared to the change between the base year and the future-year RFG case.

Because these runs represent highly hypothetical future-year scenarios, with complete substitution of each fuel for the projected base gasoline usage, the specific levels seen in any of these air quality metrics should in no sense be interpreted as predictions of achievable conditions in 2020. A more useful interpretation can be made by comparing the differences in these metrics between the alternative fuels. 


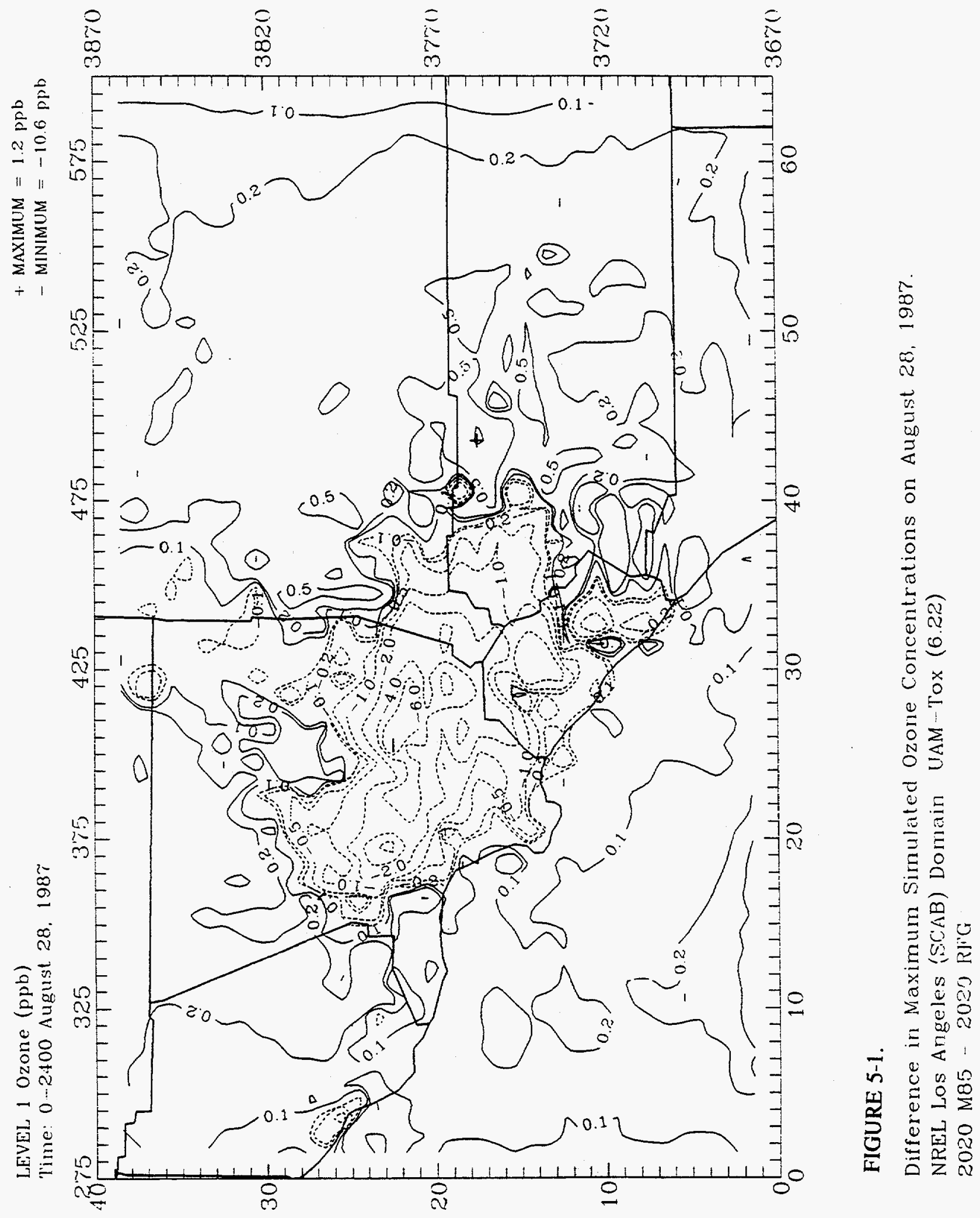




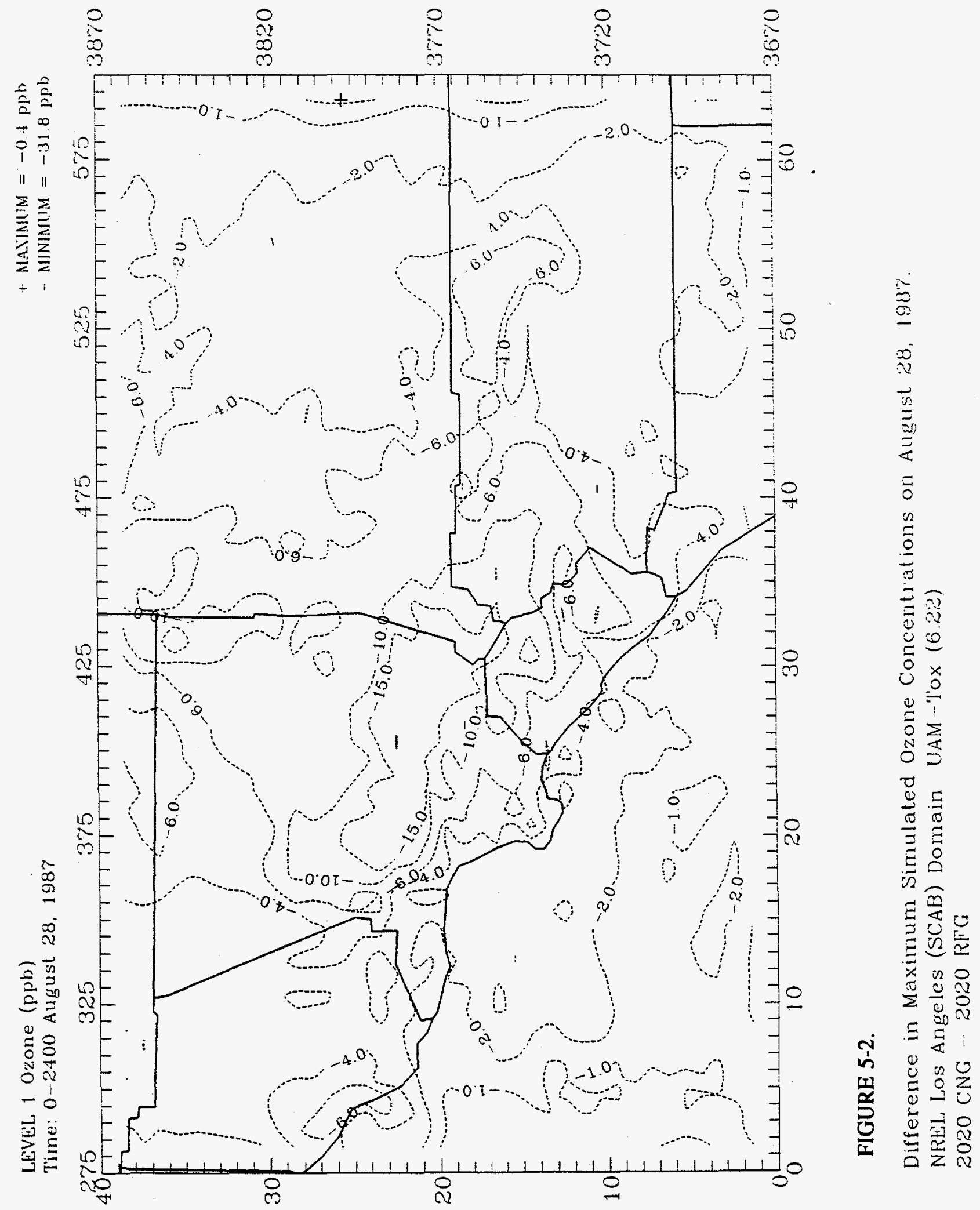


LEVEL 1 Ozone (ppb)

Time: $0-2400$ July 6,1988
+ MAXIMUM $=1.0 \mathrm{ppb}$

- MINIMUM $=-21.5 \mathrm{ppb}$

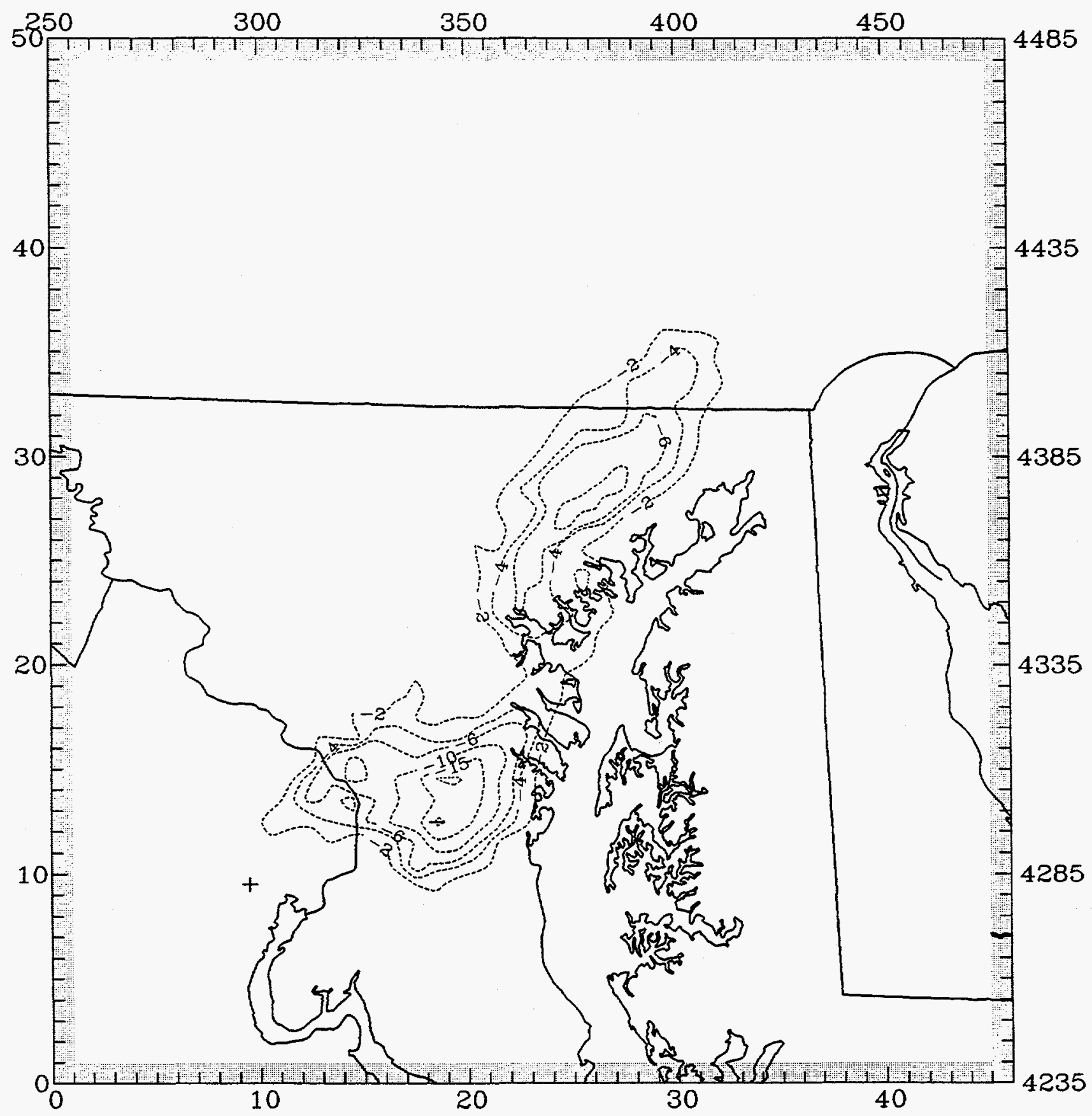

FIGURE 5-3.

Difference in Maximum Simulated Ozone Concentrations on July 6, 1988.

NREL Baltimore Domain UAM-Tox (6.22)

2020 M85 - 2020 RFG 
LEVEL 1 Ozone (ppb)

Time $0-2400$ July 6,1988
- MANMUM $=-2.7 \mathrm{ppb}$

- MINLMLM $=-289 \mathrm{ppb}$

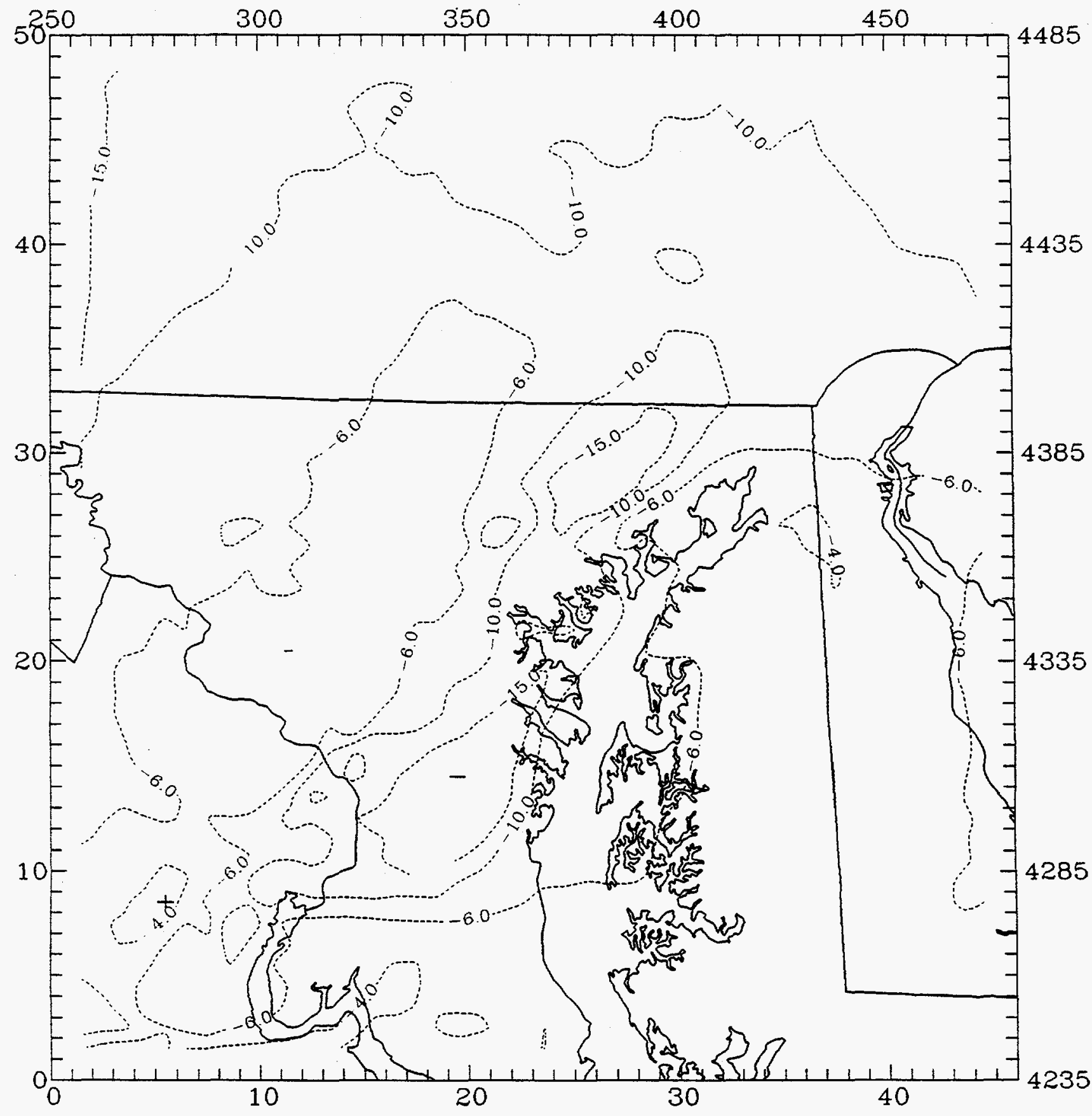

FIGURE 5-4.

Difference in Maximum Simulated Ozone Concentrations on July 6, 1988. NREL Baltimore Domain UAM-Tox (6.22) $2020 \mathrm{CNG}$ - $2020 \mathrm{RFG}$ 

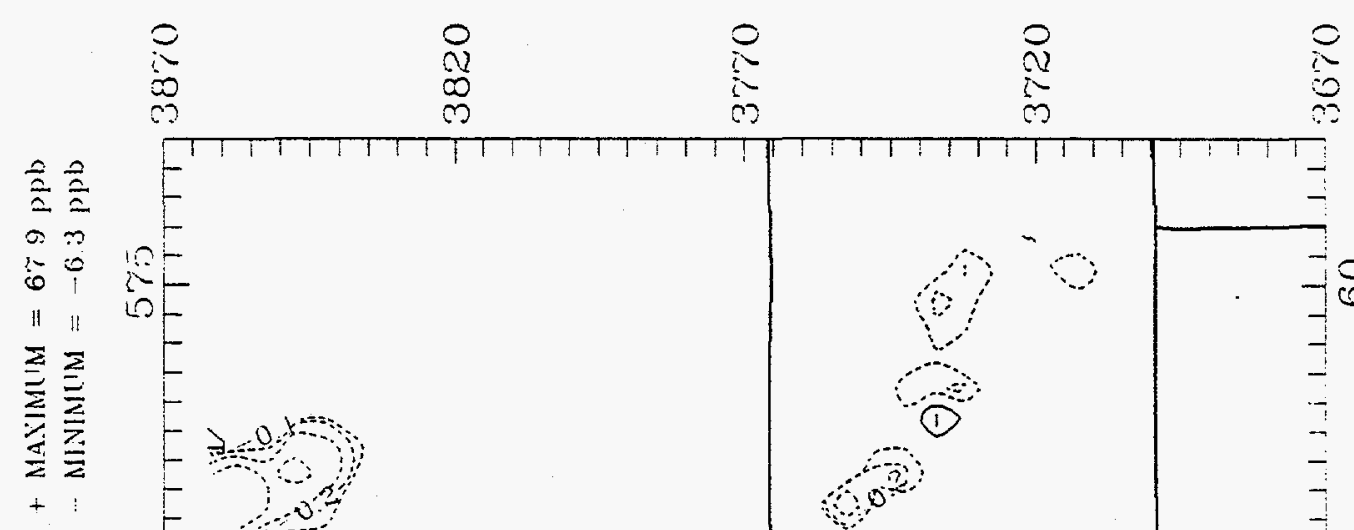

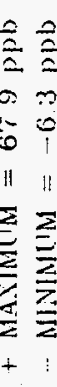

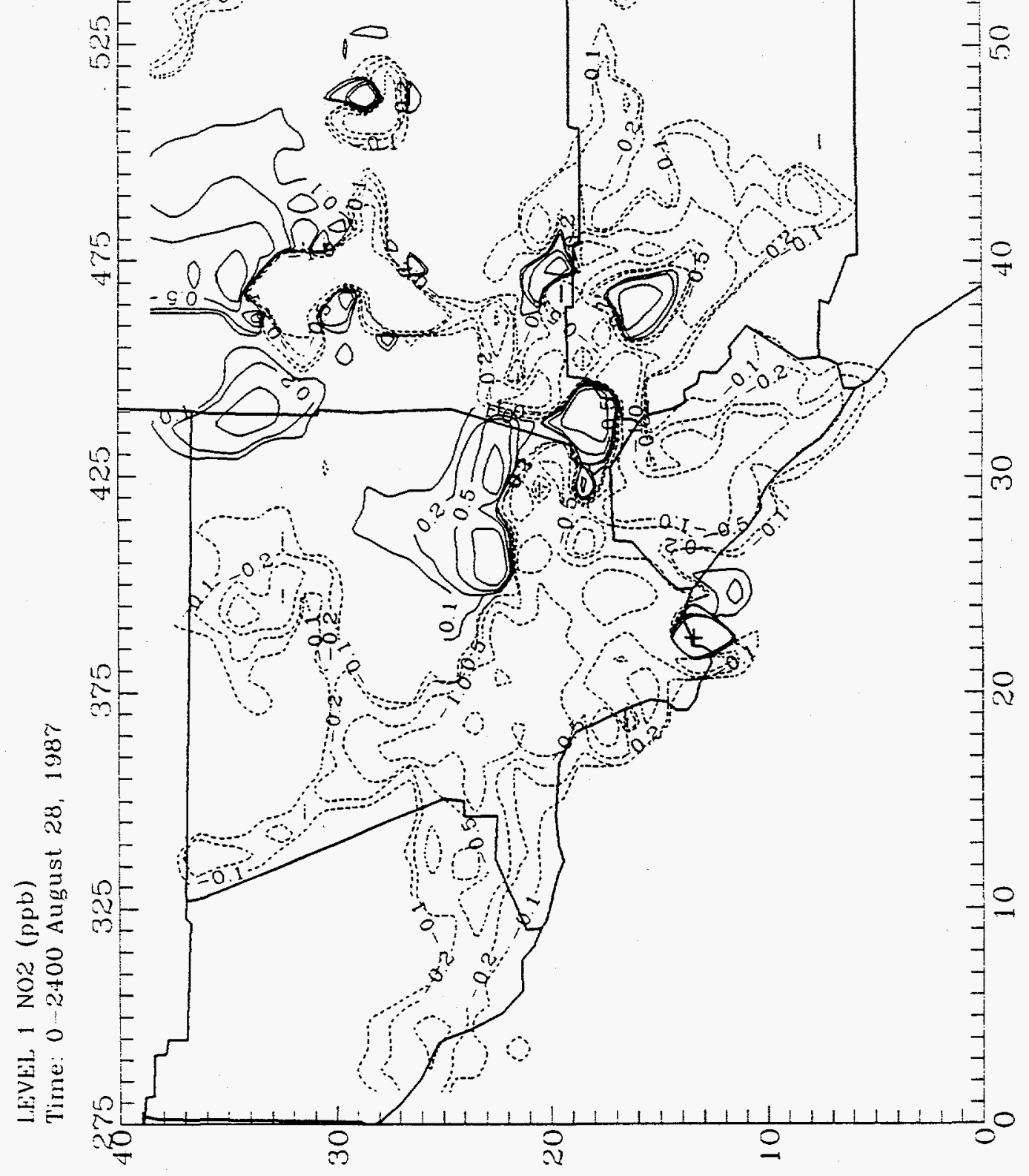

0
0
0
0
0
3
3
$=$
0
0

$\stackrel{3}{0}$

동

$=0$

$\stackrel{0}{0}$

合这

Z

离

ह

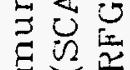

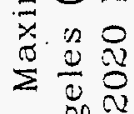

म. $\Xi \pm:$

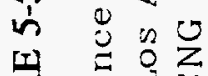

인

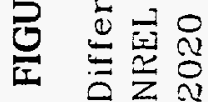


LEVEL 1 NO2 (ppb)

Time $0-2400$ july 6,1988
- MANIMLM $=0.8 \mathrm{ppb}$

- MINMLM $=-12.4 \mathrm{ppb}$

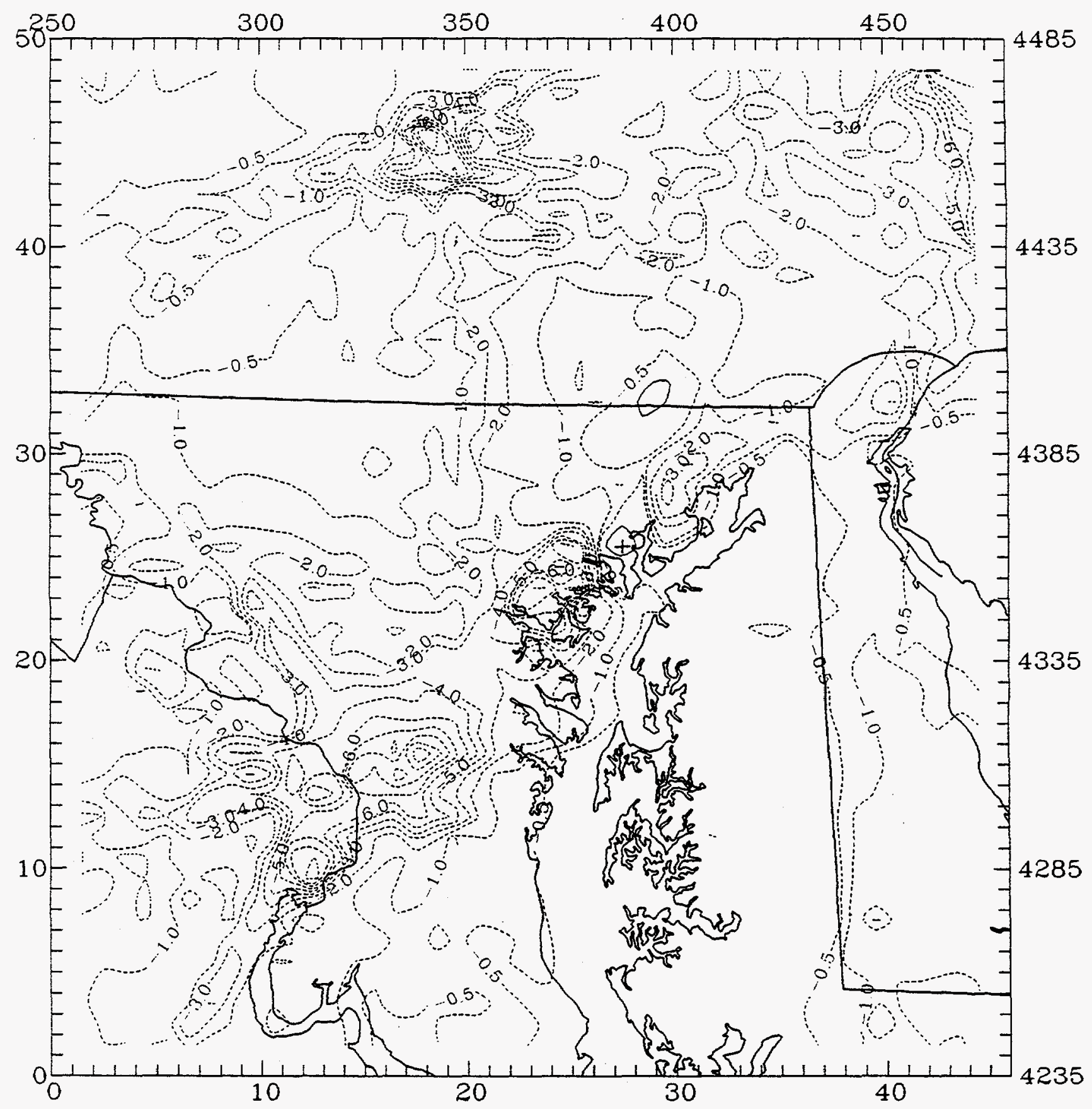

FIGURE 5-6.

Difference in Maximum Simulated NO2 Concentrations on July 6, 1988. NREL Baltimore Domain UAM-Tox (6.22) $2020 \mathrm{CNG}-2020 \mathrm{RFG}$ 
LEVEL 1 TFORM (ppb)

Time: 0-2400 July 6. 1988
+ MAXIMUM $=17.5 \mathrm{ppb}$

- MINIMUM $=1.3 \mathrm{ppb}$

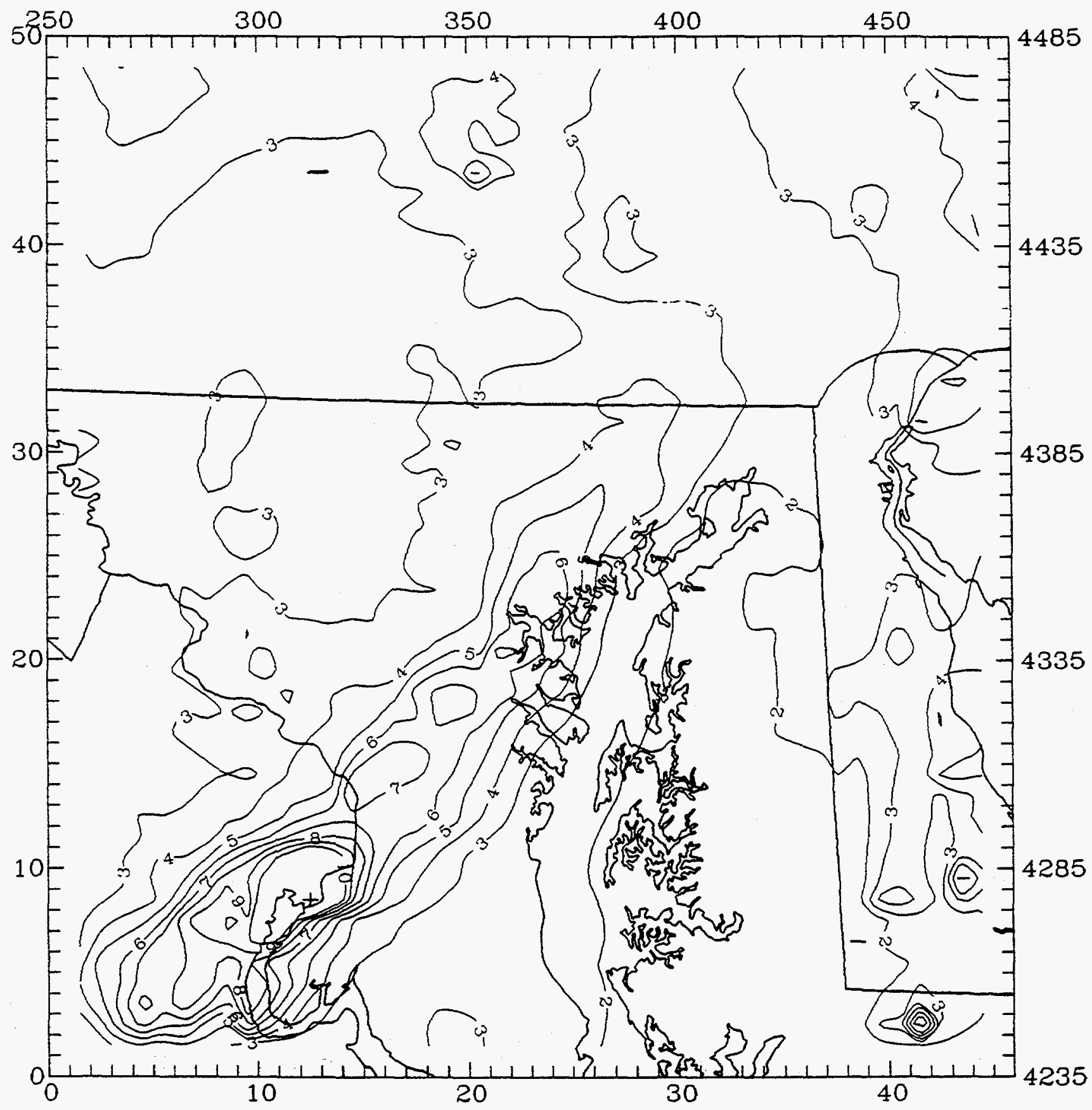

FIGURE 5-7.

Daily Average Total Formaldehyde Concentrations on July 6, 1988.

Baltimore Domain UAM-Tox (6.22)

$2020 \mathrm{M} 85$ 
LEVEL 1 TACET (ppb)

Time: $0-2400$ July 6,1988

$+\mathrm{MAXIMUM}=4.7 \mathrm{ppb}$

- MINIMUM $=0.4 \mathrm{ppD}$

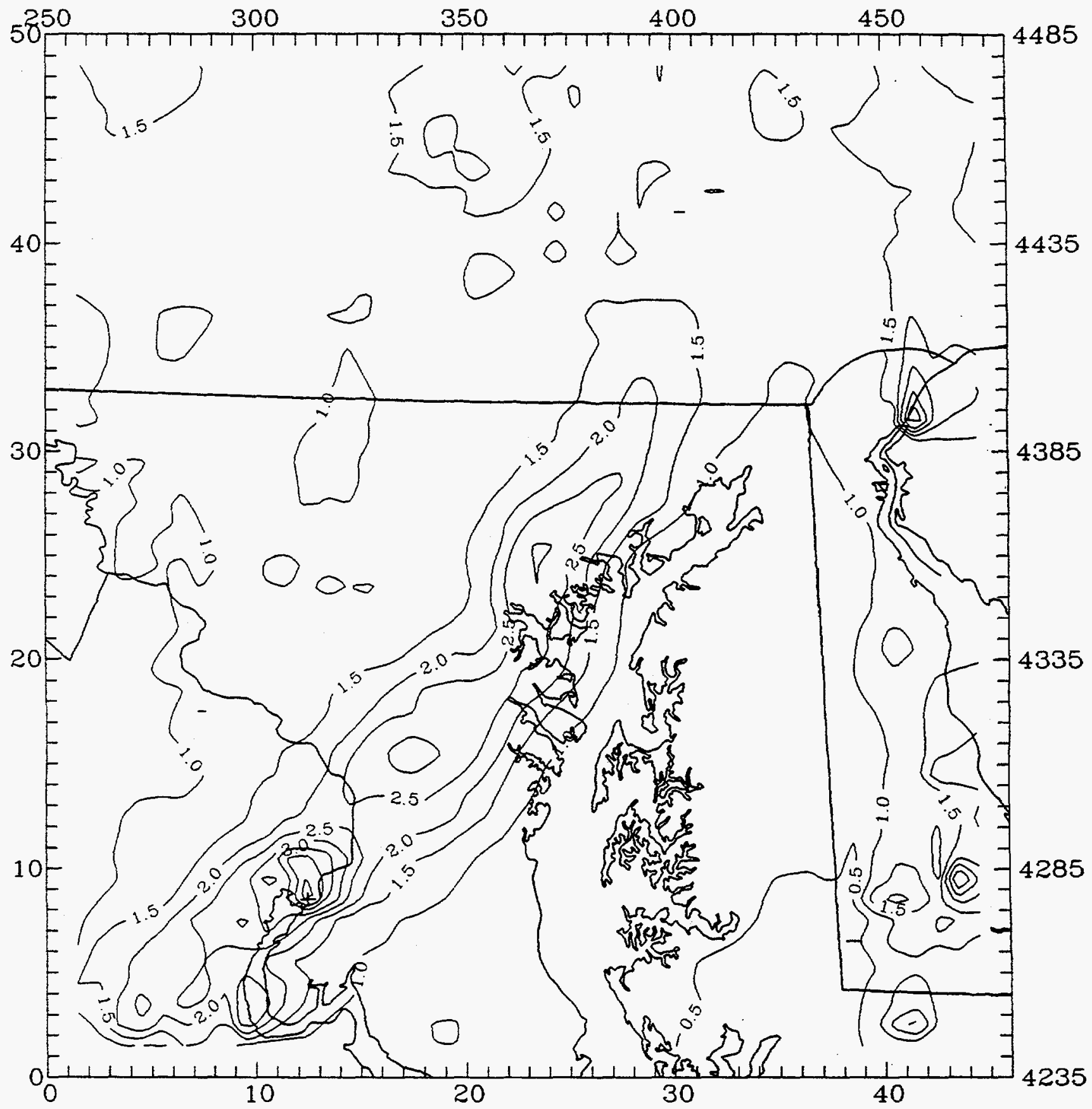

FIGURE 5-8a.

Daily Average Total Acetaldehyde Concentrations on July 6, 1988.

Baltimore Domain UAM-Tox (6.22)

2020 RFG 
LEVEL 1 TACET (ppb)

Time: $0-2400$ July 6,1988
+ MAXIMUM $=4.7 \mathrm{ppb}$

- MINIMUM $=0.4 \mathrm{ppb}$

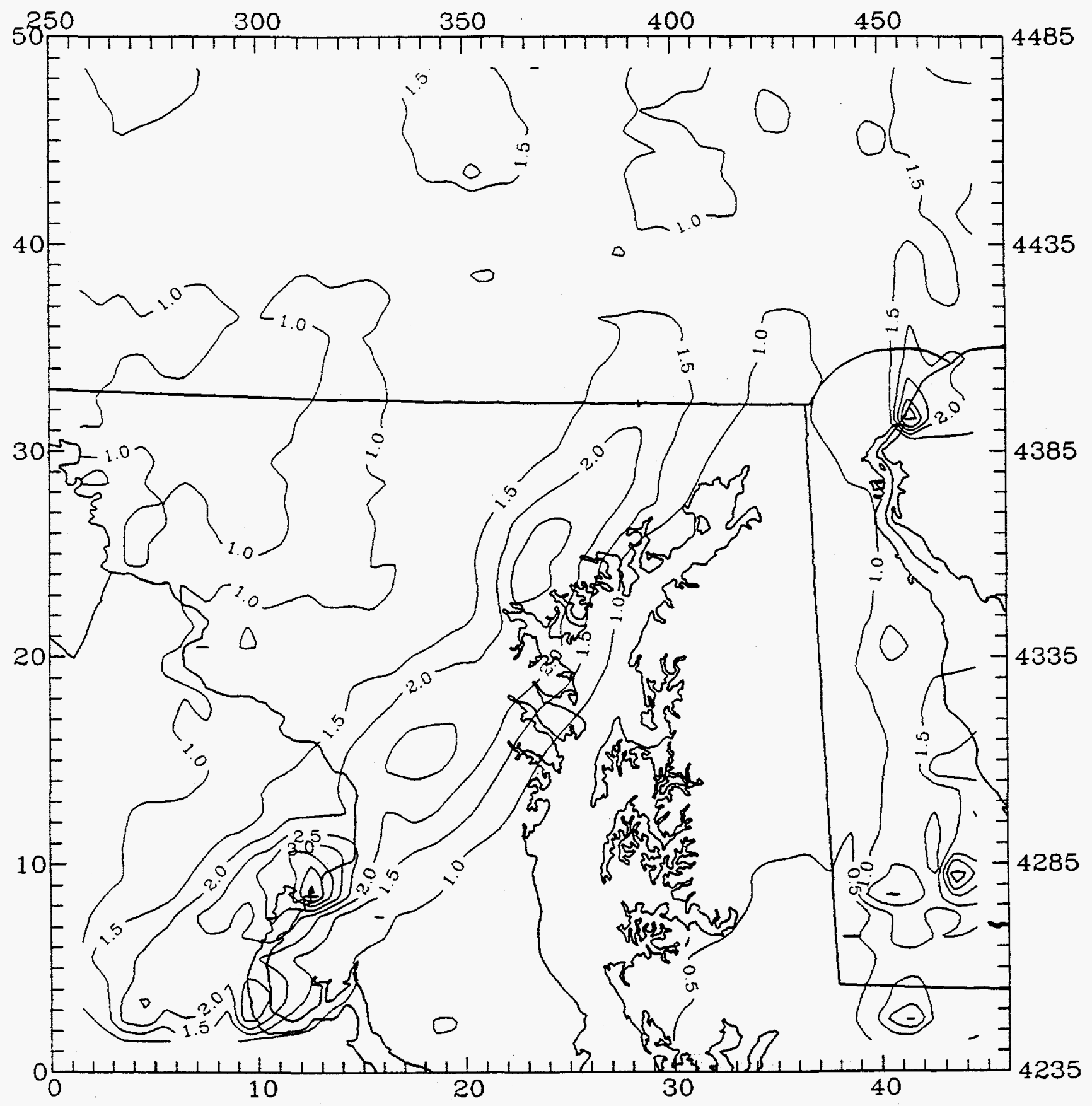

FIGURE 5-8b.

Dally Average Total Acetaldehyde Concentrations on July 6, 1988.

Baitimore Domain UAM-Tox (6.22)

2020 M85 
LEVEL 1 TACET (ppb)

Time 0-2400 July 6, 1988
- MATIMCM $=+4 \mathrm{ppb}$

- MINIMLM $=0+\mathrm{ppb}$

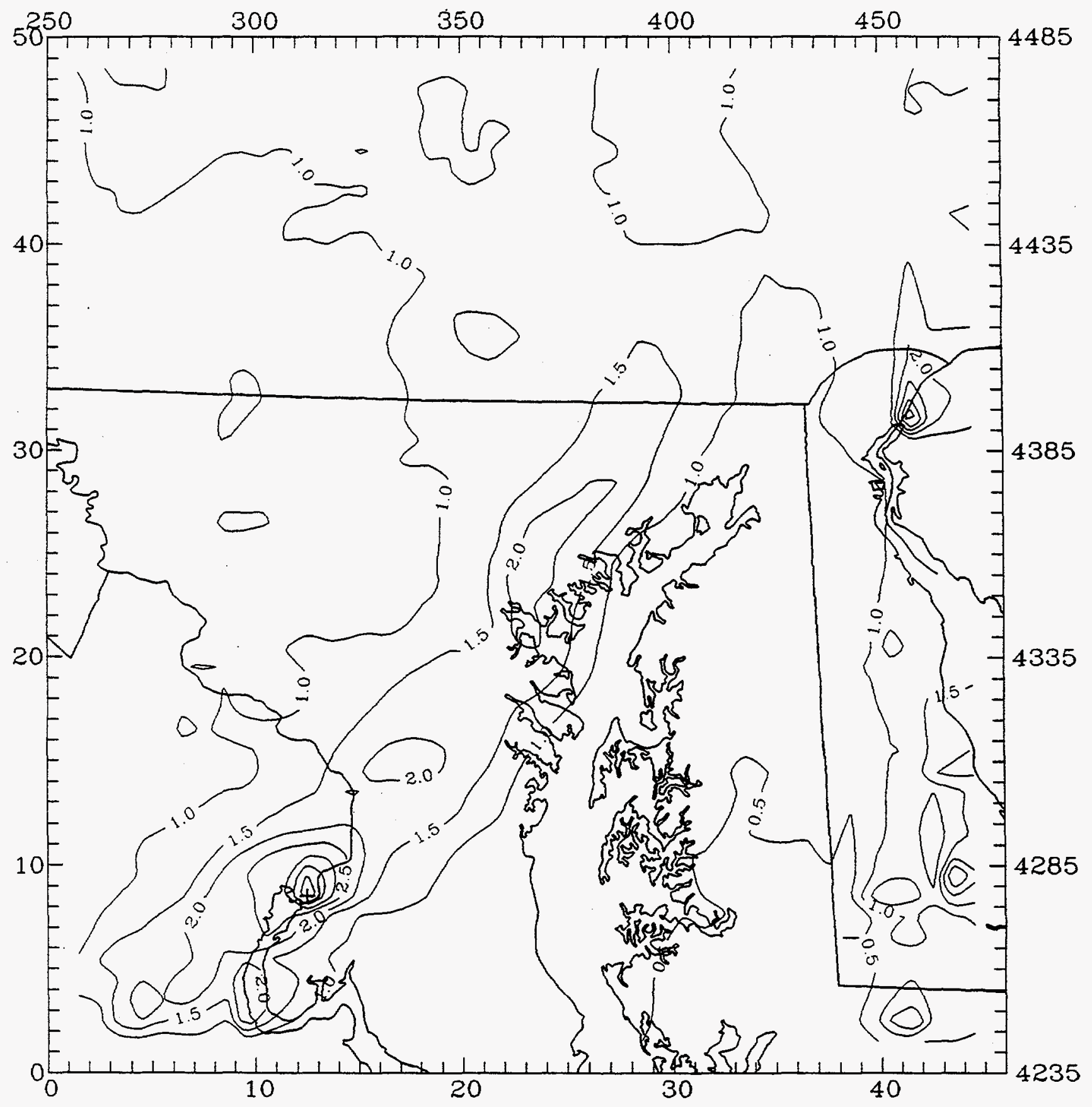

FIGURE 5-8c.

Daily Average Total Acetaldehyde Concentrations on July 6, 1988.

Baltimore Domain UAM-Tox (6.22)

$2020 \mathrm{CNG}$ 


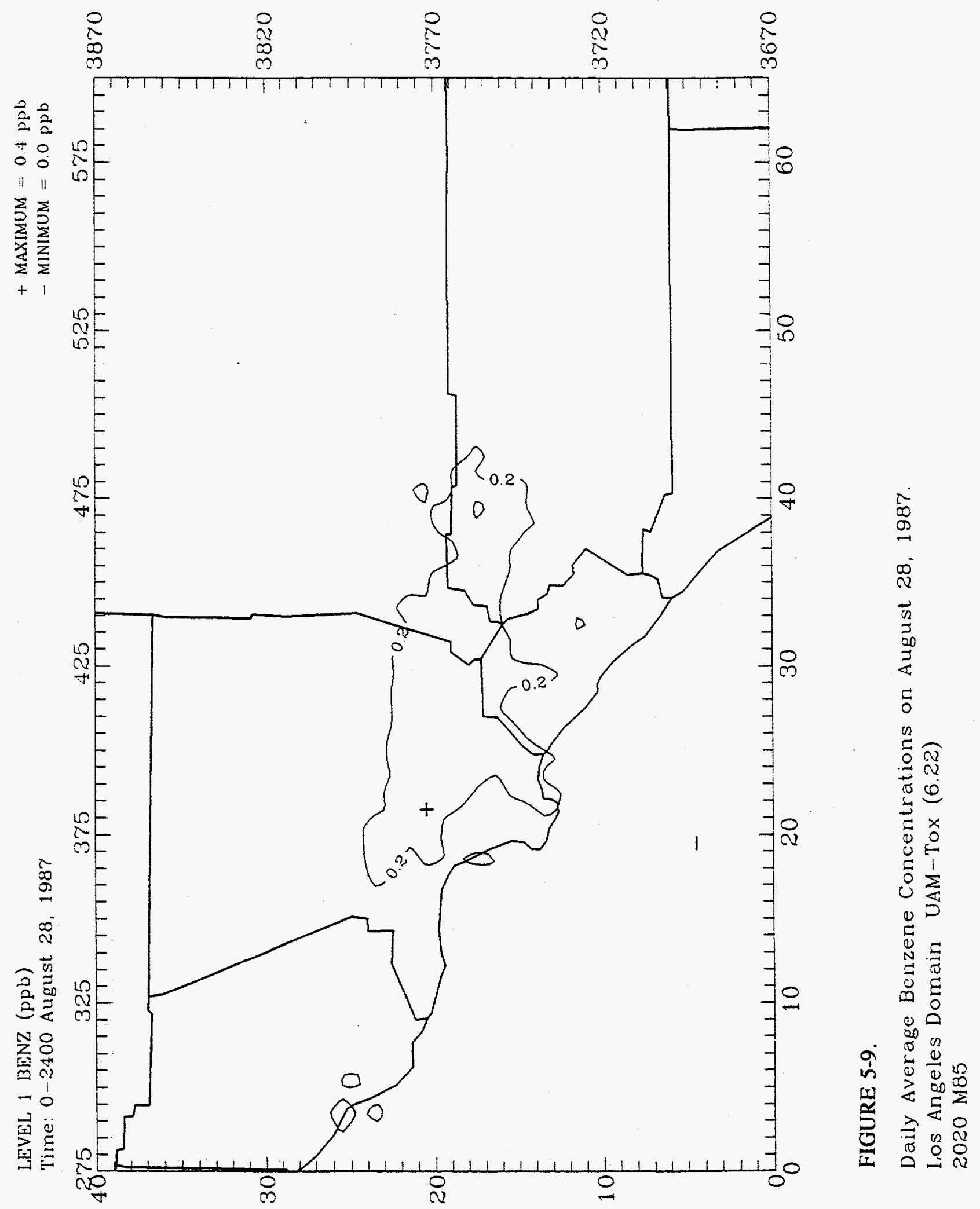




\section{CONCLUSIONS}

As noted in the Introduction and elsewhere, this study is designed to examine the relative effects of alternative motor fuels on air quality. As such it cannot be used to make predictions as to likely future values of pollutant concentrations. The results provide a quantitative comparison of the effects of complete replacement of fuels, but there is no assurance that the relative benefits or disbenefits of fuel switching will scale linearly for less than complete replacement. The conclusions to date are understandable in terms of the differences in relative reactivity of fuel-specific emissions, and are based on the latest available information on emissions from actual operating vehicles in the Federal fleet, as compiled by NREL. Whether these results prove to be robust against alternative assumptions and other ambient conditions must still be addressed.

\section{CNG}

CNG appears to be substantially beneficial in reducing ozone below the levels obtained for RFG by all measures, including peak values of hourly ozone maxima, areal exposure, and areal coverage above a threshold value. This conclusion holds for both cities. In Baltimore the peak value on the second day of the simulation is 12 percent lower than the RFG value. In Los Angeles the peak value on the second day is 9 percent lower than the RFG value. The areal measures for ozone above a threshold are lower by a factor of almost 2 for Baltimore, and a factor of more than 6 for Los Angeles. Since different thresholds were used for the two cities, reflecting the different inventory characteristics, it is difficult to extrapolate from these results to quantitative estimates for other cities, but the qualitative benefit of CNG substitution for RFG in reducing ozone concentrations over broad areas in air quality simulations is clear.

The CNG simulations also show reduced daily average concentrations of all of the mobile source air toxic species in the Baltimore simulations. In the Los Angeles simulations the concentrations of benzene and 1,3-butadiene in all of the future-year fuel runs are so low that the differences are probably not significant. The reductions in formaldehyde and acetaldehyde in Baltimore are approximately 6 percent greater than those obtained with RFG, while in Los Angeles both of these species are reduced by approximately 12 percent more than for RFG. In the Baltimore simulations, substitution of CNG for RFG reduces peak benzene concentrations in the urban areas by factors of 2 to 4 below the RFG values. The peak values of butadiene in the urban areas of the Baltimore domain are approximately a factor of 2 lower for $\mathrm{CNG}$ than for RFG.

\section{M85}

Substitution of M85 for RFG produces little or no change in the peak ozone maxima in either Los Angeles or Baltimore as compared to the RFG simulations. Total areal coverage is also little different. There is some indication that M85 leads to small reductions of ozone maxima in urban core areas, and smaller areal coverage above threshold values, in both cities. The differences are much less than those observed in the CNG simulations. 
Substitution of M85 for RFG leads to slightly (1-2\%) increased maximum daily average formaldehyde concentrations in both Baltimore and Los Angeles. There is essentially no difference in acetaldehyde maxima between the M85 and RFG simulations. In Baltimore M85 leads to reductions in peak benzene exposure in urban areas by approximately 15-40 percent, and reduces butadiene in the same areas by approximately $25-50$ percent. The benzene and butadiene reductions are both smaller than those observed for CNG.

In addition to ozone and air toxics changes, substitution of alternative motor fuels may affect overall levels of national greenhouse gas emissions. It is difficult to draw any conclusions as to greenhouse gas impacts based on this investigation. Our estimate of methane emissions for use of CNG is notably higher than for the other fuels, but it is based on immature technology. Further, ozone itself is a potent greenhouse gas in the upper troposphere and national-scale fuel substitution could produce broad-scale ozone changes aloft whose evaluation goes beyond the scope of this study. 


\section{REFERENCES}

AQIRP. 1992. "Emissions and Air Quality Modeling Results from Methanol/Gasoline Blends in Prototype Flexible/Variable Fuel Vehicles." Air Quality Improvement Research Program (Technical Bulletin No. 7).

AQIRP. 1994. "Emissions from Methanol Fuels and Reformulated Gasoline in 1993 Production Flexible/Variable Fuel and Gasoline Vehicles." Air Quality Improvement Research Program (Technical Bulletin No. 13).

AQIRP. 1995. "Exhaust Emissions of Compressed Natural Gas (CNG) Vehicles Compared with Gasoline Vehicles." Air Quality Improvement Research Program (Technical Bulletin No. 15).

BEA. 1990. "BEA Regional Projections to 2040. Volume 1: State Projections." Bureau of Economic Analysis, United States Department of Commerce.

Carr, E. L., N. K. Lolk, and J. L. Haney. 1992. "Instructional Application of the Urban Airshed Model to the Baltimore-Washington, D.C. Region." Systems Applications International, San Rafael, California (SYSAPP-92/153).

EPA. 1990. User's Guide for the Urban Airshed Model, Volume IV: User's Manual for the Emissions Preprocessor System. Office of Air Quality Planning and Standards, U.S. Environmental Protection Agency (EPA contract No. 68-D90066, work assignment No. 1-1 and 1-3; EPA contract No. 68-02-4352, work assignment No. 3-22).

EPA. 1991. Guideline for Regulatory Application of the Urban Airshed Model. U.S. Environmental Protection Agency, Office of Air Quality Planning and Standards (EPA-450/4-91-013).

EPA. 1992a. User's Guide for the Urban Airshed Model, Volume IV: User's Manual for the Emissions Preprocessor System 2.0; Part A: Core FORTRAN System. Office of Air Quality Planning and Standards, U.S. Environmental Protection Agency (EPA450/4-90-007D(R).

EPA. 1992b. Regional Oxidant Modeling - Emission Inventory Development and Emission Control Scenarios. Office of Air Quality Planning and Standards, U.S. Environmental Protection Agency (EPA contract No. 68-D9-0168, work assignment No. 043).

EPA. 1992c. VOC/PM Speciation Data System, Version 1.5. U.S. Environmental Protection Agency, Research Triangle Park, North Carolina. 
EPA. 1993. Regional Interim Emission Inventories (1987-1991), Volume I: Development Methodologies. Office of Air Quality Planning and Standards, U.S. Environmental Protection Agency (EPA-454/R-93-021a).

EPA. 1994. "Regulation of Fuels and Fuel Additives: Standards for Reformulated and Conventional Gasoline." Federal Register, 59(32):7716.

Fieber, J. L., G. M. Wilson, and R. G. Ireson. 1994. "DTIM2 User's Guide." Final report prepared for the California Department of Transportation. Systems Applications International, San Rafael, California (SYSAPP-94/051).

Fujita, E. M., B. E. Croes, C. L. Bennett, D. L. Lawson, F. W. Lurmann, and H. H. Main. 1992. Comparison of emission inventory and ambient concentration ratios of $\mathrm{CO}$, NMOG, and $\mathrm{NO}_{\mathrm{x}}$ in California's South Coast Air Basin. J. Air Waste Manage. Assoc., 42:264-276.

Fujita, E. M., J. G. Watson, J. C. Chow, and Z. Lu. 1994. Validation of the chemical mass balance receptor model applied to hydrocarbon source apportionment in the Southern California air quality study. Environ. Sci. Technol., 28:1633-1649.

Guthrie, P. D., G. Yarwood, M. P. Ligocki, and J. L. Fieber. 1995. "NREL Alternative Fuels Phase 1 Modeling Protocol." Systems Applications International, San Rafael, California (SYSAPP-94/112).

Harley, R. A., M. P. Hannigan, and G. R. Cass. 1992. Respeciation of organic gas emissions and the detection of excess unburned gasoline in the atmosphere. Environ. Sci. Technol, 26:2395-2408.

Hogo, H. and M. W. Gery. 1988. "Guidelines for Using OZIPM-4 with CBM-IV or Optional Mechanisms." Systems Applications Inc., San Rafael, California (SYSAPP88/001).

Ingalls, M. N., L. R. Smith, and R. E. Kirksey. 1989. "Measurement of On-Road Vehicle Emission Factors in the California South Coast Air Basin, Vol. I: Regulated Emissions." Report to Coordinating Research Council by Southwest Research Institute (Report No. SwRI-1604).

Lewis, C. W., T. L. Conner, R. K. Stevens, J. F. Collins, and R. C. Henry. 1993. "Receptor Modeling of Volatile Hydrocarbons Measured in the 1990 Atlanta Ozone Precursor Study." Presented at 84th Annual Meeting of the Air and Waste Management Association (Paper 93-TP-50.04).

Ligocki, M. P., R. R. Schulhof, R. E. Jackson, M. M. Jimenez, G. Z. Whitten, G. M. Wilson, T. C. Myers, and J. L. Fieber. 1992. "Modeling the Effects of Reformulated Gasoline on Ozone and Toxics Concentrations in the Baltimore and Houston Areas." Systems Applications International, San Rafael, California (SYSAPP-92/127). 
Ligocki, M. P., and G. Z. Whitten. 1992. "Modeling Air Toxics with the Urban Airshed Model." Presented at the 85th Annual Meeting of the Air and Waste Management Association, Kansas City, June 1992 (Paper 92-84.12).

McAllister, R. A., W. H. Moore, J. Rice, E. Bowles, D. P. Dayton, R. F. Jongleux, R. G. Merrill, and J. T. Bursey. 1989. Urban Air Toxics Monitoring Program. U.S. Environmental Protection Agency (EPA-450/4-91-001).

McAllister, R. A., E. G. Bowles, J. DeGarmo, J. Rice, R. F. Jongleux, R. G. Merrill, Jr., and J. Bursey. 1991a. 1990 Urban Air Toxics Monitoring Program. U.S. Environmental Protection Agency, Research Triangle Park, North Carolina (EPA450/4-91-024).

McAllister, R. A., D. L. Epperson, and R. F. Jongleux. 1991b. 1989 Urban Air Toxics Monitoring Program Aldehyde Results. U.S. Environmental Protection Agency (EPA-450/4-91-006).

Morris, R. E., A. K. Pollack, J. L. Fieber, and A. S. Rosenbaum. "Air Quality Modeling of Low Emission Vehicle Programs in the Northeast." Systems Applications International, San Rafael, California (SYSAPP-94/048).

PEI. 1989. "Urban Air Toxic Monitoring Program, Results of Aldehyde Monitoring, Fiscal Year 1988." PEI Associates, Inc., Durham, North Carolina (EPA Contract 68-024394).

Radian. 1991. "1990 Urban Air Toxics Monitoring Program Carbonyl Results." Radian Corporation, Research Triangle Park, North Carolina (EPA-450/4-91-025).

Resch, R. A. 1995. "A Voluntary Approach to Mitigate Methane Emissions: EPA's Natural Gas STAR Program for Natural Gas Producers." Presented at Air and Waste Management Association 88th Annual Meeting and Exhibition, San Antonio, Texas, 18-23 June 1995 (paper 95-RA121A.01).

SAI. 1996. "User's Guide to the Variable-Grid Urban Airshed Model (UAM-V)." Systems Applications International, San Rafael, California (SYSAPP-96-95/27r).

SCAG. 1995. Southern California 2020, a Preliminary Growth Forecast, Regional Overview. Southern California Association of Governments, Los Angeles.

SCAQMD. 1994. "Ozone Modeling - Performance Evaluation." Draft Technical Report V-B. South Coast Air Quality Management District. 


\section{Appendix A}

CHEMICAL MECHANISM OF THE UAM-TOX MODEL 
TABLE A-1. UAM-Tox organic species. All of the inorganic species in UAM-Tox are identical to those in Carbon Bond 4.

\begin{tabular}{|c|c|}
\hline Species & Label \\
\hline Formaldehyde & FORM \\
\hline Primary formaldehyde & PHCHO \\
\hline Acetaldehyde & ACET \\
\hline Primary acetaldehyde & PACET \\
\hline Higher aldehydes & ALDX \\
\hline Olefin & OLE \\
\hline Interior olefin & IOLE \\
\hline PAN & PAN \\
\hline Higher organic nitrate & PANX \\
\hline Paraffin & PAR \\
\hline Toluene & TOL \\
\hline Xylene & $\mathrm{XYL}$ \\
\hline Ethane & ETH \\
\hline Methane & METH \\
\hline Isoprene & ISOP \\
\hline Cresol & CRES \\
\hline Methanol & $\mathrm{MEOH}$ \\
\hline Ethanol & ETOH \\
\hline MTBE & MTBE \\
\hline Benzene & BENZ \\
\hline 1,3-Butadiene & BUTA \\
\hline Naphthalene & NAPH \\
\hline Polycyclic organic matter & POM1, POM2 \\
\hline
\end{tabular}


TABLE A-2. The Carbon Bond Mechanism, Version IV, used in the UAM-Tox, version 6.22.

\begin{tabular}{|c|c|c|c|}
\hline & Reaction & $\begin{array}{l}\text { Rate Constant } \\
\text { @ } 298 \mathrm{~K} \\
\left(\mathrm{ppm}^{-11} \mathrm{~min}^{-1}\right)\end{array}$ & $\mathrm{E} / \mathrm{R}(\mathrm{K})$ \\
\hline $1 \mathrm{NO} 2$ & $\rightarrow \mathrm{NO}+\mathrm{O}$ & Radiation dependent $^{b}$ & \\
\hline 20 & $\rightarrow \mathrm{O} 3$ & $4,323,000$ & -1175 \\
\hline $3 \mathrm{O} 3+\mathrm{NO}$ & $\rightarrow \mathrm{NO} 2$ & 26.64 & 1370 \\
\hline $4 \mathrm{O}+\mathrm{NO} 2$ & $\rightarrow$ NO & 13,750 & 0 \\
\hline $5 \mathrm{O}+\mathrm{NO} 2$ & $\rightarrow \mathrm{NO} 3$ & 2309 & -687 \\
\hline $6 \mathrm{O}+\mathrm{NO}$ & $\rightarrow \mathrm{NO} 2$ & 2438 & -602 \\
\hline $7 \mathrm{NO} 2+\mathrm{O} 3$ & $\rightarrow \mathrm{NO} 3$ & 0.04731 & 2450 \\
\hline 803 & $\rightarrow \mathrm{O}$ & Radiation dependent $t^{b}$ & \\
\hline 903 & $\rightarrow$ O1D & Radiation dependent $^{\mathrm{b}}$ & \\
\hline $10 \mathrm{OlD}$ & $\rightarrow 0$ & 424,600 & -390 \\
\hline $11 \mathrm{O} 1 \mathrm{D}+\mathrm{H} 2 \mathrm{O}$ & $\rightarrow 2 \mathrm{OH}$ & 3.26 & 0 \\
\hline $12 \mathrm{O} 3+\mathrm{OH}$ & $\rightarrow \mathrm{HO} 2$ & 100 & 940 \\
\hline $13 \mathrm{O} 3+\mathrm{HO} 2$ & $\rightarrow \mathrm{OH}$ & 3 & 580 \\
\hline $14 \mathrm{NO} 3$ & $\rightarrow 0.89 \mathrm{NO} 2+0.89 \mathrm{O}+0.11 \mathrm{NO}$ & Radiation dependent $t^{b}$ & \\
\hline $15 \mathrm{NO}+\mathrm{NO}$ & $\rightarrow 2 \mathrm{NO} 2$ & 44,160 & -250 \\
\hline $16 \mathrm{NO} 3+\mathrm{NO} 2$ & $\rightarrow \mathrm{NO}+\mathrm{NO} 2$ & 0.5901 & 1230 \\
\hline $17 \mathrm{NO} 3+\mathrm{NO} 2$ & $\rightarrow \mathrm{N} 205$ & 1853 & -256 \\
\hline $18 \mathrm{~N} 2 \mathrm{O} 5+\mathrm{H} 2 \mathrm{O}$ & $\rightarrow 2 \mathrm{HNO} 3$ & $1.9 \times 10^{-6}$ & 0 \\
\hline $19 \mathrm{~N} 205$ & $\rightarrow \mathrm{NO} 3+\mathrm{NO} 2$ & 2.776 & 10,900 \\
\hline $20 \mathrm{NO}+\mathrm{NO}$ & $\rightarrow 2 \mathrm{NO} 2$ & 0.00015 & -530 \\
\hline $21 \mathrm{NO}+\mathrm{NO} 2+\mathrm{H} 2 \mathrm{O}$ & $\rightarrow 2$ HONO & $3 \times 10^{-8}$ & -6348 \\
\hline $22 \mathrm{NO}+\mathrm{OH}$ & $\rightarrow$ HONO & 9799 & -806 \\
\hline 23 HONO & $\rightarrow \mathrm{NO}+\mathrm{OH}$ & Radiation dependent ${ }^{b}$ & \\
\hline $24 \mathrm{HONO}+\mathrm{OH}$ & $\rightarrow \mathrm{NO} 2$ & 9770 & 0 \\
\hline $25 \mathrm{HONO}+\mathrm{HONO}$ & $\rightarrow \mathrm{NO}+\mathrm{NO} 2$ & 0.00002 & 0 \\
\hline $26 \mathrm{NO} 2+\mathrm{OH}$ & $\rightarrow \mathrm{HNO} 3$ & 16,820 & -713 \\
\hline $27 \mathrm{HNO} 3+\mathrm{OH}$ & $\rightarrow \mathrm{NO} 3$ & 217.9 & -1000 \\
\hline $28 \mathrm{NO}+\mathrm{HO} 2$ & $\rightarrow \mathrm{OH}+\mathrm{NO} 2$ & 12,270 & -240 \\
\hline $29 \mathrm{NO} 2+\mathrm{HO} 2$ & $\rightarrow$ PNA & 2025 & -749 \\
\hline 30 PNA & $\rightarrow \mathrm{HO} 2+\mathrm{NO} 2$ & 5.115 & 10,121 \\
\hline $31 \mathrm{PNA}+\mathrm{OH}$ & $\rightarrow \mathrm{NO} 2$ & 6833 & -380 \\
\hline $32 \mathrm{HO} 2+\mathrm{HO} 2$ & $\rightarrow \mathrm{H} 2 \mathrm{O} 2$ & 4144 & -1150 \\
\hline $33 \mathrm{HO} 2+\mathrm{HO}_{2}+\mathrm{H} 2 \mathrm{O}$ & $\rightarrow \mathrm{H} 2 \mathrm{O} 2$ & 0.2181 & -5800 \\
\hline $34 \mathrm{H} 2 \mathrm{O} 2$ & $\rightarrow 2 \mathrm{OH}$ & Radiation dependent ${ }^{b}$ & \\
\hline $35 \mathrm{H} 2 \mathrm{O} 2+\mathrm{OH}$ & $\rightarrow \mathrm{HO} 2$ & 2520 & 187 \\
\hline $36 \mathrm{CO}+\mathrm{OH}$ & $\rightarrow \mathrm{HO} 2$ & 322 & 0 \\
\hline $37 \mathrm{FORM}+\mathrm{OH}$ & $\rightarrow \mathrm{HO} 2+\mathrm{CO}$ & 15,000 & 0 \\
\hline 38 FORM & $\rightarrow 2 \mathrm{HO} 2+\mathrm{CO}$ & Radiation dependent ${ }^{b}$ & \\
\hline 39 FORM & $\rightarrow \mathrm{CO}$ & Radiation dependent ${ }^{b}$ & \\
\hline
\end{tabular}

Continued 
TABLE A-2. Continued.

\begin{tabular}{|c|c|c|c|}
\hline & Reaction & $\begin{array}{l}\text { Rate Constant } \\
@ 298 \mathrm{~K} \\
\left(\mathrm{ppm}^{\mathrm{n}} \mathrm{min}^{-1}\right) \\
\end{array}$ & $\mathrm{E} / \mathrm{R}(\mathrm{K})$ \\
\hline $40 \mathrm{FORM}+\mathrm{O}$ & $\rightarrow \mathrm{OH}+\mathrm{HO} 2+\mathrm{CO}$ & 237 & 1550 \\
\hline $41 \mathrm{FORM}+\mathrm{NO} 3$ & $\rightarrow \mathrm{HNO} 3+\mathrm{HO} 2+\mathrm{CO}$ & 0.93 & 0 \\
\hline $42 \mathrm{ACET}+\mathrm{O}$ & $\rightarrow \mathrm{C} 2 \mathrm{O} 3+\mathrm{OH}$ & 636 & 986 \\
\hline $43 \mathrm{ACET}+\mathrm{OH}$ & $\rightarrow \mathrm{C} 2 \mathrm{O} 3$ & 21,900 & -205 \\
\hline $44 \mathrm{ACET}+\mathrm{NO} 3$ & $\rightarrow \mathrm{C} 2 \mathrm{O} 3+\mathrm{HNO} 3$ & 4.03 & 1860 \\
\hline 45 ACET & $\rightarrow \mathrm{FORM}+2 \mathrm{HO} 2+\mathrm{CO}+\mathrm{XO} 2$ & Radiation dependent ${ }^{b}$ & \\
\hline $46 \mathrm{C} 2 \mathrm{O} 3+\mathrm{NO}$ & $\rightarrow \mathrm{FORM}+\mathrm{NO} 2+\mathrm{HO} 2+\mathrm{XO} 2$ & 28,200 & 180 \\
\hline $47 \mathrm{C} 2 \mathrm{O} 3+\mathrm{NO} 2$ & $\rightarrow$ PAN & 13,700 & -380 \\
\hline 48 PAN & $\rightarrow \mathrm{C} 2 \mathrm{O} 3+\mathrm{NO} 2$ & 0.0254 & 13,500 \\
\hline $49 \mathrm{C} 2 \mathrm{O} 3+\mathrm{C} 2 \mathrm{O} 3$ & $\rightarrow 2 \mathrm{FORM}+2 \mathrm{XO} 2+2 \mathrm{HO} 2$ & 24,500 & -530 \\
\hline $50 \mathrm{C} 2 \mathrm{O} 3+\mathrm{HO} 2$ & $\rightarrow 0.33 \mathrm{O} 3$ & 20,900 & -1040 \\
\hline $51 \mathrm{CH} 4+\mathrm{OH}$ & $\rightarrow \mathrm{FORM}+\mathrm{XO} 2+\mathrm{HO} 2$ & 10.34 & 1885 \\
\hline $52 \mathrm{PAR}+\mathrm{OH}$ & $\begin{aligned} \rightarrow & 0.87 \mathrm{XO} 2+0.13 \mathrm{XO} 2 \mathrm{~N}+0.11 \mathrm{HO} 2 \\
& +0.05 \mathrm{ALDX}+0.06 \mathrm{ACET}+0.76 \mathrm{ROR}- \\
& 0.11 \mathrm{PAR}\end{aligned}$ & 1203 & 0 \\
\hline 53 ROR & $\begin{aligned} \rightarrow & 0.96 \mathrm{XO} 2+0.5 \text { ALDX }+0.6 \text { ACET } \\
& +0.94 \mathrm{HO} 2+0.04 \text { XO2N }-0.02 \text { ROR }-2.1 \\
& \text { PAR }\end{aligned}$ & 137,100 & 8000 \\
\hline $54 \mathrm{ROR}$ & $\rightarrow \mathrm{HO} 2$ & 95,440 & 0 \\
\hline $55 \mathrm{ROR}+\mathrm{NO} 2$ & $\rightarrow$ NTR & 22,000 & 0 \\
\hline $56 \mathrm{OLE}+\mathrm{O}$ & $\begin{aligned} \rightarrow & 0.24 \text { ALDX }+0.39 \text { ACET }+0.38 \mathrm{HO} 2 \\
& +0.28 \mathrm{XO} 2+0.3 \mathrm{CO}+0.2 \text { FORM } \\
& +0.22 \mathrm{PAR}+0.2 \mathrm{OH}\end{aligned}$ & 5920 & 324 \\
\hline $57 \mathrm{OLE}+\mathrm{OH}$ & $\begin{aligned} \rightarrow & \text { FORM + } 0.38 \text { ALDX + 0.62 ACET } \\
& +\mathrm{XO} 2+\mathrm{HO} 2-\mathrm{PAR}\end{aligned}$ & 42,000 & -504 \\
\hline $58 \mathrm{OLE}+\mathrm{O} 3$ & $\begin{aligned} \rightarrow & 0.19 \mathrm{ACET}+0.31 \mathrm{ALDX}+0.74 \mathrm{FORM}+ \\
& 0.22 \mathrm{XO} 2+0.1 \mathrm{OH}+0.33 \mathrm{CO} \\
& +0.44 \mathrm{HO} 2-\mathrm{PAR}\end{aligned}$ & 0.018 & 2105 \\
\hline 59 OLE + NO3 & $\begin{aligned} \rightarrow & 0.91 \mathrm{FORM}+0.35 \mathrm{ACET} \\
& +0.56 \mathrm{ALDX}+0.91 \mathrm{NO} 2 \\
& +0.91 \mathrm{XO} 2+0.09 \mathrm{XO} 2 \mathrm{~N}-\mathrm{PAR}\end{aligned}$ & 11.35 & 0 \\
\hline $60 \mathrm{ETH}+\mathrm{O}$ & $\begin{aligned} \rightarrow & \mathrm{FORM}+1.7 \mathrm{HO} 2+\mathrm{CO}+0.7 \mathrm{XO} 2 \\
& +0.3 \mathrm{OH}\end{aligned}$ & 1080 & 792 \\
\hline $61 \mathrm{ETH}+\mathrm{OH}$ & $\begin{aligned} \rightarrow & 1.56 \mathrm{FORM}+0.22 \mathrm{ALDX}+\mathrm{HO} 2 \\
& +\mathrm{XO} 2\end{aligned}$ & 11,920 & -411 \\
\hline $62 \mathrm{ETH}+\mathrm{O} 3$ & $\rightarrow$ FORM $+0.42 \mathrm{CO}+0.12 \mathrm{HO} 2$ & 0.0027 & 2633 \\
\hline $63 \mathrm{TOL}+\mathrm{OH}$ & $\begin{aligned} \rightarrow & 0.44 \mathrm{HO} 2+0.08 \mathrm{XO} 2+0.36 \mathrm{CRES} \\
& +0.56 \mathrm{TO} 2\end{aligned}$ & 9150 & -322 \\
\hline $64 \mathrm{TO} 2+\mathrm{NO}$ & $\begin{aligned} \rightarrow & 0.9 \mathrm{NO} 2+0.9 \mathrm{HO} 2+0.9 \mathrm{OPEN} \\
& +0.1 \mathrm{NTR}\end{aligned}$ & 12,000 & 0 \\
\hline $65 \mathrm{TO} 2$ & $\rightarrow \mathrm{CRES}+\mathrm{HO} 2$ & 250 & 0 \\
\hline $66 \mathrm{CRES}+\mathrm{OH}$ & $\begin{aligned} \rightarrow & 0.4 \mathrm{CRO}+0.6 \mathrm{XO} 2+0.6 \mathrm{HO} 2 \\
& +0.3 \mathrm{OPEN}\end{aligned}$ & 61,000 & 0 \\
\hline $67 \mathrm{CRES}+\mathrm{NO} 3$ & $\rightarrow \mathrm{CRO}+\mathrm{HNO} 3$ & 32,500 & 0 \\
\hline $68 \mathrm{CRO}+\mathrm{NO} 2$ & $\rightarrow$ NTR & 20,000 & 0 \\
\hline
\end{tabular}

Continued 
TABLE A-2. Continued.

\begin{tabular}{|c|c|c|c|}
\hline & Reaction & $\begin{array}{l}\text { Rate Constant } \\
@ 298 \mathrm{~K} \\
\left(\mathrm{ppm}^{-\mathrm{n}} \mathrm{min}^{-1}\right)\end{array}$ & $\mathrm{E} / \mathrm{R}(\mathrm{K})$ \\
\hline 69 OPEN & $\rightarrow \mathrm{C} 2 \mathrm{O} 3+\mathrm{HO} 2+\mathrm{CO}$ & Radiation dependent $\mathrm{t}^{\mathrm{b}}$ & \\
\hline $70 \mathrm{OPEN}+\mathrm{OH}$ & $\begin{aligned} \rightarrow & \mathrm{XO} 2+2 \mathrm{CO}+2 \mathrm{HO}_{2}+\mathrm{C} 2 \mathrm{O} 3 \\
& +\mathrm{FORM}\end{aligned}$ & 44,000 & 0 \\
\hline $71 \mathrm{OPEN}+\mathrm{O} 3$ & $\begin{aligned} \rightarrow & 0.03 \mathrm{ALDX}+0.62 \mathrm{C} 2 \mathrm{O} 3+0.7 \mathrm{FORM} \\
& +0.03 \mathrm{XO} 2+0.69 \mathrm{CO}+0.08 \mathrm{OH} \\
& +0.76 \mathrm{HO} 2+0.2 \mathrm{MGLY}\end{aligned}$ & 0.015 & 500 \\
\hline $72 \mathrm{XYL}+\mathrm{OH}$ & $\begin{aligned} \rightarrow & 0.7 \mathrm{HO} 2+0.5 \mathrm{XO} 2+0.2 \mathrm{CRES} \\
& +0.8 \mathrm{MGLY}+1.1 \mathrm{PAR}+0.3 \mathrm{TO} 2\end{aligned}$ & 36,200 & -116 \\
\hline $73 \mathrm{MGLY}+\mathrm{OH}$ & $\rightarrow \mathrm{XO} 2+\mathrm{C} 2 \mathrm{O} 3$ & 26,000 & 0 \\
\hline 74 MGLY & $\rightarrow \mathrm{C} 2 \mathrm{O} 3+\mathrm{HO} 2+\mathrm{CO}$ & Radiation dependent ${ }^{b}$ & \\
\hline $75 \mathrm{ISOP}+\mathrm{O}$ & $\begin{aligned} \rightarrow & 0.8 \mathrm{ALDX}+0.55 \mathrm{OLE}+0.5 \mathrm{XO} 2 \\
& +0.5 \mathrm{CO}+0.45 \mathrm{ETH}+0.6 \mathrm{HO} 2 \\
& +0.9 \mathrm{PAR}\end{aligned}$ & 27,000 & 0 \\
\hline $76 \mathrm{ISOP}+\mathrm{OH}$ & $\begin{aligned} \rightarrow & \mathrm{XO} 2+\mathrm{FORM}+0.67 \mathrm{HO} 2+\mathrm{ETH} \\
& +0.4 \mathrm{MGLY}+0.2 \mathrm{ALDX}+0.2 \mathrm{C} 2 \mathrm{O} 3+ \\
& 0.13 \mathrm{XO} 2 \mathrm{~N}\end{aligned}$ & 142,000 & 0 \\
\hline 77 ISOP + O3 & $\begin{aligned} \rightarrow & \text { FORM }+0.4 \text { ALDX }+0.55 \mathrm{ETH} \\
& +0.2 \mathrm{MGLY}+0.1 \mathrm{PAR}+0.06 \mathrm{CO} \\
& +0.44 \mathrm{HO} 2+0.1 \mathrm{OH}\end{aligned}$ & 0.018 & 0 \\
\hline $78 \mathrm{ISOP}+\mathrm{NO} 3$ & $\rightarrow \mathrm{XO} 2 \mathrm{~N}+\mathrm{NTR}$ & 470 & 0 \\
\hline $79 \mathrm{XO} 2+\mathrm{NO}$ & $\rightarrow \mathrm{NO} 2$ & 12,000 & 0 \\
\hline $80 \mathrm{XO} 2+\mathrm{XO} 2$ & $\rightarrow$ & 2000 & -1300 \\
\hline $81 \mathrm{XO} 2 \mathrm{~N}+\mathrm{NO}$ & $\rightarrow$ NTR & 12,000 & 0 \\
\hline $82^{\mathrm{d}} \mathrm{SO} 2+\mathrm{OH}$ & $\rightarrow \mathrm{SULF}+\mathrm{HO} 2$ & 1110 & -160 \\
\hline $83^{d} \mathrm{SO} 2$ & $\rightarrow$ SULF & 0.00008 & 0 \\
\hline $84 \mathrm{MEOH}+\mathrm{OH}$ & $\rightarrow$ FORM + $\mathrm{HO} 2$ & 1380 & 451 \\
\hline $85 \mathrm{ETOH}+\mathrm{OH}$ & $\begin{aligned} \rightarrow & \mathrm{HO} 2+0.95 \mathrm{ACET}+0.011 \mathrm{ALDX} \\
& +0.078 \mathrm{FORM}+0.05 \mathrm{XO} 2\end{aligned}$ & 4791 & 70 \\
\hline $86 \mathrm{XO} 2+\mathrm{HO} 2$ & $\rightarrow$ & 4,970 & -720 \\
\hline $87 \mathrm{MEOH}+\mathrm{NO} 3$ & $\rightarrow \mathrm{HO} 2+\mathrm{HNO} 3+\mathrm{FORM}$ & 0.33 & 0 \\
\hline $88 \mathrm{ETOH}+\mathrm{NO} 3$ & $\rightarrow \mathrm{HO} 2+\mathrm{HNO} 3+\mathrm{ACET}$ & 1.33 & 0 \\
\hline 89 ALDX + O & $\rightarrow \mathrm{CXO} 3+\mathrm{OH}-\mathrm{PAR}$ & 636 & 986 \\
\hline $90 \mathrm{ALDX}+\mathrm{OH}$ & $\rightarrow \mathrm{CXO} 3-\mathrm{PAR}$ & 24,000 & -250 \\
\hline $91 \mathrm{ALDX}+\mathrm{NO} 3$ & $\rightarrow \mathrm{CXO} 3+\mathrm{HNO} 3-\mathrm{PAR}$ & 4.03 & 1860 \\
\hline 92 ALDX & $\rightarrow \mathrm{ACET}+2 \mathrm{HO} 2+\mathrm{CO}+\mathrm{XO} 2-\mathrm{PAR}$ & Radiation dependent ${ }^{\mathrm{b}}$ & \\
\hline $93 \mathrm{IOLE}+\mathrm{O}$ & $\begin{aligned} \rightarrow & 1.14 \mathrm{ACET}+0.76 \mathrm{ALDX}+0.1 \mathrm{HO} 2 \\
& +0.1 \mathrm{XO} 2+0.1 \mathrm{CO}+0.1 \mathrm{PAR}\end{aligned}$ & 34,000 & 0 \\
\hline $94 \mathrm{IOLE}+\mathrm{OH}$ & $\rightarrow 1.2 \mathrm{ACET}+0.8 \mathrm{ALDX}+\mathrm{HO} 2+\mathrm{XO} 2$ & 94,300 & -550 \\
\hline 95 IOLE + O3 & $\begin{aligned} \rightarrow & 0.60 \mathrm{ACET}+0.40 \text { ALDX }+0.25 \mathrm{FORM}+ \\
& 0.25 \mathrm{CO}+0.5 \mathrm{O}+0.5 \mathrm{OH}+0.5 \mathrm{HO} 2\end{aligned}$ & 0.31 & 1100 \\
\hline $96 \mathrm{IOLE}+\mathrm{NO} 3$ & $\begin{aligned} \rightarrow & 1.09 \mathrm{ACET}+0.73 \mathrm{ALDX}+0.91 \mathrm{XO} 2 \\
& +\mathrm{NO} 2\end{aligned}$ & 573 & 0 \\
\hline $97 \mathrm{CXO} 3+\mathrm{NO}$ & $\rightarrow \mathrm{ACET}+\mathrm{NO} 2+\mathrm{HO} 2+\mathrm{XO} 2$ & 28,200 & 180 \\
\hline $98 \mathrm{CXO} 3+\mathrm{NO} 2$ & $\rightarrow$ PANX & 13,700 & -380 \\
\hline 99 PANX & $\rightarrow \mathrm{CXO} 3+\mathrm{NO} 2$ & 0.0254 & 13,500 \\
\hline
\end{tabular}

Continued 
TABLE A-2. Concluded.

\begin{tabular}{|c|c|c|c|}
\hline & Reaction & $\begin{array}{l}\text { Rate Constant } \\
\text { @ } 298 \mathrm{~K} \\
\left(\mathrm{ppm}^{\mathrm{a}} \mathrm{min}^{-1}\right)\end{array}$ & $E / R(K)$ \\
\hline $100 \mathrm{CXO} 3+\mathrm{C} 2 \mathrm{O} 3$ & $\rightarrow \mathrm{ACET}+\mathrm{FORM}+2 \mathrm{XO} 2+2 \mathrm{HO} 2$ & 24,500 & -530 \\
\hline $101 \mathrm{CXO} 3+\mathrm{HO} 2$ & $\rightarrow 0.33 \mathrm{O} 3$ & 20,900 & -1040 \\
\hline $102 \mathrm{PANX}+\mathrm{OH}$ & $\rightarrow \mathrm{ACET}+\mathrm{NO} 2$ & 1700 & 0 \\
\hline $103 \mathrm{BENZ}+\mathrm{OH}$ & $\rightarrow$ no prod $+\mathrm{OH}^{\circ}$ & 1833 & 0 \\
\hline $104 \mathrm{BUTA}+\mathrm{OH}$ & $\rightarrow$ no prod $+\mathrm{OH}^{\mathrm{c}}$ & 98,333 & -470 \\
\hline 105 BUTA + O3 & $\rightarrow$ no prod $+\mathrm{O}^{\circ}$ & 0.0103 & 2630 \\
\hline 106 BUTA + NO3 & $\rightarrow$ no prod $+\mathrm{NO}^{\mathrm{C}}$ & 145 & 0 \\
\hline $107^{\mathrm{d}} \mathrm{NAPH}+\mathrm{OH}$ & $\rightarrow 0.02 \mathrm{POMl}+0.5 \mathrm{NAPH}+\mathrm{OH}^{c}$ & 60,000 & -440 \\
\hline $108^{d} \mathrm{NAPH}+\mathrm{N} 2 \mathrm{O} 5$ & $\rightarrow 0.4 \mathrm{POM} 1+0.5 \mathrm{NAPH}+\mathrm{N}_{2} \mathrm{O}^{\mathrm{c}}$ & 0.03 & 0 \\
\hline $109^{d} \mathrm{POM} 1+\mathrm{OH}$ & $\rightarrow 0.1 \mathrm{POM} 2+0.5 \mathrm{POM} 1+\mathrm{OH}^{\mathrm{c}}$ & 70,000 & -440 \\
\hline $110^{\mathrm{d}} \mathrm{POM} 1+\mathrm{N} 2 \mathrm{O} 5$ & $\rightarrow \mathrm{POM} 2+\mathrm{N} 2 \mathrm{O}^{\mathrm{C}}$ & 0.05 & 0 \\
\hline $111 \mathrm{XO} 2 \mathrm{~N}+\mathrm{HO} 2$ & $\rightarrow$ & 4970 & -720 \\
\hline $112 \mathrm{XO} 2 \mathrm{~N}+\mathrm{XO} 2 \mathrm{~N}$ & $\rightarrow$ & 2000 & -1300 \\
\hline $113 \mathrm{XO} 2 \mathrm{~N}+\mathrm{XO} 2$ & $\rightarrow$ & 4000 & -1300 \\
\hline $114 \mathrm{OH}+\mathrm{HO} 2$ & $\rightarrow$ & 162,600 & -250 \\
\hline $115 \mathrm{MTBE}+\mathrm{OH}$ & $\begin{aligned} \rightarrow & 1.37 \mathrm{XO} 2+0.98 \mathrm{HO} 2+0.42 \mathrm{FORM} \\
& +0.97 \mathrm{PAR}+0.02 \mathrm{XO} 2 \mathrm{~N}\end{aligned}$ & 4180 & 0 \\
\hline
\end{tabular}

${ }^{a}$ Pressure dependent values for the concentrations of $\mathrm{M}$ and $\mathrm{O}_{2}$ are included in the rate constants where appropriate: $[\mathrm{M}]=10^{6} \mathrm{ppm},\left[\mathrm{O}_{2}\right]=2.095 \times 10^{5} \mathrm{ppm}$.

${ }^{\mathrm{b}}$ Photolysis reaction with rate specified as a function of solar zenith angle.

'No carbon-containing products included because reactivity is accounted for in the CBM representation. Non-carbon containing reactant is also included as a product so as not to perturb its concentration.

${ }^{\mathrm{d}}$ Not used in this application. 
TABLE A-3. Photolysis rates $\left(\mathrm{min}^{-1}\right)$ used in the UAM-Tox.

\begin{tabular}{|c|c|c|c|c|c|c|c|c|c|c|}
\hline \multirow[b]{2}{*}{ Reaction } & \multicolumn{10}{|c|}{ Zenith Angle } \\
\hline & 0 & 10 & 20 & 30 & 40 & 50 & 60 & 70 & 78 & 86 \\
\hline 1 & 0.6140 & 0.6084 & 0.5914 & 0.5623 & 0.5194 & 0.4596 & 0.3777 & 0.2649 & 0.1490 & $4.408 \mathrm{E}-2$ \\
\hline 8 & $2.400 \mathrm{E}-2$ & $2.400 \mathrm{E}-2$ & $2.300 \mathrm{E}-2$ & $2.200 \mathrm{E}-2$ & $2.100 \mathrm{E}-2$ & $1.900 \mathrm{E}-2$ & $1.700 \mathrm{E}-2$ & $1.200 \mathrm{E}-2$ & $7.400 \mathrm{E}-3$ & $1.100 \mathrm{E}-3$ \\
\hline 9 & $2.798 \mathrm{E}-3$ & $2.699 \mathrm{E}-3$ & $2.415 \mathrm{E}-3$ & $1.983 \mathrm{E}-3$ & $1.458 \mathrm{E}-3$ & $9.195 \mathrm{E}-4$ & $4.558 \mathrm{E}-4$ & $1.502 \mathrm{E}-4$ & $3.881 \mathrm{E}-5$ & $4.702 \mathrm{E}-6$ \\
\hline 14 & 14.11 & 14.11 & 13.88 & 13.54 & 12.98 & 12.10 & 10.73 & 8.290 & 5.110 & 0.7400 \\
\hline 23 & 0.1157 & 0.1146 & 0.1113 & 0.1057 & $9.728 \mathrm{E}-2$ & $8.561 \mathrm{E}-2$ & $6.965 \mathrm{E}-2$ & $4.792 \mathrm{E}-2$ & $2.619 \mathrm{E}-2$ & $7.382 \mathrm{E}-3$ \\
\hline 34 & $5.125 \mathrm{E}-4$ & $5.044 \mathrm{E}-4$ & $4.800 \mathrm{E}-4$ & $4.397 \mathrm{E}-4$ & $3.838 \mathrm{E}-4$ & $3.130 \mathrm{E}-4$ & $2.285 \mathrm{E}-4$ & $1.344 \mathrm{E}-4$ & $6.129 \mathrm{E}-5$ & $1.247 \mathrm{E}-5$ \\
\hline 38 & $2.284 \mathrm{E}-3$ & $2.247 \mathrm{E}-3$ & $2.134 \mathrm{E}-3$ & $1.946 \mathrm{E}-3$ & $1.685 \mathrm{E}-3$ & $1.353 \mathrm{E}-3$ & $9.606 \mathrm{E}-4$ & $5.363 \mathrm{E}-4$ & $2.265 \mathrm{E}-4$ & 3.927E-5 \\
\hline 39 & $3.057 \mathrm{E}-3$ & $3.019 \mathrm{E}-3$ & $2.906 \mathrm{E}-3$ & $2.714 \mathrm{E}-3$ & $2.437 \mathrm{E}-3$ & $2.065 \mathrm{E}-3$ & $1.587 \mathrm{E}-3$ & $9.967 \mathrm{E}-4$ & $4.846 \mathrm{E}-4$ & $1.065 \mathrm{E}-4$ \\
\hline 45 & $4.199 \mathrm{E}-4$ & $4.099 \mathrm{E}-4$ & $3.804 \mathrm{E}-4$ & $3.332 \mathrm{E}-4$ & $2.712 \mathrm{E}-4$ & $1.993 \mathrm{E}-4$ & $1.246 \mathrm{E}-4$ & $5.802 \mathrm{E}-5$ & $2.024 \mathrm{E}-5$ & $2.813 \mathrm{E}-6$ \\
\hline 69 & $2.065 \mathrm{E}-2$ & $2.031 \mathrm{E}-2$ & $1.929 \mathrm{E}-2$ & $1.759 \mathrm{E}-2$ & $1.523 \mathrm{E}-2$ & $1.223 \mathrm{E}-2$ & $8.684 \mathrm{E}-3$ & $4.848 \mathrm{E}-3$ & $2.048 \mathrm{E}-3$ & $3.550 \mathrm{E}-4$ \\
\hline 74 & $2.202 \mathrm{E}-2$ & $2.166 \mathrm{E}-2$ & $2.057 \mathrm{E}-2$ & $1.876 \mathrm{E}-2$ & $1.624 \mathrm{E}-2$ & $1.304 \mathrm{E}-2$ & $9.260 \mathrm{E}-3$ & $5.170 \mathrm{E}-3$ & $2.183 \mathrm{E}-3$ & $3.786 \mathrm{E}-4$ \\
\hline 92 & $1.444 \mathrm{E}-3$ & $1.413 \mathrm{E}-3$ & $1.323 \mathrm{E}-3$ & $1.176 \mathrm{E}-3$ & $9.810 \mathrm{E}-4$ & $7.480 \mathrm{E}-4$ & $4.950 \mathrm{E}-4$ & $2.518 \mathrm{E}-4$ & $9.738 \mathrm{E}-5$ & $1.549 \mathrm{E}-5$ \\
\hline
\end{tabular}


Appendix B

EMISSION DENSITY PLOTS 


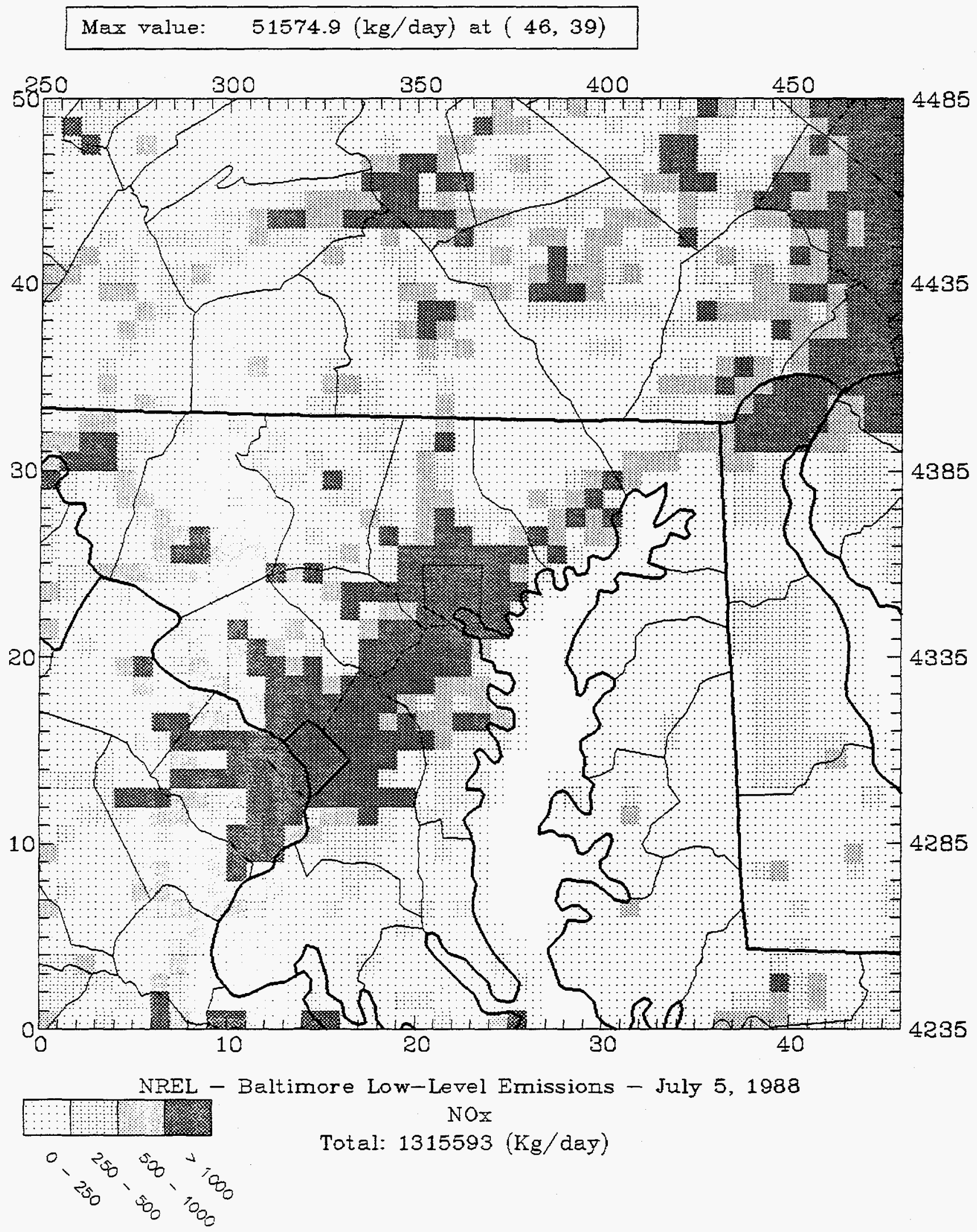




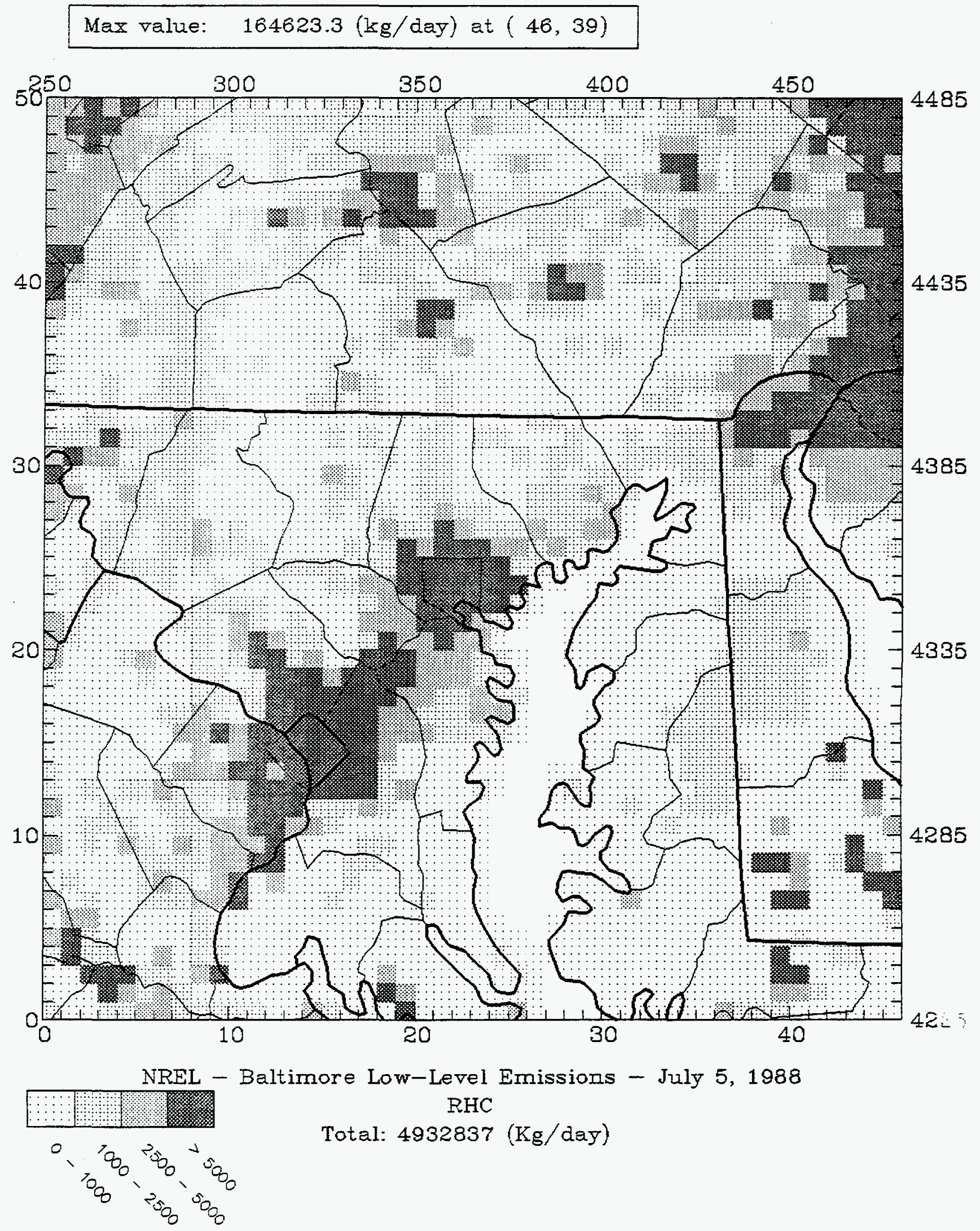




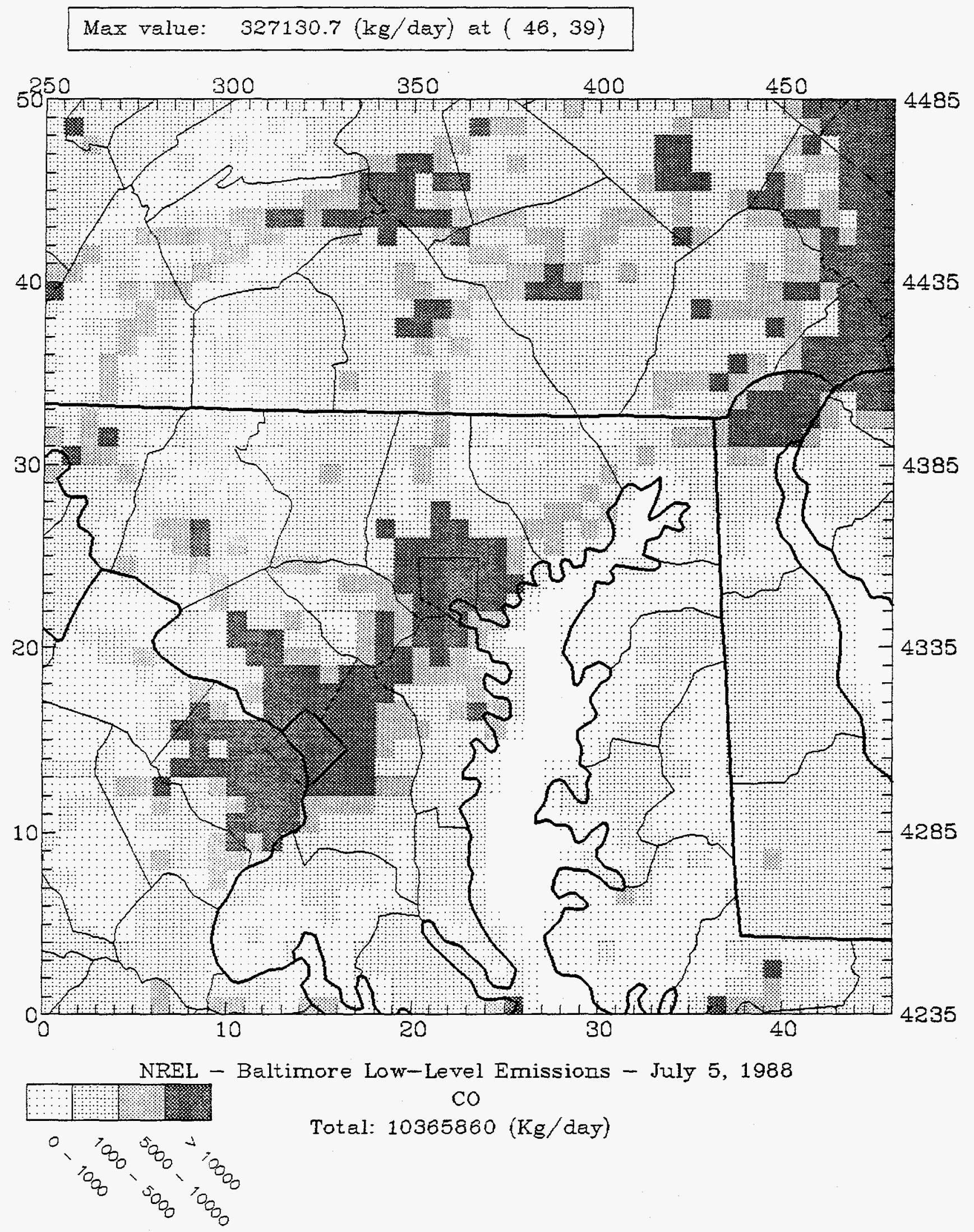




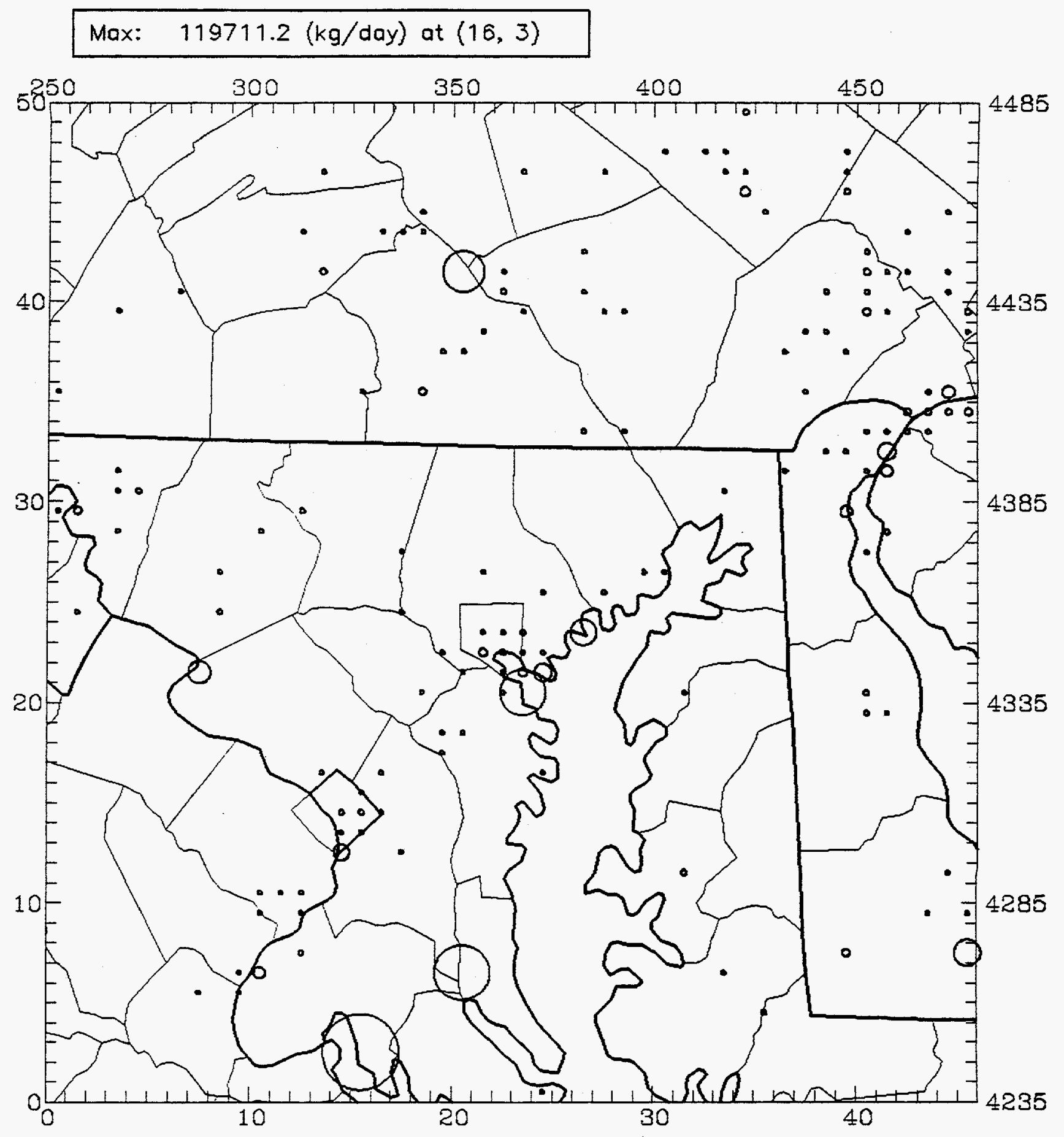

NREL - Baltimore Elevated Point Sources - July 5, 1988 NOX

Total: $680810(\mathrm{Kg} /$ day $)$

$\square=1.2 \mathrm{E} 5=6.054 \cdot=0.6 \mathrm{EO}$ 
Max: $93174.8(\mathrm{~kg} /$ day $)$ at $(38,36)$

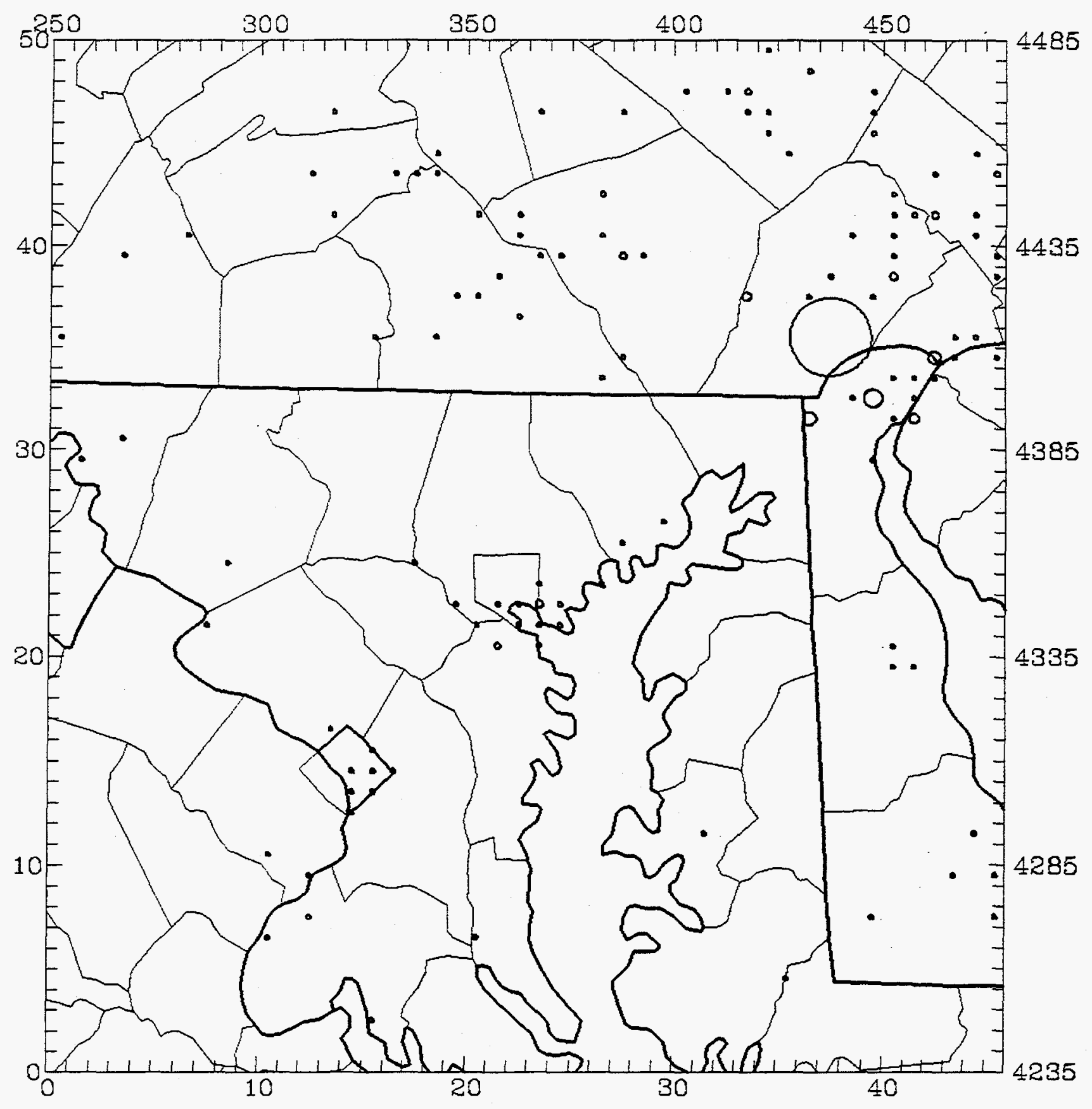

NREL - Baltimore Elevated Point Sources - July 5, 1988 $\mathrm{RHC}$

Total: $176561(\mathrm{Kg} /$ day)

$$
\bigcirc=9.3 E 4 \bigcirc=4.7 E 4 \quad \bullet=1.4 E-1
$$




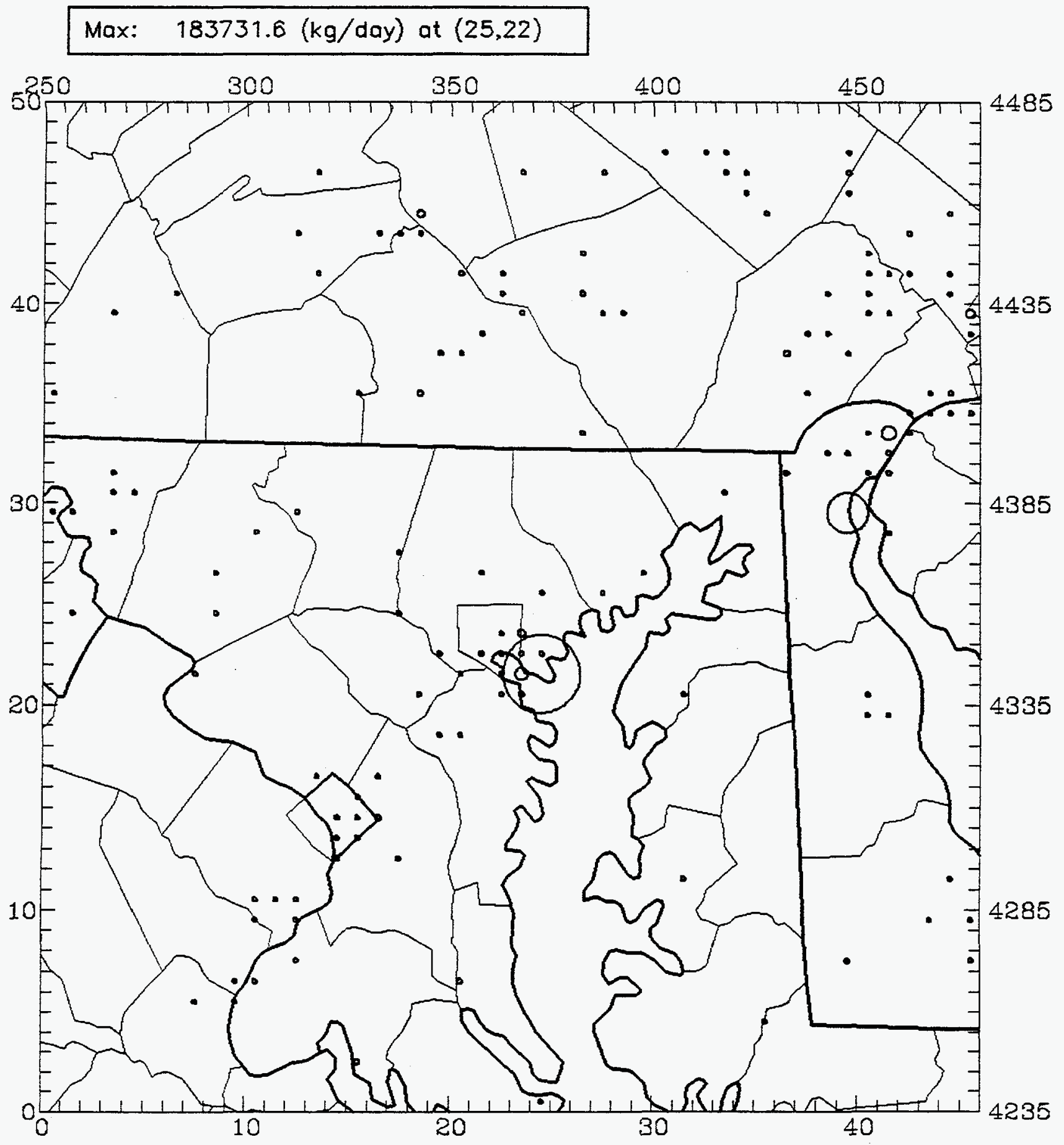

NREL - Baltimore Elevated Point Sources - July 5, 1988 CO

Total: 399277 ( $\mathrm{kg} /$ day)

$\bigcirc=1.8 \mathrm{E} 5 \bigcirc=9.2 \mathrm{E} 4 \quad \cdot=0.7 \mathrm{EO}$ 


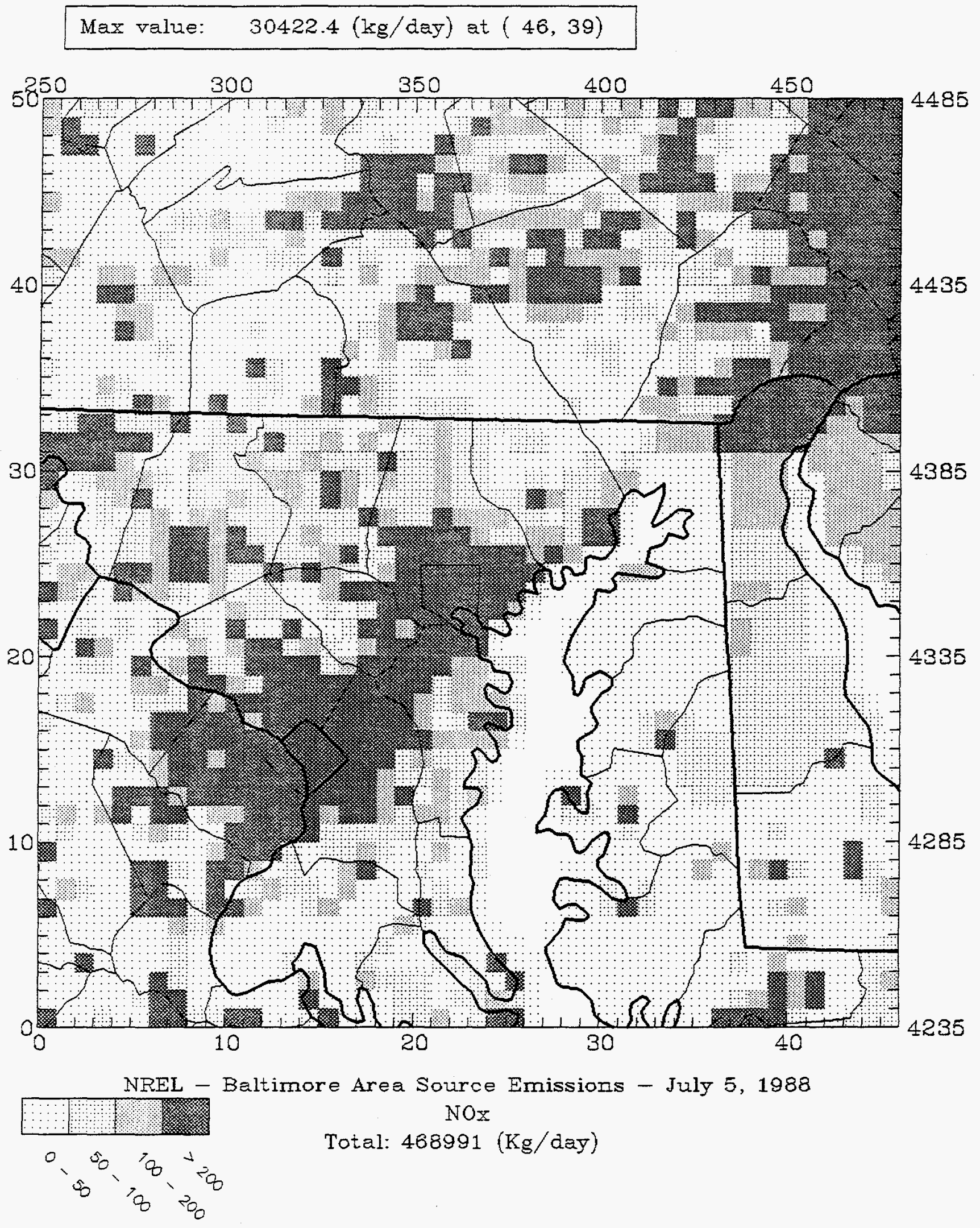




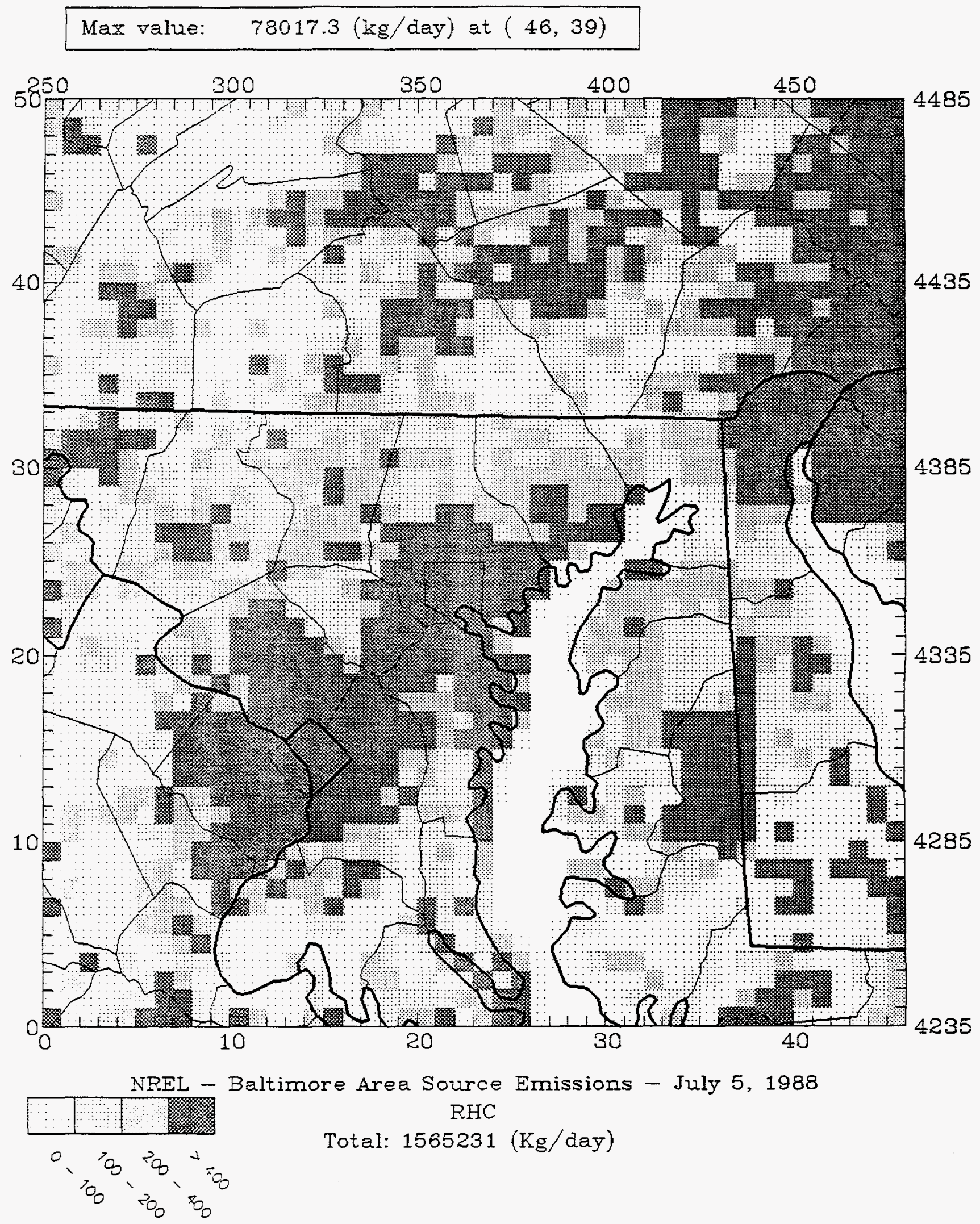




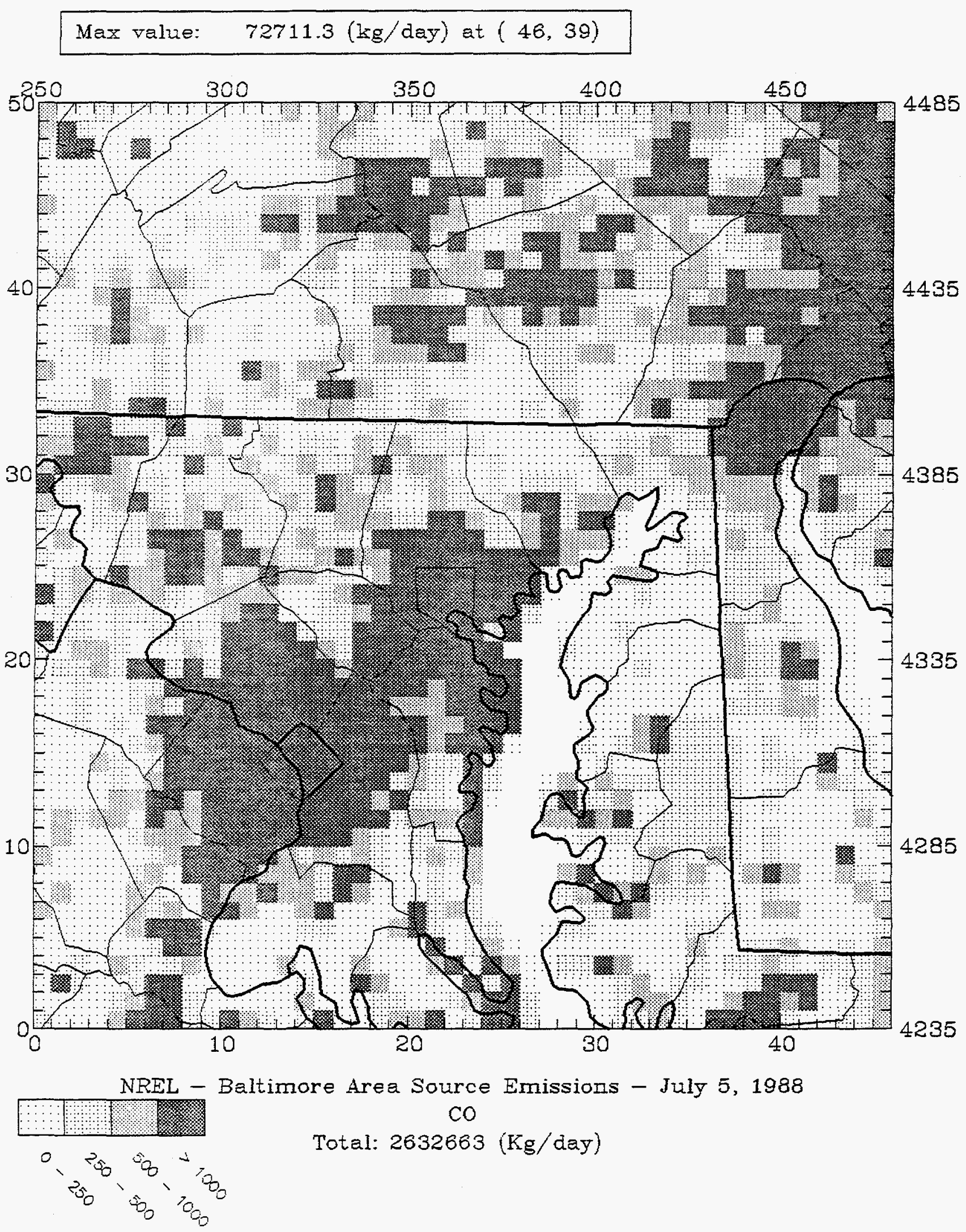




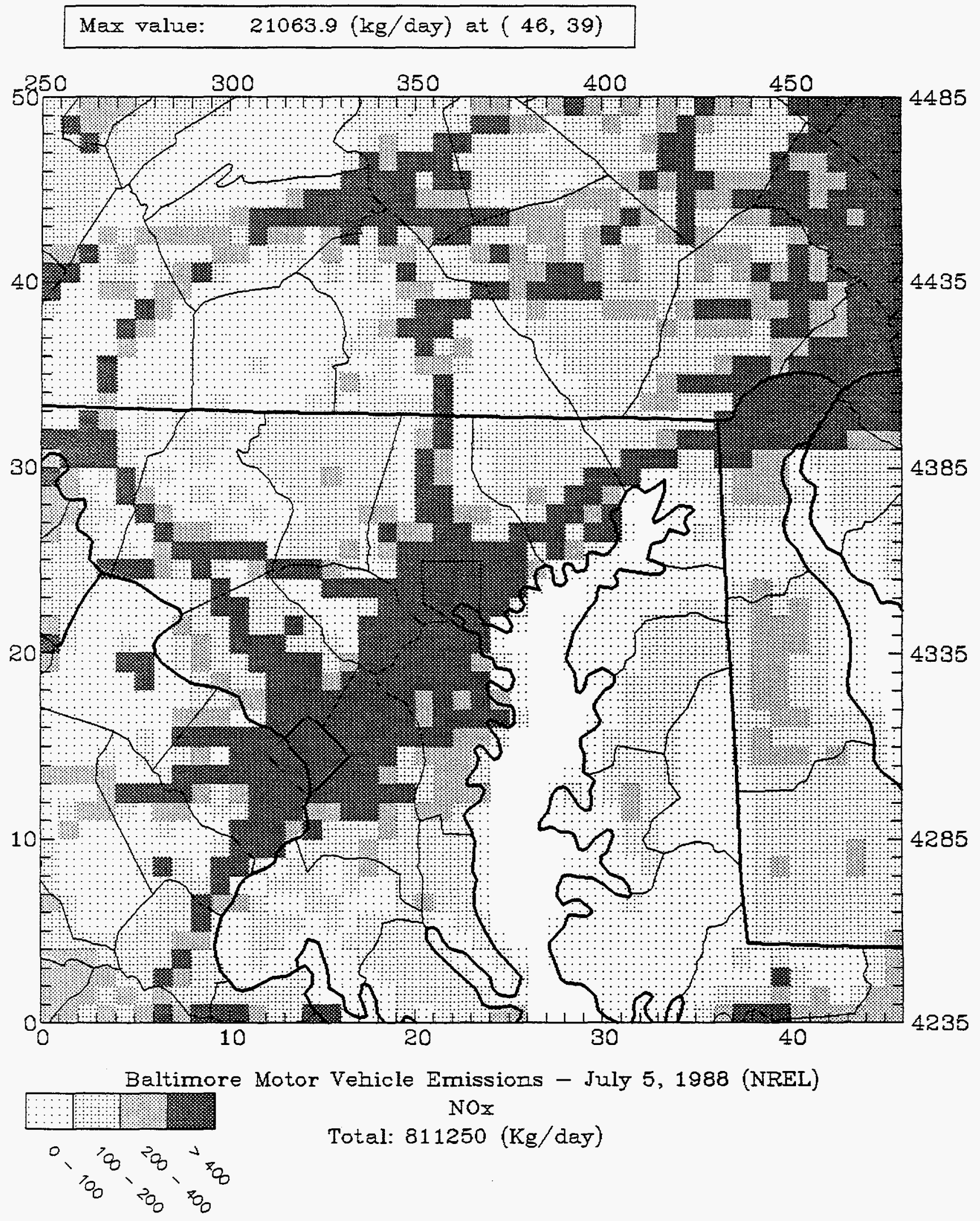




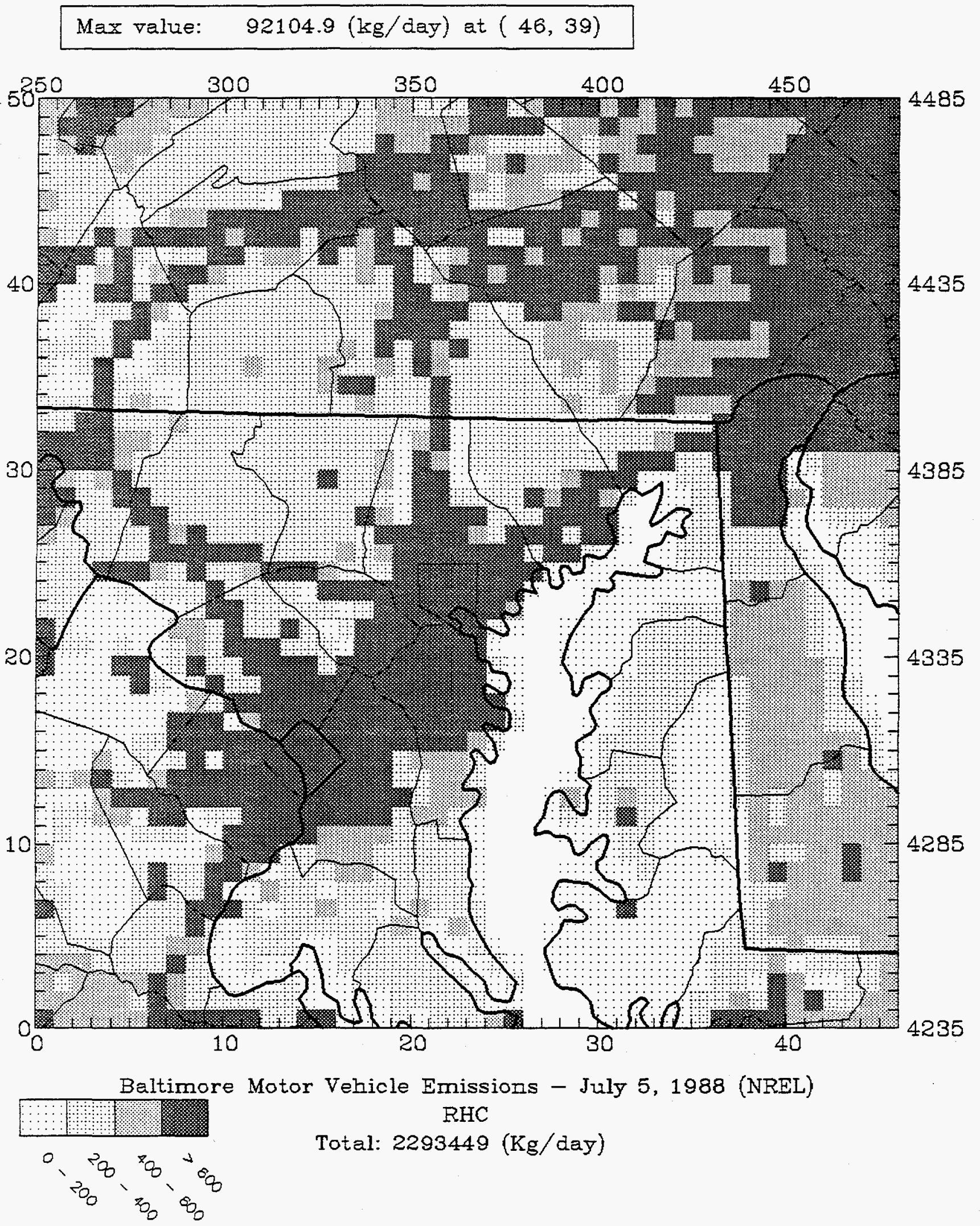




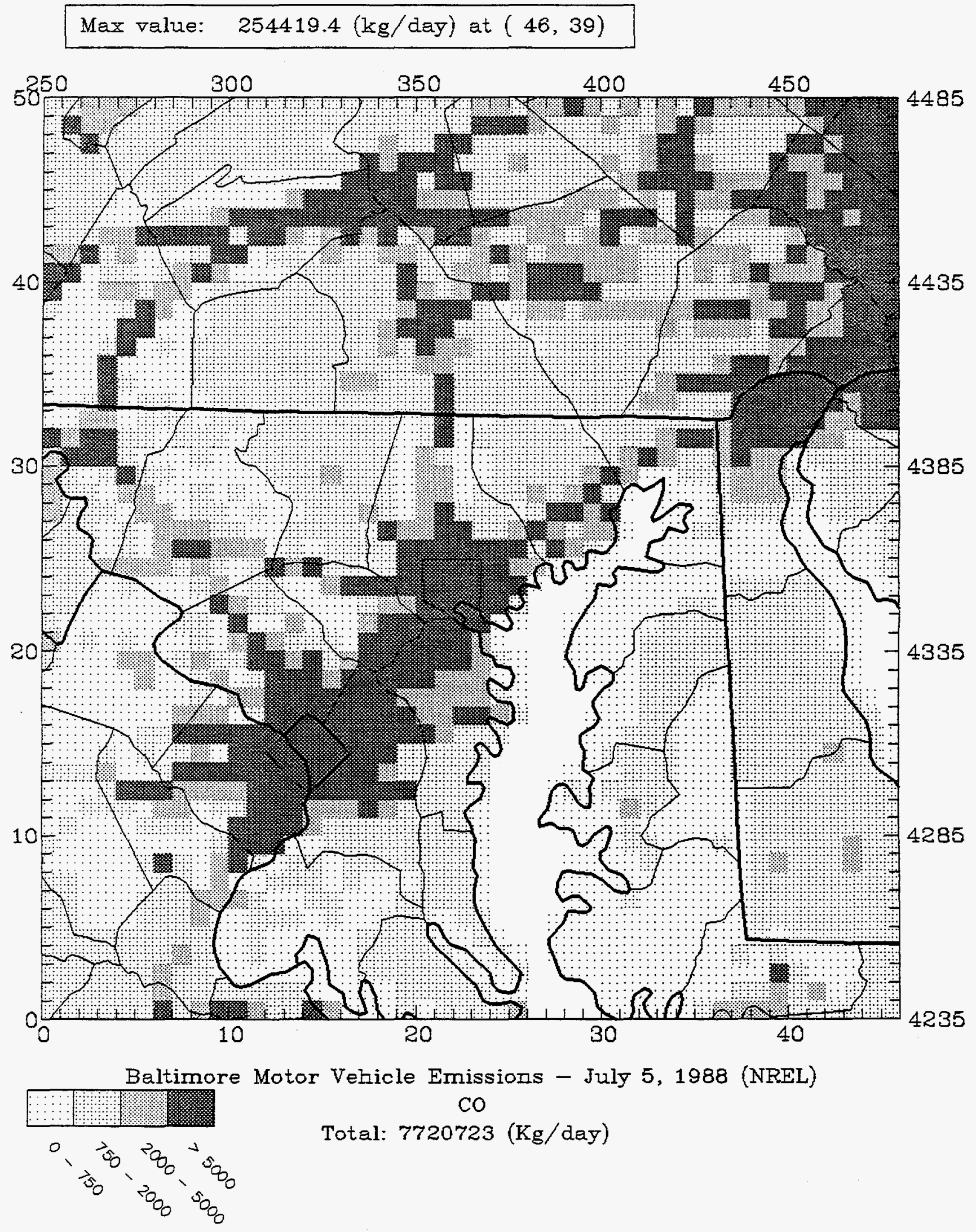




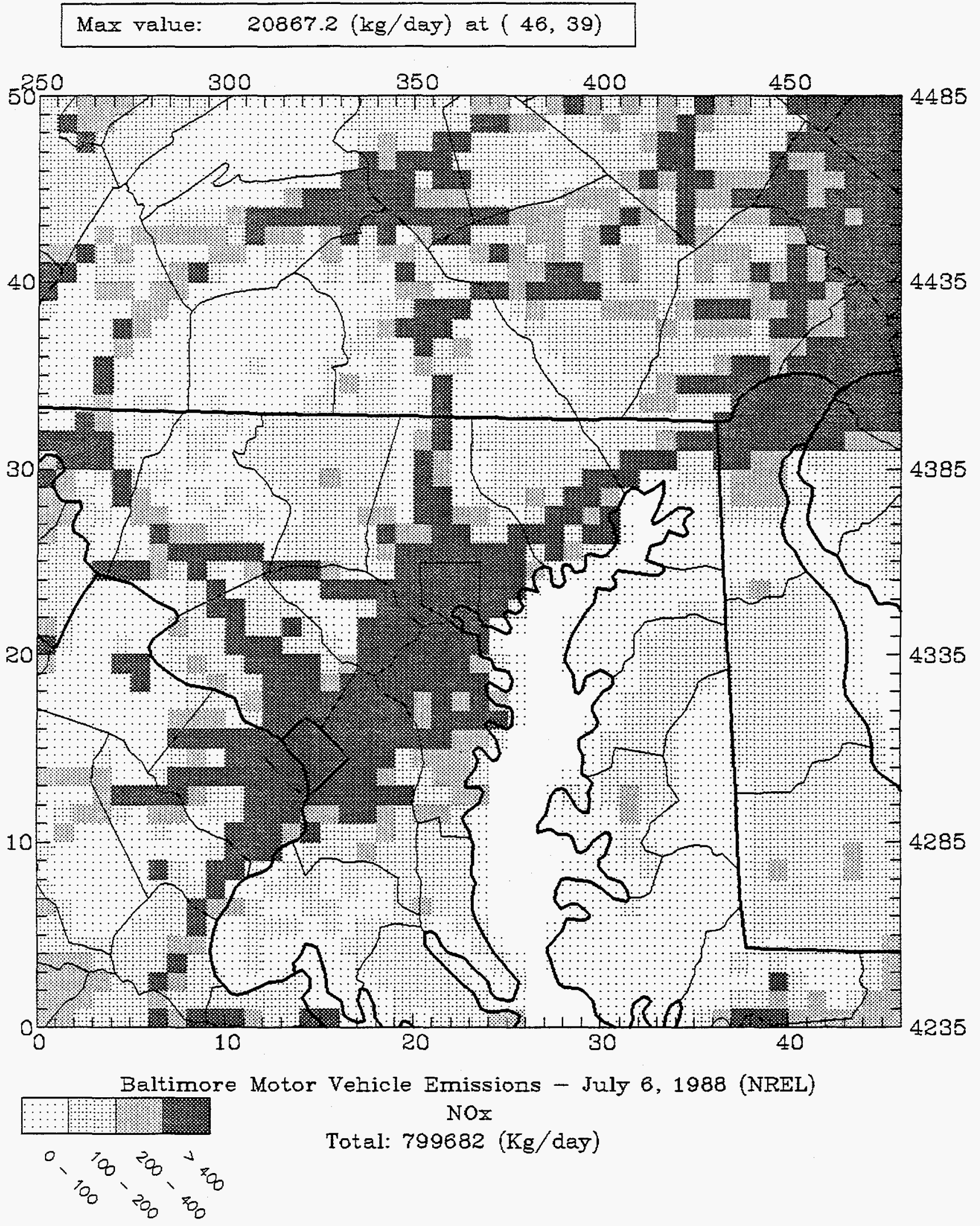




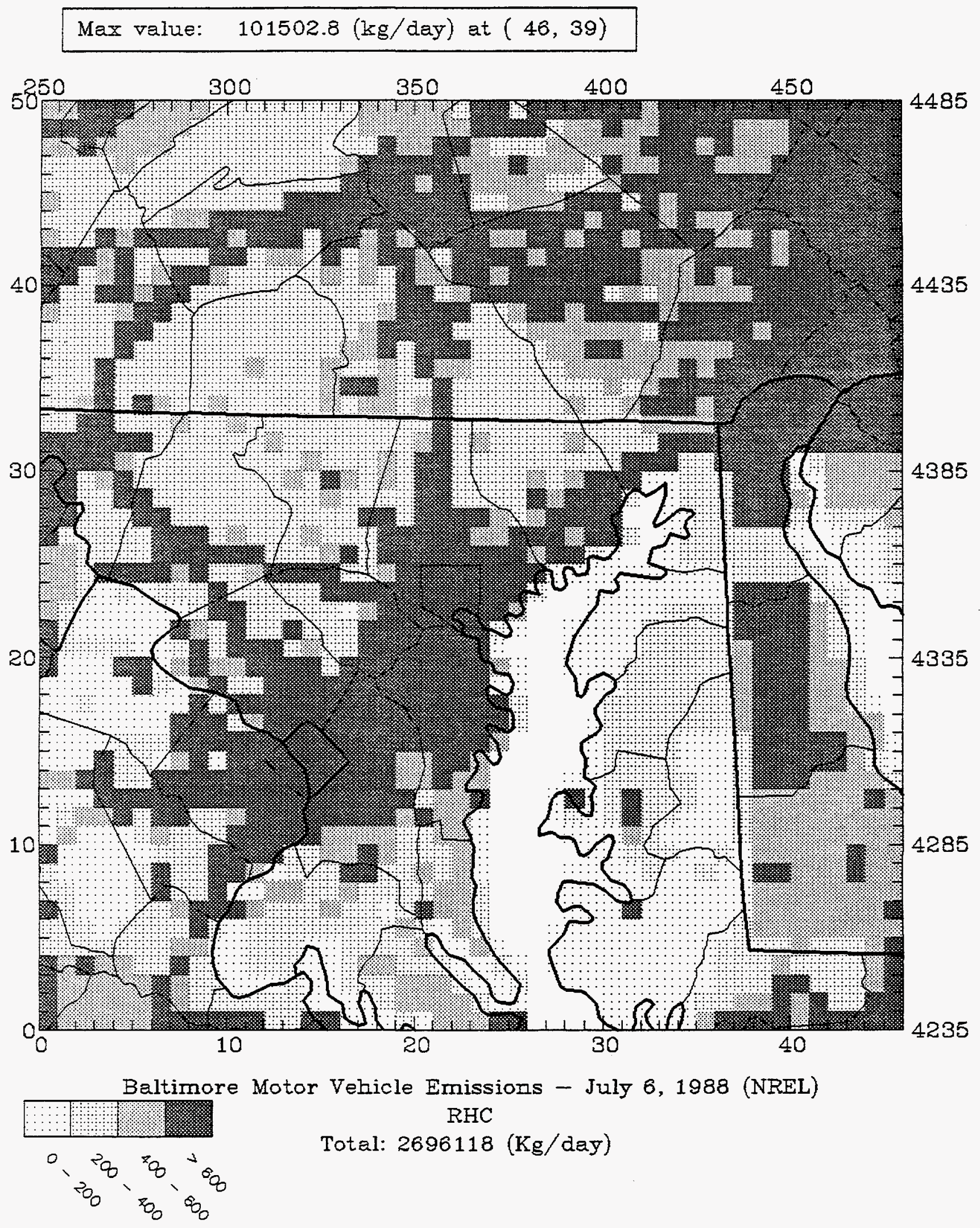




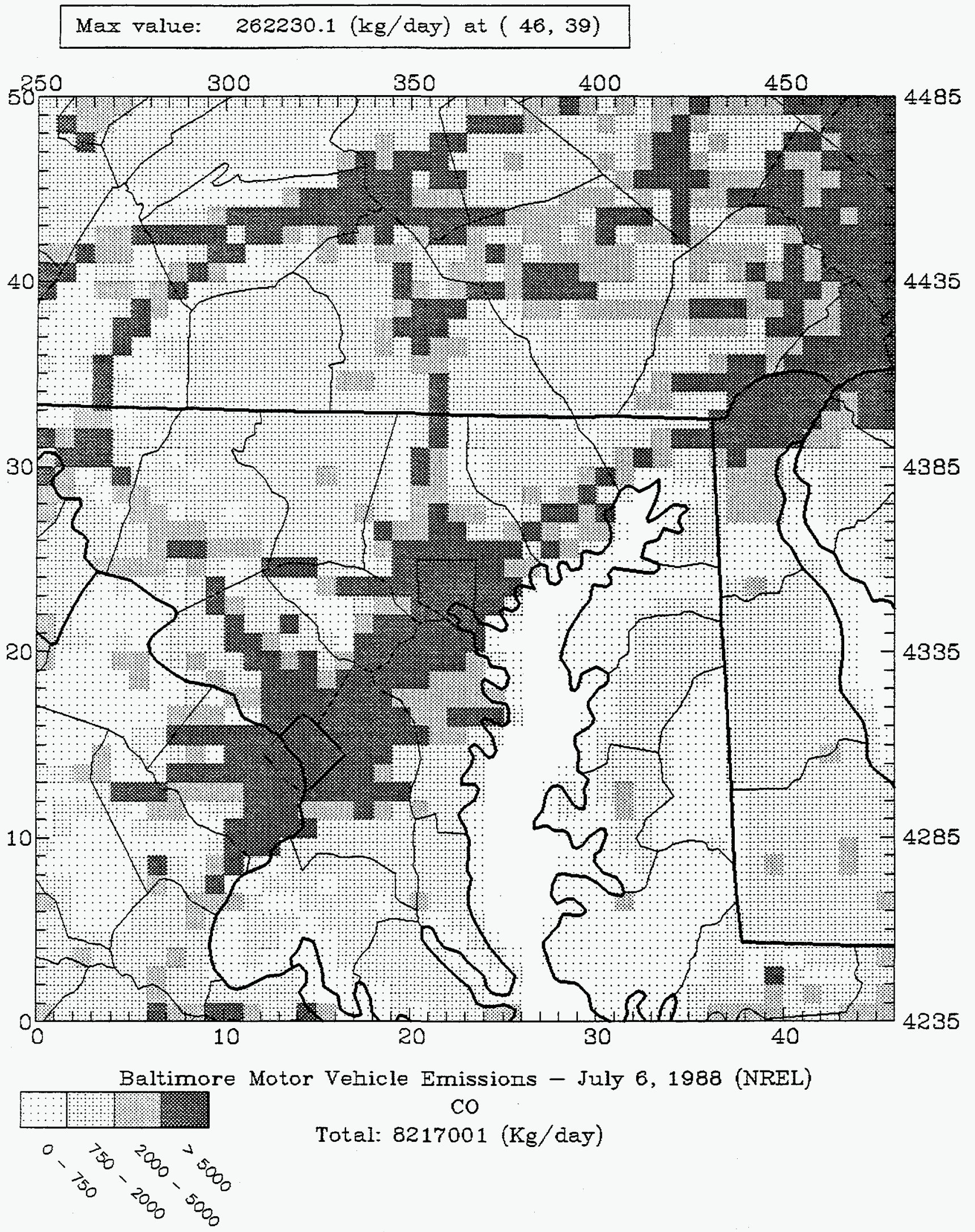




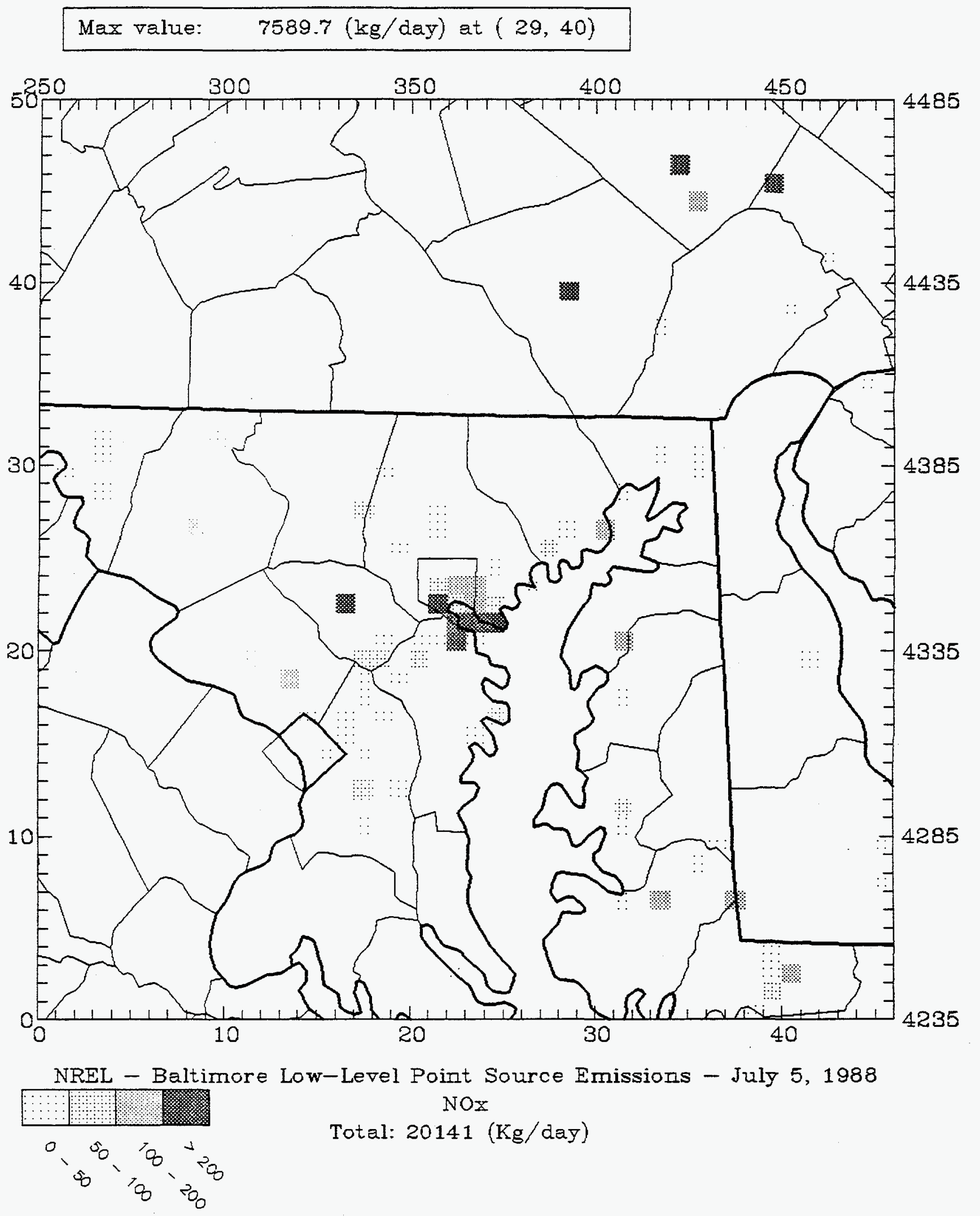




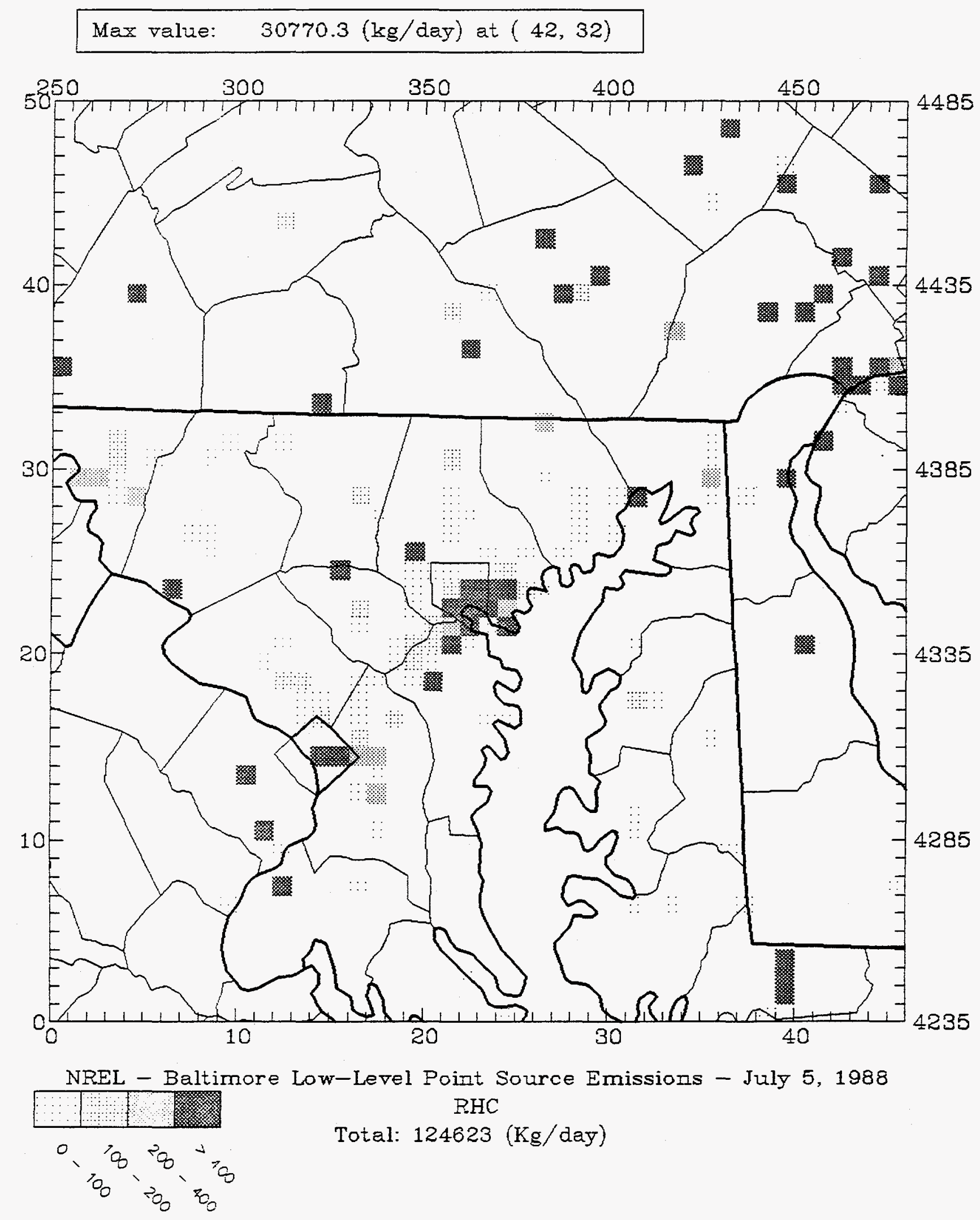




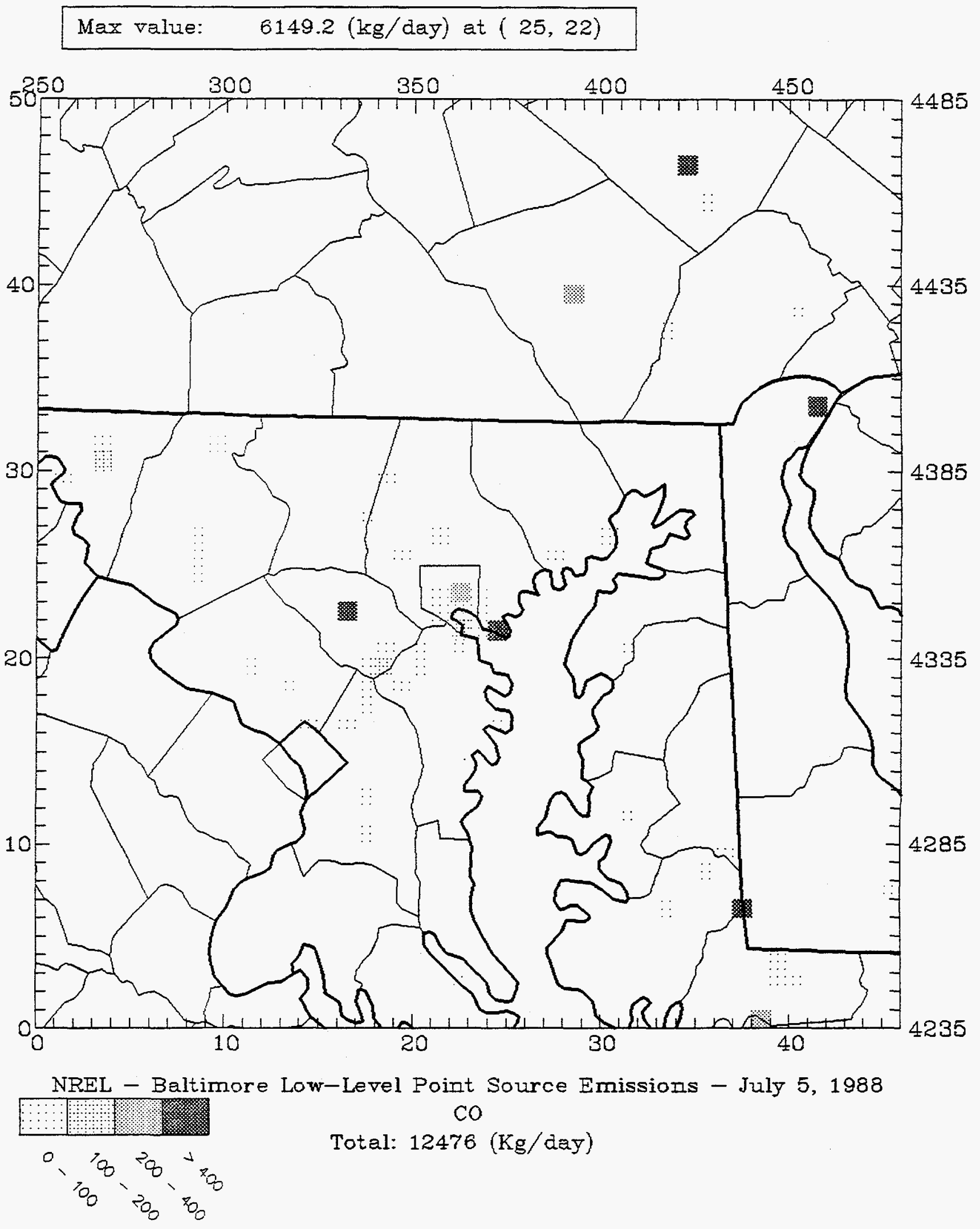




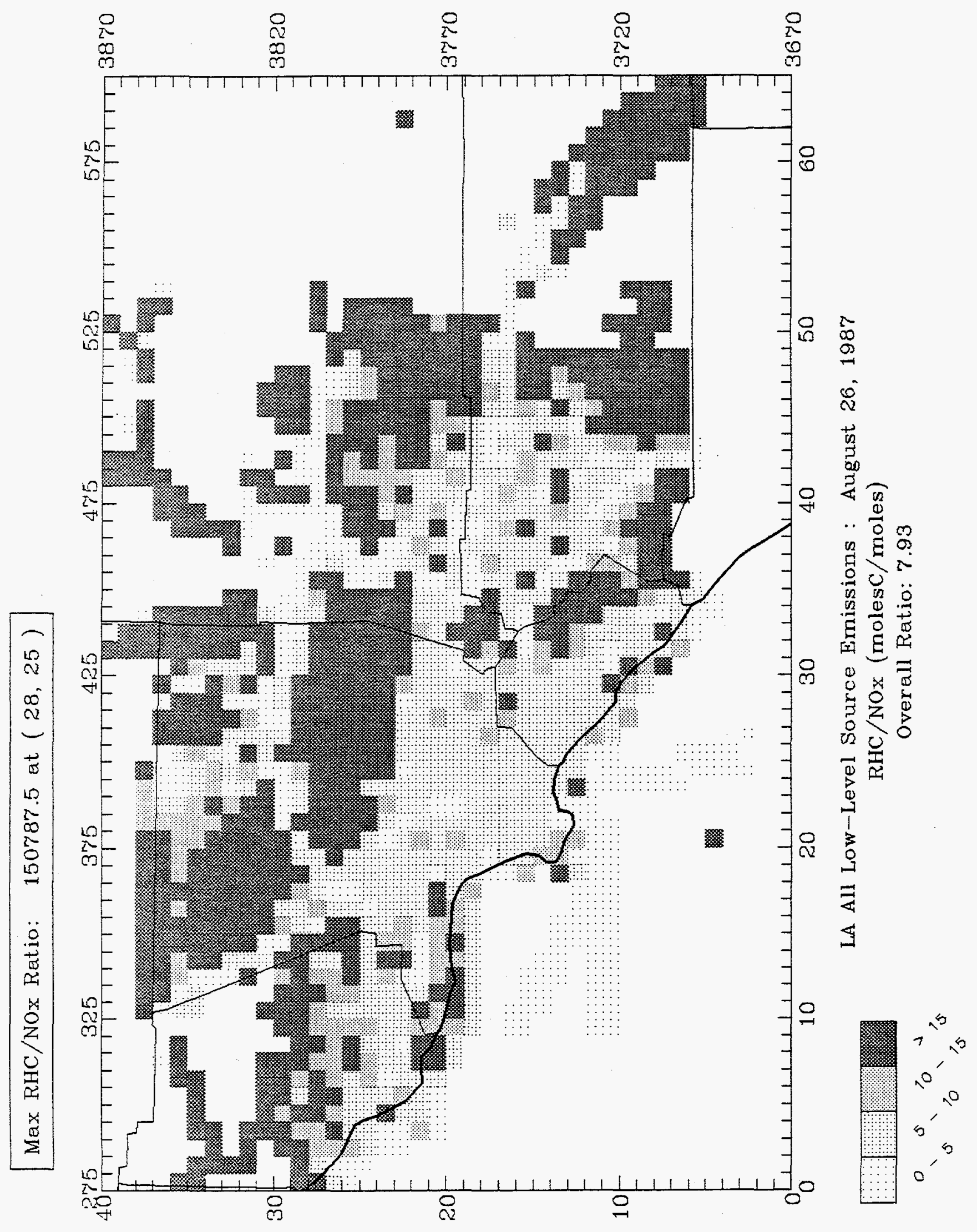




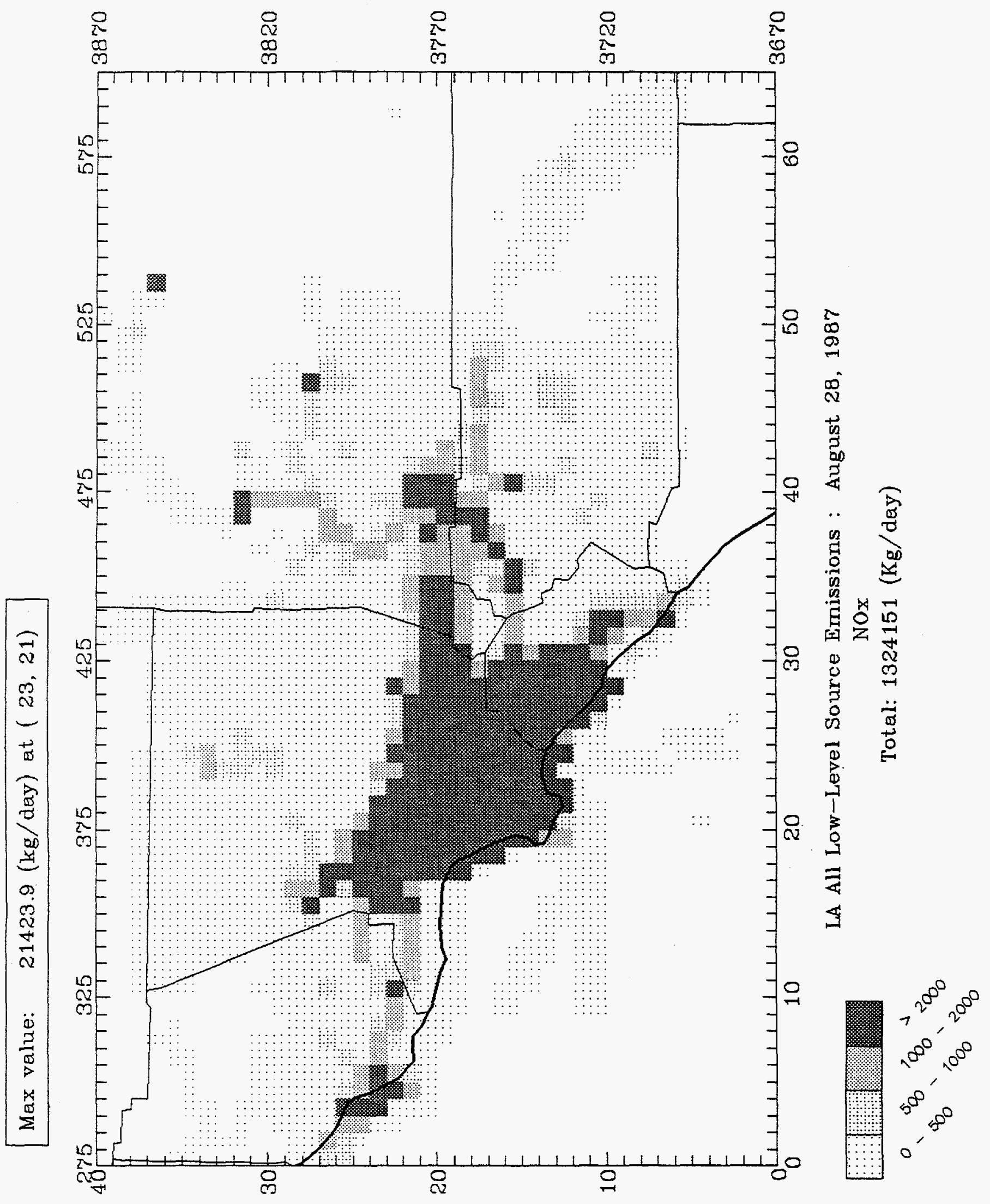




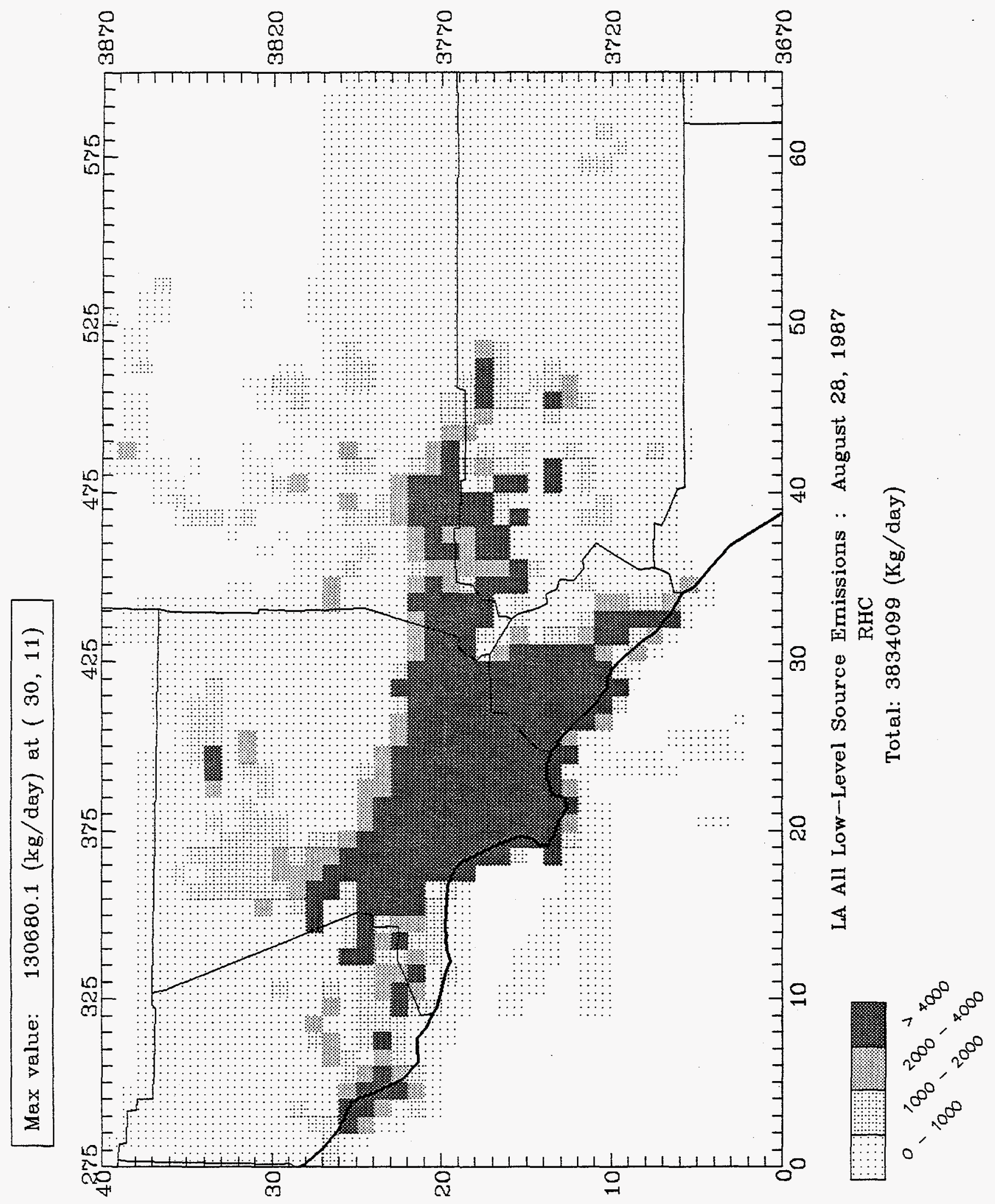




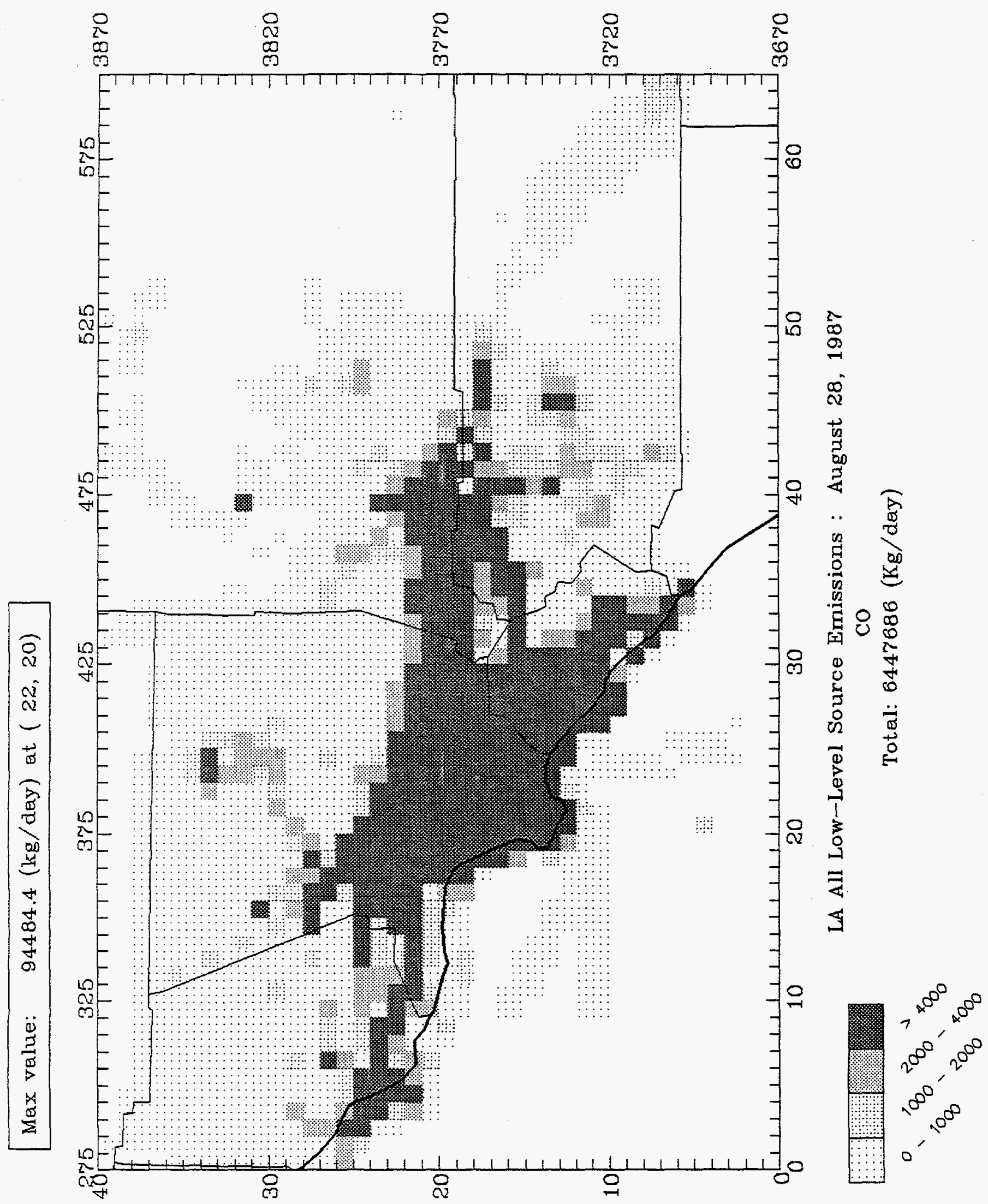




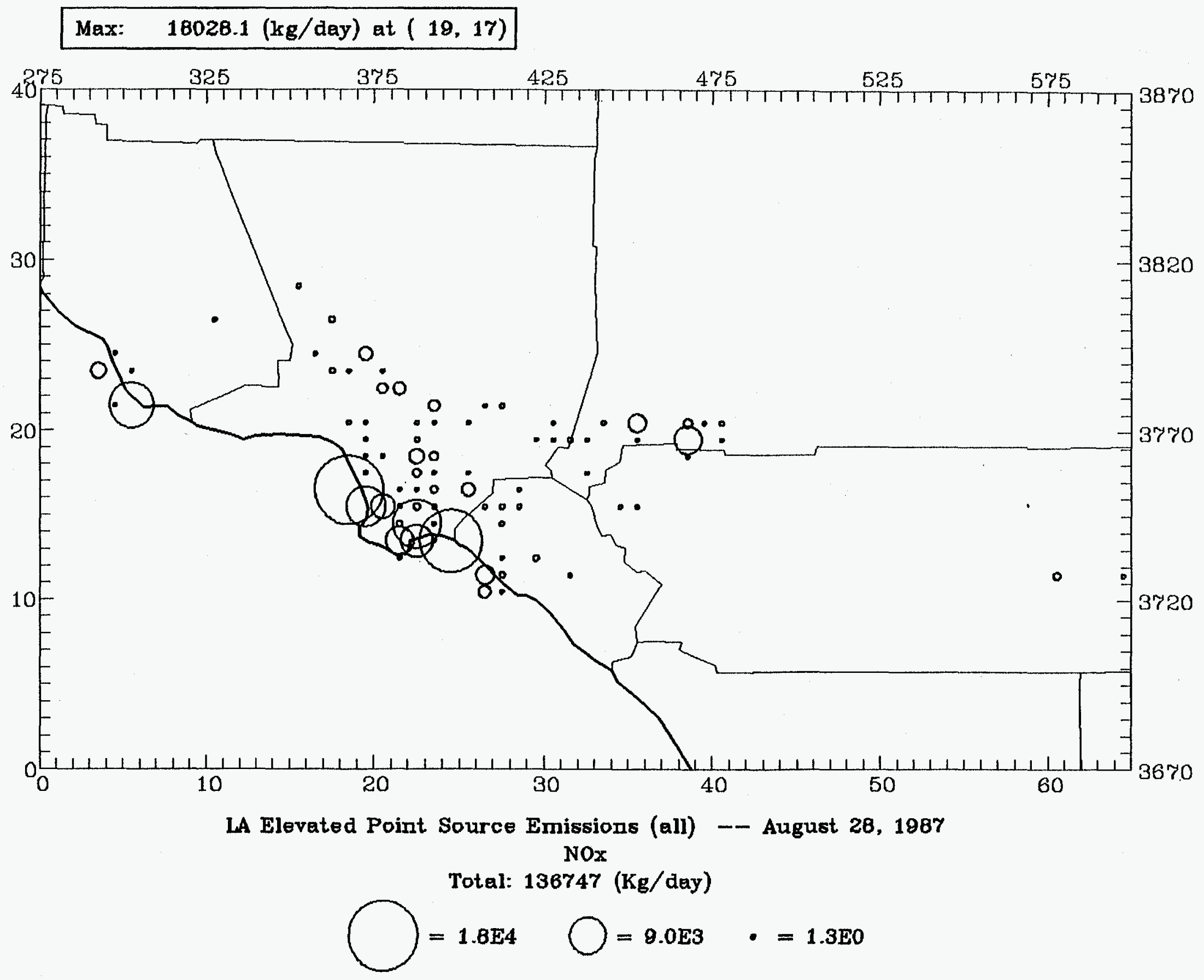




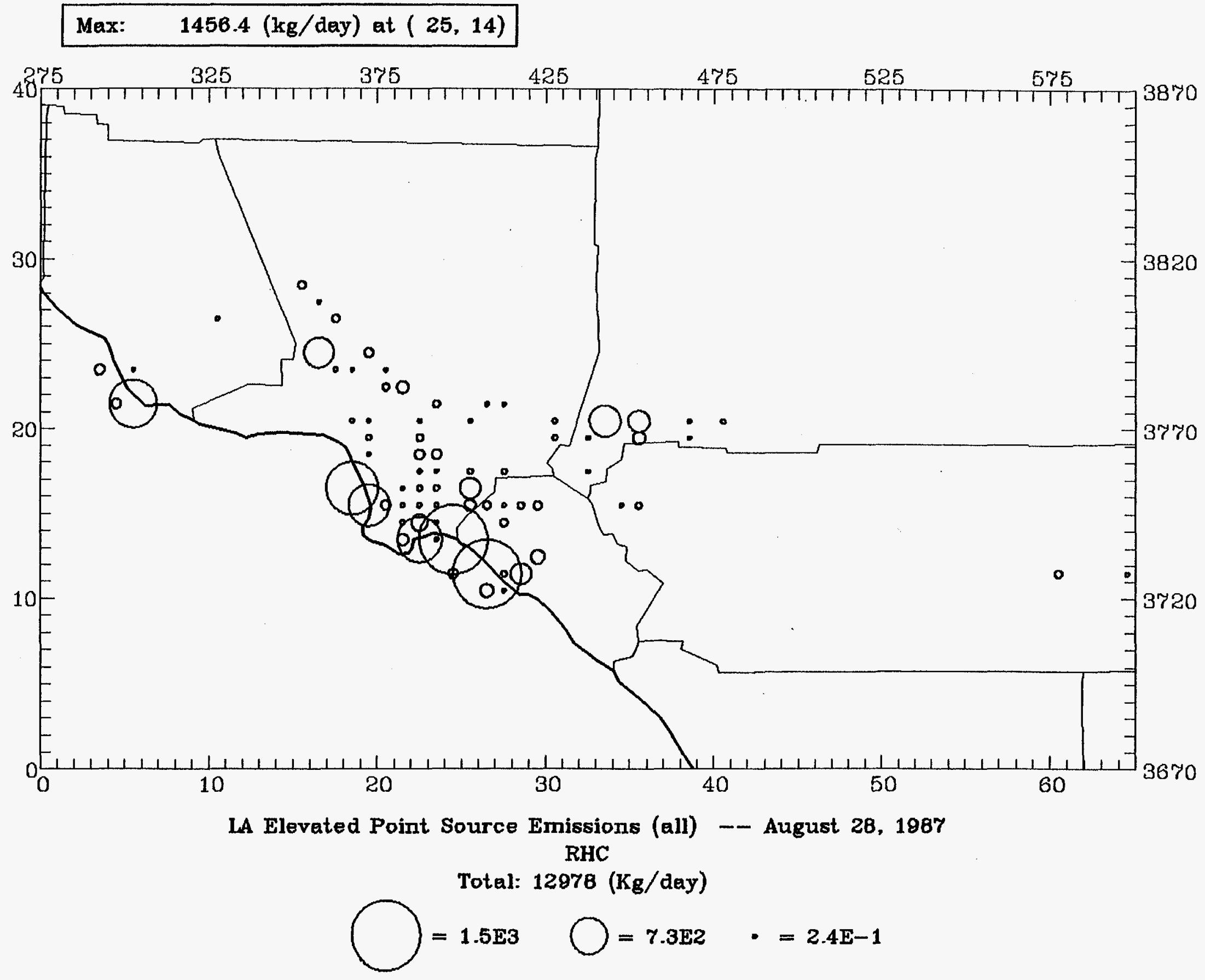




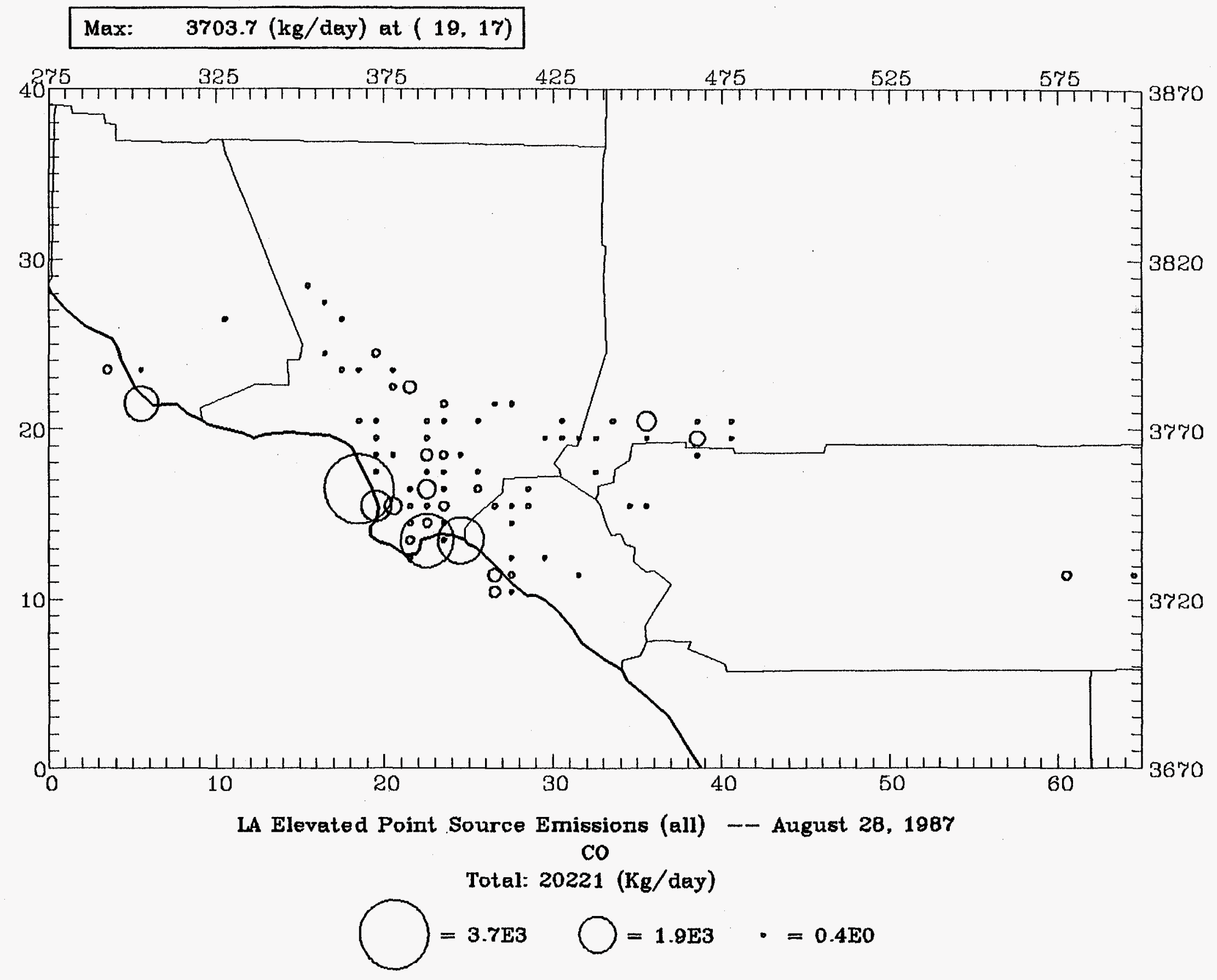




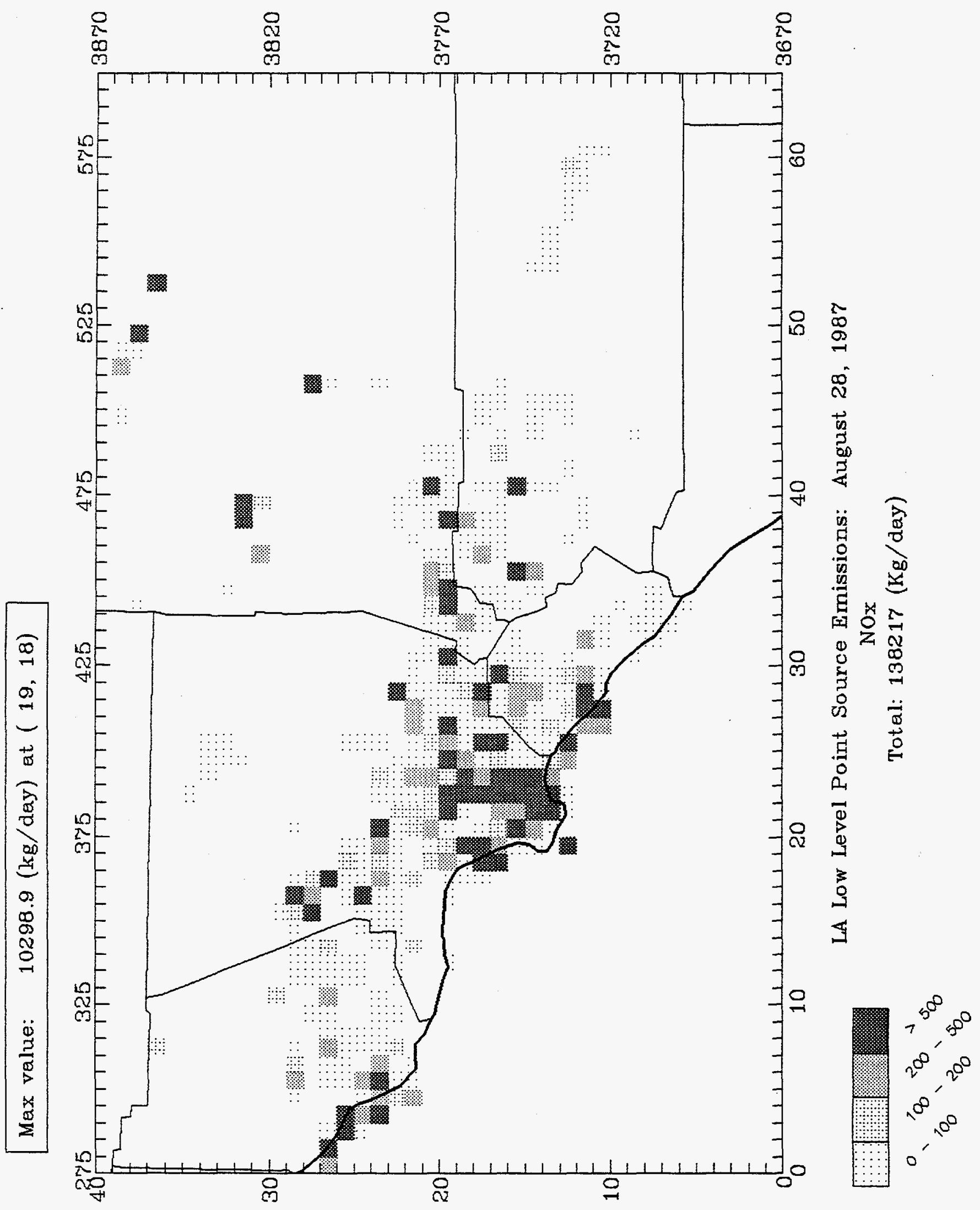




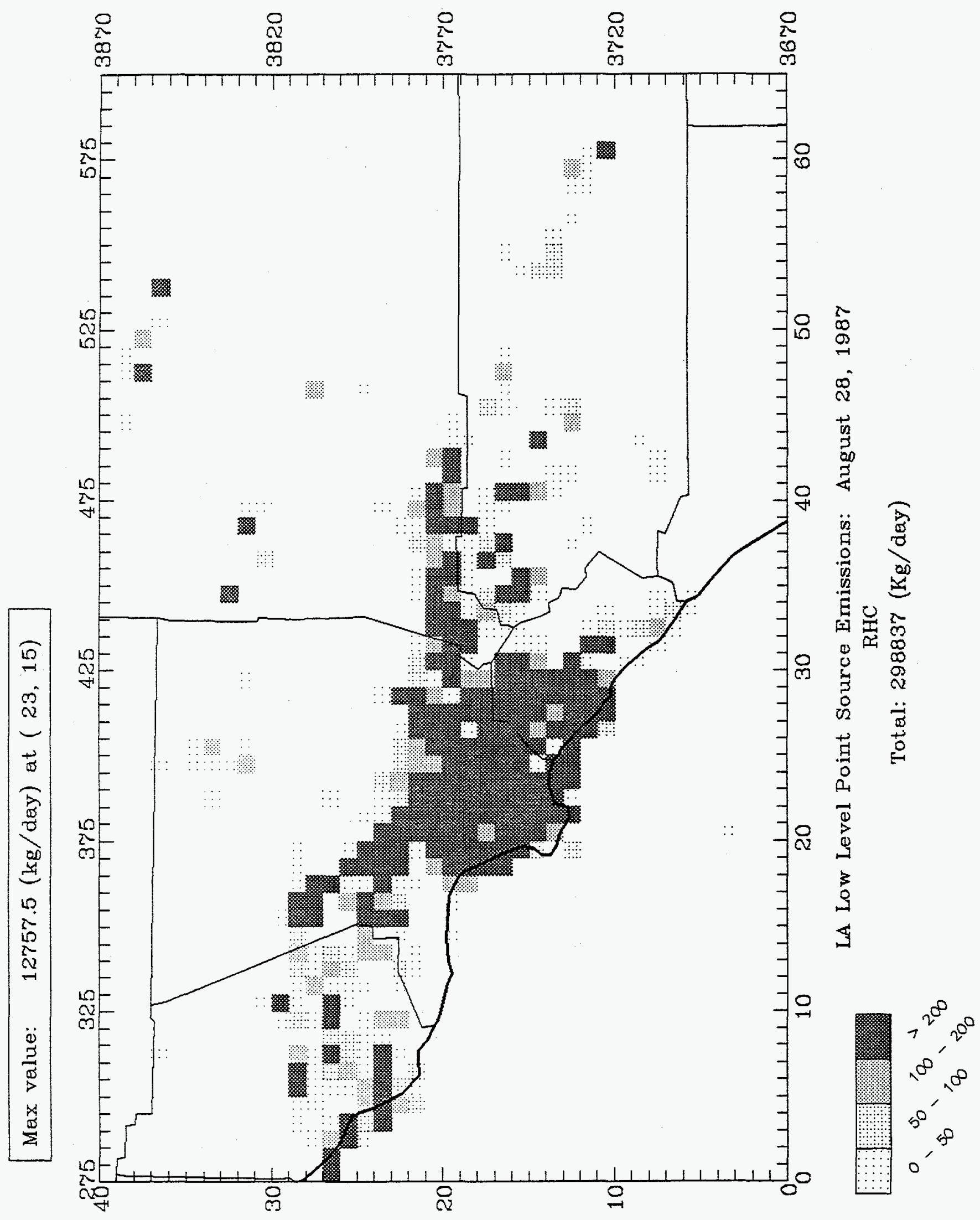




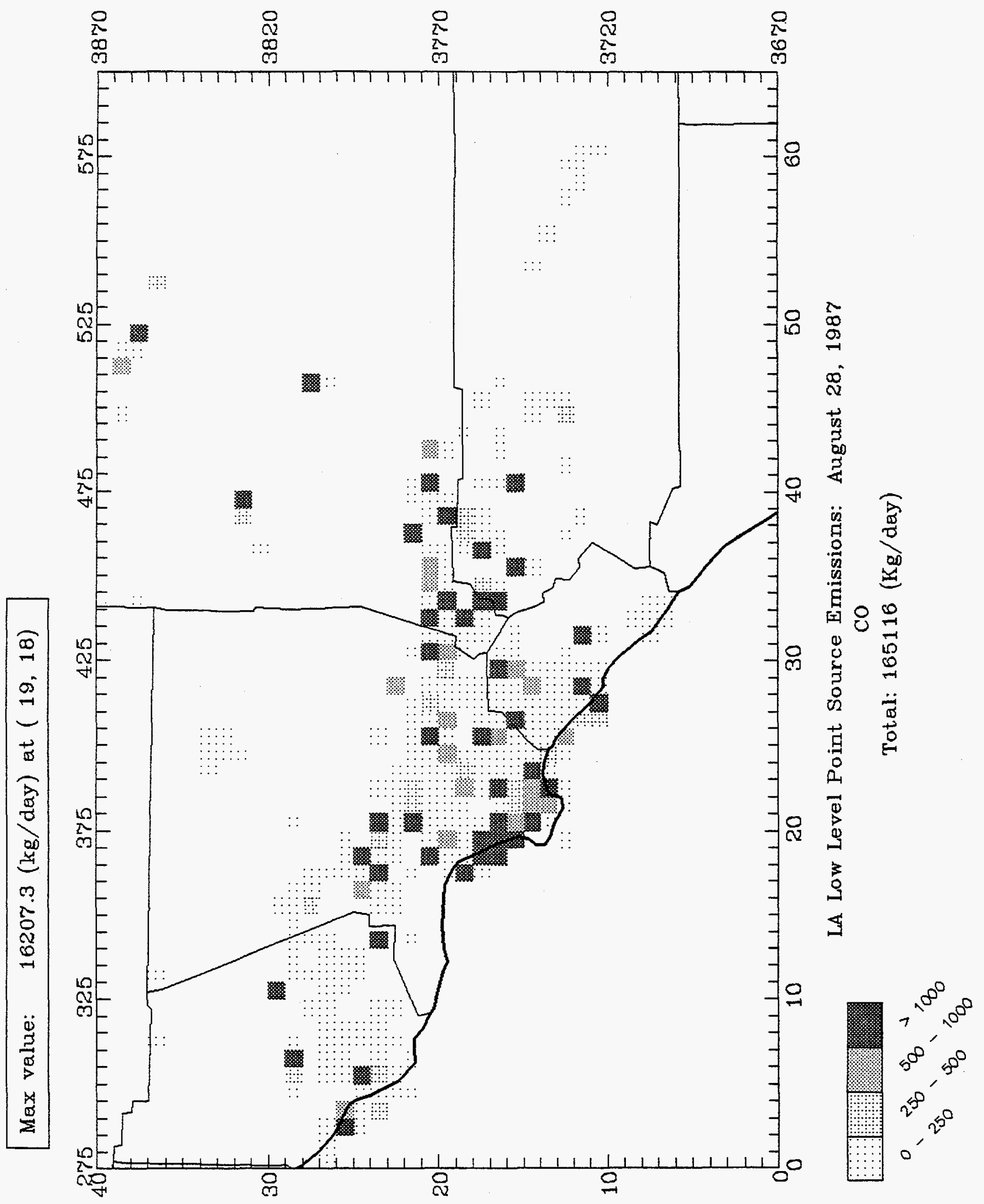




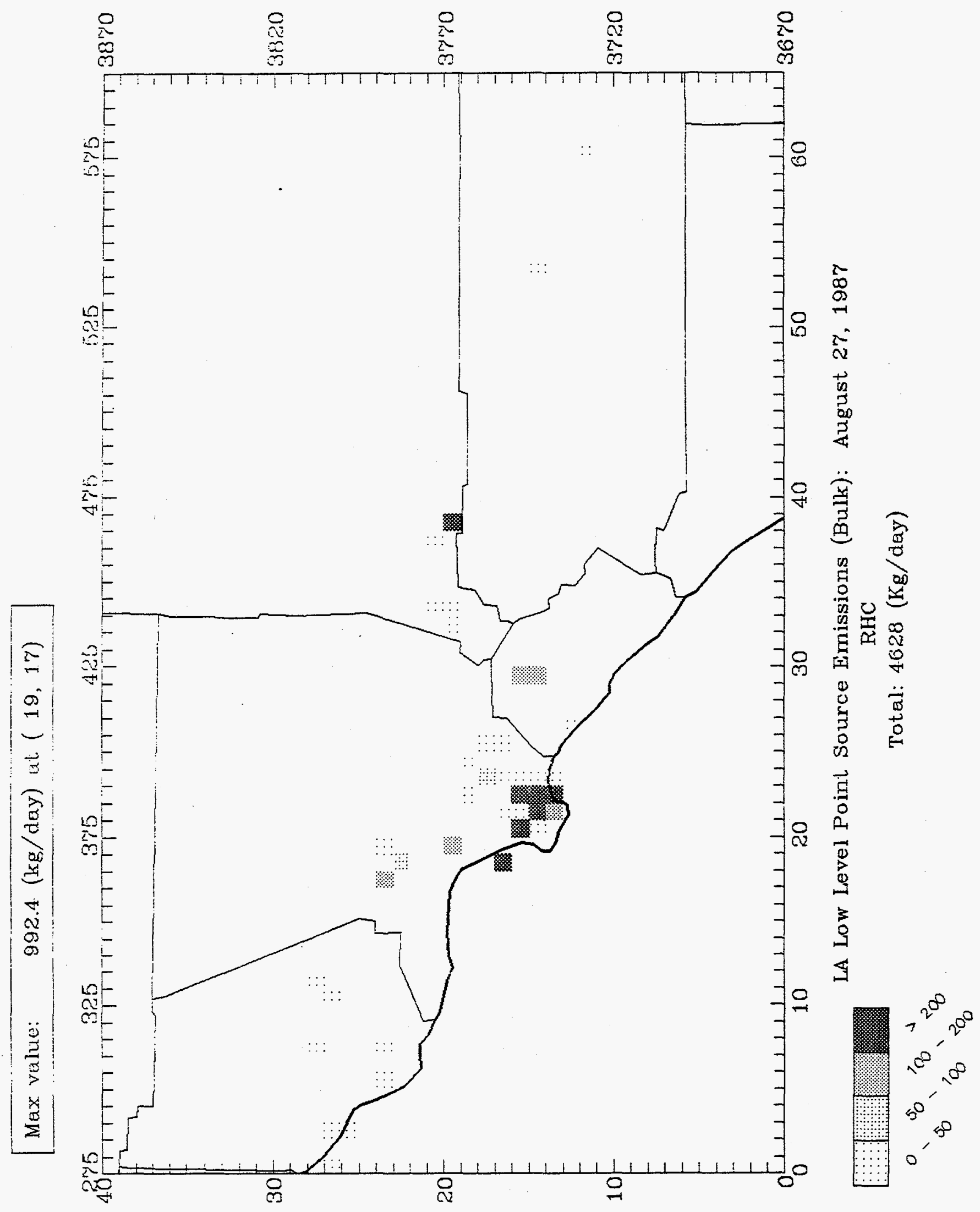




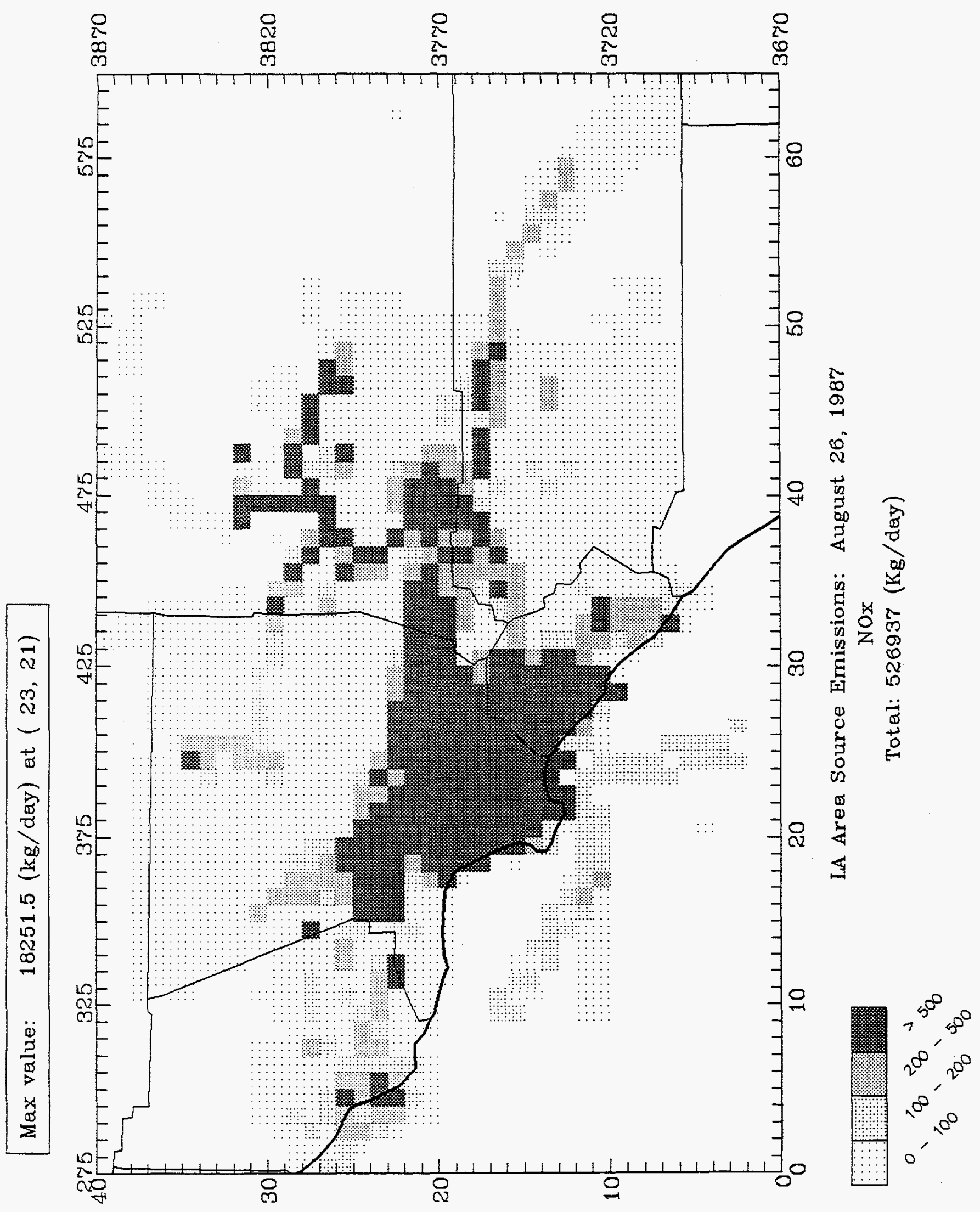




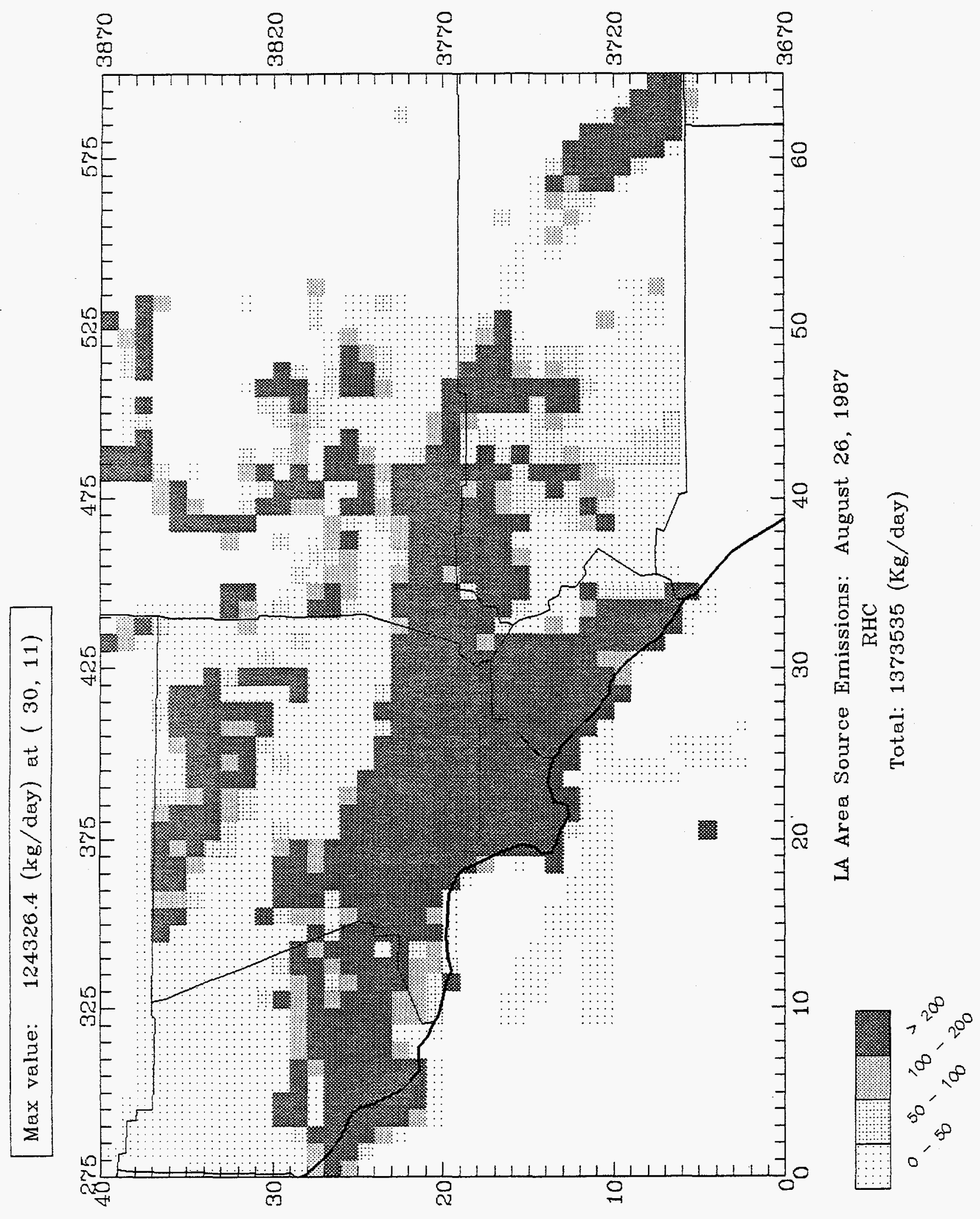




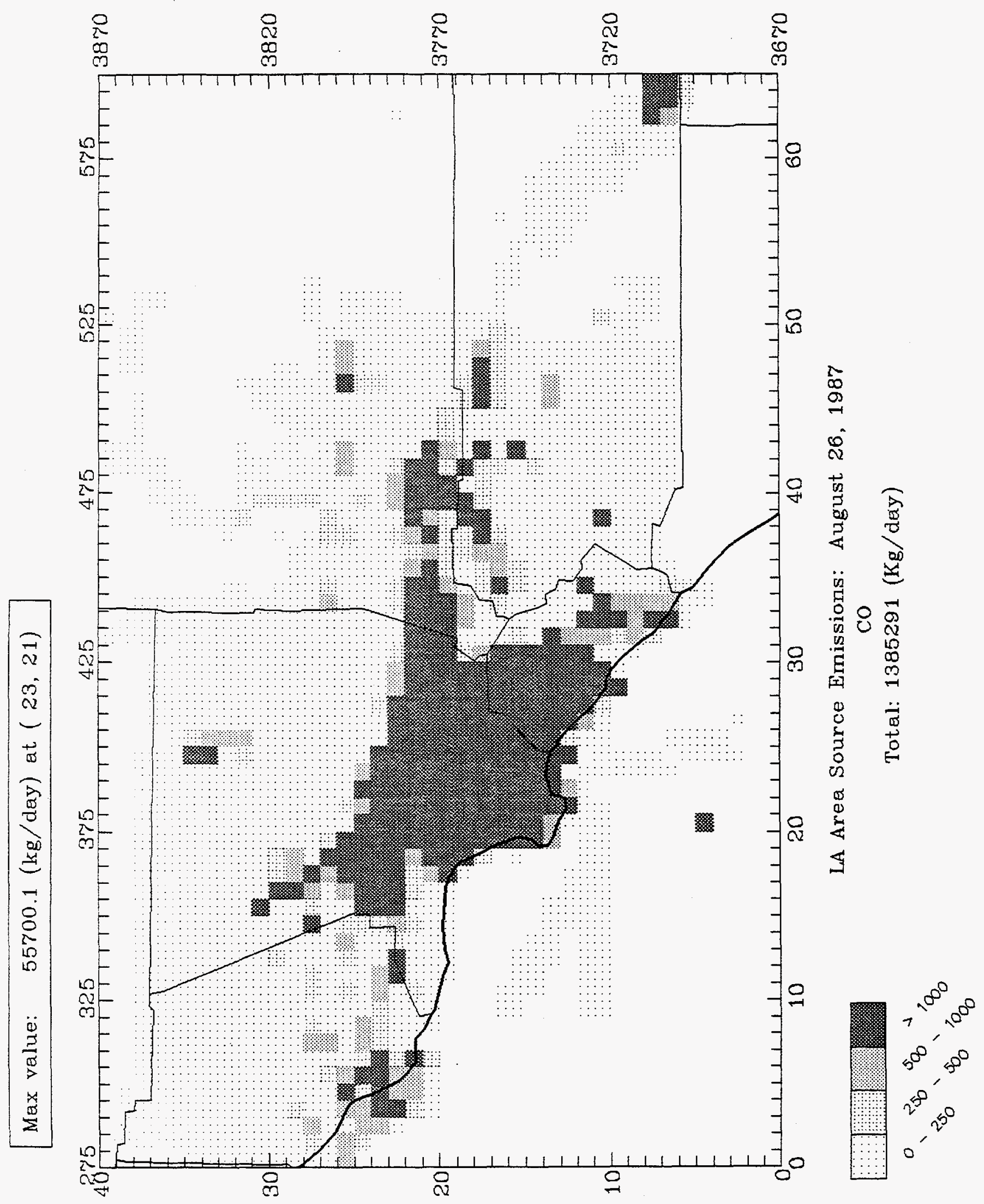




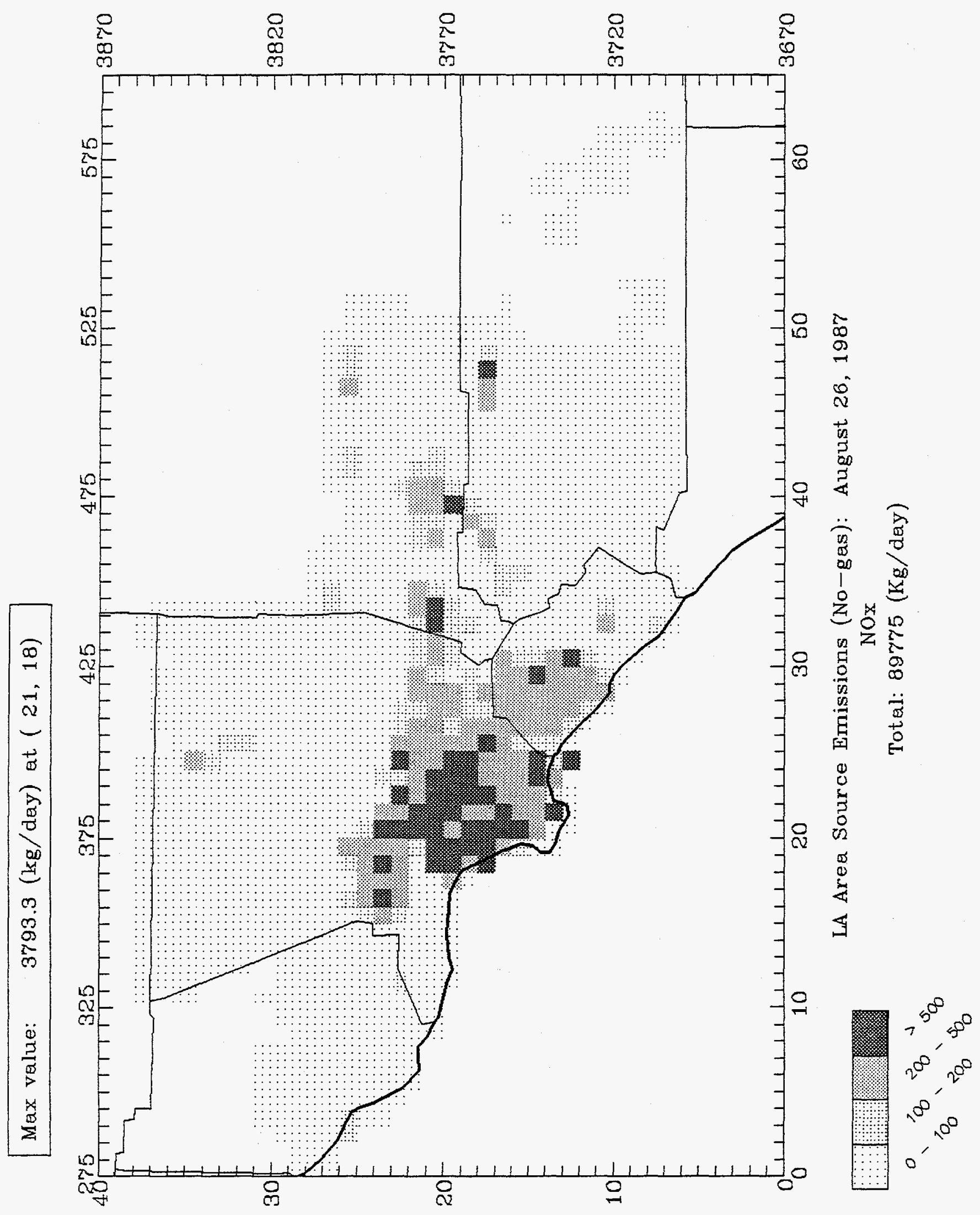




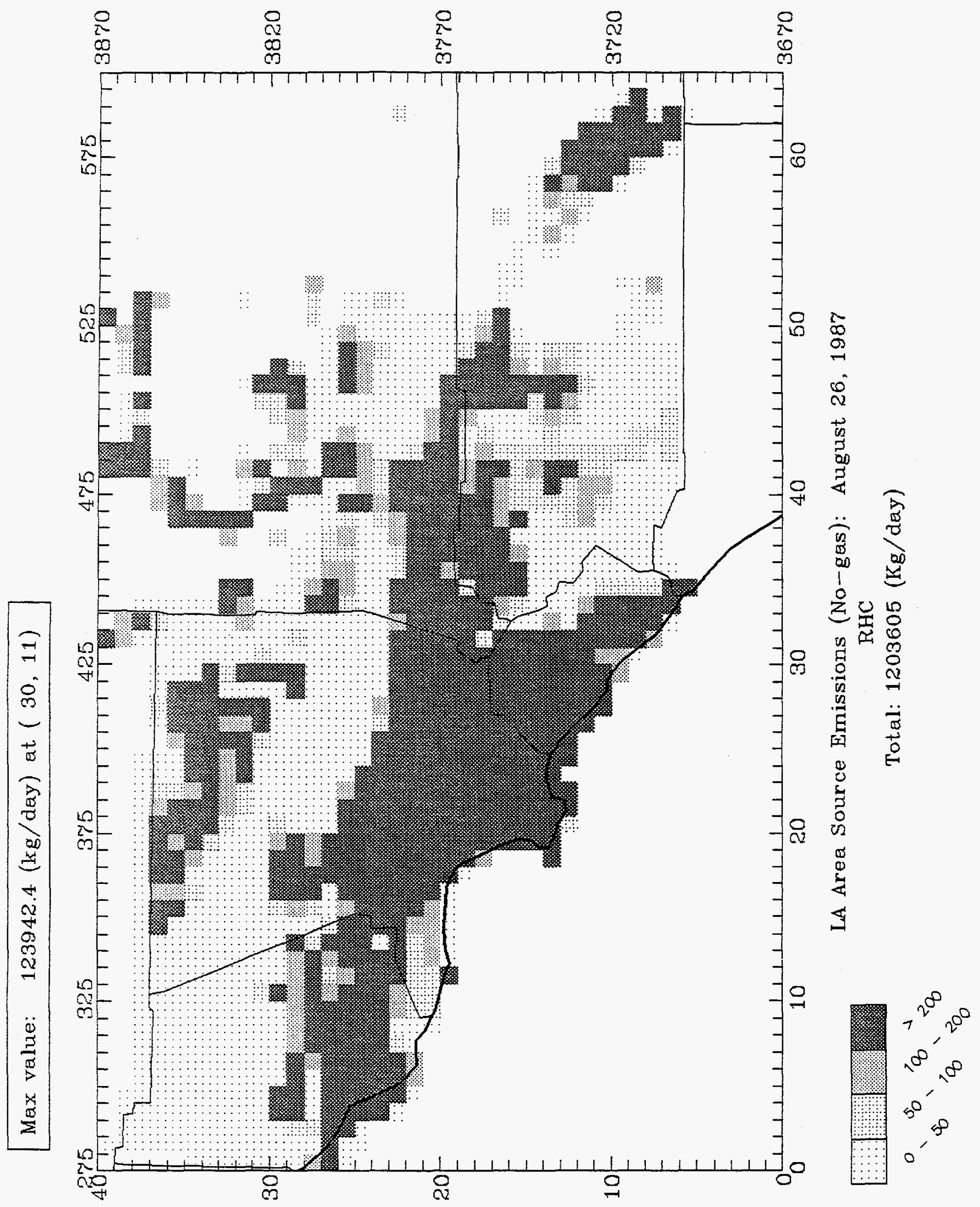




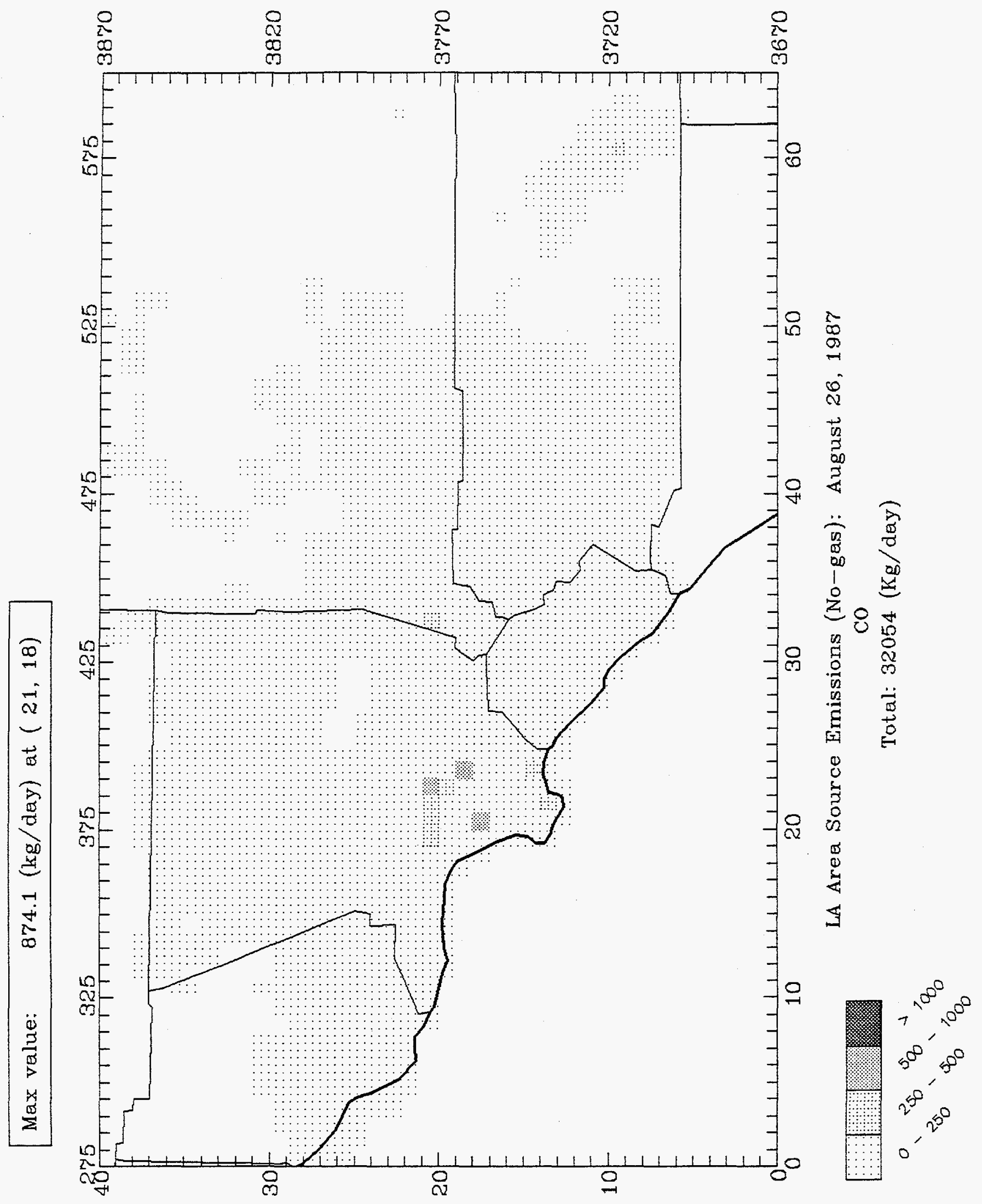




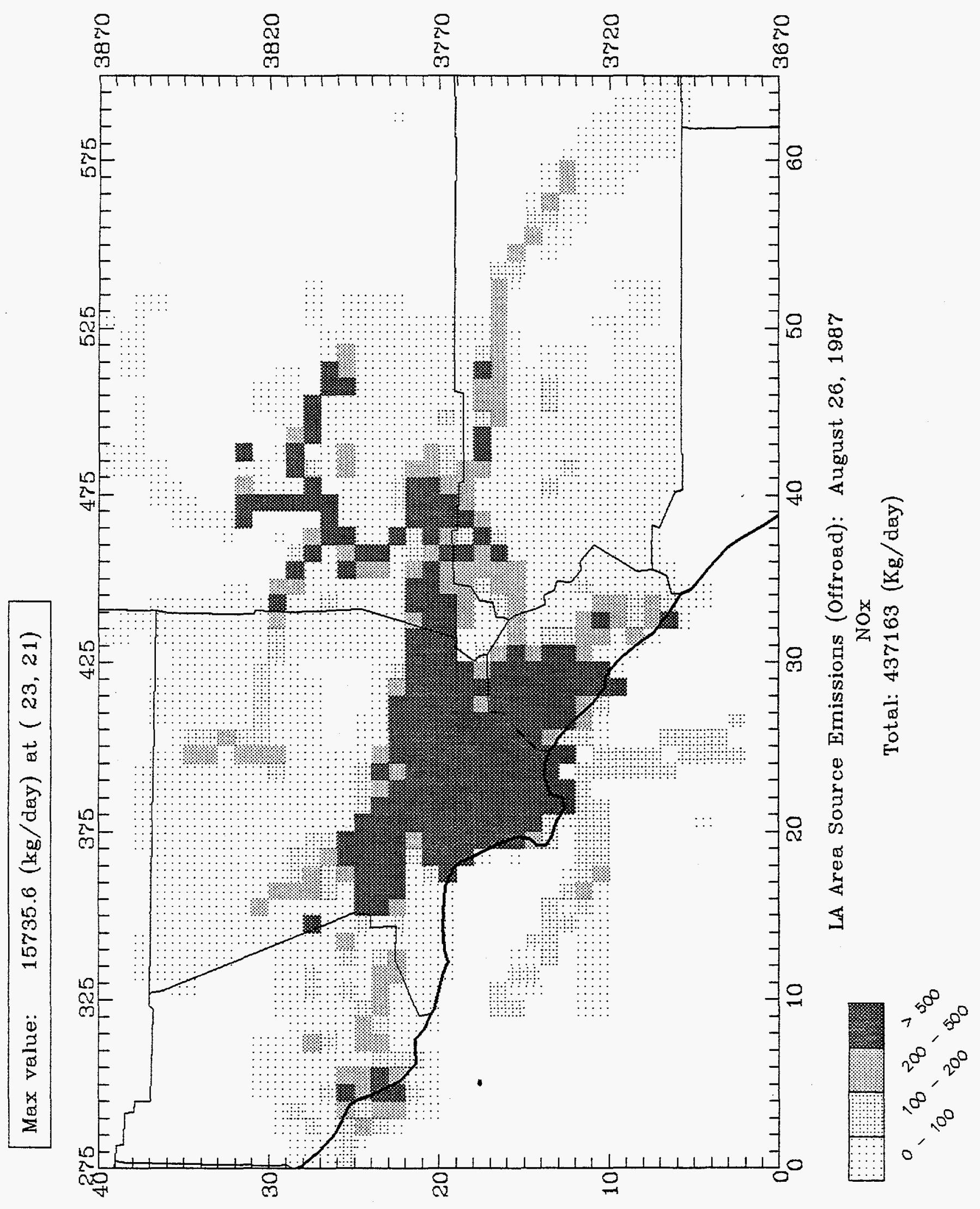




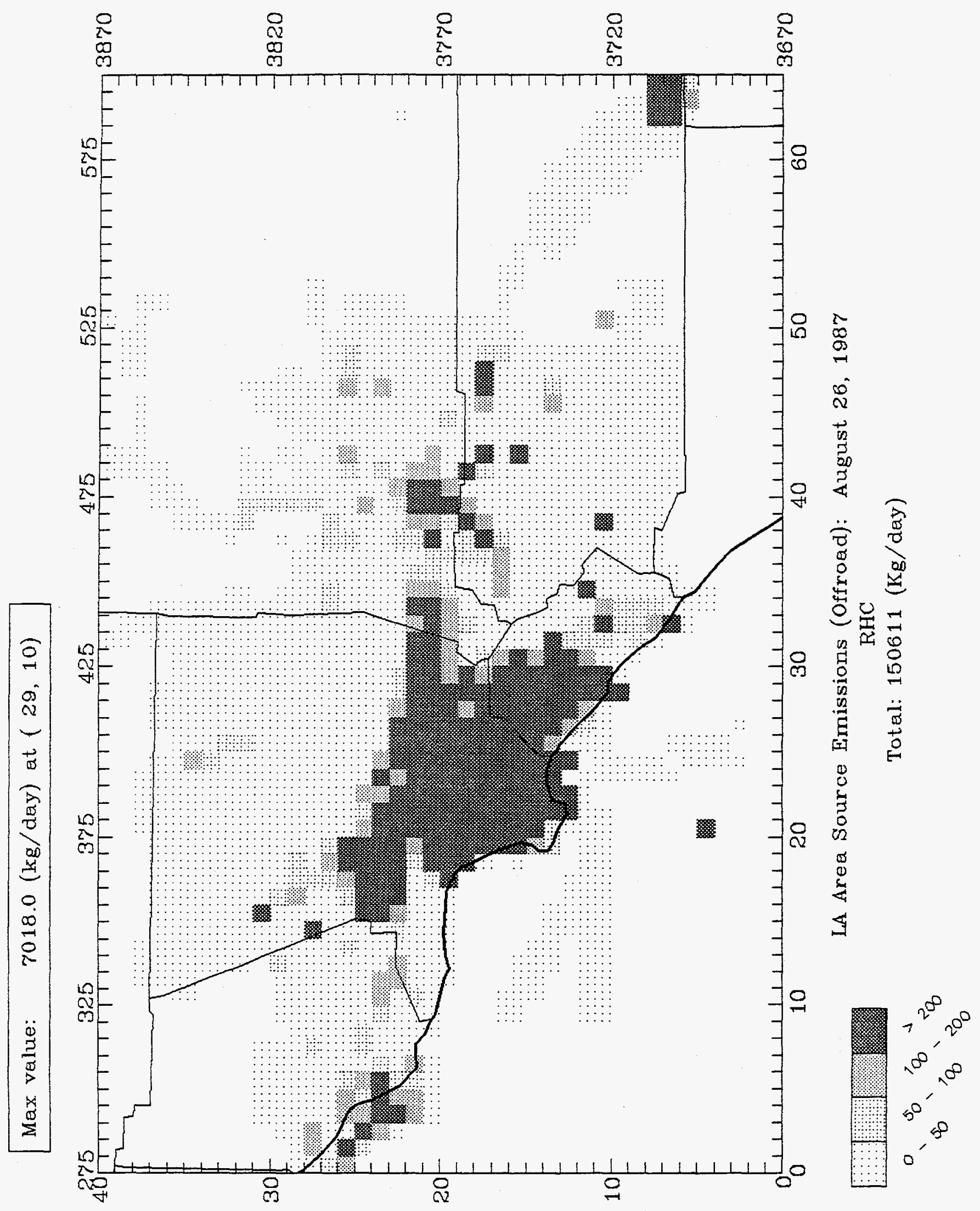




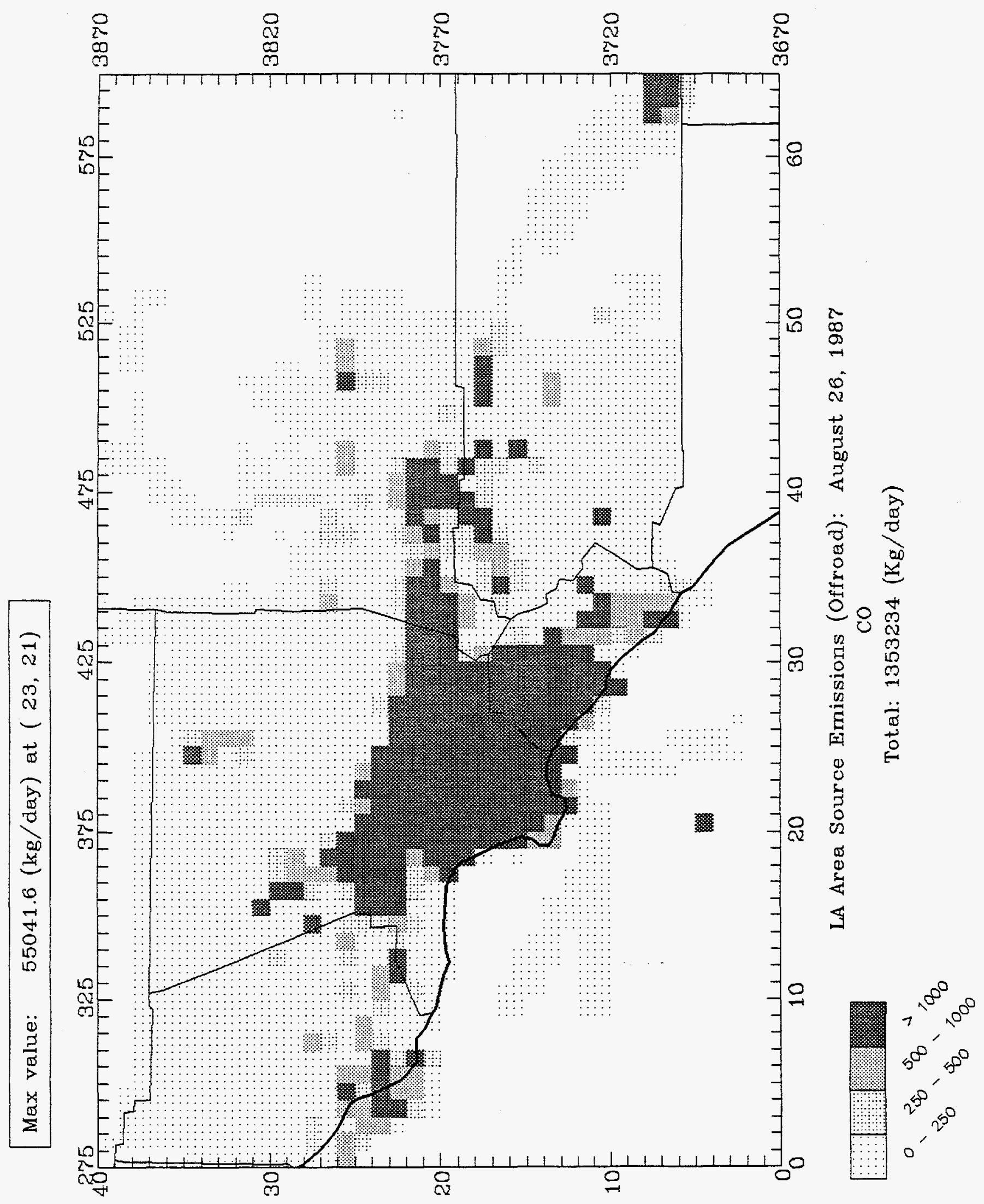




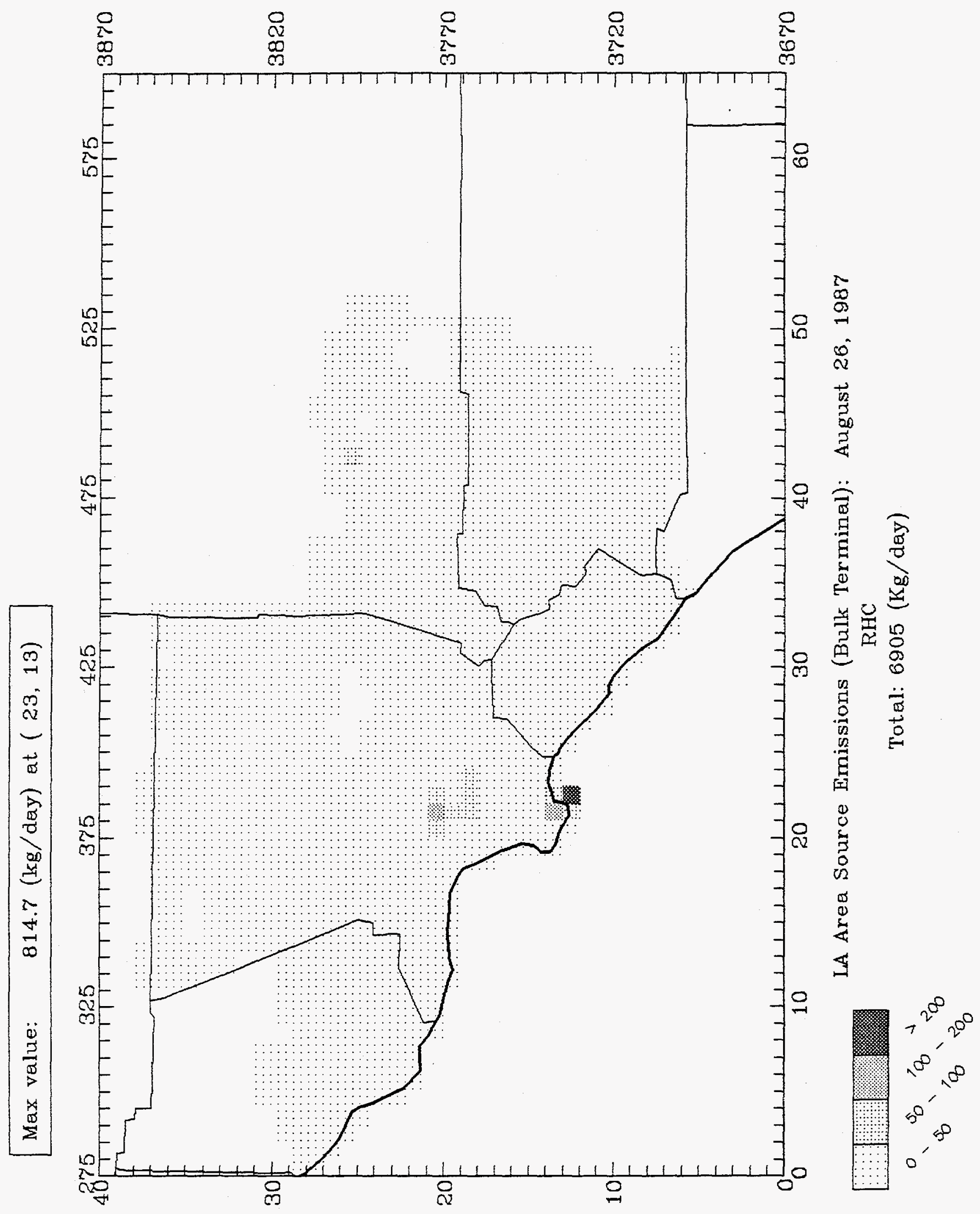




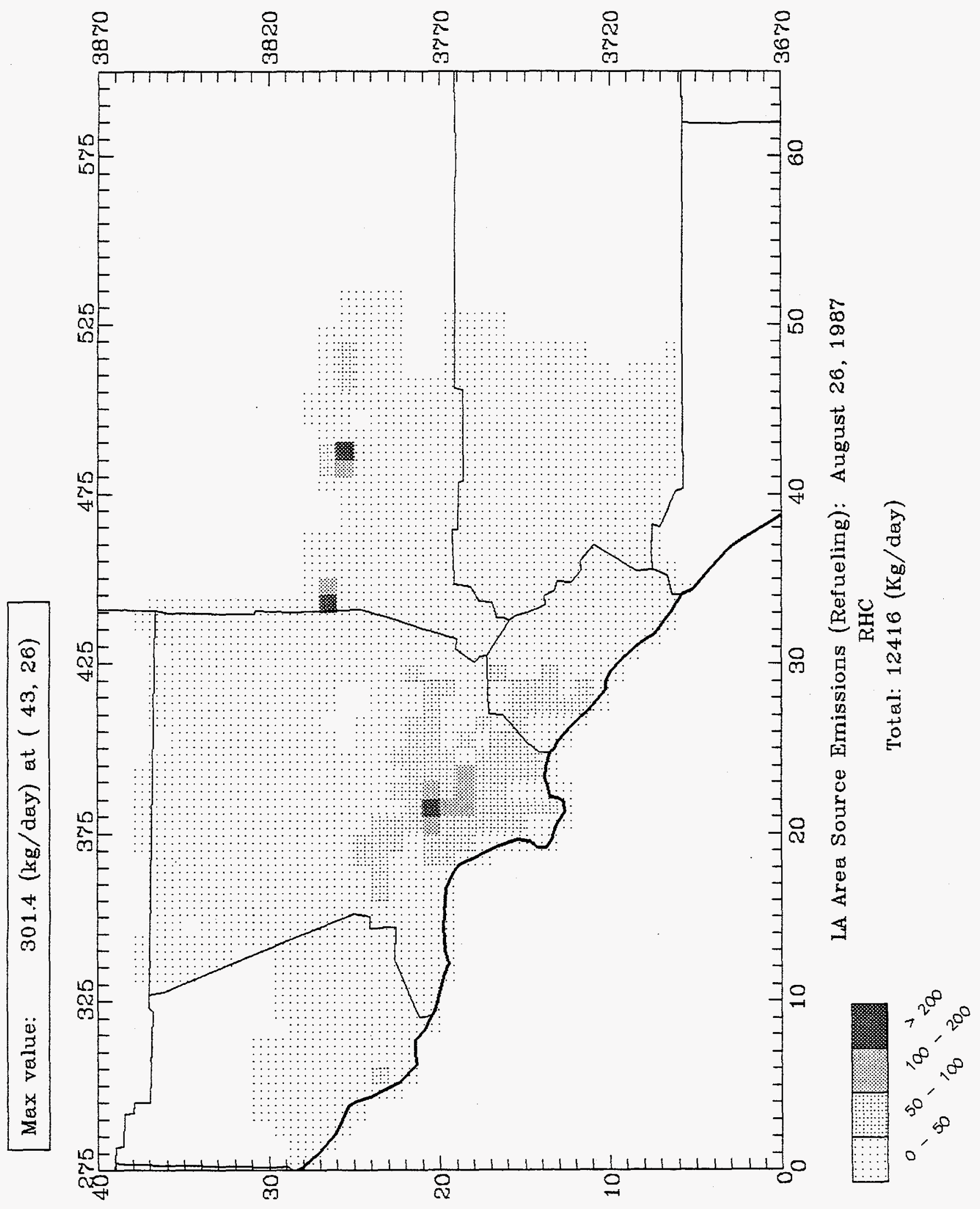



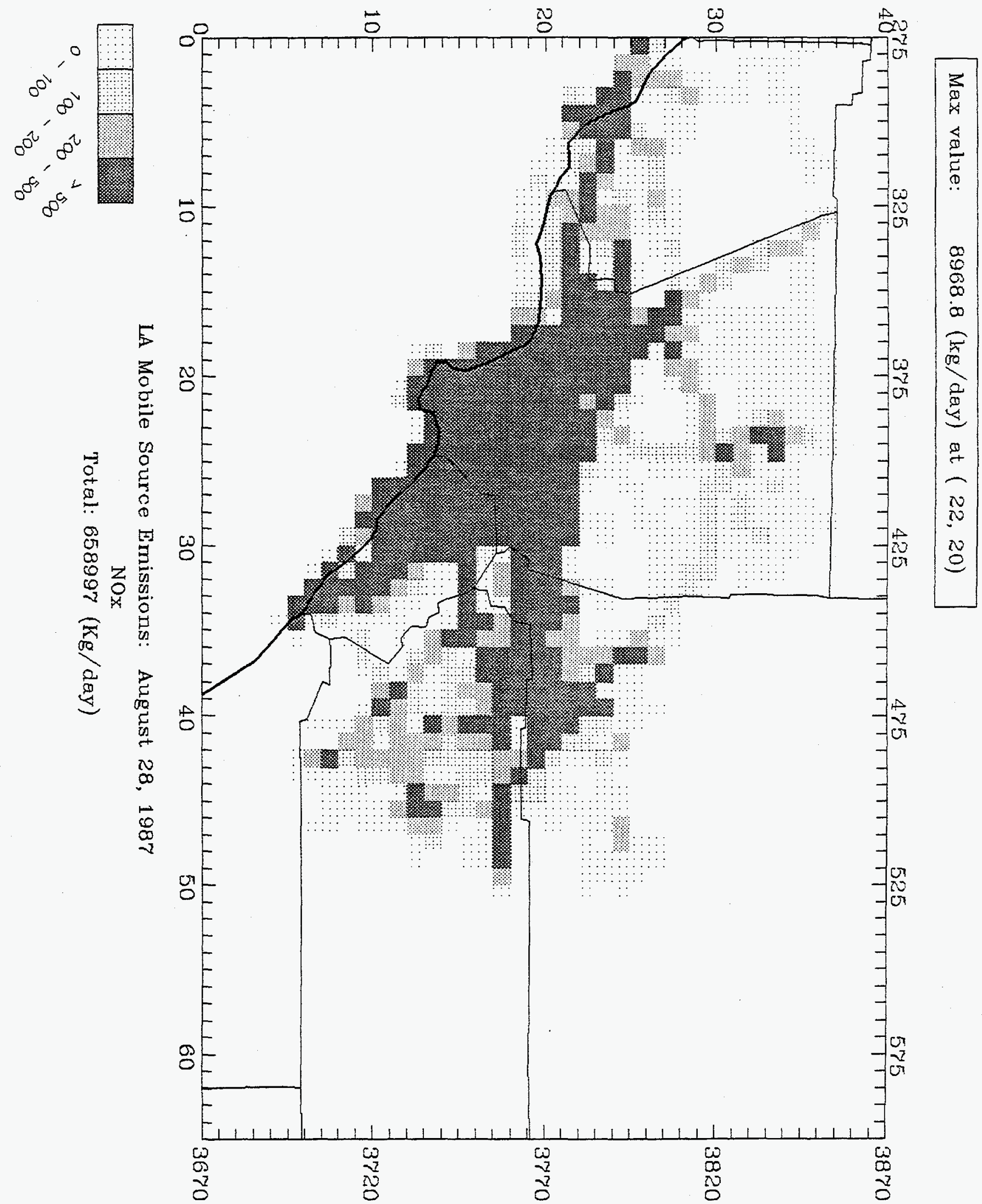


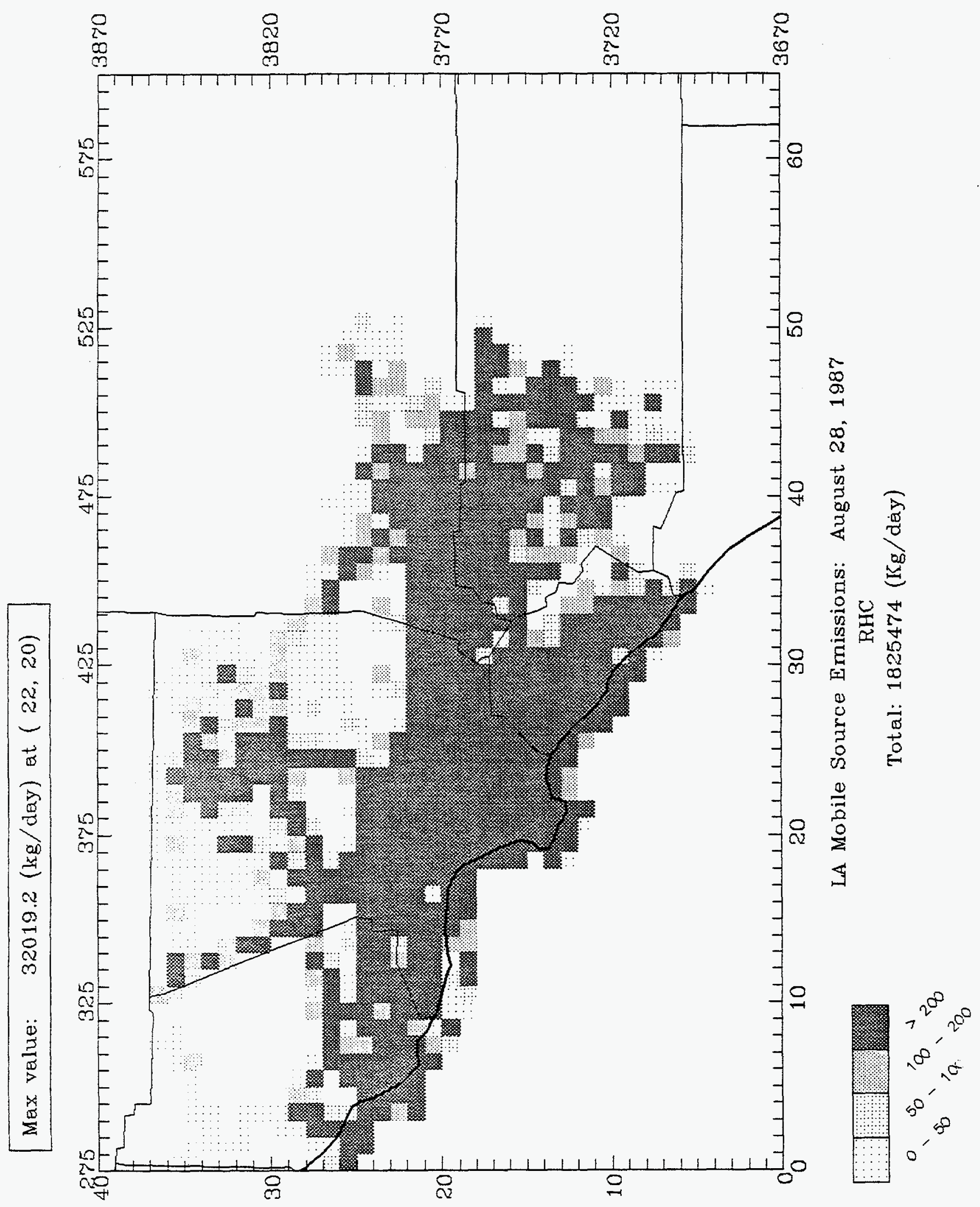




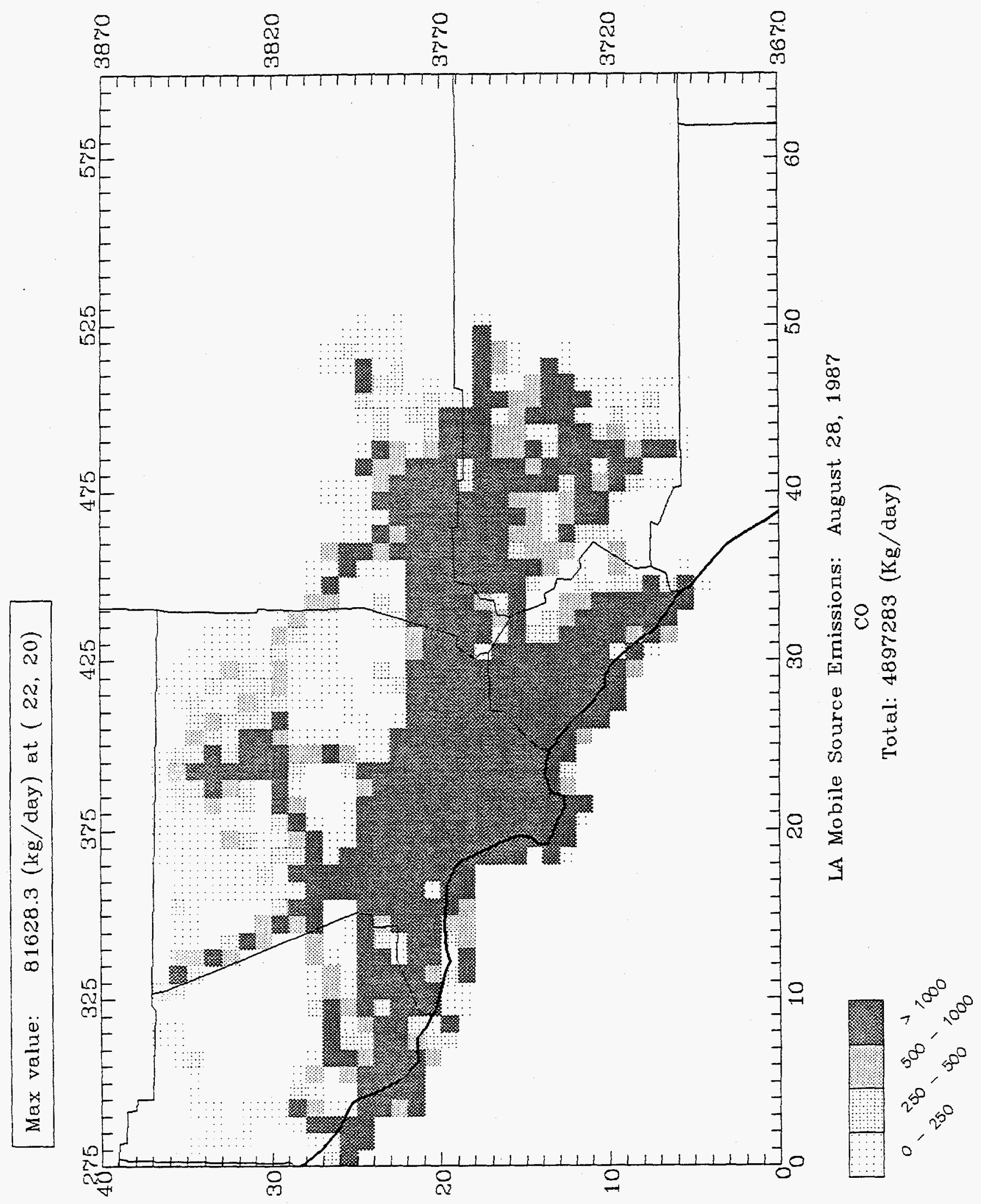

